\title{
Unclassified Source Term and Radionuclide Data for Corrective Action Unit 97: Yucca Flat/Climax Mine, Nevada Test Site, Nevada
}

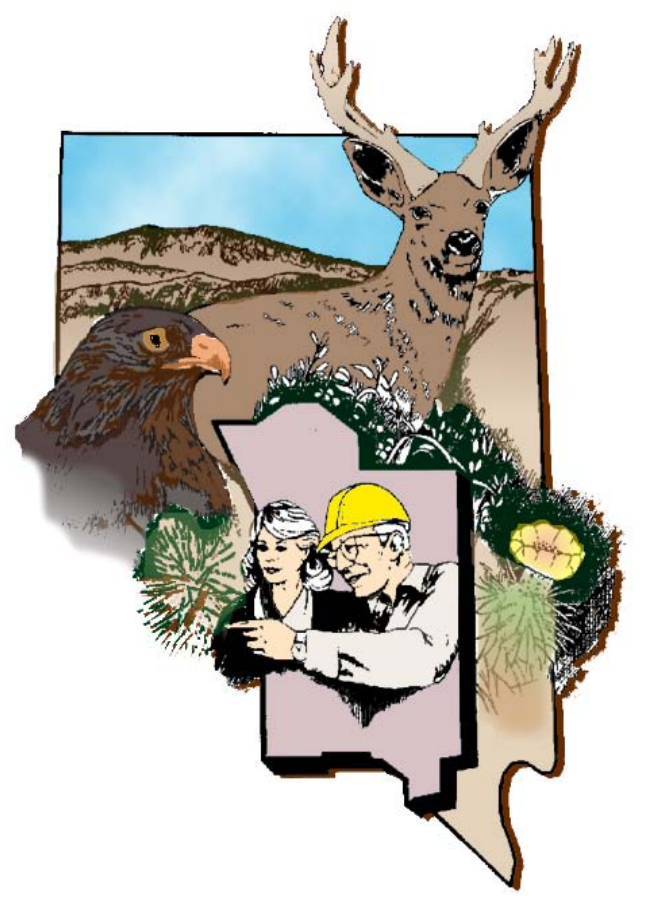

\author{
Revision No.: 2
}

August 2009

Prepared for U.S. Department of Energy under Contract No. DE-AC52-03NA99205.

Approved for public release; further dissemination unlimited. 
Available for sale to the public from:

\author{
U.S. Department of Commerce \\ National Technical Information Service \\ 5285 Port Royal Road \\ Springfield, VA 22161 \\ Phone: 800.553.6847 \\ Fax: 703.605.6900 \\ Email: orders@ntis.gov \\ Online ordering: http://www.ntis.gov/ordering.htm
}

Available electronically at $\underline{\text { htp: }: / w w w . o s t i . g o v / b r i d g e}$

Available for a processing fee to U.S. Department of Energy and its contractors, in paper, from:

\author{
U.S. Department of Energy \\ Office of Scientific and Technical Information \\ P.O. Box 62 \\ Oak Ridge, TN 37831-0062 \\ Phone: 865.576.8401 \\ Fax: 865.576.5728 \\ Email: reports@adonis.osti.gov
}

Reference herein to any specific commercial product, process, or service by trade name, trademark, manufacturer, or otherwise, does not necessarily constitute or imply its endorsement, recommendation, or favoring by the United States Government or any agency thereof or its contractors or subcontractors. 


\section{UNCLASSIFIED SOURCE TERM AND RADIONUCLIDE DATA FOR CORRECTIVE ACTION UNIT 97: YUCCA FLAT/CLIMAX MINE, NEVADA TEST SITE, NEVADA}

Revision No.: 2

August 2009

Stoller-Navarro Joint Venture c/o U.S. DOE P.O. Box 98952

Las Vegas, NV 89193-8952

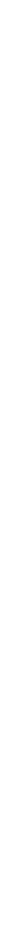

Reviewed and determined to be UNCLASSIFIED.

Derivative Classifier: Joseph Johnston SNJV Classification Officer Signature: /s/Joseph Johnston

Date: $8 / 20 / 2009$

Prepared for U.S. Department of Energy under Contract No. DE-AC52-03NA99205.

Approved for public release; further dissemination unlimited. 
UNCLASSIFIED SOURCE TERM AND RADIONUCLIDE

DATA FOR CORRECTIVE ACTION UNIT 97:

YUCCA FLAT/CLIMAX MINE, NEVADA TEST SITE, NEVADA

Approved by: /s/Greg Ruskauff for

Date: 8/20/2009

Sam Marutzky, UGTA Project Manager

Stoller-Navarro Joint Venture 


\section{TABLE of ConTENTS (Continued)}

3.3.3 Chimney Drainage $\ldots \ldots \ldots \ldots \ldots \ldots \ldots \ldots \ldots \ldots \ldots \ldots \ldots . \ldots \ldots \ldots$

3.3.4 Drilling-fluid Injection . . . . . . . . . . . . . . . . . . . . 3-13

3.3.5 Gas-phase Migration ............................. 3-14

3.3.5.1 Gas-phase Radionuclide Diffusion and

Phase Partitioning ...................... 3-15

3.3.5.2 $\mathrm{CO}_{2}$ Gas Production and Expansion $\ldots \ldots \ldots \ldots \ldots . . .3-17$

3.3.5.3 Steam Bubble Expansion ................... 3-18

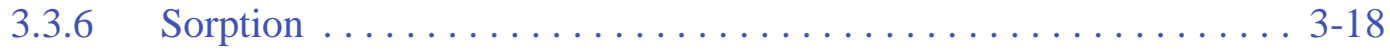

3.3.7 Unsaturated Conceptual Model Summary .................. 3-19

$3.4 \quad$ Saturated Zone Conceptual Models . . . . . . . . . . . . . . . . . . . . . . . . 3-21

3.4.1 Ambient Groundwater Flow..................... 3-22

3.4.2 Test-induced Pressure. ......................... 3-26

3.4.3 Test-induced Thermal Convection .................... 3-27

3.4.4 Melt-glass Presence and Dissolution ................. 3-28

3.4.5 Sorption in the Saturated Zone.................... 3-29

3.4.6 Saturated Zone Conceptual Model Summary................. 3-30

3.5 Hydrologic Source Term Uncertainty. . . . . . . . . . . . . . . . . . . . . . 3-31

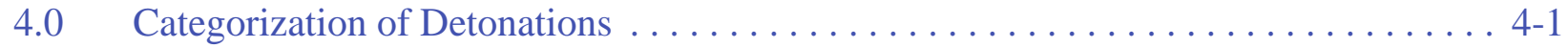

$4.1 \quad$ Above Water Table Test Categorization Criteria ................ 4-4

4.2 Below the Water Table Test Categorization Criteria . . . . . . . . . . . . . 4-7

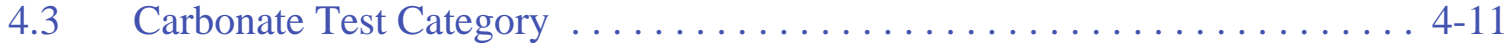

4.4 Summary of Test Categorization $\ldots \ldots \ldots \ldots \ldots \ldots \ldots \ldots \ldots \ldots, 4-12$

5.0 Evaluation of Unsaturated Zone Transport of Carbon-14 and Tritium . . . . . . . . . 5-1

$5.1 \quad$ Multiphase Flow and Transport Modeling Objectives ................ 5-1

$5.2 \quad$ Multiphase Conceptual Model ............................. 5-2

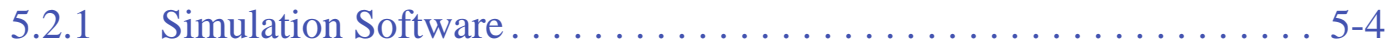

$5.3 \quad$ Conceptual Model Implementation $\ldots \ldots \ldots \ldots \ldots \ldots \ldots \ldots \ldots \ldots \ldots . \ldots \ldots$

$5.3 .1 \quad$ Lithology ........................... 5

5.3.2 Disturbed Zone Physical Characteristics ................. 5-6

5.3.3 Hydraulic Properties....................... 5-7

5.3.3.1 Alluvium Hydraulic Properties . . . . . . . . . . 5-8

5.3.4 Transport Properties .......................... 5-9

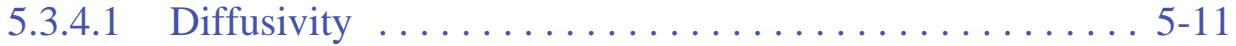

5.3.4.2 Dispersion ......................... 5-12

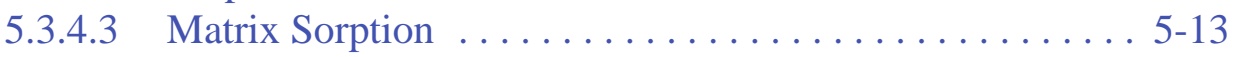

5.3.4.4 Gas-phase Partitioning .................... 5-15

5.3.5 Boundary Conditions .......................... 5-16

5.3.5.1 Background Precipitation $\ldots \ldots \ldots \ldots \ldots \ldots \ldots .5-16$

5.3.5.2 Crater Recharge . . . . . . . . . . . . . . . . . . 5-16

5.3.5.3 Aquifer ............................ 5-17

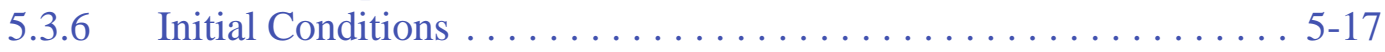

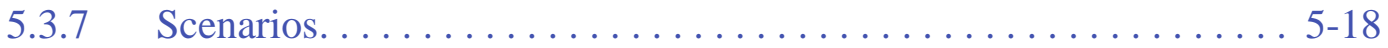




\section{TABle of Contents (Continued)}

$5.4 \quad$ Simulation Results . .............................. 5-20

5.4.1 Baseline Carbon-14 Transport for a Shallow Test . . . . . . . . . . 5-20

5.4.1.1 Effect of Crater Recharge Rates ............. 5-22

5.4.1.2 Effect of Gas- and Solid-phase Partitioning . ......... 5-27

5.4.1.3 Effect of Crushed Zone Hydraulic Properties ........ . 5-30

5.4.2 Baseline Carbon-14 Transport for a Deep Test ............ 5-32

5.4.2.1 Effect of Crater Recharge Rates .............. 5-36

5.4.2.2 Effect of Gas- and Solid-phase Partitioning .......... 5-37

5.4.2.3 Effect of Crushed Zone Hydraulic Properties ........ . 5-38

5.4.3 Tritium Transport for a Shallow Test................ 5-42

5.4.3.1 Effect of High Crater-enhanced Recharge

on Tritium Transport ..................... 5-43

5.4.4 Tritium Transport for a Deep Test ................... 5-47

5.4.4.1 Effect of Crater Recharge Rates . ............. 5-49

5.4.4.2 Effect of Gas- and Solid-phase Partitioning ........ 5-49

5.4.4.3 Effect of Crushed Zone Hydraulic Properties ........ 5-52

$5.5 \quad$ Model Limitations................................. $5-54$

$5.6 \quad$ Conclusions. . . . . . . . . . . . . . . . . . . . . . . . . . . . 5-58

6.0 Summary, Limitations, and Path Forward $\ldots \ldots \ldots \ldots \ldots \ldots \ldots \ldots \ldots .6 \ldots \ldots$

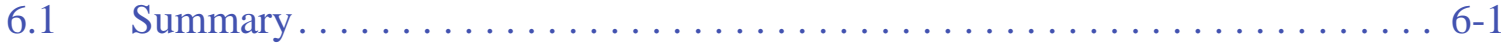

$6.2 \quad$ Limitations ...................................... $6-2$

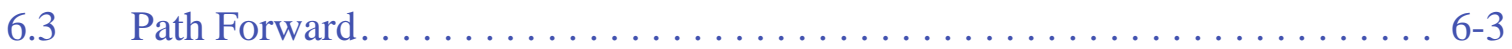

$7.0 \quad$ References.................................. $7-1$

Appendix A - Underground Nuclear Tests in the Yucca Flat/Climax Mine Corrective Action Unit

A.1.0 Underground Nuclear Tests in the Yucca Flat/Climax Mine Corrective Action Unit . . A-1 A.2.0 References....................................... A-3

Appendix B - Radionuclide Inventory of the Yucca Flat/Climax Mine Corrective Action Unit

B.1.0 Radionuclide Inventory of the Yucca Flat/Climax Mine Corrective Action Unit . . . . . B-1

B.2.0 References.......................................

Appendix C - FEHM Simulations of a Multiphase Radionuclide Experiment

C.1.0 FEHM Simulations of a Multiphase Radionuclide Experiment . . . . . . . . . . . C-1

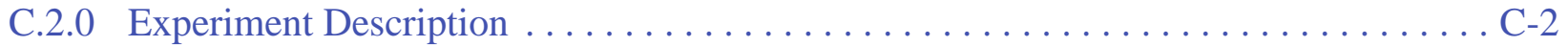

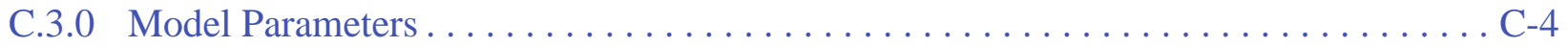

C.4.0 Estimating Soil Hydraulic Properties . . . . . . . . . . . . . . . . . . . C-5 


\section{TABLE of Contents (Continued)}

C.5.0 Estimating Transport Properties . . . . . . . . . . . . . . . . .

C.6.0 Simulation Profile. . . . . . . . . . . . . . . . . . . . . . . . . C-10

C.7.0 Simulation Results $\ldots \ldots \ldots \ldots \ldots \ldots \ldots \ldots \ldots \ldots \ldots \ldots \ldots \ldots \ldots \ldots$

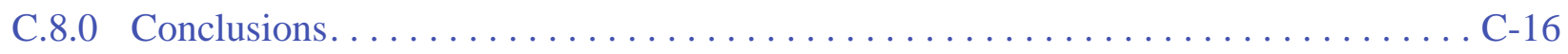

C.9.0 References. .............................. C-17

Appendix D - Comments from Nevada Division of Environmental Protection 


\section{LIST OF FIGURES}

NUMBER

TITLE

PAGE

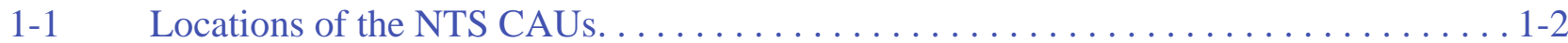

1-2 Unsaturated Zone CAU Model Grids. . . . . . . . . . . . . . . . . . . 1-7

1-3 Process Flow Diagram for the Underground Test Area CAUs . . . . . . . . . . . . . 1-9

2-1 Phenomenology of Silicate Tests . . . . . . . . . . . . .

3-1 Schematic Diagram of the Silicic Rock Test Altered Zones . . . . . . . . . . . . . . . 3-4

3-2 Idealized Phenomenology of a Carbonate Test $\ldots \ldots \ldots \ldots \ldots \ldots \ldots \ldots \ldots \ldots \ldots$

3-3 Schematic Diagram of the Carbonate Rock Test Altered Zones . . . . . . . . . . . 3-8

3-4 Mass Breakthrough and Streamtraces in the Saturated Zone. . . . . . . . . . . . . . . 3-24

4-1 Yucca Flat CAU Underground Tests Plan View . . . . . . . . . . . . . . . 4-2

4-2 Yucca Flat CAU Underground Tests South-East View . . . . . . . . . . . . . 4-3

5-1 Model Domain and Disturbed Zones for the Shallow and Deep Tests . . . . . . . . . . 5-5

5-2 Meshing Scheme for the Shallow and Deep Models . . . . . . . . . . . . . 5-6

5-3 Regression Analysis of the van Genuchten Parameters . . . . . . . . . . . . . . . 5-10

5-4 Alluvium Moisture Characteristic Curves . . . . . . . . . . . . . . . . . . . 5-10

5-5 Steady-state Saturation Profile in Alluvium after 1,000 Years . . . . . . . . . . . . 5-18

5-6 Shallow Test Saturation Profiles of Various Recharge Models . . . . . . . . . . . . . 5-23

5-7 $\quad{ }^{14} \mathrm{C}$ Shallow Test Breakthrough and Peak Aquifer Concentration. . . . . . . . . . . . 5-24

5-8 $\quad{ }^{14} \mathrm{C}$ Shallow Test Concentration Profiles of Various Recharge Models . . . . . . . . 5-25

5-9 $\quad{ }^{14}$ C Shallow Test Concentration Profiles of Increased Playa Area and Low Permeability Models . . . . . . . . . . . . . . . . . . . 5-28

5-10 $\quad{ }^{14} \mathrm{C}$ Shallow Test Concentration Profiles of Gas/Solid-phase Partitioning Models. . . . 5-29

5-11 Shallow Test Saturation Profiles of the Low Permeability/Low Porosity Models . . . 5-31

5-12 ${ }^{14} \mathrm{C}$ Deep Test Breakthrough and Peak Aquifer Concentration . . . . . . . . . . . 5-33 


\section{LIST OF FIGURES (CONTINUED)}

NUMBER

5-13 Deep Test Saturation Profiles of the Various Recharge Models . . . . . . . . . . . . 5-34

5-14 $\quad{ }^{14}$ C Deep Test Concentration Profiles of Various Recharge Models. . . . . . . . . . . 5-35

5-15 $\quad{ }^{14}$ C Deep Test Concentration Profiles of Gas/Solid-phase Partitioning Models . . . . . 5-39

5-16 $\quad{ }^{14}$ C Deep Test Concentration Profiles of Increased Playa Area and Low Permeability Models . . . . . . . . . . . . .

5-17 Deep Test Saturation Profiles of the Low Permeability/Low Porosity Models . . . . . . 5-41

5-18 $\quad{ }^{3} \mathrm{H}$ Shallow Test Concentration Profiles of Various Recharge Models . . . . . . . . . . 5-44

5-19 ${ }^{3}$ H Shallow Test Concentration Profiles of Gas/Solid-phase Partitioning Models . . . 5-45

5-20 $\quad{ }^{3}$ H Shallow Test Concentration Profiles of Increased Playa Area and Low Permeability Models . . . . . . . . . . . . . . . . . . . . . .

5-21 ${ }^{3}$ H Shallow Test Breakthrough and Peak Aquifer Concentration . . . . . . . . . . . . 5-47

5-22 $\quad{ }^{3}$ H Deep Test Breakthrough and Peak Aquifer Concentration. . . . . . . . . . . . . . . 5-48

5-23 ${ }^{3}$ H Deep Test Concentration Profiles of Various Recharge Models . . . . . . . . . . . 5-50

5-24 $\quad{ }^{3} \mathrm{H}$ Deep Test Concentration Profiles of Gas/Solid-phase Partitioning Models. . . . . . 5-51

C.2-1 Mesoscale Column Experiment . . . . . . . . . . . . . . . . . . . . . -3

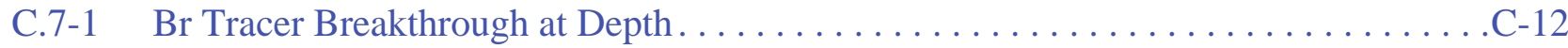

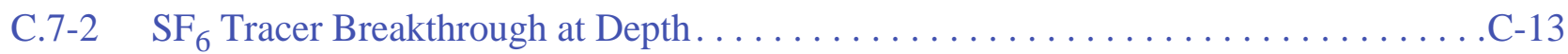

C.7-3 Aqueous ${ }^{14} \mathrm{C}$ Tracer Breakthrough at Depth . . . . . . . . . . . . . . . . . . . C-14

C.7-4 Gaseous ${ }^{14} \mathrm{C}$ Tracer Breakthrough at Depth. . . . . . . . . . . . . . . . . . . . C-15 


\section{LIST OF TABLES}

NUMBER

TITLE

PAGE

2-1 Estimated Accuracies for Various Groups of Radionuclides . . . . . . . . . . . . 2-6

2-2 Radionuclide Inventory for Yucca Flat $\ldots \ldots \ldots \ldots \ldots \ldots \ldots \ldots \ldots \ldots \ldots$

2-3 Unclassified Inventory and Radionuclide Distributions for Noncarbonate Tests . . . . . 2-11

2-4 Unclassified Inventory and Radionuclide Distributions for Carbonate Tests . . . . . . 2-13

3-1 Silicic Rock Test Altered Zone Volume Multiplicative Factors . . . . . . . . . . . . . . 3-5

3-2 Recharge Estimates from Crater Infiltration Studies . . . . . . . . . . . . . . . . . . 3-13

4-1 Grouped HSU Classes Used in Yucca Flat Tests Categorization . . . . . . . . . . . . 4-5

4-2 Above the Water Table Tests Categorization Summary by HSU . . . . . . . . . . . . . 4-8

4-3 Above the Water Table Tests Categorization Summary by Depth . . . . . . . . . . . 4-8

4-4 Below the Water Table Detonations Categorization Summary for

Confining Unit Tests . . . . . . . . . . . . . . . . . . . . 4-11

4-5 Saturated Detonations Categorization Summary by HSU . . . . . . . . . . . . . . . 4-11

4-6 Carbonate Detonations Summary . . . . . . . . . . . . . . . . . . . . . . 4-12

5-1 van Genuchten Model Parameters for Alluvium . . . . . . . . . . . . . . . . . . . . 5-10

5-2 Summary of Transport Properties in Yucca Flat Alluvium. . . . . . . . . . . . . . . 5-11

5-3 Bulk Mineralogy Comparison of INL SDA Sediment and Yucca Flat Alluvium. . . . . 5-14

5-4 $\quad{ }^{14} \mathrm{C}$ and ${ }^{3} \mathrm{H}$ Multiphase Source Term Simulations $\ldots \ldots \ldots \ldots \ldots \ldots \ldots \ldots \ldots$ 5-19

5-5 Summary of ${ }^{14} \mathrm{C}$ and ${ }^{3} \mathrm{H}$ Transport Simulations $\ldots \ldots \ldots \ldots \ldots \ldots \ldots \ldots \ldots$

C.4-1 Hydrologic Constitutive Parameters . . . . . . . . . . . . . . . . . . . . C-6

C.5-1 Transport Parameters . . . . . . . . . . . . . . . . . . 


\section{LIST OF ACRONYMS AND ABBREVIATIONS}

1-D One-dimensional

2-D Two-dimensional

3-D Three-dimensional

atm Atmosphere

bgs Below ground surface

BJY Buster Jangle Y

bls $\quad$ Below land surface

${ }^{\circ} \mathrm{C} \quad$ Degrees Celsius

CADD Corrective action decision document

CAI Corrective action investigation

CAIP Corrective action investigation plan

CAP Corrective action plan

CAS Corrective action site

CAU Corrective action unit

CD Compact disc

CFR Code of Federal Regulations

CI Confidence interval

$\mathrm{Ci} \quad$ Curie

$\mathrm{cm}^{3} \quad$ Cubic centimeter

$\mathrm{cm} / \mathrm{yr} \quad$ Centimeters per year

CR Closure report

$\mathrm{cz} \quad$ Crushed zone

DIC Dissolved inorganic carbon

DKM Dual continuum

DOB Depth of burial

DOE U.S. Department of Energy

DRI Desert Research Institute

EBTF Engineered Barrier Test Facility

EC/IT Electron Capture/Isomeric Transition

ECM Equivalent continuum

ET Evapotranspiration

FEHM Finite Element Heat and Mass Transfer code

FFACO Federal Facility Agreement and Consent Order

$\mathrm{ft} \quad$ Foot 


\section{List OF ACRONYMS AND ABBREVIATIONS (CONTINUED)}

\begin{tabular}{|c|c|}
\hline $\mathrm{ft} / \mathrm{hr}$ & Feet per hour \\
\hline $\mathrm{g} / \mathrm{cm}^{3}$ & Grams per cubic centimeter \\
\hline GIS & Geographic Information Systems \\
\hline gpm & Gallons per minute \\
\hline HST & Hydrologic source term \\
\hline HSU & Hydrostratigraphic unit \\
\hline HTO & Tritiated water \\
\hline IAEA & International Atomic Energy Agency \\
\hline INL & Idaho National Laboratory \\
\hline $\mathrm{K}_{\mathrm{d}}$ & Distribution coefficient \\
\hline $\mathrm{kg} / \mathrm{m}^{3}$ & Kilograms per cubic meter \\
\hline $\mathrm{km}$ & Kilometer \\
\hline $\mathrm{kt}$ & Kiloton \\
\hline $\mathrm{L}$ & Liter \\
\hline L/day & Liters per day \\
\hline LANL & Los Alamos National Laboratory \\
\hline LLNL & Lawrence Livermore National Laboratory \\
\hline $\mathrm{m}$ & Meter \\
\hline M & Multiplier \\
\hline $\mathrm{m}^{2}$ & Square meter \\
\hline $\mathrm{m}^{2} / \mathrm{d}$ & Square meters per day \\
\hline $\mathrm{m}^{2} / \mathrm{g}$ & Square meters per gram \\
\hline $\mathrm{m}^{2} / \mathrm{s}$ & Square meters per second \\
\hline $\mathrm{m}^{3}$ & Cubic meter \\
\hline $\mathrm{m}^{3} / \mathrm{d}$ & Cubic meters per day \\
\hline $\mathrm{m} / \mathrm{s}$ & Meters per second \\
\hline $\mathrm{m} / \mathrm{yr}$ & Meters per year \\
\hline $\mathrm{mCi}$ & Millicurie \\
\hline MCL & Maximum contaminant level \\
\hline $\mathrm{mL} / \mathrm{g}$ & Milliliters per gram \\
\hline $\mathrm{mm} / \mathrm{yr}$ & Millimeters per year \\
\hline Mt & Megaton \\
\hline NAD27 & North American Datum of 1927 \\
\hline NDEP & Nevada Division of Environmental Protec \\
\hline
\end{tabular}




\section{LIST OF ACRONYMS AND ABBREVIATIONS (CONTINUED)}

\begin{tabular}{|c|c|}
\hline NM & Not measured \\
\hline $\mathrm{nm}^{2}$ & Square nanometer \\
\hline NNSA/NSO & U.S. Department of Energy, National Nuclear Security Administration Nevada Site Office \\
\hline NOAA & National Oceanic and Atmospheric Administration \\
\hline NTS & Nevada Test Site \\
\hline NUFT & Nonisothermal Unsaturated-Saturated Flow and Transport model \\
\hline $\mathrm{pCi}$ & Picocurie \\
\hline $\mathrm{pCi} / \mathrm{g}$ & Picocuries per gram \\
\hline $\mathrm{pCi} / \mathrm{L}$ & Picocuries per liter \\
\hline $\mathrm{pCi} / \mathrm{mL}$ & Picocuries per milliliter \\
\hline $\mathrm{pCi} / \mathrm{mm}$ & Picocuries per milliliter \\
\hline $\mathrm{pCi} / \mathrm{yr}$ & Picocuries per year \\
\hline PET & Potential evapotranspiration \\
\hline psi & Pounds per square inch \\
\hline $\mathrm{R}$ & Radius \\
\hline $\mathrm{R}_{\mathrm{C}}$ & Cavity radius \\
\hline RST & Radiologic source term \\
\hline RWMS & Radioactive Waste Management Site \\
\hline SDA & Subsurface Disposal Area \\
\hline SDWA & Safe Drinking Water Act \\
\hline SNJV & Stoller-Navarro Joint Venture \\
\hline SSM & Simplified source term model \\
\hline $\mathrm{t}_{0}$ & Time zero \\
\hline TNT & Trinitrotoluene \\
\hline UGTA & Underground Test Area \\
\hline USGS & U.S. Geological Survey \\
\hline UTM & Universal Transverse Mercator \\
\hline wt $\%$ & Weight percent \\
\hline yr & Year \\
\hline$\mu \mathrm{g} / \mathrm{mL}$ & Micrograms per milliliter \\
\hline$\mu \mathrm{m}$ & Micrometer \\
\hline
\end{tabular}




\section{LIST OF HYDROSTRATIGRAPHIC UNIT ABBREVIATIONS AND SYMBOLS}

\begin{tabular}{ll} 
AA & Alluvial aquifer \\
ARG & Argillic \\
ATCU & Argillic tuff confining unit \\
BRA & Belted Range aquifer \\
BRCU & Belted Range confining unit \\
DMP & Devitrified mafic-poor \\
DMR & Devitrified mafic-rich \\
LCA & Lower carbonate aquifer \\
LCA3 & Lower carbonate aquifer-thrust plate \\
LTCU & Lower tuff confining unit \\
OSBCU & Oak Spring Butte confining unit \\
PCUT & Playa confining unit \\
RMC & Reactive mineral category \\
TCU & Tuff confining unit \\
TM-LVTA & Timber Mountain-Lower Vitric Tuff aquifer \\
TM-UVTA & Timber Mountain-Upper Vitric Tuff aquifer \\
TM-WTA & Timber Mountain-Welded Tuff aquifer \\
TSA & Topopah Spring aquifer \\
TUBA & Tub Spring aquifer \\
UTCU & Upper tuff confining unit \\
VMP & Vitric mafic-poor \\
VTA & Vitric-tuff aquifer \\
WTA & Welded-tuff aquifer \\
ZEOL & Zeolitic \\
\hline
\end{tabular}




\section{LIST OF SYMBOLS FOR ELEMENTS AND COMPOUNDS}

\begin{tabular}{|c|c|}
\hline $\mathrm{Al}$ & Aluminum \\
\hline Am & Americium \\
\hline $\mathrm{Ar}$ & Argon \\
\hline $\mathrm{Br}^{-}$ & Bromide \\
\hline $\mathrm{C}$ & Carbon \\
\hline${ }^{14} \mathrm{C}$ & Radio-carbon \\
\hline $\mathrm{Ca}$ & Calcium \\
\hline $\mathrm{CaO}$ & Calcium oxide \\
\hline $\mathrm{CaCO}_{3}$ & Calcite \\
\hline $\mathrm{CaMg}\left(\mathrm{CO}_{3}\right)_{2}$ & Dolomite \\
\hline $\mathrm{Cd}$ & Cadmium \\
\hline $\mathrm{CH}_{4}$ & Methane \\
\hline${ }^{14} \mathrm{CH}_{4}$ & Radio-methane \\
\hline $\mathrm{Cl}$ & Chlorine \\
\hline $\mathrm{Cm}$ & Curium \\
\hline CO & Carbon monoxide \\
\hline Co & Cobalt \\
\hline $\mathrm{CO}_{2}$ & Carbon dioxide \\
\hline${ }^{14} \mathrm{CO}_{2}$ & Radio-carbon dioxide \\
\hline $\mathrm{CO}_{3}^{2-}$ & Carbonate \\
\hline Cs & Cesium \\
\hline Eu & Europium \\
\hline${ }^{3} \mathrm{H}$ & Tritium \\
\hline $\mathrm{H}_{2} \mathrm{CO}_{3}$ & Carbonic acid \\
\hline $\mathrm{HCO}_{3}{ }^{-}$ & Bicarbonate \\
\hline Ho & Holmium \\
\hline I & Iodine \\
\hline K & Potassium \\
\hline $\mathrm{Kr}$ & Krypton \\
\hline MgO & Magnesium oxide \\
\hline $\mathrm{Nb}$ & Niobium \\
\hline $\mathrm{Ni}$ & Nickel \\
\hline $\mathrm{Np}$ & Neptunium \\
\hline
\end{tabular}




\section{LIST OF SYMBOLS FOR ELEMENTS AND COMPOUNDS (CONTINUED)}

$\begin{array}{ll}\mathrm{Pd} & \text { Palladium } \\ \mathrm{Pu} & \text { Plutonium } \\ \mathrm{SF}_{6} & \text { Sulfur hexafluoride } \\ \mathrm{Sm} & \text { Samarium } \\ \mathrm{Sn} & \text { Tin } \\ \mathrm{Sr} & \text { Strontium } \\ \mathrm{Tc} & \text { Technetium } \\ \mathrm{Th} & \text { Thorium } \\ \mathrm{U} & \text { Uranium } \\ \mathrm{Zr} & \text { Zirconium }\end{array}$




\subsection{INTRODUCTION}

Yucca Flat is one of several areas on the Nevada Test Site (NTS) that was used for underground nuclear testing. The testing resulted in groundwater contamination in the vicinity of the underground test areas. As a result, the U.S. Department of Energy (DOE), National Nuclear Security Administration Nevada Site Office (NNSA/NSO) is currently conducting a corrective action investigation of the Yucca Flat underground test areas.

Since 1996, the Nevada Division of Environmental Protection (NDEP) has regulated the NNSA/NSO corrective action program for the NTS through the Federal Facility Agreement and Consent Order (FFACO) that was agreed to by the State of Nevada; U.S. Department of Energy (DOE); Environmental Management; U.S. Department of Defense; and DOE Legacy Management (FFACO, 1996; as amended February, 2008). The Underground Test Area (UGTA) corrective action strategy is described in Appendix VI, Revision No. 2 of the FFACO (1996; as amended February 2008). This strategy describes the processes that will be used to complete corrective actions, including those in the UGTA Project. The individual locations covered by the agreement are known as corrective action sites (CASs), which are grouped into corrective action units (CAUs). The UGTA CASs are grouped geographically into five CAUs: Frenchman Flat, Central and Western Pahute Mesa, Yucca Flat/Climax Mine, and Rainier Mesa/Shoshone Mountain (Figure 1-1). These CAUs have distinctly different contaminant source, geologic, and hydrogeologic characteristics related to location (FFACO, 1996; as amended February 2008). The Yucca Flat/Climax Mine CAU consists of 720 CASs located in the northeastern part of the NTS (Figure 1-1).

This report documents the evaluation of the information and data available on the unclassified source term and radionuclide contamination for CAU 97: Yucca Flat/Climax Mine. The total residual inventory of radionuclides associated with one or more tests is known as the radiologic source term (RST). The RST is comprised of radionuclides in water, glass, or other phases or mineralogic forms. The hydrologic source term (HST) of an underground nuclear test is the portion of the total RST that is released into the groundwater over time following the test. In this report, the HST 


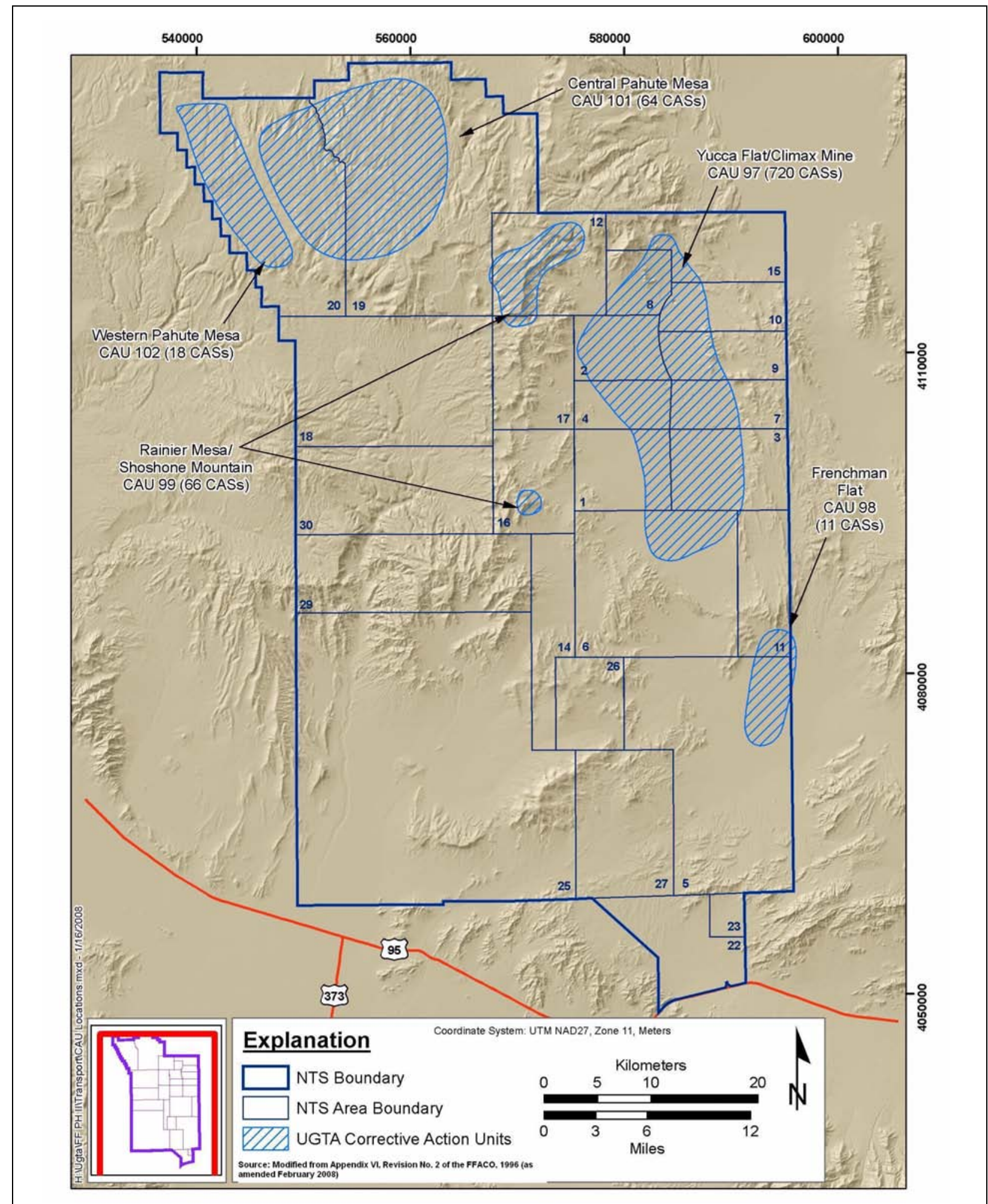

Figure 1-1

Locations of the NTS CAUs 
represents radionuclide release some time after the explosion and does not include the rapidly evolving mechanical, thermal, and chemical processes during the explosion.

The CAU 97: Yucca Flat/Climax Mine has many more detonations and a wider variety of settings to consider compared to other CAUs. For instance, the source term analysis and evaluation performed for CAUs 101 and 102: Central and Western Pahute Mesa and CAU 98: Frenchman Flat did not consider vadose zone attenuation because many detonations were located near or below the water table. However, the large number of Yucca Flat/Climax Mine tests and the location of many tests above the water table warrant a more robust analysis of the unsaturated zone.

\subsection{Purpose and Scope}

The purpose of this report is to develop and document conceptual models of the Yucca Flat/Climax Mine HST for use in implementing source terms for the Yucca Flat/Climax Mine models. This document presents future plans to incorporate the radionuclide attenuation mechanisms due to unsaturated/multiphase flow and transport within the Yucca Flat CAU scale modeling. The important processes that influence radionuclide migration for the unsaturated and saturated tests in alluvial, volcanic, and carbonate settings are identified. Many different flow and transport models developed by Lawrence Livermore National Laboratory (LLNL) and Los Alamos National Laboratory (LANL), including original modeling of multiphase flow and transport by the Stoller-Navarro Joint Venture (SNJV), are integrated to form a general understanding of how the RST relates to the HST. This report is unlike the Frenchman Flat source term analysis because it does not calculate the HST for each test. Instead, this work only identifies the important processes that must be considered when the CAU-transport modeling is performed.

The Yucca Flat/Climax Mine HST has three general hydrogeologic settings: 1) the unsaturated zone, 2) the saturated zone including the unique conditions occurring within the tuff confining unit(s) (TCU), which sometimes result in anomalously high pressures from testing effects, and 3) the vadose zone and saturated zone for tests performed in carbonate rock. Developing and implementing carbonate vadose zone and saturated zone transport conceptual models is original to Yucca Flat/Climax Mine work for the UGTA modeling effort. 
Additional analyses presented in this document focuses on evaluating the multiphase flow and transport process occurring in the alluvium, including radionuclide partitioning between the aqueous and gaseous phase, for two reasons: 1) the Yucca Flat CAU scale vadose zone model is not complete and is a less computationally practical platform for investigations of processes; and 2) calculation of radionuclide migration away from the saturated tests requires knowledge of the groundwater flow rates, and the Yucca Flat CAU-flow models are being developed while this work is being performed.

Specific objectives include:

- Compiling and reviewing available information and data relating to the unclassified source term.

- Compiling and reviewing available information and data relating to flow and transport processes occurring within the vadose zone, saturated zone, and carbonate rock within the Yucca Flat and other CAUs. This data includes near-field and CAU scale modeling performed by LLNL, LANL and Desert Research Institute (DRI).

- Identifying significant contributing processes for the Yucca Flat CAU-model source term.

- Conceptualizing multiphase transport through the alluvium and developing numerical models for testing these conceptual models.

- Identifying the general hydrogeologic conditions for the 747 underground shaft and tunnel detonations performed within the Yucca Flat/Climax Mine CAU (SNJV, 2006b).

The scope of this work includes literature search, information and data compilation, conceptualization of significant processes that effect radionuclide transport, and categorization of detonation/CAS conditions.

The LLNL and LANL HST groundwater modeling studies are of particular interest. The amount of infiltrating water through the vadose zone is likely one of the most important factors transporting radionuclides from the unsaturated tests. Several infiltration studies have been performed at subsidence crater locations because the craters may be focusing precipitation. These data are also of interest to the unsaturated conceptual models. 


\subsection{Yucca Flat/Climax Mine Background}

The Yucca Flat/Climax Mine CAU area is a large ( 19 kilometers [km] east-west by $35 \mathrm{~km}$ north-south [12 by 22 miles]) structural valley located in the northeastern part of the NTS. The Yucca Flat/Climax Mine CAU constitutes the largest of the five NTS CAUs used for underground nuclear testing in terms of total tests and second largest in terms of inventory. This CAU includes portions of NTS Areas 1 through 4, 6 through 12, and 15 (Figure 1-1).

A total of 747 underground nuclear detonations were conducted in shafts and tunnels in this CAU between 1957 and 1992. These included 744 underground shaft detonations in Yucca Flat proper and three tunnel detonations in the Climax Mine tunnel complex (DOE/NV, 2000a). Underground nuclear tests are designated (individually or as groups) as CASs in the FFACO (1996, as amended February 2008). The tests comprise 720 CASs; the reduced number of CASs is the result of multiple (2 or 3) detonations for some CASs. Appendix A discusses Microsoft Excel files that contain a complete list of the underground nuclear shaft and tunnel detonations and related information. These files are included on the document compact disc (CD).

Announced test yields for the Yucca Flat/Climax Mine CAU range from 0 to 500 kilotons (kt), and the depth of burial (DOB) ranges from 58 to 780 meters (m) below ground surface (bgs). Nuclear devices were emplaced in one of four types of geologic media: alluvial deposits, Tertiary volcanics, carbonates, or granitic intrusives (DOE/NV, 2000b). Approximately 23 percent of these detonations were conducted below or within $100 \mathrm{~m}$ of the water table.

\subsection{Corrective Action Strategy}

The focus of the UGTA corrective action strategy is to determine contaminant boundaries for each CAU in compliance with future monitoring requirements (FFACO, 1996; as amended February 2008). The contaminant boundary is defined to encompass the predicted aggregate maximum extent of radionuclide contamination from underground testing exceeding the Safe Drinking Water Act (SDWA) standards (CFR, 2008). As such, it will be composed of both a perimeter boundary and a lower hydrostratigraphic unit (HSU) boundary. Groundwater flow and contaminant transport models will be used to predict the location of this boundary during a future period of 1,000 years at a 95 percent level of confidence. However, recent modeling performed for 
Frenchman Flat and Pahute Mesa CAUs recognize that the 95 percent level of confidence likely cannot be achieved, and the modeling represents the 95th percentile and not a level of confidence.

For the UGTA Project, the corrective action strategy includes two major phases: the first is a regional evaluation addressing all CAUs and CAU-specific evaluations addressing each of the individual CAUs, which was completed with the document Regional Groundwater Flow and Tritium Transport Modeling and Risk Assessment of the Underground Test Area, Nevada Test Site, Nevada (DOE/NV, 1997a). The flow and transport model provided the initial basis for determining the magnitude of risk from the source areas on the NTS to potential receptors and a regional context for future individual CAU investigations. The second phase focuses on refining the results of the regional-scale modeling through acquisition and analysis of CAU-specific data, and development of CAU scale flow and transport models.

Three CAU scale models are being developed by LANL and SNJV. These models consist of: 1) the Yucca Flat unsaturated zone, 2) the saturated Tertiary volcanics and alluvium stratigraphic units, and 3) the Paleozoic carbonate aquifer known as the lower carbonate aquifer (LCA).

The unsaturated-zone model for Yucca Flat considers enhanced infiltration in subsidence craters as the primary driver for radionuclide transport and accounts for local catchment runoff within and beyond individual crater boundaries. The unsaturated-zone model consist of twelve three-dimensional (3-D) sections. Each section is 13 by $2 \mathrm{~km}$ extending from ground surface to the water table (Figure 1-2). The 12 models divide the Yucca Flat into manageable computational grids. The models have sufficiently refined discretization to simulate individual test geometries of the crater, chimney and cavity. The dipping volcanic stratigraphy and presence of faults in the unsaturated zone in conjunction with enhanced subsidence crater recharge likely result in lateral flow, which requires a 3-D model. The unsaturated zone model will provide transient recharge rates and radionuclide fluxes to the saturated alluvium/volcanic and carbonate aquifer models (Kwicklis, 2008).

The saturated alluvium/volcanic aquifer model considers the anomalously high groundwater heads that occurred in the saturated volcanic tuffs following the underground nuclear testing. The testing may have introduced significant changes in both aquifer properties and head gradients that may create fast transport pathways between volcanics and the LCA. The pressure dissipation time scale is likely 


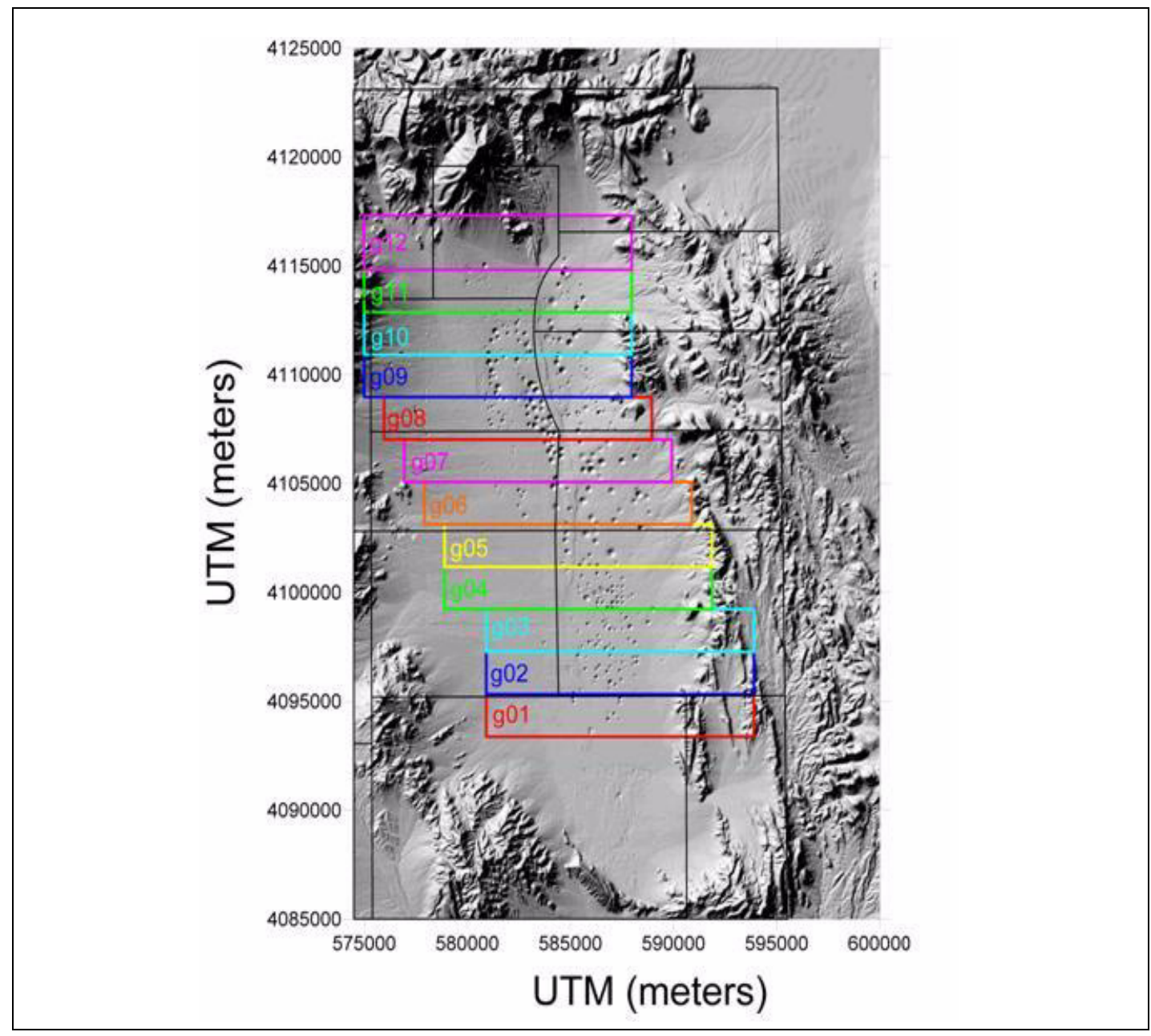

\section{Figure 1-2 \\ Unsaturated Zone CAU Model Grids}

Source: Kwicklis, 2008

influenced by specific geologic conditions, and tests performed in very low conductivity rock will likely experience the longest time scale. The tuff pressurization is most predominant in the central Yucca Flat “Tuff Pile” area. The saturated alluvium/volcanic aquifer model will provide transient recharge and radionuclide flux to the LCA model.

The LCA model considers the thick Paleozoic carbonate rock sequence that transmits all of the groundwater flowing out of Yucca Flat (Laczniak et al., 1996). The LCA is the primary conduit for radionuclides to migrate away from Yucca Flat. 
The process flow diagram for implementing the corrective action strategy for the UGTA CAUs, as required by the FFACO (1996, as amended February 2008), is shown in Figure 1-3. The CAU-specific corrective action process includes six major elements:

1. Corrective Action Investigation Plan (CAIP) - This plan provides or references all specific information for planning investigation activities associated with CAUs or CASs.

2. Corrective Action Investigation (CAI) - This investigation includes the collection of new data, the evaluation of new and existing data, and the development and use of CAU-specific groundwater flow and transport model(s). The CAI process may be iterative, resulting in several phases of data collection, analysis, and modeling, with assessment of confidence in the results at the completion of each phase (Figure 1-3). If further data collection, analysis, and modeling are required, a CAIP addendum will be issued to direct the new phase of activities.

3. Corrective Action Decision Document (CADD) - This document describes the results of the CAI, the selected corrective action, and the selection rationale. The selection rationale will consist of an analysis of possible corrective action alternatives.

4. Corrective Action Plan (CAP) - This plan describes how the selected remedial alternative is to be implemented. The CAP will contain the engineering design and necessary specifications to implement the selected remedial alternative.

5. Closure Report (CR) - This report details closure activities, including the preparation of a $\mathrm{CR}$, NDEP review of the CR, and long-term closure monitoring by DOE.

6. Long-term post-closure monitoring - The monitoring is designed to test whether the remedial action strategy is working and to ensure the model forecasts used to develop the compliance boundary are not violated.

\subsection{Corrective Action Investigation Documentation}

The Yucca Flat CAI planning activities are documented in several reports. The strategy for development of the flow and transport modeling is presented in the Yucca Flat/Climax Mine modeling strategy report (Shaw, 2003). The planning documents include:

- Value of Information Analysis for Corrective Action Unit 97: Yucca Flat, Nevada Test Site, Nevada (IT, 1999). Describes the evaluation of the sufficiency of existing information to support the CAI and identifies the major problems anticipated in developing the geologic, flow, and transport models. Potential data collection activities to improve characterization data are evaluated for potential benefit and prioritization. 


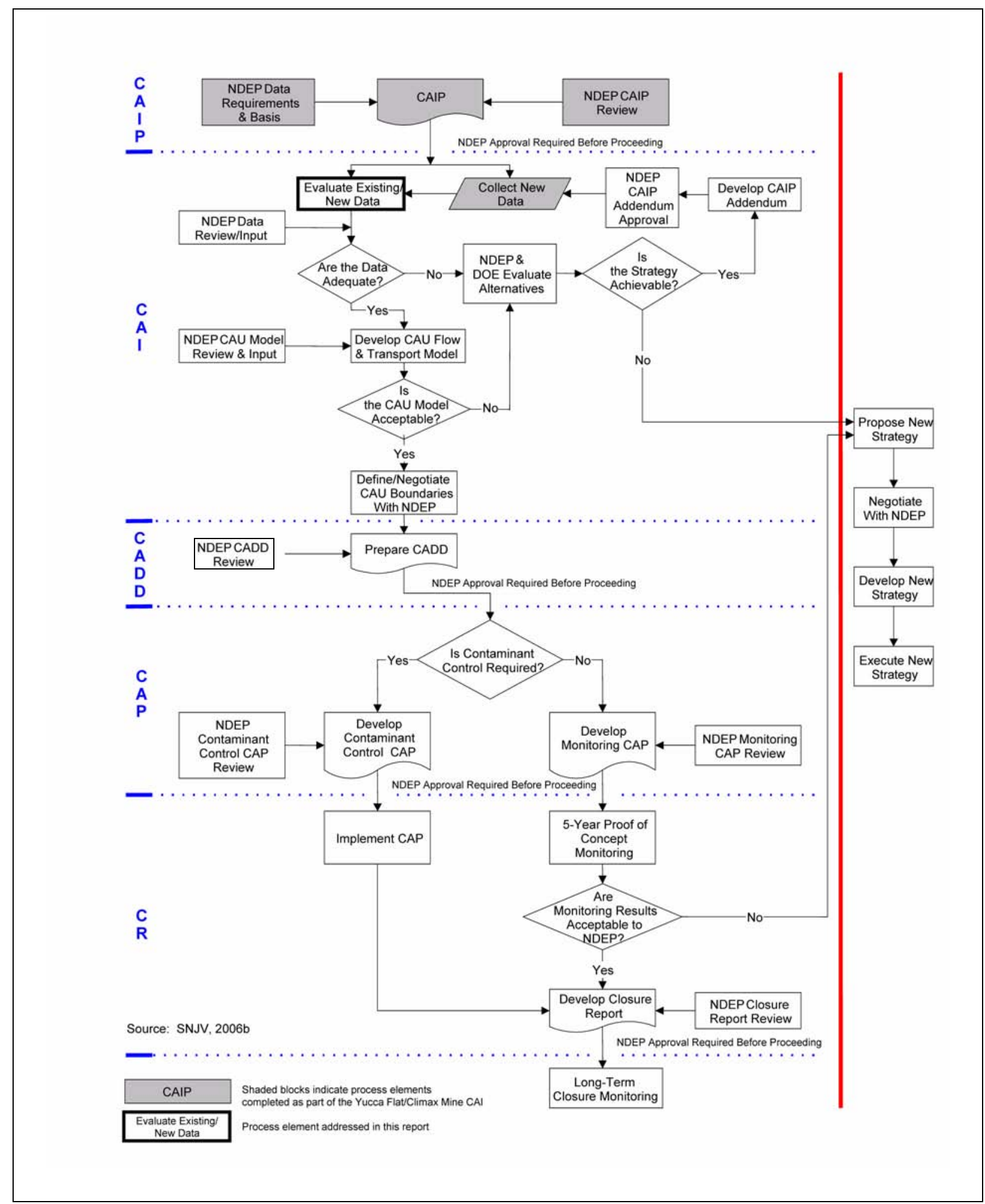

Figure 1-3

Process Flow Diagram for the Underground Test Area CAUs 
- Corrective Action Investigation Plan for Corrective Action Unit 97: Yucca Flat/Climax Mine, Nevada Test Site, Nevada (DOE/NV, 2000a). An FFACO (1996, as amended February 2008) requirement that summarizes the historical data for the Yucca Flat/Climax Mine CAU. Describes the characterization activities that will be implemented to evaluate the extent of contamination in groundwater due to underground nuclear testing and to support the development of groundwater flow and transport models to predict the contaminant boundary.

- Modeling Approach/Strategy for Corrective Action Unit 97, Yucca Flat and Climax Mine (Shaw, 2003). Describes approaches to modeling flow and transport over time through the hydrogeologic system. One approach is the development of numerical process models to represent the processes that control flow and transport. The other approach uses simplified representations of the process models to assess the interactions between model and parameter uncertainty.

The Yucca Flat/Climax Mine CAIP (DOE/NV, 2000a) identifies that CAU modeling will be performed in the following steps: 1) acquisition/compilation and analysis of geologic and groundwater flow data, 2) acquisition/compilation and analysis of transport and source term data, 3) HSU model development, 4) groundwater flow and transport simulations, 5) sensitivity and uncertainty analysis, 6) model evaluation, and 7) contaminant boundary prediction. Much of the geologic, groundwater flow, and transport data acquisition/compilation and assessment steps have been completed. The HSU model development has been completed. The development of the flow and transport models is currently being performed. The flow and transport data compilation and analysis, and HSU development reports include the following:

- $\quad$ Phase I Hydrologic Data for the Groundwater Flow and Contaminant Transport Model of Corrective Action Unit 97: Yucca Flat/Climax Mine, Nevada Test Site, Nye County, Nevada (SNJV, 2006b). Identifies, compiles, and analyzes the available hydrologic data for the groundwater flow model. The work assesses the quality of the data and identifies the associated uncertainty/variability.

- $\quad$ Phase I Contaminant Transport Parameters for the Groundwater Flow and Contaminant Transport Model of Corrective Action Unit 97: Yucca Flat/Climax Mine, Nevada Test Site, Nye County, Nevada (SNJV, 2007). Identifies, compiles, and analyzes the available transport parameter data for the groundwater flow model. The work assesses the quality of the data and identifies the associated uncertainty/variability.

- A Hydrostratigraphic Model and Alternatives for the Groundwater Flow and Contaminant Transport Model of Corrective Action Unit 97: Yucca Flat-Climax Mine, Lincoln and Nye Counties, Nevada (BN, 2006). Geological and geophysical data collected over the past 50 years was used to develop a structural model and hydrostratigraphic system for the basin. 


\subsection{Hydrologic Source Term Modeling and Radionuclide Data Documentation}

Numerous analyses and reports were used to support the development of the Yucca Flat source term conceptual models. These data include complex mechanistic model simulation results for individual detonation sites, radionuclide inventories, crater infiltration studies, and hydrologic and contaminant transport parameter studies. The HSTs developed for the other CAUs may be used in the Yucca Flat HST. These documents include:

- A written communication describing the HANDCAR, NASH, KANKAKEE, and BOURBON near-field environment titled Evaluation of Hydrologic Source Term Processes for Underground Nuclear Tests in Yucca Flat, Nevada Test Site: Carbonate Tests (Carle et al., 2008).

- A written communication describing simplified flow and transport analyses to understand the role of crater infiltration on potential mass transport from the unsaturated tests titled Evaluation of Hydrologic Source Term Processes for Underground Nuclear Tests in Yucca Flat, Nevada Test Site: Unsaturated Tests and the Impact of Recharge (McNab, 2008).

- A written communication describing evaluation of test pressurization and heat effects on HST in regions distinct from the Tuff Pile area titled Evaluation of Hydrologic Source Term Processes for Underground Nuclear Tests in Yucca Flat, Nevada Test Site: Saturated Tests (Maxwell et al., 2008).

- A written communication attempting to categorize underground nuclear tests in the Yucca Flat/Climax Mine CAU to reduce the number of tests that must be individually modeled and to understand the ranges of data that will be used in sensitivity studies of source term models titled Categorization of Underground Nuclear Tests on Yucca Flat and Climax Mine, Nevada Test Site, for Use in Radionuclide Transport Models (Pawloski et al., 2005).

- A report evaluating anomalously high groundwater heads and their relationship to hydrologic properties and InSar-detected land subsidence between the Topgallant Fault and the Yucca Fault titled Hydraulic Characterization Of Overpressured Tuffs in Central Yucca Flat, Nevada Test Site, Nye County, Nevada (Halford et al., 2005).

- A written communication investigating the processes that resulted in large rises and slow pressure declines observed in groundwater occurring between the Topgallant and Yucca Faults titled Analysis and Evaluation of Elevated Groundwater Heads and Their Impact on Flow and Solute Transport in the Tuff Pile: Areas 3, 4, and 7 of the Nevada Test Site, Nye County, Nevada (Wolfsberg et al., 2006).

- A description of the estimated unclassified radionuclide inventories for each UGTA CAU and the uncertainties associated with the inventories titled Nevada Test Site Radionuclide Inventory, 1951-1992 (Bowen et al., 2001). 
- A report describing the U-3fd crater infiltration study at Yucca Flat titled Assessment of Soil Moisture Movement in Nuclear Subsidence Craters (Tyler et al., 1992). Soil water tritium $\left({ }^{3} \mathrm{H}\right)$ and traditional soil physics approaches were used to estimated the recharge rate.

- A report describing the infiltration into crater U-10i located in northern Yucca Flat titled Evaluation of Recharge Potential at Subsidence Crater U10i, Northern Yucca Flat, Nevada Test Site (Hokett et al., 2000).

- A report describing an infiltration study at the Frenchman Flat U-5a crater titled Evaluation of Recharge Potential at Crater U5a (Wishbone) (Hokett and French, 1998). The study performed overland flow and infiltration modeling of a small watershed for the U-5a crater.

- A report describing the analysis of hydrologic data in support of the CAU groundwater flow model titled Phase I Hydrologic Data for the Groundwater Flow and Transport Model of Corrective Unit 97: Yucca Flat/Climax Mine, Nevada Test Site, Nye County, Nevada (SNJV, 2006b).

- A report describing the analysis of contaminant transport parameter data titled Phase I Contaminant Transport Parameters Data for the Groundwater Flow and Transport Model of Corrective Unit 97: Yucca Flat/Climax Mine, Nevada Test Site, Nye County, Nevada (SNJV, 2007).

- A report describing sub-CAU scale modeling of groundwater flow and radionuclide transport for the weapons effects testing detonations, in the Climax Mine granite stock located in Area 15 at the northern end of Yucca Flat, titled Modeling of Groundwater Flow and Radionuclide Transport at the Climax Mine sub-CAU, Nevada Test Site (Pohlmann et al., 2007).

\subsection{Document Organization}

This report is organized into the following:

- Section 1.0 provides a description of the project background, the purpose and scope of this report, and a summary of the document.

- Section 2.0 provides background information regarding the HST for Yucca Flat. This section includes a review of available data regarding flow and transport through the unsaturated and saturated zones above the LCA. The unsaturated zone data focuses on crater infiltration. The saturated zone data focuses on test-induced aquifer pressurization and heating. Section 2.0 also includes summary descriptions of the information available on radionuclide contamination sources and extent for the Yucca Flat CAU, which includes radionuclide data, available to date. 
- Section 3.0 identifies processes important for the Yucca Flat HST, and the conceptual models for each hydrogeologic setting (i.e., saturated, unsaturated, and carbonate).

- Section 4.0 categorizes the 744 underground shaft detonations performed within the Yucca Flat proper into representative classes. This work identifies general hydrogeologic conditions of each test (i.e., saturated, unsaturated, and carbonate) and evaluates the relative importance of categories to the Yucca Flat HST.

- Section 5.0 describes modeling performed to evaluate multiphase flow and transport through the unsaturated zone.

- Section 6.0 provides a summary, describes the limitations associated with the information presented in this document, and suggests approaches for calculating the HST during the CAU transport modeling phase.

- $\quad$ Section 7.0 provides a list of references cited in this document.

- Appendix A contains a summary of each Yucca Flat detonation including the name and date of each detonation, name and location of the emplacement holes, announced yields, DOBs (i.e., the working point), estimated depths to the water table, and the HSU associated with the working point.

- Appendix B contains the yield weighted radionuclide inventory for each detonation within the Yucca Flat CAU.

- Appendix C presents Finite Element Heat and Mass Transfer code (FEHM) simulations of a multiphase, meso-scale experiment of radionuclide transport. The multiphase parameterization of the FEHM model was verified by simulating aqueous/gaseous phase transport and history matching experimental data.

- Appendices D Comments from Nevada Division of Environmental Protection. 


\subsection{REVIEW of AVAILABLE SOURCE TERM INFORMATION}

Modeling the release of radionuclides from the cavity/chimney environment and their migration to the water table requires an understanding of the sources of radionuclides and the processes involved in their near-field environment. The available information on the sources of radionuclide contamination includes underground nuclear test data, the phenomenology of underground nuclear tests, unclassified radionuclide inventory, radionuclide distribution in the near-field, and specific processes occurring within the vadose zone and saturated zone.

To better understand and quantify the processes involved in the release and migration of radionuclides within the near-field, LLNL has developed near-field HST models for Yucca Flat, Frenchman Flat, and Pahute Mesa. The LLNL defines the near-field as the subsurface environment located within several (1-10) cavity radii $\left(\mathrm{R}_{\mathrm{c}}\right)$ of the test. In addition, LANL performed sub-CAU scale modeling to understand the processes important for radionuclide migration from the saturated volcanic tuffs at Yucca Flat. Specifically, these modeling efforts include:

- Phase I and Phase II CAMBRIC HST models (Tompson et al., 1999 and 2005, and Carle et al., 2007). The Phase I CAMBRIC HST evaluates radionuclide migration in the near-field. The Phase II CAMBRIC HST analyses are available to help understand the processes involved to quantitatively forecast the HST within the near-field environment of the CAMBRIC detonation (transient) and other simplified source terms model(s) (SSMs) for other Frenchman Flat tests (steady-state).

- Methods for Calculating Frenchman Flat Source Term Sensitivity (Tompson et al., 2004). Provides an approach for the development of simplified unclassified HSTs.

- TYBO-BENHAM groundwater model (Wolfsberg et al., 2002). Evaluates the processes important for intermediate scale radionuclide migration from the TYBO and BENHAM detonations at Pahute Mesa.

- CHESHIRE HST model (Pawloski et al., 2001). Evaluates how radionuclides move from the CHESHIRE detonation in the near-field into the groundwater at Pahute Mesa. 
- HANDCAR, NASH, BOURBON and KANKAKEE carbonate HST modeling (Carle et al., 2008). Evaluates the effects of carbonate-specific phenomenology and chemistry on near-field radionuclide migration at Yucca Flat.

- Unsaturated test modeling (McNab, 2008). Evaluates the role of crater infiltration on radionuclide migration through the vadose zone from the unsaturated tests using simplified flow and transport analysis.

- Saturated test modeling (Maxwell et al., 2008). Evaluates the role of test pressurization and heat effects on radionuclide migration from tests in an area distinct from the Tuff Pile.

- Saturated test modeling (Wolfsberg et al., 2006). Evaluates the potential for high pressure with slow pressure decline to sustain rapid flow and transport to other units.

- Climax Mine sub-CAU scale modeling (Pohlmann et al., 2007). Evaluates the Climax Mine groundwater flow and radionuclide transport and provides boundary conditions for the Yucca Flat CAU scale modeling.

A description of these LLNL near-field HST models along with the LANL sub-CAU scale modeling is presented in this section, and the available radionuclide inventory data for Yucca Flat CAU are described.

\subsection{Underground Nuclear Test Data}

Unclassified information related to the underground nuclear tests conducted within the Yucca Flat/Climax Mine CAU is compiled primarily in two reports, United States Nuclear Tests, July 1945 through September 1992 (DOE/NV, 2000b) and Shaft and Tunnel Nuclear Detonations at the Nevada Test Site: Development of a Primary Database for the Estimation of Potential Interactions with the Regional Groundwater System (DOE/NV, 1997b). The data in these reports, including the name and date of each detonation, name of the emplacement holes, announced yields, DOBs (i.e., the working point), estimated depths to the water table and HSU associated with the working point are discussed in Appendix A and included on the document CD.

The term yield refers to the total effective energy released in a nuclear explosion and is usually expressed in terms of equivalent tonnage of trinitrotoluene (TNT) required to produce the same energy release in an explosion. Announced yield ranges are reported in DOE/NV (2000b); the specific yields for many tests remain classified. The announced yields for some detonations were termed slight, low, or intermediate (see Appendix A). Between 1945 and 1963, a less than 20 kt yield 
was defined as low, while a 20- to 200-kt yield range was defined as intermediate. In a few cases, the term slight was used without amplification (DOE/NV, 2000b). If a yield range is presented in DOE/NV (2000b), the maximum value is used for the Yucca Flat unclassified source term calculations. A few detonations were reported to have a slight yield without assignment of a numerical value. Those detonations with a slight yield are assumed to have a maximum 20 kt yield.

The maximum upper limit of the announced yield range for Yucca Flat is $500 \mathrm{kt}$, whereas the Climax Mine detonations maximum is $62 \mathrm{kt}$. A zero yield was reported for three detonations - SAN JUAN (Operation Hardtack II), COURSER (Operation Whetstone), and TRANSOM (Operation Cresset). The TRANSOM nuclear device did not detonate and was destroyed $\sim 16$ months later, as planned, by the HEARTS detonation (Operation Quicksilver) (DOE/NV, 2000b).

The total inventory (or quantity) of radionuclides associated with each individual detonation, regardless of form and distribution, is referred to as the RST. Radionuclides listed in Bowen et al. (2001) are the most relevant radionuclides for consideration. These radionuclides should be considered as those with sufficiently long half-lives and abundance to be of regulatory concern over the next 1,000 years.

The HST is the amount of radionuclides available for transport in groundwater. The HST is a subset of the RST in terms of the specific radionuclides and the amounts of radionuclides, because the mobility of radionuclides is moderated by both chemical and hydrologic processes (Bowen et al., 2001). The exchange volume is the initially contaminated region following each detonation and contains radionuclides in the rubble, gas, and water phases. Inventory fractions are assigned to the exchange volume, where they are distributed among aqueous, gaseous, and sorbed states described below. The melt glass comprises a storage component for radionuclides from which the radionuclides are released slowly with dissolution of the glass.

\subsection{Phenomenology of Underground Nuclear Explosions}

Phenomenology describes the effects of a nuclear explosion on the host media as a function of time. Phenomenological models describe the impact to the media resulting from the explosion. The unsaturated, saturated, and carbonate tests each have unique phenomenological aspects. This section includes an overview of the general phenomenology of an underground nuclear explosion. 
The unique phenomenology associated with unsaturated, saturated, and carbonate tests is presented in Section 3.0.

\subsubsection{Phenomenology Overview}

The testing of an underground nuclear explosion results in successive, physical phenomena that occur within measured time frames. The following describes the time frames and corresponding phenomena based on a report prepared by the U.S. Congress, Office of Technology Assessment (1989):

- Within microseconds, billions of atoms release their energy. Temperatures can increase to several hundred million degrees Centigrade and pressures of several million pounds per square inch (psi) are created. This results in a powerful shock wave that spreads outward from the point of origin.

- Within tens of milliseconds, the shock wave expands and the surrounding rock is crushed, melted, and vaporized, creating an expanding cavity. It is estimated that the shock wave vaporizes $\sim 70$ metric tons and melts 700 metric tons of rock for each kiloton of explosive yield (Olsen, 1967).

- Within tenths of a second, the cavity reaches its fullest growth potential. The shock wave generated by the explosion fractures and crushes the rock as it extends outward from the cavity. The shock wave eventually loses its strength and momentum and becomes too weak to continue to crush rock. Thus, the crushed rock is characterized by a compression and relaxation phase that become seismic waves.

- Within minutes, or up to days, molten rock collects, solidifies, and forms at the bottom of the cavity. Cooling results in a decrease in the gas pressure of the cavity.

- Within minutes, or up to days, cavity collapse occurs because of the decreased gas pressure, which causes the overlying rock that supports the cavity to weaken. A process referred to as "chimneying” is a result of rock debris and loose rubble falling into the cavity and causing the void area to rise. Chimneying continues until one of the following occurs to the void region: the void becomes completely filled with loose rubble, the shape of the void in conjunction with the strength of the rock can sustain the overburden material, or the chimney reaches ground surface.

Other phenomena related to underground nuclear testing may occur, including hydrofracturing, prompt injection of radionuclides, groundwater effects (e.g., mounding and pressurization), and movement of pre-existing structural features (e.g., faults). These may affect cavity growth, residual 
stress, collapse, and crater formation. Figure 2-1 illustrates early and late time phenomenology of an underground nuclear explosion (Tompson et al., 1999).

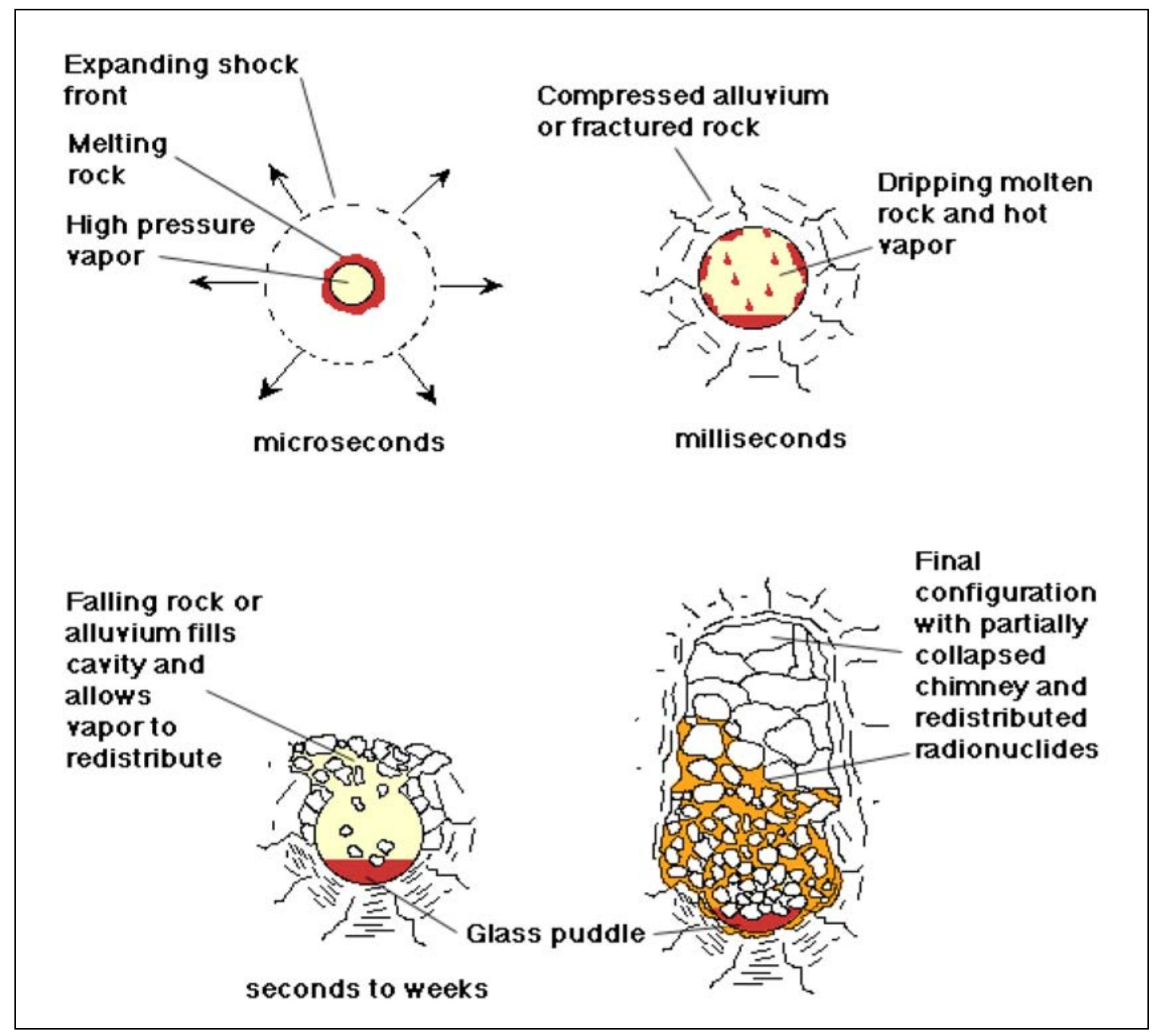

Figure 2-1

Phenomenology of Silicate Tests

Source: Tompson et al., 1999

\subsection{Unclassified Radionuclide Inventory and Distribution}

Definition of the HST requires knowledge of the total inventory of radionuclides associated with each test and the subsequent release of these radionuclides over time. The release of radionuclides over time will depend on the distribution of radionuclides within the subsurface. Radionuclides distributed in the cavity water and gas will be readily available for transport by groundwater. However, radionuclides incorporated in the melt glass matrix are available to the groundwater only through the slow process of melt glass dissolution. 


\subsubsection{Inventory}

A comprehensive unclassified inventory of the radionuclide source term for the NTS is found in the report, Nevada Test Site Radionuclide Inventory, 1951-1992 (Bowen et al., 2001). This inventory provides an estimate of radioactivity remaining underground at the NTS after nuclear testing. The inventory was subdivided into five areas that correspond to the principal geographic test centers. The five areas roughly correspond to the UGTA CAUs. The Rainier Mesa/Shoshone Mountain group includes Areas 12, 16, and 17. The inventory for Yucca Flat was further subdivided by detonations where the working point depth is more than $100 \mathrm{~m}$ above the water table and detonations that were detonated below that level. The inventory includes ${ }^{3} \mathrm{H}$, fission products, unspent fuel materials, and activation products. The radionuclide inventory reported in Bowen et al. (2001) is decay-corrected to September 23, 1992, the date of the last underground nuclear test. Table 2-1 lists the estimated accuracies of this inventory for various groups of radionuclides, as reported by Bowen et al. (2001).

Table 2-1

Estimated Accuracies for Various Groups of Radionuclides

\begin{tabular}{|c|c|}
\hline Radionuclide Group & Accuracy (Approximate) \\
\hline \hline Fission Products & 10 to 30 percent \\
\hline Unspent Fuel Materials & 20 percent or better \\
\hline Fuel Activation Products & 50 percent or better \\
\hline Residual Tritium & 300 percent or better \\
\hline Activation Products & 1,000 percent \\
\hline
\end{tabular}

Source: SNJV, 2005

The Bowen et al. (2001) inventory includes: 1) residual fissile and tracer materials, 2) fission products, 3) tritium, and 4) neutron activation of device parts and the surrounding geologic medium. Criteria for inclusion of radionuclides in the inventory are discussed in the Bowen et al. (2001) report and the inventory includes 43 radiological contaminants that have half-lives greater than 10 years (with the exception of europium [Eu]-154). The source of ${ }^{40} \mathrm{~K}$ is mostly natural, whereas the others $\left({ }^{232} \mathrm{Th},{ }^{234} \mathrm{U},{ }^{235} \mathrm{U}\right.$, and ${ }^{238} \mathrm{U}$ ) are naturally occurring as well as device components. 
The Bowen et al. (2001) radionuclide inventory for Yucca Flat is provided in Table 2-2. The total inventory of detonations located $100 \mathrm{~m}$ or more above the water table is approximately half that for detonations located within $100 \mathrm{~m}$ or below the water table. The individual detonation RST may be estimated from the individual yield in three steps: 1) separately normalizing the Yucca Flat above and below the water table inventories reported in Bowen et al. (2001), 2) multiplying the normalized inventory by the individual detonation yield, and 3) decay correcting the individual detonation yield from September 23, 1992, to time $\left(t_{0}\right)$ of each test. The decay correction for each radionuclide was accomplished using the following formula:

$$
n(t)=n(0) e^{-\lambda_{2} t}
$$

where:

$\lambda_{2}=1 \mathrm{n}(2) / \mathrm{T}_{1 / 2}$ is the decay constant

$\mathrm{n}(0)=$ Number of moles of radionuclide at time $\mathrm{t}_{0}$ of the test

$t \quad=$ Time elapsed between time of test and September 23, 1992

$\mathrm{n}(\mathrm{t})$ = Number of moles of radionuclide reported in Bowen et al. (2001)

(decay corrected to September 23, 1992)

This equation applies to the first member in a radionuclide decay chain, but is incorrect for daughter products in a decay chain for which another radionuclide in the RST is the parent. The radionuclides americium (Am)-241 and neptunium (Np)-237 are part of a decay chain plutonium $(\mathrm{Pu})-241 \rightarrow{ }^{241} \mathrm{Am} \rightarrow{ }^{237} \mathrm{~Np}$. However, the correct amount of parent radionuclide at the $t_{0}$ cannot be calculated from the Bowen et al. (2001) inventory because the amount of daughter radionuclide is the total from many different tests performed at different times. The ratio of parent and daughter radionuclide is incorrect for the elapsed time, and erroneous amounts of parent radionuclide will be calculated.

The yield weighted and decay-corrected inventories for each radionuclide considered in the Yucca Flat source term are discussed in Appendix B and included on the document CD. The daughter radionuclides in the ${ }^{241} \mathrm{Pu} \rightarrow{ }^{241} \mathrm{Am} \rightarrow{ }^{237} \mathrm{~Np}$ decay chain were not decay corrected and therefore conservatively overestimated the amount of longer lived and more mobile ${ }^{237} \mathrm{~Np}$ at the date of the individual detonation.

Carle et al. (2008) identified additional unclassified sources of information for estimating the carbon (C)-14 and argon (Ar)-39 inventory for the HANDCAR detonation and the ${ }^{3} \mathrm{H}$ and krypton (Kr)-85 
Table 2-2

Radionuclide Inventory for Yucca Flat

(Page 1 of 2)

\begin{tabular}{|c|c|c|c|c|c|}
\hline \multirow[b]{2}{*}{ Radionuclide } & \multirow{2}{*}{$\begin{array}{l}\text { Half-life } \\
\text { (Years) }\end{array}$} & \multicolumn{2}{|c|}{ Atoms } & \multicolumn{2}{|c|}{ Curies } \\
\hline & & $\begin{array}{l}\text { Yucca Flat } \\
\text { - Above }\end{array}$ & $\begin{array}{l}\text { Yucca Flat } \\
\text { - Below }{ }^{b}\end{array}$ & $\begin{array}{l}\text { Yucca Flat } \\
\text { - Above }\end{array}$ & $\begin{array}{l}\text { Yucca Flat } \\
\text { - Below b }\end{array}$ \\
\hline${ }^{3} \mathrm{H}$ & $1.23 \times 10^{1}$ & $3.055 E+26$ & $6.881 E+26$ & $1.472 \mathrm{E}+07$ & $3.316 \mathrm{E}+07$ \\
\hline${ }^{14} \mathrm{C}$ & $5.73 \times 10^{3}$ & $1.094 \mathrm{E}+25$ & $8.076 E+24$ & 1.137E+03 & 8.389E+02 \\
\hline${ }^{26} \mathrm{Al}$ & $7.3 \times 10^{5}$ & $6.665 E+22$ & 4.300E+22 & 5.573E-02 & 3.595E-02 \\
\hline${ }^{36} \mathrm{Cl}$ & $3.01 \times 10^{5}$ & 5.899E+25 & 1.171E+26 & 1.163E+02 & $2.309 E+02$ \\
\hline${ }^{39} \mathrm{Ar}$ & $2.69 \times 10^{2}$ & $1.452 E+23$ & $4.328 E+23$ & $3.204 \mathrm{E}+02$ & $9.551 E+02$ \\
\hline${ }^{40} \mathrm{~K}$ & $1.27 \times 10^{9}$ & 1.758E+29 & $5.181 E+29$ & 8.219E+01 & $2.422 E+02$ \\
\hline${ }^{41} \mathrm{Ca}$ & $1.03 \times 10^{5}$ & $1.483 E+26$ & $2.882 E+26$ & $8.545 E+02$ & $1.661 \mathrm{E}+03$ \\
\hline${ }^{59} \mathrm{Ni}$ & $7.51 \times 10^{4}$ & $2.738 E+24$ & $5.460 \mathrm{E}+24$ & $2.139 E+01$ & $4.265 E+01$ \\
\hline${ }^{63} \mathrm{Ni}$ & $1.00 \times 10^{2}$ & $3.932 E+23$ & 8.808E+23 & 2.334E+03 & $5.229 E+03$ \\
\hline${ }^{85} \mathrm{Kr}$ & $1.07 \times 10^{1}$ & $2.06 \mathrm{E}+23$ & $1.052 E+24$ & 1.137E+04 & $5.805 E+04$ \\
\hline${ }^{90} \mathrm{Sr}$ & $2.91 \times 10^{1}$ & $7.265 E+24$ & $3.626 \mathrm{E}+25$ & 1.499E+05 & $7.479 E+05$ \\
\hline${ }^{93} \mathrm{Zr}$ & $1.5 \times 10^{6}$ & $1.731 E+25$ & $6.587 E+25$ & $6.852 E+00$ & 2.607E+01 \\
\hline $93 \mathrm{~m} N b$ & $1.61 \times 10^{1}$ & 1.694E+22 & $1.825 E+23$ & $6.246 \mathrm{E}+02$ & $6.730 \mathrm{E}+03$ \\
\hline${ }^{94} \mathrm{Nb}$ & $2.03 \times 10^{4}$ & $7.734 \mathrm{E}+23$ & $6.652 E+24$ & 2.296E+01 & 1.975E+02 \\
\hline${ }^{99} \mathrm{Tc}$ & $2.13 \times 10^{5}$ & $2.208 E+25$ & $6.727 E+25$ & $6.153 E+01$ & 1.875E+02 \\
\hline${ }^{107} \mathrm{Pd}$ & $6.5 \times 10^{6}$ & $8.359 E+24$ & $1.010 \mathrm{E}+25$ & 7.634E-01 & 9.226E-01 \\
\hline${ }^{113 m} \mathrm{Cd}$ & $1.41 \times 10^{1}$ & $3.719 E+21$ & $1.186 \mathrm{E}+22$ & $1.566 \mathrm{E}+02$ & 4.994E+02 \\
\hline${ }^{121 m} \mathrm{Sn}$ & $5.50 \times 10^{1}$ & $6.243 E+22$ & $1.777 E+23$ & $6.738 E+02$ & 1.918E+03 \\
\hline${ }^{126} \mathrm{Sn}$ & $1.00 \times 10^{5}$ & 1.433E+24 & $3.858 E+24$ & $3.402 E+00$ & $9.161 \mathrm{E}+00$ \\
\hline 129 & $1.57 \times 10^{7}$ & $5.498 E+24$ & $1.434 \mathrm{E}+25$ & 2.079E-01 & 5.422E-01 \\
\hline${ }^{135} \mathrm{Cs}$ & $2.3 \times 10^{6}$ & 2.683E+25 & 7.633E+25 & $6.926 \mathrm{E}+00$ & 1.970E+01 \\
\hline${ }^{137} \mathrm{Cs}$ & $3.02 \times 10^{1}$ & $1.478 \mathrm{E}+25$ & $4.710 \mathrm{E}+25$ & $2.919 E+05$ & $9.299 E+05$ \\
\hline${ }^{151} \mathrm{Sm}$ & $9.00 \times 10^{1}$ & $2.105 E+24$ & $4.835 E+24$ & $1.388 E+04$ & $3.189 E+04$ \\
\hline${ }^{150} \mathrm{Eu}$ & $3.60 \times 10^{1}$ & $8.209 E+23$ & $6.664 \mathrm{E}+21$ & $1.354 \mathrm{E}+04$ & 1.099E+02 \\
\hline${ }^{152} \mathrm{Eu}$ & $1.35 \times 10^{1}$ & $8.288 E+23$ & 1.615E+24 & 3.634E+04 & 7.083E+04 \\
\hline${ }^{154} \mathrm{Eu}$ & $8.59 \times 10^{0}$ & $4.297 E+23$ & $7.932 E+23$ & $2.968 E+04$ & $5.480 \mathrm{E}+04$ \\
\hline${ }^{166 \mathrm{~m}} \mathrm{Ho}$ & $1.20 \times 10^{3}$ & $5.387 E+22$ & $1.115 \mathrm{E}+23$ & $2.665 E+01$ & $5.514 \mathrm{E}+01$ \\
\hline $232 \mathrm{Th}$ & $1.40 \times 10^{10}$ & 1.408E+29 & 4.133E+29 & 5.969E+00 & $1.752 E+01$ \\
\hline${ }^{232} \mathrm{U}$ & $6.89 \times 10^{1}$ & $1.059 E+22$ & $4.338 E+22$ & $9.004 \mathrm{E}+01$ & $3.690 E+02$ \\
\hline${ }^{233} \mathrm{U}$ & $1.59 \times 10^{5}$ & $3.223 E+25$ & $4.090 E+25$ & $1.202 E+02$ & $1.525 \mathrm{E}+02$ \\
\hline${ }^{234} \mathrm{U}$ & $2.46 \times 10^{5}$ & $3.534 E+25$ & $6.194 \mathrm{E}+25$ & 8.528E+01 & 1.495E+02 \\
\hline
\end{tabular}


Table 2-2

Radionuclide Inventory for Yucca Flat

(Page 2 of 2)

\begin{tabular}{|c|c|c|c|c|c|}
\hline \multirow[b]{2}{*}{ Radionuclide } & \multirow{2}{*}{$\begin{array}{l}\text { Half-life } \\
\text { (Years) }\end{array}$} & \multicolumn{2}{|c|}{ Atoms } & \multicolumn{2}{|c|}{ Curies } \\
\hline & & $\begin{array}{l}\text { Yucca Flat } \\
\text { - Above }\end{array}$ & $\begin{array}{l}\text { Yucca Flat } \\
\text { - Below }\end{array}$ & $\begin{array}{l}\text { Yucca Flat } \\
\text { - Above }\end{array}$ & $\begin{array}{l}\text { Yucca Flat } \\
\text { - Below b }\end{array}$ \\
\hline $235 \mathrm{U}$ & $7.04 \times 10^{8}$ & $3.032 E+27$ & $3.819 E+27$ & $2.557 \mathrm{E}+00$ & $3.220 E+00$ \\
\hline${ }^{236} U$ & $2.34 \times 10^{7}$ & $3.599 E+25$ & $1.364 \mathrm{E}+26$ & 9.123E-01 & $3.458 \mathrm{E}+00$ \\
\hline $238 \mathrm{U}$ & $4.47 \times 10^{9}$ & $6.531 E+28$ & $1.182 E+29$ & $8.674 \mathrm{E}+00$ & 1.570E+01 \\
\hline${ }^{237} \mathrm{~Np}$ & $2.14 \times 10^{6}$ & $4.108 E+24$ & $3.863 E+25$ & $1.140 \mathrm{E}+00$ & $1.072 \mathrm{E}+01$ \\
\hline${ }^{238} \mathrm{Pu}$ & $8.77 \times 10^{1}$ & $2.621 E+24$ & $1.647 \mathrm{E}+24$ & 1.774E+04 & $1.115 \mathrm{E}+04$ \\
\hline${ }^{239} \mathrm{Pu}$ & $2.41 \times 10^{4}$ & $4.058 \mathrm{E}+27$ & $1.115 \mathrm{E}+27$ & 9.997E+04 & $2.746 \mathrm{E}+04$ \\
\hline${ }^{240} \mathrm{Pu}$ & $6.56 \times 10^{3}$ & $2.798 \mathrm{E}+26$ & $7.785 E+25$ & $2.523 E+04$ & $7.045 \mathrm{E}+03$ \\
\hline${ }^{241} \mathrm{Pu}$ & $1.44 \times 10^{1}$ & $8.284 \mathrm{E}+24$ & $2.508 \mathrm{E}+24$ & $3.415 E+05$ & $1.034 \mathrm{E}+05$ \\
\hline${ }^{242} \mathrm{Pu}$ & $3.75 \times 10^{5}$ & $4.728 E+24$ & $2.919 E+24$ & $7.485 E+00$ & $4.621 \mathrm{E}+00$ \\
\hline${ }^{241} \mathrm{Am}$ & $4.33 \times 10^{2}$ & $1.683 E+25$ & $4.437 \mathrm{E}+24$ & $2.309 E+04$ & $6.088 \mathrm{E}+03$ \\
\hline${ }^{243} \mathrm{Am}$ & $7.37 \times 10^{3}$ & $3.33 E+22$ & $4.241 E+22$ & $2.682 E+00$ & $3.416 \mathrm{E}+00$ \\
\hline${ }^{244} \mathrm{Cm}$ & $1.81 \times 10^{1}$ & $4.836 E+22$ & $7.641 \mathrm{E}+22$ & $1.586 E+03$ & $2.506 E+03$ \\
\hline Total & & $3.901 E+29$ & $1.057 \mathrm{E}+30$ & $1.578 E+07$ & 3.523E+07 \\
\hline
\end{tabular}

Source: Modified from Bowen et al., 2001

a Total inventory for detonations detonated more than $100 \mathrm{~m}$ above the water table.

${ }^{\mathrm{b}}$ Total inventory for detonations detonated below or within $100 \mathrm{~m}$ of the water table.

Note: Data are decay corrected to September 23, 1992 (date of last underground nuclear test).

inventory for the NASH detonation. The additional sources provided lower or comparable inventories for each radionuclide except the HANDCAR ${ }^{14} \mathrm{C}$. A total of 5.3 Curies (Ci) (0.085 moles) of ${ }^{14} \mathrm{C}$ was reported loaded onto the HANDCAR device as a tracer, which is approximately one order of magnitude greater than the yield-weighted estimate. This value was used in place of the Bowen et al. (2001) yield weighted ${ }^{14} \mathrm{C}$ inventory for the HANDCAR detonation.

\subsubsection{Radionuclide Distribution in the Subsurface}

The nuclear explosion phenomena described in Section 2.2 are responsible for the observed distribution of materials that were introduced into the subsurface during testing. Radioactive 
elements are not distributed uniformly in the cavity/chimney region, but are partitioned based on physical and chemical characteristics.

Smith (1993) indicates that the partitioning can be described in terms of a three-stage condensation process. The refractory radionuclides (e.g., actinides), with melting points significantly greater than the melting temperature of the adjacent geologic media, are scavenged by the molten material that lines the cavity. These radionuclides are deposited within the melt glass. Further, condensation occurs as cavity gas moves into the crushed rubble and fractured material surrounding the working point. During this stage, the radioisotopes of intermediate volatility, often with gaseous precursors (e.g., ${ }^{137} \mathrm{Cs}$ ), condense and deposit on rubble and fracture surfaces. Final condensation occurs as residual gas moves radially outward and ascends toward the ground surface. Condensation during this stage also occurs on surfaces. The above process leads to a distribution of radionuclides that is fractionated, with heavier refractory radionuclides concentrated within the melt glass and lighter and volatile radionuclides concentrated higher in the chimney (Smith, 1993). Tritium initially is distributed in the gas phase and later as tritiated water (HTO) in steam (Smith, 1995a).

The distribution of radionuclides in the cavity/chimney region greatly influences the availability of potential contaminants for transport by groundwater. Radionuclides incorporated in the melt glass matrix are accessible to groundwater only through slow processes such as melt glass dissolution. Other radionuclides are predominantly associated with surfaces and are accessible to groundwater through relatively fast processes such as ion exchange (Smith, 1995b).

The inventory can be distributed into the melt glass, rubble, gas, and water based on the recommended values from the International Atomic Energy Agency ([IAEA], 1998) and Maxwell et al., (2008) (Table 2-3). The terms glass, rubble, water, and gas and are interpreted as follows (SNJV, 2005):

- Glass refers to the solidified melt glass. Radionuclides in the glass are not released until glass dissolution mobilizes them for transport in the groundwater.

- Rubble refers to the rubble zones, excluding the melt glass. During the cooling process after a test, vaporized radionuclides in the rubble are assumed to condense throughout the pore spaces of the disturbed zone (i.e., the exchange volume). These radionuclides are immediately available to dissolve and mobilize in the pore water when it returns after the test. 
Table 2-3

Unclassified Inventory and Radionuclide Distributions for Noncarbonate Tests (Page 1 of 2)

\begin{tabular}{|c|c|c|c|c|c|}
\hline \multirow{2}{*}{ Radionuclide } & \multirow{2}{*}{$\begin{array}{l}\text { Half-Life } \\
\text { (Years) }\end{array}$} & \multicolumn{4}{|c|}{ Partitioning Percent } \\
\hline & & Glass & Rubble & Gas & Water \\
\hline${ }^{3} \mathrm{H}$ & $1.23 \times 10^{1}$ & 0 & 0 & 2 & 98 \\
\hline${ }^{14} \mathrm{C}$ & $5.73 \times 10^{3}$ & 0 & 10 & 80 & 10 \\
\hline${ }^{26} \mathrm{Al}$ & $7.3 \times 10^{5}$ & 95 & 5 & 0 & 0 \\
\hline${ }^{36} \mathrm{Cl}$ & $3.01 \times 10^{5}$ & 50 & 40 & 0 & 10 \\
\hline${ }^{39} \mathrm{Ar}$ & $2.69 \times 10^{2}$ & 0 & 10 & 80 & 10 \\
\hline${ }^{40} \mathrm{~K}$ & $1.28 \times 10^{9}$ & 100 & 0 & 0 & 0 \\
\hline${ }^{41} \mathrm{Ca}$ & $1.03 \times 10^{5}$ & 70 & 30 & 0 & 0 \\
\hline${ }^{59} \mathrm{Ni}$ & $7.51 \times 10^{4}$ & 95 & 5 & 0 & 0 \\
\hline${ }^{63} \mathrm{Ni}$ & $1.00 \times 10^{2}$ & 95 & 5 & 0 & 0 \\
\hline${ }^{85} \mathrm{Kr}$ & $1.07 \times 10^{1}$ & 0 & 10 & 80 & 10 \\
\hline${ }^{90} \mathrm{Sr}$ & $2.91 \times 10^{1}$ & 40 & 60 & 0 & 0 \\
\hline${ }^{93} \mathrm{Zr}$ & $1.50 \times 10^{6}$ & 95 & 5 & 0 & 0 \\
\hline${ }^{93 \mathrm{~m}} \mathrm{Nb}$ & $1.61 \times 10^{1}$ & 95 & 5 & 0 & 0 \\
\hline${ }^{94} \mathrm{Nb}$ & $2.03 \times 10^{4}$ & 95 & 5 & 0 & 0 \\
\hline${ }^{99} \mathrm{Tc}$ & $2.13 \times 10^{5}$ & 80 & 20 & 0 & 0 \\
\hline${ }^{107} \mathrm{Pd}$ & $6.5 \times 10^{6}$ & 70 & 30 & 0 & 0 \\
\hline${ }^{113 m} \mathrm{Cd}$ & $1.41 \times 10^{1}$ & 70 & 30 & 0 & 0 \\
\hline $121 \mathrm{~m} S \mathrm{Sn}$ & $5.50 \times 10^{1}$ & 60 & 40 & 0 & 0 \\
\hline${ }^{126} \mathrm{Sn}$ & $1.00 \times 10^{5}$ & 70 & 30 & 0 & 0 \\
\hline 129 & $1.57 \times 10^{7}$ & 50 & 40 & 0 & 10 \\
\hline${ }^{135} \mathrm{Cs}$ & $2.30 \times 10^{6}$ & 20 & 80 & 0 & 0 \\
\hline${ }^{137} \mathrm{Cs}$ & $3.02 \times 10^{1}$ & 20 & 80 & 0 & 0 \\
\hline${ }^{151} \mathrm{Sm}$ & $9.00 \times 10^{1}$ & 95 & 5 & 0 & 0 \\
\hline${ }^{150} \mathrm{Eu}$ & $3.60 \times 10^{1}$ & 95 & 5 & 0 & 0 \\
\hline${ }^{152} \mathrm{Eu}$ & $1.35 \times 10^{1}$ & 95 & 5 & 0 & 0 \\
\hline${ }^{154} \mathrm{Eu}$ & $8.59 \times 10^{0}$ & 95 & 5 & 0 & 0 \\
\hline $166 \mathrm{~m} \mathrm{Ho}$ & $1.20 \times 10^{3}$ & 95 & 5 & 0 & 0 \\
\hline $232 \mathrm{U}$ & $6.89 \times 10^{1}$ & 90 & 10 & 0 & 0 \\
\hline${ }^{232} \mathrm{Th}$ & $1.40 \times 10^{10}$ & 95 & 5 & 0 & 0 \\
\hline $233 \mathrm{U}$ & $1.59 \times 10^{5}$ & 90 & 10 & 0 & 0 \\
\hline${ }^{234} \mathrm{U}$ & $2.46 \times 10^{5}$ & 90 & 10 & 0 & 0 \\
\hline
\end{tabular}


Table 2-3

Unclassified Inventory and Radionuclide Distributions for Noncarbonate Tests (Page 2 of 2)

\begin{tabular}{|c|c|c|c|c|c||}
\hline \multirow{2}{*}{ Radionuclide } & \multirow{2}{*}{$\begin{array}{c}\text { Half-Life } \\
\text { (Years) }\end{array}$} & Glass & Rubble & Gas & Water \\
\cline { 3 - 6 } & & 90 & 10 & 0 & 0 \\
\hline \hline${ }^{235 \mathrm{U}}$ & $7.04 \times 10^{8}$ & 90 & 10 & 0 & 0 \\
\hline${ }^{236} \mathrm{U}$ & $2.34 \times 10^{7}$ & 90 & 10 & 0 & 0 \\
\hline${ }^{238} \mathrm{U}$ & $4.47 \times 10^{9}$ & 95 & 5 & 0 & 0 \\
\hline${ }^{237} \mathrm{~Np}$ & $2.14 \times 10^{6}$ & 95 & 5 & 0 \\
\hline${ }^{238} \mathrm{Pu}$ & $8.77 \times 10^{1}$ & 95 & 5 & 0 \\
\hline${ }^{239} \mathrm{Pu}$ & $2.41 \times 10^{4}$ & 95 & 5 & 0 & 0 \\
\hline${ }^{240} \mathrm{Pu}$ & $6.56 \times 10^{3}$ & 95 & 5 & 0 & 0 \\
\hline${ }^{241} \mathrm{Pu}$ & $1.44 \times 10^{1}$ & 95 & 5 & 0 & 0 \\
\hline${ }^{242} \mathrm{Pu}$ & $3.75 \times 10^{5}$ & 95 & 5 & 0 & 0 \\
\hline${ }^{241} \mathrm{Am}$ & $4.33 \times 10^{2}$ & 95 & 5 & 0 & 0 \\
\hline${ }^{244} \mathrm{Cm}$ & $1.81 \times 10^{1}$ & 95 & & 5 & 0 \\
\hline
\end{tabular}

Sources: SNJV, 2005; Maxwell et al., 2008

- Water refers to gaseous radionuclides in steam that would condense into liquid water as steam condenses. This condensation is assumed to occur in the pore spaces of the cavity, melt glass, and nearby surrounding rock. These radionuclides are immediately available to dissolve and mobilize in the pore water when it returns after the test.

- Gas refers to noncondensible radionuclides that may exist as gases or coexist as bubbles in the pore fluids in the cavity, melt glass, and nearby surrounding rock at normal pressures and temperatures. Again, these radionuclides are available immediately to dissolve and mobilize in the pore water when it returns after the test.

Table 2-3 lists the radionuclides and their partitioning based primarily on the IAEA (1998) for the noncarbonate tests. Table 2-4 presents the carbonate test radionuclides screened by Carle et al. (2008) and their partitioning. Carle et al. (2008) screened the carbonate test radionuclides based on criteria of activity being less than 0.1 percent of $\alpha,-\beta$-, or EC/IT-decay or of being less than the natural inventory in soil or rock. Two radionuclides could be excluded because they are overwhelmingly of a natural background source. Four radionuclides were excluded based on the 0.1 percent criterion. The excluded radionuclides are ${ }^{26} \mathrm{Al},{ }^{40} \mathrm{~K},{ }^{113 \mathrm{~m}} \mathrm{Cd},{ }^{232} \mathrm{Th},{ }^{242} \mathrm{Pu}$, and ${ }^{243} \mathrm{Am}$. 
Table 2-4

Unclassified Inventory and Radionuclide Distributions for Carbonate Tests

(Page 1 of 2)

\begin{tabular}{|c|c|c|c|c|c|c|}
\hline \multirow{2}{*}{ Radionuclide } & \multirow{2}{*}{$\begin{array}{c}\text { Half-life } \\
\text { (Years) }\end{array}$} & \multicolumn{4}{|c|}{ Partitioning Percent } & \multirow{2}{*}{$\begin{array}{c}\text { Exchange } \\
\text { Volume } \\
\text { Cavity Radiib }\end{array}$} \\
\hline & & Glass $^{a}$ & Rubble & Gas & Water & \\
\hline${ }^{3} \mathrm{H}$ & $1.23 \times 10^{1}$ & 0 & 0 & 2 & 98 & 2 \\
\hline${ }^{14} \mathrm{C}$ & $5.73 \times 10^{3}$ & 0 & 10 & 80 & 10 & 8 \\
\hline${ }^{36} \mathrm{Cl}$ & $3.01 \times 10^{5}$ & 50 & 40 & 0 & 10 & 2 \\
\hline${ }^{39} \mathrm{Ar}$ & $2.69 \times 10^{2}$ & 0 & 10 & 80 & 10 & 8 \\
\hline${ }^{41} \mathrm{Ca}$ & $1.03 \times 10^{5}$ & 70 & 30 & 0 & 0 & 2 \\
\hline${ }^{59} \mathrm{Ni}$ & $7.51 \times 10^{4}$ & 95 & 5 & 0 & 0 & 2 \\
\hline${ }^{63} \mathrm{Ni}$ & $1.00 \times 10^{2}$ & 95 & 5 & 0 & 0 & 2 \\
\hline${ }^{85} \mathrm{Kr}$ & $1.07 \times 10^{1}$ & 0 & 10 & 80 & 10 & 8 \\
\hline${ }^{90} \mathrm{Sr}$ & $2.91 \times 10^{1}$ & 5 & 95 & 0 & 0 & 6 \\
\hline${ }^{93} \mathrm{Zr}$ & $1.50 \times 10^{6}$ & 95 & 5 & 0 & 0 & 2 \\
\hline${ }^{93 \mathrm{~m} N b}$ & $1.61 \times 10^{1}$ & 95 & 5 & 0 & 0 & 2 \\
\hline${ }^{94} \mathrm{Nb}$ & $2.03 \times 10^{4}$ & 95 & 5 & 0 & 0 & 2 \\
\hline${ }^{99} \mathrm{TC}$ & $2.13 \times 10^{5}$ & 80 & 20 & 0 & 0 & 2 \\
\hline${ }^{107} \mathrm{Pd}$ & $6.50 \times 10^{6}$ & 70 & 30 & 0 & 0 & 2 \\
\hline${ }^{121 \mathrm{~m} S n}$ & $5.50 \times 10^{1}$ & 60 & 40 & 0 & 0 & 2 \\
\hline${ }^{126} \mathrm{Sn}$ & $1.00 \times 10^{5}$ & 70 & 30 & 0 & 0 & 2 \\
\hline 129 & $1.57 \times 10^{7}$ & 50 & 40 & 0 & 10 & 2 \\
\hline${ }^{135} \mathrm{Cs}$ & $2.30 \times 10^{6}$ & 5 & 95 & 0 & 0 & 6 \\
\hline${ }^{137} \mathrm{Cs}$ & $3.02 \times 10^{1}$ & 5 & 95 & 0 & 0 & 6 \\
\hline${ }^{151} \mathrm{Sm}$ & $9.00 \times 10^{1}$ & 95 & 5 & 0 & 0 & 2 \\
\hline${ }^{150} \mathrm{Eu}$ & $3.60 \times 10^{1}$ & 95 & 5 & 0 & 0 & 2 \\
\hline${ }^{152} \mathrm{Eu}$ & $1.35 \times 10^{1}$ & 95 & 5 & 0 & 0 & 2 \\
\hline${ }^{154} \mathrm{Eu}$ & $8.59 \times 10^{0}$ & 95 & 5 & 0 & 0 & 2 \\
\hline $166 \mathrm{~m} H o$ & $1.20 \times 10^{3}$ & 95 & 5 & 0 & 0 & 2 \\
\hline${ }^{232} U$ & $6.89 \times 10^{1}$ & 90 & 10 & 0 & 0 & 2 \\
\hline${ }^{233} \mathrm{U}$ & $1.59 \times 10^{5}$ & 90 & 10 & 0 & 0 & 2 \\
\hline${ }^{234} \mathrm{U}$ & $2.46 \times 10^{5}$ & 90 & 10 & 0 & 0 & 2 \\
\hline $235 \mathrm{U}$ & $7.04 \times 10^{8}$ & 90 & 10 & 0 & 0 & 2 \\
\hline${ }^{236} \mathrm{U}$ & $2.34 \times 10^{7}$ & 90 & 10 & 0 & 0 & 2 \\
\hline${ }^{238} \mathrm{U}$ & $4.47 \times 10^{9}$ & 90 & 10 & 0 & 0 & 2 \\
\hline${ }^{237} \mathrm{~Np}$ & $2.14 \times 10^{6}$ & 95 & 5 & 0 & 0 & 2 \\
\hline
\end{tabular}


Table 2-4

Unclassified Inventory and Radionuclide Distributions for Carbonate Tests (Page 2 of 2)

\begin{tabular}{||c|c|c|c|c|c|c||}
\hline \multirow{2}{*}{ Radionuclide } & \multirow{2}{*}{$\begin{array}{c}\text { Half-life } \\
\text { (Years) }\end{array}$} & \multicolumn{4}{|c|}{ Partitioning Percent } & $\begin{array}{c}\text { Exchange } \\
\text { Volume } \\
\text { Cavity Radii }\end{array}$ \\
\cline { 3 - 7 } & Glass $^{\mathbf{a}}$ & Rubble & Gas & Water & 2 \\
\hline \hline${ }^{238} \mathrm{Pu}$ & $8.77 \times 10^{1}$ & 95 & 5 & 0 & 0 & 2 \\
\hline${ }^{239} \mathrm{Pu}$ & $2.41 \times 10^{4}$ & 95 & 5 & 0 & 0 & 2 \\
\hline${ }^{240} \mathrm{Pu}$ & $6.56 \times 10^{3}$ & 95 & 5 & 0 & 0 & 2 \\
\hline${ }^{241} \mathrm{Pu}$ & $1.44 \times 10^{1}$ & 95 & 5 & 0 & 0 & 2 \\
\hline${ }^{241} \mathrm{Am}$ & $4.33 \times 10^{2}$ & 95 & 5 & 0 & 0 & 2 \\
\hline${ }^{244} \mathrm{Cm}$ & $1.81 \times 10^{1}$ & 95 & 5 & 0 & 0 & \\
\hline
\end{tabular}

Source: Modified from Carle et al., 2008

aThe carbonate tests "glass" will consist of calcite, dolomite, and their decomposition products instead of silicate glass. Only the BOURBON carbonate test will have silicate glass puddle.

${ }^{\mathrm{b}}$ The carbonate tests exchange volumes are larger for the more volatile radionuclides.

The carbonate tests have a different partitioning for some radionuclides and this was primarily due to the behavior of volatile radionuclides in tests detonated in carbonate rock (Carle et al., 2008). The ${ }^{137} \mathrm{Cs},{ }^{135} \mathrm{Cs}$, and ${ }^{90} \mathrm{Sr}$ partitioning to the rubble was set to 95 percent, significantly higher than the 60 to 75 percent reported in IAEA (1998). Setting the rubble partitioning to 95 percent is consistent with ${ }^{90} \mathrm{Sr}$ observations at HANDCAR. The carbonate tests have different exchange volume radii for some radionuclides, because the large amount of carbon dioxide $\left(\mathrm{CO}_{2}\right)$ gas generated by the carbonate tests will expand, and move the more volatile radionuclides further away from the cavity center.

The carbonate tests "glass” will be comprised of calcite, dolomite and their decomposition products instead of a silicate glass. The phenomenology of a carbonate test will not result in a true glass, but in a highly radioactive zone in the cavity bottom (see Section 3.2.2). Only the BOURBON carbonate is expected to have a silicate glass puddle. The release of radionuclides from the carbonate tests glass will be different than the noncarbonate tests (Carle et al., 2008).

The partitioning used the assumptions presented in Carle et al. (2008) for the radionuclides not reported in the IAEA (1998). For example, ${ }^{39} \mathrm{Ar}$ partitioning was not reported in the IAEA (1998) but should be similar to ${ }^{85} \mathrm{Kr}$. The ${ }^{94} \mathrm{Nb}$ partitioning was not reported but should be analogous to ${ }^{93} \mathrm{Nb}$. The ${ }^{150} \mathrm{Eu}$ and ${ }^{166} \mathrm{Ho}$ partitioning should be analogous to ${ }^{152} \mathrm{Eu}$. The ${ }^{232} \mathrm{U},{ }^{234} \mathrm{U},{ }^{235} \mathrm{U}$, and ${ }^{238} \mathrm{U}$ partitioning should be analogous to ${ }^{233} \mathrm{U}$ and ${ }^{236} \mathrm{U}$ partitioning. 
The partitioning of $\mathrm{Pu}$ and Am isotopes into the rubble fraction (5 percent) is higher than that recommended by the IAEA (1998) (2 percent). Previous HST modeling efforts at the NTS have used the 5 percent rubble partitioning to provide more conservative radionuclide transport simulation results (Tompson et al., 1999; Pawloski et al., 2001; Carle et al., 2008).

\subsection{Near-field Hydrologic Studies Available for Use in the Yucca Flat CAU Source Term}

The Yucca Flat/Climax Mine CAU detonations were performed in a wide variety of hydrogeologic settings including alluvium, fractured lava and tuffs, granites and carbonates. The Yucca Flat source term modeling will be based on LLNL near-field HSTs, LANL sub-CAU scale modeling, and DRI sub-CAU scale modeling, and will build on source term modeling concepts developed for the other CAUs.

\subsubsection{Near-field Studies within Yucca Flat}

The LLNL studied Yucca Flat HST processes for three settings: unsaturated, saturated, and carbonate. The modeling focused on improving understanding the specific processes related to the three settings (Pawloski et al., 2008). The LANL performed modeling to evaluate the potential for the anomalously high groundwater heads observed in Yucca Flat to sustain a slow decline and rapid flow towards faults (Wolfsberg et al., 2006).

\subsubsection{Unsaturated Test Studies}

McNab (2008) performed a study to determine the potential for radionuclides from the unsaturated tests conducted at Yucca Flat to impact groundwater. The study included: 1) a review of prior assessments of crater ponding and wetting from migration, 2) process numerical modeling of crater infiltration, 3) screening one-dimensional (1-D) analytical transport modeling, and 4) analytical modeling of gaseous radionuclide migration. The modeling developed relationships between saturated hydraulic conductivity, soil moisture retention, and unsaturated conductivity using alluvium data and extended these relationships into the volcanic rock lithology.

The numerical process modeling investigated several factors that could affect wetting front propagation to the working point and aquifer. These included: 1) many pulsed recharge events, 
2) hydraulic conductivity anisotropy, 3) hydraulic property heterogeneity, 4) low permeability crater playa deposit, and 5) initial moisture content. The numerical process modeling used lithology from the AARDVARK detonation and extended from the land surface to the water table. The lithology at the AARDVARK detonation included alluvium, welded tuff aquifer (WTA), vitric tuff aquifer (VTA), and TCUs. The modeling included a two-dimensional (2-D) radial model implemented in the U.S. Geological Survey (USGS) VS2D code (Hsieh et al., 2000) and a 3-D model implemented in the LLNL ParFlow code (Ashby, 1996). The findings of the numerical modeling included:

- Wetting front propagation appears to be mostly 1-D where saturated hydraulic conductivity values exceed the time-averaged recharge rate.

- Pulsed recharge events are rapidly merged into a uniform wetting profile with time and depth.

- Little capillary spreading is evident, in the longitudinal or transverse directions, with respect to wetting front propagation direction.

- Anisotropy does appreciably slow the advance of the wetting front.

- Pronounced lateral spreading that curtails downward movement of the wetting front will occur when the time-averaged steady-state recharge rate exceeds the local saturated hydraulic conductivity.

- In the absence of preferential flow through fractures, the very low matrix saturated hydraulic conductivities of confining units such as the LTCU could greatly limit the depth of wetting front propagation.

- Land surface to water table travel time for 0.2 meters per year $(\mathrm{m} / \mathrm{yr})$ recharge rate is $\sim 300$ years.

The 1-D analytical modeling of tracer transport from each unsaturated detonation with a subsidence crater was performed to estimate mean recharge rates required to transport radionuclides of different distribution coefficient $\left(\mathrm{K}_{\mathrm{d}}\right)$ values to the water table within 1,000 years. The modeling concluded that radionuclides with $\mathrm{K}_{\mathrm{d}}$ values above 10 milliliters per gram $(\mathrm{mL} / \mathrm{g})$ required time-averaged recharge rates in excess of $1 \mathrm{~m} / \mathrm{yr}$.

The 3-D analytical modeling of gaseous radionuclides investigated the mobility of radionuclides with a gaseous phase component. The modeling included ${ }^{39} \mathrm{Ar},{ }^{85} \mathrm{Kr}$, and ${ }^{14} \mathrm{C}$ and calculated a retardation coefficient for gaseous phase diffusion. The radionuclides with a stronger affinity for the aqueous phase will have larger retardation factors because the mass ratio of aqueous to gaseous phase increases. The modeling considered a typical unsaturated detonation with a $40 \mathrm{~m}$ detonation cavity 
diameter located $250 \mathrm{~m}$ above the water table. A ${ }^{14} \mathrm{C}$ retardation coefficient of 10 was estimated from $\mathrm{CO}_{2}$ equilibrium concentrations calculated using the PHREEQC geochemical speciation model (Parkhurst and Appelo, 2002) and Yucca Flat well geochemical data. The findings of the modeling included:

- Gaseous diffusion is capable of transporting radionuclides that are predominantly in the gaseous phase over longer distances from the detonation cavity than aqueous phase advection with a recharge rate of 250 millimeters per year (mm/yr).

- The spherical geometry resulting from gaseous diffusion will substantially dilute concentrations over time scales of decades.

- Carbon-14 is strongly partitioned into the aqueous phase at observed soil moisture and $\mathrm{pH}$ values. Transport calculations in the unsaturated zone must consider the aqueous phase.

- Significant partitioning of the ${ }^{14} \mathrm{C}$ aqueous phase onto the solid phase will occur and retard aqueous phase movement.

\subsubsection{Saturated Tests Modeling}

Maxwell et al. (2008) performed a modeling study of selected tests performed in test Areas 2 and 3. The objectives of the modeling study and report included the following:

- Develop and simplify an HST for 166 underground tests conducted in the saturated zone of the Yucca Flat CAU.

- Examine the role of residual high pore water pressures on HST evolution in areas different from the Tuff Pile.

- Use previous HST analyses in other HSUs to develop general guidelines for assessing the relative importance of test related transient phenomena, including heat- and pressure-induced, on HST evolution across the remaining saturated tests in Yucca Flat.

The modeling performed for Area 3 focused on the AARDVARK, BILBY and WAGTAIL detonations. The AARDVARK and WAGTAIL detonations were performed in the lower tuff confining unit (LTCU) and the BILBY detonation was performed in the Oak Spring Butte confining unit (OSBCU). The BILBY detonation had radiochemical data available in nearby wells that were used to confirm the diameter of the cavity and exchange volumes. 
The modeling performed for the Area 2 focused on the FLAX-SOURCE detonation. The FLAX-SOURCE detonation is located east of the Topgallant Fault and West of the Yucca Fault. The working point is in a VTA and the exchange volume extends into the Alluvial Aquifer (AA).

The final radius of the cavity is a result of vaporization, melting and movement of the cavity walls further out as a result compressive rock failure. The conceptual model for determining the initial elevated pressure resulting from the detonation in a tuff confining unit was that immediately after the detonation, the cavity wall lay closer to the detonation point than the final $\mathrm{R}_{\mathrm{c}}$. The thermal and compressive effects of the explosion are assumed to crush, compress, and push the cavity wall to a final state further from the initial cavity center of the detonation. The mass of solid rock in these two states is assumed to be unchanged but occupies a smaller volume. The smaller volume resulting from the compressive effect culminates in a crushed zone with reduced porosity, reduced permeability and increased pore water pressure. Typical values of the crushed zone radius were estimated to be $\sim 2.5$ to $3 \mathrm{R}_{\mathrm{c}}$.

The conceptual model also included a larger compressed zone, which is a sphere larger than the crushed zone. The compressed zone extends from the outer crushed zone to a distance $\sim 20 \mathrm{R}_{\mathrm{c}}$ centered about the working point. The material in the compressed volume is assumed to undergo elastic deformation with minor fracturing resulting from shockwave and compressive forces from the explosion. The porosity of the compressed zone is assumed to be slightly elastically reduced and the pore water pressure is slightly increased.

The conceptual model also included thermal effects and the initial high temperatures in the melt glass and cavity zones, which was obtained from previous analyses of high-temperature effects in HST models developed for Pahute Mesa and Frenchman Flat.

This conceptual model was implemented for the selected Areas 2 and 3 tests. Groundwater flow resulting from the high water pressures and temperatures was simulated through the test altered zones. The models were calibrated to the transient observed pressure responses seen in nearby wells, and parameter values were obtained that provided reasonable agreement with the observations. Transport was simulated in the models using particle tracking. The transport simulations were performed to determine which processes would have a significant effect on radionuclide migration away from a test location. 
The goal of the saturated test modeling study was to identify the important transient flow processes that may significantly influence radionuclide migration. The conclusions of the study included:

Test-induced pore-water pressurization. Increased pore pressure resulting from nuclear testing in areas outside of the Tuff Pile region dissipates relatively quickly compared to areas inside the Tuff Pile. The time scale pressure dissipation is likely influenced by specific geologic conditions, and tests performed in very low conductivity rock will likely experience the longest time scale. The pressure dissipates within days to years, and the short period of high pressure does not result in significant radionuclide migration. The tests also have negligible influence on each other. The HSTs for the saturated tests will need to consider the regional gradient for flow conditions. The long-lived pressure increase observed in the Tuff Pile tests is unique to the hydrogeologic structure of the Tuff Pile.

Cavity refilling. The refilling of water into the test cavity likely has a larger impact on radionuclide migration than test-induced high pressure moving water radially away from the source area. The radionuclides distributed in the near-field following the test will be entrained in the water refilling the cavity and move back into the cavity as it refills. The pressurization effects do not create large enough groundwater flow velocities for long enough periods of time to drive radionuclides away from the test cavity.

Temperature effects. The increased temperature resulting from the test will likely have a negligible effect on pressure transients for tests with conditions similar to those simulated (AARDVARK, BILBY, WAGTAIL, and FLAX-SOURCE), if multiphase flow is considered. However, temperature effects on melt-glass dissolution are significant. Temperature effects may also have a significant effect on radionuclide migration, when the high permeability chimney intersects an aquifer. The buoyancy-driven vertical flow may bring radionuclides to these high permeability layers, allowing rapid lateral spreading.

Vertical drainage in the chimney. The impact of perched water draining from the high permeability chimney following the test is negligible in the saturated areas of central Yucca Flat. However, the impact may be significant in other locations and will depend on the hydrogeologic conditions over the past 1,000 to 2,000 years. 
Model calibration. The model calibration for the simulated tests in Areas 2 and 3 provided a consistent set of parameter values for different regions of the NTS. The parameter values were for large-scale HSUs.

Recommendations for the key process that must be considered for each test when developing saturated test HSTs for the CAU scale model were presented. The recommendations were derived from the modeling of the selected Areas 2 and 3 tests and other LLNL work. The processes included:

Test-induced pressure. Tests where pressurization is important (conditions similar to the Tuff Pile study [Wolfsberg et al., 2006]). The criteria for this process is the location in the Tuff Pile.

Test crater-enhanced infiltration. Tests where enhanced crater infiltration may affect radionuclide migration. The criteria for this process is the presence of a subsidence crater.

Paleo-drainage. Tests where perched water might be liberated by test effects (i.e., increased chimney permeability) and drain down the chimney. Only the WAGTAIL detonation was identified as having possible paleo-drainage effects on an HST, although the modeling of the WAGTAIL detonation concluded paleo-drainage would have little affect on the HST.

Test-induced heat. Tests where thermal processes may be important (conditions similar to the Pahute Mesa HST [Pawloski et al., 2001]). The criteria for this process is the location of the test in a confining unit and presence of a high permeability aquifer layer between the test and the water table. The high permeability of the chimney may allow buoyancy-driven flow upwards to the aquifer. A convection cell may develop within the high permeability chimney and any aquifer that intersects the convection cell will experience a source of radionuclides. Although the effect of test-induced heat would be most pronounced with an aquifer in both the exchange volume and chimney, only tests with exchange volumes and chimneys fully contained in confining units can likely be screened from the source term.

In conclusion, the work in this document presents flow modeling, transport modeling, and RSTs for the specific tests selected for modeling in Areas 2 and 3. The transport simulations presented were restricted to particle tracking and concluded significant radionuclide migration does not occur during the short period of transient pressure. The document identifies key transient flow processes that may 
influence radionuclide migration and assigns each saturated test to categories in which these key processes may be present.

\subsubsection{Saturated Tests Modeling Within Tuff Pile}

Wolfsberg et al. (2006) performed a modeling study of the anomalously high groundwater heads that were recorded in emplacement holes and wells in Yucca Flat after subsurface testing began. The high groundwater heads only occur within the saturated volcanic tuffs known as the volcanic Tuff Pile. The elevated heads have created 1) large vertical gradients towards the deeper regional carbonate aquifer and upwards toward the water table, and 2) lateral gradients towards faults that may be very transmissive. The large gradients have raised concerns about possible fast radionuclide migration towards the regional carbonate aquifer, which is a groundwater resource for southern Nevada.

The study focused on the area between the Yucca Fault and the Topgallant Fault in the NTS Areas 1, 2, 3, 4, and 7. The study had two primary goals, which included: 1) evaluate processes and properties in the Tuff Pile that explain the high groundwater heads and the slow declines observed in the Tuff Pile and 2) evaluate the potential for the system to have slowly declining heads and also have rapid transport. The second goal hypothesized that thin-welded ash-flow tuffs found between thick TCUs can be characterized as high permeability with open fractures and can act as lateral conduits towards faults.

The study reviewed the literature of studies attempting to explain the anomalously high, post-testing water levels and assumed the high levels to be caused by:

- Coseismic stress-induced head increase immediately following the test.

- Dissipation of head in the low permeability, high-porosity stratigraphic units far from the tests to be in the elastic range of deformation.

- $\quad$ Redistribution of pore fluid pressure into adjacent stratigraphic units from stress-induced hydraulic fracturing near tests in the inelastic range of deformation.

The study was comprised of components that included:

- Development of a stratigraphic framework model that has higher resolution of material types than used in the CAU scale modeling. 
- Development of method of estimating initial post-testing high heads for the tests conducted near or below the water table.

- Simulation of groundwater flow and calibration of the model parameters to match the declining head observations.

- Simulation of solute transport using a transient flow field to investigate contaminant migration downward to the carbonate aquifer or laterally to the faults.

A total of 28 Tertiary stratigraphic units were delineated above the LCA and correlated with CAU scale HSUs. The properties of the stratigraphic units were specified or calibrated. An equation for the change in pore fluid pressure as a function of test yield, radial distance, and rock properties was developed and used to predict the initial heads surrounding the test location following a detonation. The simulations included the changes in porosity and permeability due to changes in pore fluid pressure change. The initial pressure condition and altered rock properties were implemented in an initial condition derived from steady-state regional flow. The model was calibrated using inverse methods. However, the calibration dataset was insufficient to estimate all uncertain parameters and those parameters with the highest uncertainty were adjusted during model calibration.

The modeling study concluded that specifying high permeability and low porosity in the welded tuff interbeds results in a reasonably well calibrated model matching the time history of heads. The model demonstrated that it was possible to match the elevated heads in the low permeability units and also to have high permeability units present. The high permeability and low porosity welded tuff simulations representative of a fractured rock resulted in transport to the faults. In contrast, simulations with homogeneous low permeability resulted in no transport to the faults. The fracture parameters are highly uncertain, and the model head calibration to tuff confining unit water level measurements was insensitive to fracture parameters.

The modeling study presented corroborating geochemistry evidence. The Yucca Flat geochemical evaluation by SNJV (2006a) found the water chemistry in well UE-1q indicates a significant volcanic water source. Well UE-1q is located immediately outside the Tuff Pile model domain and near the Topgallant Fault. 


\subsubsection{Carbonate Studies}

Carle et al. (2008) studied the unique phenomenology, geochemistry, mineralogy, and hydrogeology of the four carbonate tests and integrated their findings with multiphase thermal modeling to improve understanding of hydrologic source term processes for carbonate tests. The carbonate tests included the HANDCAR, NASH, BOURBON and KANKAKEE detonations. The carbonate tests are of particular concern because the contamination resulting from these tests is in direct contact with the regional carbonate aquifer. The carbonate test phenomenology is fundamentally different from the tests detonated in other geologic settings. Thermal decomposition of carbonate rock will release enormous amounts of $\mathrm{CO}_{2}$ gas that will contribute to pressure-driven gas advection. The carbonate rock will likely decompose into magnesium oxide ( $\mathrm{MgO})$, calcium oxide $(\mathrm{CaO})$, and carbon dioxide $\left(\mathrm{CO}_{2}\right)$. The melt glass as observed in silicate rock will not form in carbonate rock because $\mathrm{MgO}$ and $\mathrm{CaO}$ have a very high melting point. This may result in debris solidifying before some radionuclides condense. The absence of extensive melt glass formation may result in higher mobility of refractory or semivolatile radionuclides than the tests with a working point in silicate rock (Carle et al., 2008) (see Section 3.2.2). The objectives of the near-field modeling included the following:

- Collect, assess, and describe data on four carbonate tests at the NTS.

- Understand phenomenology, define source term geochemical conditions, and show radionuclide distribution.

- Conceptualize and determine flow and transport processes that contribute to the HST.

- Estimate for each test and radionuclide class the combination of geochemical conditions, source term distribution, and flow and transport processes that contribute to a source term at the water table.

The near-field modeling was performed for the HANDCAR and NASH detonations because these detonations had more data available compared to the BOURBON and KANKAKEE detonations. The HANDCAR detonation was thought to be the most thoroughly characterized in terms of phenomenology and chemistry and the NASH detonation was thought to be the most thoroughly characterized in terms of hydrologic processes. The HANDCAR detonation was part of the Plowshare program and significant post-test characterization was performed (Carle et al., 2008). The modeling emphasis was on understanding the differences in hydrogeochemical settings and processes 
compared to previous HST work for the Frenchman Flat and Pahute Mesa CAUs. The major differences included:

- Unsaturated conditions including thermal effects, injection of drill-back hole fluids, chimney and vadose zone drainage, and crater infiltration.

- Carbonate rock and groundwater chemistry.

- Mixing of carbonate and volcanic rocks in source zones.

- Release of $\mathrm{CO}_{2}$ from decomposition of carbonate rock with gaseous expansion and density-driven flow.

- $\quad$ Effects of fracture-matrix interactions on flow and transport.

- Transient interaction of transport processes involving both gas and liquid-phase flow including steam bubble expansion (enhanced by drill-back hole fluids) and partitioning of components between gas and liquid phases.

The amount of $\mathrm{CO}_{2}$ produced by the tests was estimated using empirical relationships for the initial distribution of heat surrounding the test working point and decomposition temperatures of dolomite and calcite. Several other methods were used to verify the estimates of $\mathrm{CO}_{2}$ produced by the tests, when additional data such as cavity gas sampling were available.

Two porous media conceptualizations were used in the HST modeling. The first was an equivalent continuum (ECM) conceptualization, which assumes the matrix and fractures are in equilibrium and are represented by single effective properties. The second was a dual continuum (DKM) conceptualization, which allows the fracture and matrix to be represented by separate and very different properties.

The HST modeling also used two conceptualizations of flow and transport processes. These included: 1) a single, isothermal, variably saturated liquid-phase flow (i.e., Richards' equation) with one transport component $\left({ }^{3} \mathrm{H}\right)$, which was designated as the LF-1CT conceptualization; and 2) a thermal multiphase flow with multiple transport components $\left({ }^{3} \mathrm{H}\right.$ and $\left.\mathrm{CO}_{2}\right)$, which was designated as the T-GLF-MCT conceptualization. The conceptual models were implemented in the NUFT code (Nitao, 1998). The T-GLF-MCT simulations used 2-D radially symmetric mesh geometry, which could not account for horizontal flow (e.g., underflow) from the regional aquifer gradient. 
The ECM LF-1CT conceptualization was used for investigating vadose zone drainage and ${ }^{3} \mathrm{H}$ transport through the chimney at the NASH detonation and included horizontal groundwater fluxes based on groundwater velocities given by SNJV (2006). The DKM T-GLF-MCT and ECM TGLF-MCT conceptualizations were used for investigating the combined effects of $\mathrm{CO}_{2}$ advection, diffusion and dissolution in water, water liquid-gas phase changes, and ${ }^{3} \mathrm{H}$ transport. The DKM T-GLF-MCT conceptualization was used for modeling the NASH detonation. Both ECM TGLF-MCT and DKM T-GLF-MCT conceptualizations were used for modeling the HANDCAR detonation. The simulations included $\mathrm{CO}_{2}$ gas solubility dependence on temperature and pressure, but did not include solubility dependence on $\mathrm{pH}$, temperature, and $\mathrm{CO}_{2}$ concentrations in water.

Some of the most important conclusions of the modeling included:

- Cavity radii estimates should be calculated for carbonate tests using the empirical formula of Boardman (1970) rather than Pawloski (1999).

- The net $\mathrm{CO}_{2}$ production at all tests is $\sim 4 \times 10^{6}$ moles of $\mathrm{CO}_{2}$ per kiloton yield.

- Test-related temperature distribution curves based on the Hugoniot relationships reported in Butkovich (1974) can predict energy deposition and $\mathrm{CO}_{2}$ release.

- At HANDCAR, refractory radionuclides reside in the lower $15 \mathrm{~m}$ of the cavity. The HANDCAR chimney terminated in carbonate rock and the overlying tuff did not play an important role in the cavity mineralogy. For other tests, the cavity debris will contain carbonate and noncarbonate rock. The refractory radionuclides appear to be distributed over a larger volume, perhaps as much as the lower half of the cavity.

- Data from HANDCAR along with mass balance calculations indicate that volatile radionuclides (or radionuclides with volatile precursors) will be distributed as much as $10 \mathrm{R}_{\mathrm{c}}$ from the working point.

- At NASH and KANKAKEE, data indicate that refractory radionuclides will be sequestered by calcite, dolomite and their decomposition products in a highly radioactive zone in the cavity bottom. The overlying tuffs deposited in the cavity after cavity collapse will have moderate radioactivity.

- Bourbon was detonated in a silty limestone and the cavity debris would have a substantial quantity of silicate material. Refractory radionuclides at BOURBON will be sequestered by a nuclear melt glass not unlike that found in silicate (tuff, alluvium, granite) tests. 
- Seven processes are identified as important to the carbonate HST. The seven processes will have interacting effects on the HST, and be different for each carbonate test. These processes are: 1) $\mathrm{CO}_{2}$ bubble expansion and density-driven flow, 2) steam bubble expansion, 3) drill-back hole fluid injection, 4) gas-liquid phase exchange, 5) chimney and vadose zone drainage, 6) crater infiltration, and 7) cavity location being below the water table.

- Flow and transport simulations indicate volatile radionuclide gases, particularly ${ }^{14} \mathrm{C}$, can be transported to the water table by the $\mathrm{CO}_{2}$ bubble expansion and density-driven flow processes at all four carbonate detonations. However, the $\mathrm{CO}_{2}$ bubble expansion, density flow, and gaseous diffusion processes contribute to wide dispersal and attenuation of ${ }^{14} \mathrm{C}$ concentrations within the vadose zone and water table.

- Flow and transport simulations indicate steam bubble expansion toward the water table would be limited to within tens of meters of the cavity. Steam bubble expansion would only contribute directly to an HST for detonations that may be close to the water table (e.g., HANDCAR and BOURBON). However, steam bubble expansion would contribute to gas-liquid exchange processes to enhance liquid-phase transport of more mobile radionuclides (e.g., $\left.{ }^{3} \mathrm{H}\right)$.

- The drill-back hole fluid injection process could contribute to the HST for mobile radionuclides such as ${ }^{3} \mathrm{H}$ at all carbonate detonations.

- Considering that the BOURBON cavity likely extends below the water table, the BOURBON puddle zone would likely be situated below the water table, providing direct contact between radiologic source zones for both volatile and refractory radionuclide classes.

In conclusion, the work in Carle et al. (2008) presents flow modeling, transport modeling, and RSTs for the carbonate detonations. The transport simulations presented were restricted to $\mathrm{CO}_{2}$ and ${ }^{3} \mathrm{H}$, because most ${ }^{14} \mathrm{C}$ is in the form of ${ }^{14} \mathrm{CO}_{2}$ (Section 3.3.5.1) and the $\mathrm{CO}_{2}$ transport simulation results can be scaled to ${ }^{14} \mathrm{C}$ transport by the molar ratio of ${ }^{14} \mathrm{C}$ to test-released $\mathrm{CO}_{2}$. The simulations concluded that thermal gas-liquid-phase flow process effects are inseparably intertwined and likely cannot be addressed using simplified flow modeling. The document identifies the key flow processes that may influence radionuclide migration and assigns the relative importance of each process based on the hydrogeologic setting.

\subsubsection{Near-field Studies for Climax Mine}

Pohlmann et al. (2007) performed near-field modeling of the three detonations performed in the Climax Mine granite stock. The three Climax Mine detonations were conducted in the very different hydrogeologic setting of the Climax Mine granite stock and require evaluation to a higher level of detail than the CAU scale Yucca Flat model can provide. 
The objectives of the Climax Mine sub-CAU work were to provide simulated heads and groundwater flows for the northern boundaries of the Yucca Flat-Climax Mine CAU model and provide radionuclide fluxes from the three tests using modeling techniques that account for groundwater flow in fractured granite. The modeling included alternative conceptualizations of the hydrogeologic system with the associated uncertainty. The modeling included two different scales consisting of: 1) Death Valley Regional Flow System model (Belcher et al., 2004) developed by the USGS with refined hydrostratigraphy in a zone north of Yucca Flat and Climax stock, and 2) a separate model of the granite stock using a groundwater flux provided by the Death Valley Regional Flow System model for the northern boundary.

The modeling study conclusions included:

- Significant conceptual model uncertainty exists for the area north of Yucca Flat and conceptual model uncertainty is greater than parametric model uncertainty.

- The averaged flow into northern Yucca Flat is substantially higher than previous estimates.

- The groundwater flow times from the three Climax Mine nuclear tests to the edge of the granite that are well within the 1,000-year period of investigation for the CAU and the majority of breakthrough out of the granite occurs along the southern boundary where flow and contaminants are likely to enter the regional carbonate aquifer.

- Radionuclides within the nuclear melt glass play a minor role in contaminant transport. Sorption is a key controlling factor on radionuclide transport. No strongly sorbing radionuclides were transported to the edge of the granite stock in 1,000 years. Only minor amounts of moderately sorbing radionuclides were transported to the boundary. Significant migration was only calculated for radionuclides assumed to not react with the rock matrix.

- Nonreacting radionuclides from all three nuclear tests contribute to breakthrough at the granite boundary.

- Only nonsorbing nuclides from the nuclear tests in Climax Mine granite stock need to be considered for the CAU scale transport model. Sorbing nuclides likely will not contribute to a contaminant boundary for the CAU.

Climax Mine groundwater flow and transport modeling placed particular focus on assessment of conceptual and parametric uncertainty. The uncertainty assessment developed a model averaging approach that considered model performance. The model combinations performing better relative to calibration targets were given higher weights than those performing poorly. 


\subsubsection{Near-field Studies for Other CAUs}

The HSTs developed for other CAUs may be used in the Yucca Flat HST, if the relevant and important processes are similar to those for Yucca Flat (Pawloski et al., 2008). For example, the HST for tests in a fractured volcanic setting will be similar to the Pahute Mesa HST. The HST for tests in an alluvium setting will be similar to the Frenchman Flat HST.

\subsubsection{Alluvium Studies}

The Frenchman Flat SSMs were developed from the LLNL near-field model of the CAMBRIC detonation and the CAMBRIC detonation was performed in alluvium. The LLNL Frenchman Flat HSTs and SNJV SSMs may be used to represent the source terms for the Yucca Flat saturated alluvium tests. The LLNL near-field models developed for Frenchman Flat include:

1) the CAMBRIC HST model (Tompson et al., 1999); 2) the updated CAMBRIC steady-state model (Tompson et al., 2005); 3) the Frenchman Flat simplified HST model (Tompson et al., 2002); and 4) evaluation of the transient HST for the CAMBRIC detonation including unsaturated processes (Carle et al., 2007) for the Frenchman Flat Phase II transport analysis. A summary of the first three LLNL near-field models and SSMs can be found in the Frenchman Flat unclassified source term (SNJV, 2005).

The objective of the Phase II HST modeling by Carle et al. (2007) was to improve understanding of HST processes relative to previous Frenchman Flat HST work (Tompson et al., 1999 and Pawloski et al., 2001). The modeling focused on relatively short-term processes (50 years or less) in the near-field (less than $300 \mathrm{~m}$ ). The modeling incorporated new data and considered several additional processes relative to the previous HST work including: 1) unsaturated groundwater flow, 2) residual test heat, and 3) initial test pressure.

\subsubsection{Fractured Volcanics Studies}

The Pahute Mesa SSMs were developed from the LLNL near-field model of the CHESHIRE detonation. Most of the Pahute Mesa detonations were performed in the Tertiary volcanics including: fractured lava, tuffs, and altered tuffs. The Pahute Mesa SSM and HSTs may be used to help develop concepts representing the HST for the Yucca Flat saturated volcanics tests. The LLNL near-field and LANL sub-CAU scale models developed for Pahute Mesa include: 1) The CHESHIRE detonation in 
fractured lava and tuffs (Pawloski et al., 2001), and 2) the TYBO/BENHAM (Wolfsberg et al., 2002), which incorporated several HSUs in the test-effected zones. The LLNL and LANL modeling included thermally induced, buoyancy-driven flow in the chimney. A summary of these near-field models and SSMs can be found in the Pahute Mesa unclassified source term (SNJV, 2004). 


\subsection{Source Term Conceptual Models}

This section presents the important processes that influence radionuclide migration to the CAU scale models and how these processes can be implemented into the CAU scale transport calculations with SSMs or with CAU scale model parameters. Descriptions of simplified conceptual models are presented in this section along with discussions of the important processes influencing radionuclide migration away from the unsaturated, saturated, and carbonate tests. This report will not perform calculations of the radionuclide flux to the CAU scale models because key inputs (i.e., the CAU scale regional gradient and groundwater flux in the near-field) are still being developed at the time this report was written. Instead this report describes the conceptual components that will be used to develop the HST during the Yucca Flat CAU-transport modeling.

Bowen et al. (2001) subdivided the Yucca Flat inventory as above and below the water table. All tests below or within $100 \mathrm{~m}$ of the water table were included in the below-the-water-table inventory. This criteria has been used as the definition of a saturated test because those tests located within $100 \mathrm{~m}$ of the water table are assumed to potentially interact with the regional water table. The Yucca Flat source term models will assume that a test with any portion of the exchange volume intersecting the water table will be partially saturated and have a two part source term consisting of: 1) an unsaturated portion of the exchange volume above the water table, and 2) a saturated portion of the exchange volume below the water table. The partially saturated tests will include the processes important to both the unsaturated and saturated conceptual model.

\subsection{Relation of the Radiologic and Hydrologic Source Term}

The RST represents all the radioactivity remaining after an underground nuclear test. The RST is comprised of radionuclides in water, glass, or other phases or mineralogic forms. Only a subset of the RST radionuclides are available to the HST. The HST of an underground nuclear test is the portion of the RST that is released into the groundwater over time following the test. The HST can be considerably less than the RST because the mobility of some radionuclides is sufficiently slow. As 
such, the radionuclide cannot contribute to the contaminant boundary (i.e., strongly sorbed or incorporated in melt glass). The HST models include the processes important to the radionuclide distribution, release, and migration away from the source area. The conceptual model identifies these processes.

The HST can be computed with varying degrees of physical process detail. A complete representation of all physical processes such as that embodied in LLNL's work, requires a great deal of time to compute, and a great deal of information that is not well known. This approach cannot practically be implemented for any but a few tests. The complex models allow identification of key processes that can be used to simplify the source representation while still retaining the essence of the results. Simple source term representation must capture the full range of output fluxes of the process model as well as the uncertainty in those fluxes and pass this uncertainty to the CAU-scale transport models.

\subsection{Conceptual Phenomenological Models of Underground Nuclear Tests}

Phenomenological models describe effects of the underground nuclear explosion. The silicic and carbonate tests each have unique phenomenological aspects. The unique phenomenology associated with silicic and carbonate tests is presented in this section. A general overview of underground nuclear phenomenology can be found in Section 2.2.

\subsubsection{Silicic Rock Conceptual Model}

An underground nuclear explosion will release an enormous amount of energy. Temperatures increase as high as several hundred million degrees Celsius $\left({ }^{\circ} \mathrm{C}\right)$ and pressures of several million pounds per square inch are created. This generates a compressive shockwave that spreads radially outward from the point of origin. Within tens of milliseconds, the shock wave expands and the surrounding rock is crushed, melted, and vaporized, creating an expanding cavity (Pawloski et al., 2008).

Within seconds and minutes, the expanding cavity has reached its maximum size and the molten silicate rock will begin collecting and solidifying at the bottom of the test cavity in a melt glass pool. The refractory radionuclides (e.g., actinides), whose melting points are significantly greater than the 
melting temperature of the adjacent geologic media, are scavenged by the molten material within the cavity and are deposited within the melt glass. Further condensation occurs as cavity gas moves into the crushed rubble and fractured material surrounding the working point. The radioisotopes of intermediate volatility condense and deposit on rubble and fracture surfaces. Final condensation occurs as residual gas moves radially outward and ascends toward the ground surface. Further condensation during this stage occurs on outer and higher surfaces beyond the cavity (SNJV, 2006b).

The shock wave will create a high or low permeability crushed zone surrounding the cavity. If the test was performed in alluvium or vitric tuff aquifer, a low permeability zone may be created. If the test was performed in hard fractured rock, an enhanced permeability crushed zone may be created. The initial radionuclide distribution will be contained mostly within the cavity, melt glass, and crushed zone. For the tests performed below the water table, the high pressure will move radially outward into the surrounding groundwater creating groundwater mounding effects. As the high pressures and temperatures dissipate, water will return to the test cavity. The returning water will encounter higher temperatures in the cavity and may convect heat and water up the chimney due to buoyancy-driven flow. If the test was performed in a low permeability TCU, the high pressure and temperature may persist for long periods of time (Pawloski et al., 2008; Wolfsberg et al., 2006).

\subsubsection{Silicic Rock Test Altered Zones}

The source term models must be a simple alternate conceptual model of the numerically intensive process models. The process models are complex, multi-dimensional tools that simulate the thermal, hydrogeological, and chemical processes. The altered zone conceptual model is the simplification of the volumes of geologic material physically affected by the tests, which will be used in the source term models. Radionuclides will be distributed within the altered zones due to short-term processes.

The silicic rock altered zones (Figure 3-1) are assumed to occupy spheres centered on the working point along with the chimney extending toward land surface. The silicic rock altered zones will include:

- The cavity zone consisting of the cavity above the melt glass, which includes the unconsolidated rubble from the collapsed chimney and the cavity walls. 


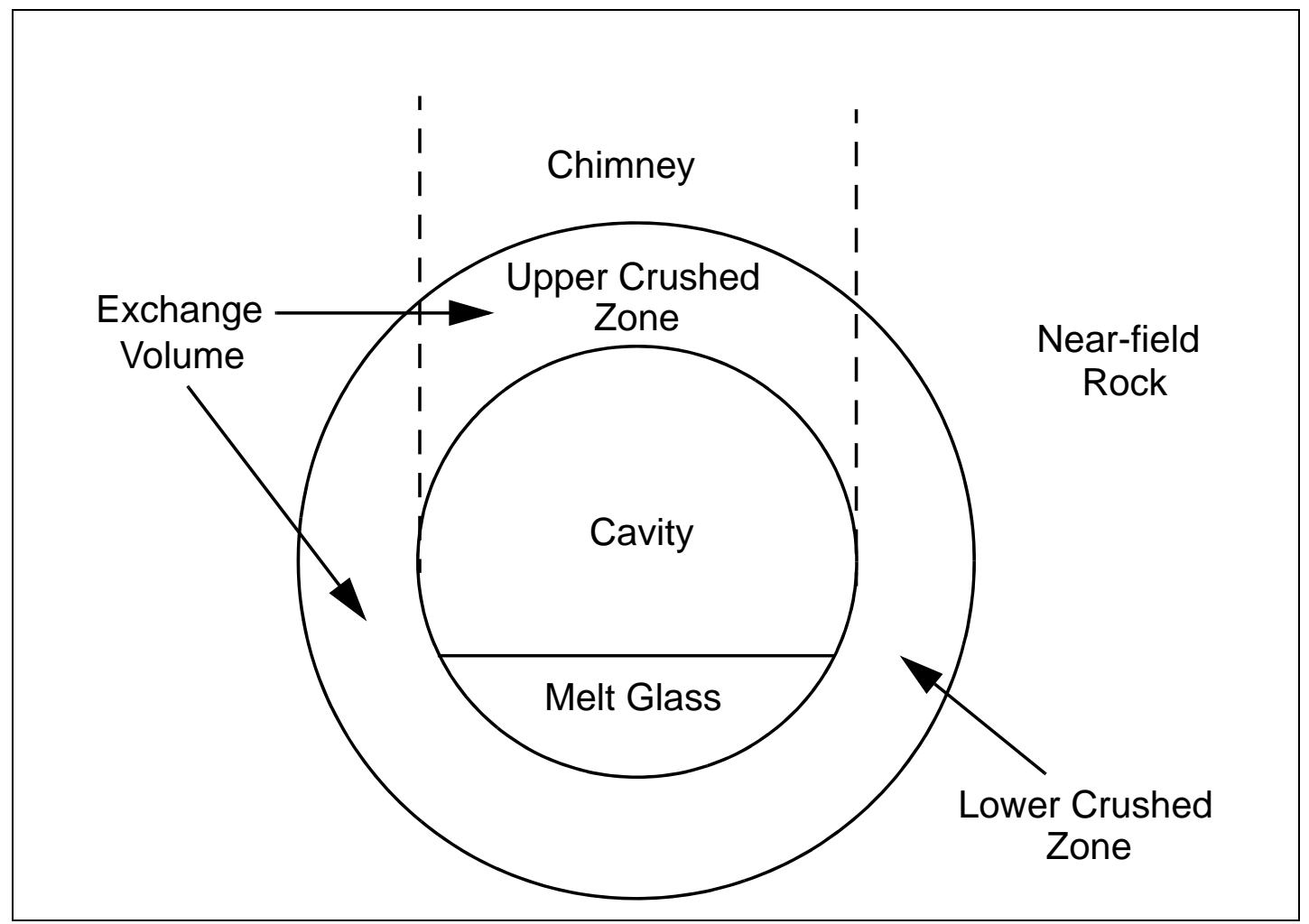

Figure 3-1

Schematic Diagram of the Silicic Rock Test Altered Zones

- The nuclear melt glass zone at the bottom of the cavity consisting of vaporized material, melted material, and infallen rubble that accumulates at the cavity bottom. The melt glass zone at the bottom of the cavity is not composed of pure nuclear melt glass. It is a mixture of glass and infallen rubble. The fraction of rubble that mixes with melt glass is primarily dependent on the collapse time of the cavity (Carle et al., 2007).

- The crushed zone consisting of the rock surrounding the cavity, which has mechanically failed and permanently lost permeability and porosity due to the compressional shock wave.

- The exchange volume, which contains radionuclides immediately following the test. The exchange volume will encompass the cavity, melt glass, and crushed zone.

The saturated test HST modeling performed by Maxwell et al. (2008) also included a compressed zone extending beyond the crushed zone, which was assumed to undergo elastic deformation resulting from shockwave and compressive forces from the explosion. However, this zone has been excluded from the source term altered zone conceptual models because the source term modeling will not directly include short-term test-induced transient effects. The initial conditions of the source term modeling will account for these transient effects. 
The cavity radius is calculated from the maximum announced yield, the bulk overburden density, and the DOB (Pawloski, 1999):

$$
R_{c}=\frac{70.2 Y^{1 / 3}}{\left(\rho_{b} D O B\right)^{1 / 4}}
$$

where:

$R_{c} \quad=$ Cavity radius in meters

$Y \quad=$ Maximum yield in kilotons

$\rho_{b} \quad=$ Overburden density (grams per cubic centimeter $\left[\mathrm{g} / \mathrm{cm}^{3}\right]$ )

$D O B=$ Depth of burial in meters

The mass of the melt glass is estimated on the basis of 700 metric tons of melt glass $\left(\mathrm{M}_{\mathrm{MG}}\right)$ produced per kiloton of yield as described by Pawloski (1999). The volume of the silicate melt glass is calculated, based on a density $\left(\rho_{\mathrm{MG}}\right)$ of 2,500 kilograms per cubic meter $\left(\mathrm{kg} / \mathrm{m}^{3}\right)$ and a porosity $\left(\phi_{\mathrm{MG}}\right)$ of 20 percent, as:

$$
V_{M G}=\frac{M_{M G}}{\left(1-\phi_{M G}\right) \rho_{M G}}
$$

The radius $(\mathrm{R})$ of the crushed zone and exchange volume is estimated as the product of the calculated cavity radius and a multiplier $(\mathrm{M})$ :

$$
R=M R_{C}
$$

The multiplicative factor depends on the rock hosting the detonation. The crushed zone represents the maximum extent of the exchange volume radius. The values have been estimated in various HST modeling efforts from post-test gamma surveys (Thompson et al., 2005), phenomenologic models, and hydraulic data (Pawloski et al., 2001) for different rock types and are summarized in Table 3-1.

Table 3-1

Silicic Rock Test Altered Zone Volume Multiplicative Factors

\begin{tabular}{|c|c|c|}
\hline Rock Type & $\begin{array}{c}\text { Exchange Volume } \\
\text { Multiplier }\end{array}$ & Source \\
\hline \hline Unconsolidated Alluvium & $1.3-2.0$ & $\begin{array}{c}\text { SNJV, 2005 } \\
\text { Tompson, 2004 }\end{array}$ \\
\hline Zeolitic Tuff & 1.5 & Wolfsberg et al., 2006 \\
& $2.0-2.5$ & Maxwell et al., 2008 \\
\hline
\end{tabular}




\subsubsection{Carbonate Rock Test Conceptual Model}

The carbonate test phenomenology is fundamentally different from the tests detonated in silicate geologic settings for several reasons. The thermal decomposition of carbonate rock will release enormous amounts of $\mathrm{CO}_{2}$ gas that will contribute to pressure-driven and density-driven gas advection. The shocked zone surrounding the cavity will be fractured instead of crushed/consolidated as may occur in tests conducted in alluvium of tuffaceous rock. The test-induced fractures will increase fracture porosity and permeability in the carbonate rock surrounding the cavity. The degree of fracturing will decrease with distance from the cavity (Carle et al., 2008).

The phenomenology of a carbonate test will not result in formation of a carbonate rock melt glass because the carbonate rock melting and vaporization temperatures are much higher than the decomposition temperatures. The dolomite $\left[\mathrm{CaMg}\left(\mathrm{CO}_{3}\right)_{2}\right]$ will decompose into calcite $\left(\mathrm{CaCO}_{3}\right)+$ $\mathrm{MgO}+\mathrm{CO}_{2}$ and calcite will decompose into $\mathrm{CaO}+\mathrm{CO}_{2}$. These reactions probably did not go to completion and various amounts of highly radioactive $\mathrm{CaMg}\left(\mathrm{CO}_{3}\right)_{2}, \mathrm{CaCO}_{3}, \mathrm{MgO}$, and $\mathrm{CaO}$ are coated onto the sides of the cavity immediately following the detonation. During the cavity collapse, the highly radioactive decomposition products will fall to the cavity bottom creating a highly radioactive zone. The highly radioactive zone will then be covered by moderately radioactive rubble from the chimney. The refractory radionuclides are mixed into $\mathrm{CaCO}_{3}, \mathrm{MgO}, \mathrm{CaO}$, and rubble. Some $\mathrm{CaCO}_{3}$ is formed by back-reaction of $\mathrm{CO}_{2}$ with $\mathrm{CaO}$ (Werth, 1970; Carle et al., 2008). Figure 3-2 illustrates an idealized phenomenology of a carbonate test.

The absence of extensive melt glass formation may partition a greater percentage of refractory or semivolatile radionuclides into the rubble and makes these radionuclides more available to groundwater than the tests with a working point in silicate rock. Only the BOURBON carbonate detonation is expected to have a silicate melt glass (Carle et al., 2008) because the detonation was detonated in a silty limestone and the cavity intersects overlying tuff rock. The dissolution of the highly radioactive material and subsequent release of radionuclides will be drastically different from what is expected for silicate glasses. Additionally, the cavities of BOURBON, NASH, and KANKAKEE will include a large amount of argillic and zeolitized tuffs as a result of cavity collapse and mixing with overlying tuffs. This will reduce mobility of many of the radionuclides. The initial radionuclide distribution may extend beyond the fractured zone because of low porosity and the high 


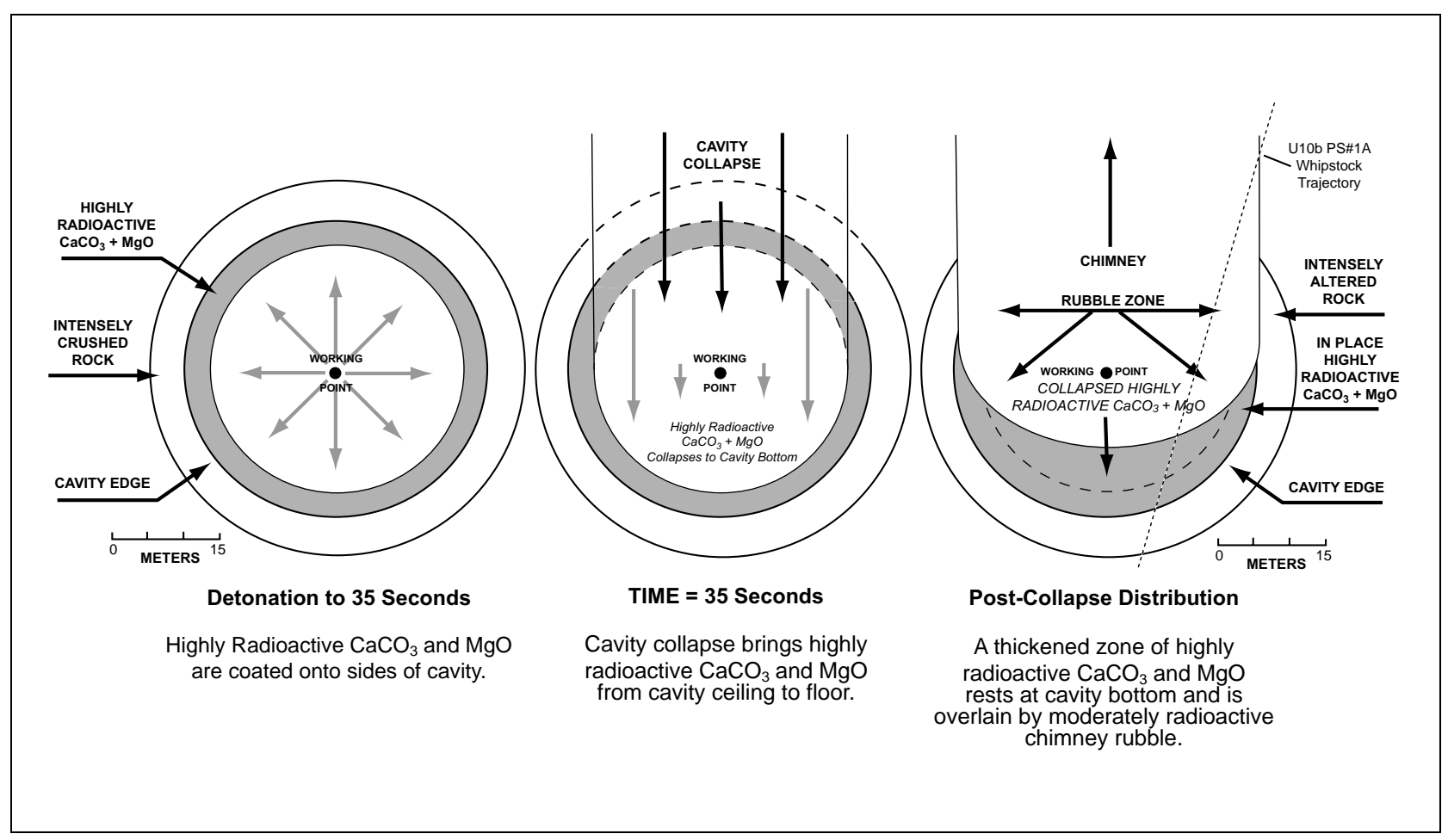

\section{Figure 3-2 \\ Idealized Phenomenology of a Carbonate Test}

Source: Carle et al., 2008

gas pressure in the carbonate rock, which results from the large quantity of $\mathrm{CO}_{2}$ gas released during the test.

\subsubsection{Carbonate Rock Altered Zones}

The test altered zones will be different for the silicate and carbonate rock tests. The most notable difference is that the exchange volume for radionuclides present in the gaseous phase will be much larger because of the large amount of $\mathrm{CO}_{2}$ gas generated. The carbonate rock altered zones (Figure 3-3) are assumed to occupy spheres centered on the working point along with the chimney extending towards land surface. The carbonate rock altered zones will include.

- The cavity zone consisting of the cavity above the highly radioactive zone including the unconsolidated rubble from the collapsed chimney and the cavity walls.

- The highly radioactive zone at the bottom of the cavity consisting of the carbonate rock decomposition products that accumulate at the cavity bottom due to gravity. 


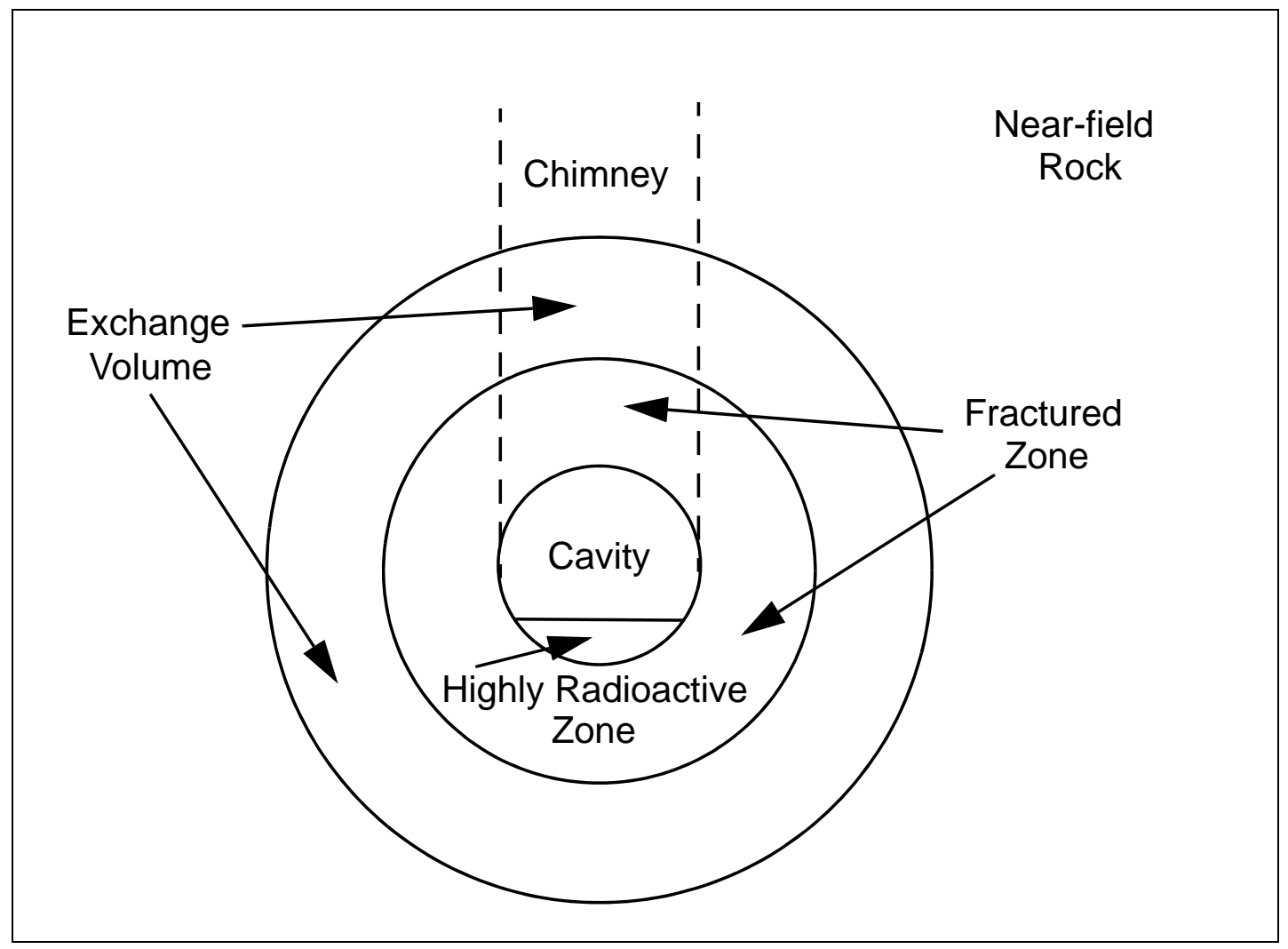

Figure 3-3

\section{Schematic Diagram of the Carbonate Rock Test Altered Zones}

- The fractured zone consisting of the rock surrounding the cavity, which has mechanically failed and permanently gained fracture permeability and porosity due to the compressional shock wave.

- The exchange volume which contains radionuclides due to short-term detonation forces. The exchange volume will encompass the cavity, highly radioactive zone, fractured zone, and a portion of the near-field beyond the fractured zone.

The carbonate tests have significantly smaller measured $R_{c}$ than predicted by using the empirical model expressed in Equation 3-1 (Carle et al., 2008). The cube-root energy scaling equation developed by Boardman (1970) will be used for the carbonate tests:

$$
R_{c}=C Y^{1 / 3}
$$

where:

$R_{c}=$ Cavity radius (meter)

$Y=$ Maximum yield in kilotons

$C=29.7$ for dense dolomite and limestone 
The test-induced fractures will decrease with distance from the cavity. Carle et al. (2008) used concentric fractured zones with decreased fracture permeability in the outer zones. The HANDCAR ECM modeling used three fractured zone radii: 1 to $2 R_{c}$, 2 to $3.5 R_{c}$, and 3.5 to $5 R_{c}$. The HANDCAR DKM modeling used two fractured zone radii: 1 to $1.5 R_{c}$ and 1.5 to $3.5 R_{c}$.

The large quantity of $\mathrm{CO}_{2}$ gas released and high gas pressure, in combination with low porosity in the carbonate rock, will increase the distribution of radionuclides external to the cavity region compared to the silicate rock tests (Carle et al., 2008). The exchange volume will capture this process by using larger volumes for the more volatile radionuclides. Carle et al. (2008) recommended using the following exchange volume radii for different classes of radionuclides: 1 to $3 R_{c}$ for nonvolatile radionuclides, 3 to $6 R_{c}$ for volatile radionuclides, and 5 to $10 R_{c}$ for gaseous radionuclides.

\subsection{Unsaturated Zone Conceptual Model}

The unsaturated zone at Yucca Flat extends to $~ 500 \mathrm{~m}$ below land surface (bls) and contains alluvium, volcanic tuff aquifers, volcanic TCUs, and carbonate aquifer. The alluvium comprises most of the unsaturated zone and is 300 to 460 m thick in the east-central portion of Yucca Flat (BN, 1998). The carbonate aquifer rises above the water table near the perimeter of the Yucca Flat basin. A complete description of the Yucca Flat geologic and hydrogeologic setting can be found in the Phase I hydrologic data document (SNJV, 2006b).

The amount of water infiltrating through the unsaturated zone is likely the most important factor transporting radionuclides from the contaminated unsaturated zone to the water table. The subsidence craters above the tests may capture precipitation and focus recharge water through the test contaminated area. However, the enhancement of permeability within and adjacent to the chimney rubble may result in dewatering of the chimney and also transport radionuclides to the water table. This appears to be the dominant process for transporting ${ }^{3} \mathrm{H}$ to the water table at the HANDCAR detonation (Carle et al., 2008).

\subsubsection{Precipitation and Evapotranspiration}

The climate at Yucca Flat is one of the most arid within the United States. A 47-year precipitation record (1960 through 2006) was collected by the National Oceanic and Atmospheric Administration 
(NOAA) for the Buster Jangle Y (BJY) meteorology station in Yucca Valley. The average rainfall based on a the 47-year record is $160 \mathrm{~mm} / \mathrm{yr}$, and the majority of this rainfall occurs between November and March. The potential evapotranspiration (PET) is the maximum water loss to the atmosphere that can occur and is a function of meteorological conditions. The Yucca Flat PET is $\sim 1,480 \mathrm{~mm} / \mathrm{yr}$. This rate is calculated using meteorological data acquired from the $3 \mathrm{~m}$ level of the Area 3 Radioactive Waste Management Site (RWMS) tower in Yucca Flat from 1997 through 2006 and the Hargreaves Method (FAO, 1998).

The low average annual rainfall and high potential evaporation rates are consistent with characterization studies from Area 3 (BN, 1998), which concluded that nearly all the precipitation infiltration is removed via potential PET, and significant recharge does not occur in the interfluve regions of Yucca Flat.

\subsubsection{Crater-enhanced Infiltration}

Several studies of infiltration occurring in Yucca Flat and Frenchman Flat subsidence craters have been performed. The craters selected for most of the studies were those with observed ponding following precipitation events. These studies are likely biased towards the highest infiltration rates occurring within the subsidence craters.

Hokett and Gillespie (1996), Hokett and French (1998), and Wilson et al. (2000) studied possible recharge at the U-5a subsidence crater. The U-5a crater is located at the WISHBONE underground nuclear detonation in Frenchman Flat. The U-5a crater was studied because extensive vegetation, large erosional gullies, and a playa near the collapse sink center suggested that this crater received substantial storm runoff.

Hokett and Gillespie (1996) performed data collection and preliminary data analysis. Hokett and French (1998) performed surface water modeling that was used to estimate the timing and magnitude of ponding events occurring within the crater. The total volume of ponded water for the entire simulation period was $\sim 5,900$ cubic meters $\left(\mathrm{m}^{3}\right)$. The recharge estimates ranged from 0.36 to $1.18 \mathrm{~m} / \mathrm{yr}$, which depended on the area assumed for the recharge calculation. 
Wilson et al. (2000) found that soil moisture under the subsidence crater playa was greatly increased over a nearby undisturbed area. Wilson et al. (2000) concluded that a single large ponding event of $\sim 60,000 \mathrm{~m}^{3}$ was introduced into the crater and water from this event was estimated to have reached the water table within 32 years. The study also concluded that this large ponding event deposited fine sediment, which could prevent future recharge by limiting infiltration and increasing PET.

Tyler et al. (1986 and 1992), and Pohll et al. (1996) studied infiltration occurring at the U-3fd subsidence crater resulting from the LAGUNA detonation performed in southern Yucca Flat. A well was placed in the bottom of the U-3fd crater and another well was placed $207 \mathrm{~m}$ outside of the crater. Soil moisture and other characterization data were collected from the two wells. The well in the subsidence crater bottom showed an enhanced moisture profile from recharge while the distal well did not. The distal well data suggested little or no infiltration occurs. The recharge within the crater was estimated to be 0.54 to $4.22 \mathrm{~m} / \mathrm{yr}$ from core hydraulic conductivity.

Tyler et al. (1992) revisited the Tyler et al. (1986) analysis of the U-3fd crater by studying soil-moisture ${ }^{3} \mathrm{H}$ concentrations, which were used to estimate the age of infiltrated water. The vertical flux beneath the subsidence crater was estimated to be on the order of $0.6 \mathrm{~m} / \mathrm{yr}$. The study concluded that the combination of surface topography, coarse soils at the crater bottom, and periodic ponding events allows for deep infiltration at the crater bottom.

Pohll et al. (1996) studied the infiltration occurring at the U-3fd crater by linking an overland flow model with a subsurface, unsaturated flow model. The inflow to the crater was converted to a pond depth by an empirical stage and volume relationship and reasonable agreement was obtained between the simulated and observed water levels following precipitation events. The simulations suggested that the flux at $10 \mathrm{~m}$ below the surface was temporally stable and was $0.75 \mathrm{~m} / \mathrm{yr}$.

Hokett et al. (2000) studied infiltration in northern Yucca Flat near the U-10i subsidence crater formed by the underground nuclear detonation, BYE. Hokett et al. (2000) collected rain data and crater stage data for two years. The largest rainfall event produced $2.4 \mathrm{~m}$ of ponding in the crater bottom. Simulation analysis indicated it took 84 days for the wetting front to reach a depth below the crater of $30 \mathrm{~m}$. No obvious preferential flow was observed, and it was suggested that such paths might be self-healing due to deposition of fine-grained material during runoff events. Soil analysis 
indicates at least six significant ponding events have occurred in the crater since its formation. An average long- term recharge rate was not estimated.

Hokett and French (2000) analyzed data from U-19b, which is characterized by a comparatively large drainage on Pahute Mesa. Borehole hydraulic and moisture content data were collected from beneath the crater as well as outside of the crater. A vadose zone model was developed to help constrain the rate of the wetting front migration under the crater. The rate of crater recharge was estimated from precipitation data and the Soil Conservation Service curve number approach. Simulation results suggested an infiltration depth of $200 \mathrm{~m}$ for a coarse-grained alluvial material and $100 \mathrm{~m}$ for fine-grained materials over 30 -year spans. The average recharge rate was estimated to be 32 centimeters per year ( $\mathrm{cm} / \mathrm{yr})$ for both materials.

Bechtel Nevada (1998) studied infiltration in craters used for waste disposal in the U-3ah waste cell within the Area 3 RWMS at Yucca Flat. Soil samples taken inside and outside the crater indicated that there was no significant change in soil properties within the crater. The modeling of a single 1,000-year event resulted in an equivalent $3.6 \mathrm{~mm} / \mathrm{yr}$ steady-state recharge rate and 950-year arrival time to the aquifer.

All the studies concluded enhanced subsidence crater recharge is occurring and the recharge estimates in these studies range from a few millimeters per year to approximately $1 \mathrm{~m}$ per year. Table 3-2 summarizes the recharge estimates. McNab (2008) inferred the average crater recharge rate to be $\sim 0.25 \mathrm{~m} / \mathrm{yr}$ from reviewing the NTS crater infiltration literature. This recharge rate represents $\sim 0.2$ percent of the precipitation falling on the Yucca Flat drainage basin. This percentage is calculated from the average daily precipitation falling on the Yucca Flat drainage basin and the total Yucca Flat Crater recharge area (i.e., $0.25 \mathrm{~m} / \mathrm{yr}$ infiltrates through playas one-tenth of the crater area). The average daily precipitation falling on the Yucca Flat drainage basin is $\sim 461,491$ cubic meters per day $\left(\mathrm{m}^{3} / \mathrm{d}\right)$ (SNJV, 2006b) and the total crater area is $\sim 12$ million $\mathrm{m}^{2}$ and was calculated using Geographic Information Systems (GIS) data from the LANL GIS laboratory (Kwicklis, 2007).

The modeling of crater infiltration performed by McNab (2008) investigated several factors that could affect wetting front propagation to the working point and aquifer. McNab (2008) concluded that the wetting front propagation will be mostly 1-D and transients will be damped quickly with depth. 
Table 3-2

Recharge Estimates from Crater Infiltration Studies

\begin{tabular}{|c|c|c|}
\hline Author, Date & Crater/Location & $\begin{array}{c}\text { Recharge } \\
\text { (m/yr) }\end{array}$ \\
\hline \hline Hokett and French, 1998 & U-5a/Frenchman Flat & $0.36-1.18$ \\
\hline Tyler et al., 1986 & Uf-3d/Yucca Flat & $0.54-4.22$ \\
\hline Tyler et al., 1992 & Uf-3d/Yucca Flat & 0.60 \\
\hline BN, 1998 & U-3ah/Yucca Flat & 0.0036 \\
\hline Hokett and French, 2000 & U-19b/Pahute Mesa & 0.32 \\
\hline Pohll et al., 1996 & Uf-3d/Yucca Flat & 0.75 \\
\hline
\end{tabular}

\subsubsection{Chimney Drainage}

Carle et al. (2008) performed near-field modeling of variably saturated flow and transport processes at the NASH carbonate detonation. The modeling hypothesized water level transients observed in the UE-2ce satellite well resulted from chimney and vadose zone drainage of perched water. Cavity collapse and subsequent chimney formation appears to have induced drainage of in situ vadose zone water through the test-contaminated zone. This hypothesis was based on water level, ${ }^{3} \mathrm{H}$, and chloride data from the UE-2ce NASH satellite well and model calibration.

\subsubsection{Drilling-fluid Injection}

Re-entry holes were drilled into the test-affected areas soon after each test was performed and drilling fluids were injected into the borehole for lubrication and cooling of the drilling bits and stems. The residual test heat and the need for radiologic control required more fluids to be injected compared to typical boreholes in the same setting (Carle et al., 2008). In general, post-test drilling/sampling activities within Yucca Flat started within 24 hours of detonation. Most post-test drillbacks were angle holes that started from outside the surface collapse crater, although some were vertical for the first $800 \mathrm{ft}$ then kicked off toward the target. The number of sidetracks ranged from 0 to 10 , averaging 2 to 3 per underground test, and varying from 300 to $500 \mathrm{ft}$ in length. Drilling fluid returns from the cavity region to the surface were not desired due to radiological concerns. Loss of circulation was forced at $\sim 200 \mathrm{ft}$ above the cavity by closing the blowout preventers and increasing pump pressure, thus hydrofracturing the formation. Pumping rates ranged from 150 gallons per minute (gpm) (the minimum amount to cool and rotate the downhole motor) to $700 \mathrm{gpm}$ (the amount 
required to initially start the downhole motor) and averaged $\sim 400 \mathrm{gpm}$. On average, the Yucca Flat drillback hole consisted of a 2,000 ft main hole with two 400-ft side tracks. Typically drilling mud circulation was lost at a depth of $300 \mathrm{ft}$. This corresponds to 2,500 drilling feet of lost circulation at a drilling rate of 60 feet per hour (ft/hr) and mud injection rate of $400 \mathrm{gpm}$, which yields $\sim 1,000,000$ gallons $\left(3,788 \mathrm{~m}^{3}\right)$ of drilling mud lost to the formation and/or into the chimney and cavity per Yucca Flat underground test (Drellack, 2008).

Nearly all the tests have higher saturations in the exchange volumes than would be expected from natural recharge alone. The effect of the re-entry hole drilling fluid may be to drive the mobile radionuclides to the aquifer quickly. This effect would likely be the greatest for unsaturated tests close to the water table. The effect on tests high in the unsaturated zone would likely be much less because less water is needed for shallow holes and the water pulse from the drilling fluid would quickly damp with depth.

At the HANDCAR detonation site, a total of 5,660 $\mathrm{m}^{3}$ of drilling fluid was injected during a week beginning 21 days after the test. This corresponds to nearly $148 \mathrm{gpm}$. The volume of drilling fluid is much greater than in situ water in the pretest cavity region, which is $\sim 1,100 \mathrm{~m}^{3}$, assuming 1 percent in situ water content by weight (Carle et al., 2008). The HANDCAR modeling also suggests that the water resulting from drilling fluid injection may reach the water table in months to years.

\subsubsection{Gas-phase Migration}

The relatively dry nature of the Yucca Flat vadose zone indicates gas phase advection and diffusion are important radionuclide transport mechanisms. The thermal decomposition of carbonate rock will release enormous amounts of $\mathrm{CO}_{2}$ gas that will contribute to early pressure-driven gas advection away from the exchange volume and later density-driven gas advection toward the water table. Residual test heat is expected to raise temperatures above the boiling point for water and create a pressurized water vapor bubble within the cavity, which will expand and rise up the chimney (Carle et al., 2008). Additionally, the water from drill-back injection will produce more steam than would occur without drill-back fluid injection. 


\subsubsection{Gas-phase Radionuclide Diffusion and Phase Partitioning}

The free-diffusion coefficients for the gaseous phase are generally four orders of magnitude greater than aqueous-phase diffusion coefficients. Gas-phase transport in a dry vadose zone is typically much more rapid than aqueous phase transport. Soil moisture will increase the gas-phase tortuosity and will retard radionuclides that exist in both the gaseous and aqueous phases by partitioning of the gas phase into the relatively immobile aqueous phase.

Smith (2002) reported that the radionuclides that have initial distributions in the gas phase are: ${ }^{14} \mathrm{C}$, ${ }^{39} \mathrm{Ar}$, ${ }^{85} \mathrm{Kr}$, and to a lesser degree, ${ }^{3} \mathrm{H}$. Gaseous ${ }^{14} \mathrm{C}$ may be present in ${ }^{14} \mathrm{CO}_{2},{ }^{14} \mathrm{CO}$, and ${ }^{14} \mathrm{CH}_{4}$ (Smith, 2002). Gas samples taken from the CAMEMBERT borehole indicated the presence of hydrogen, methane, and a depletion of oxygen suggesting anoxic conditions are present in an isolated system. However, most of the ${ }^{14} \mathrm{C}$ is likely in the form of ${ }^{14} \mathrm{CO}_{2}$ because of the test heat volatilization of carbonate minerals (Smith, 2002). Gaseous ${ }^{3} \mathrm{H}$ will be present as both HTO vapor and elemental hydrogen gas; however, most of the ${ }^{3} \mathrm{H}$ source term is associated with HTO (Thompson, 1999).

Gas diffusion in a porous medium is described by Fick’s First Law of Diffusion, which states the contaminant flux is proportional to the concentration gradient. The proportionality constant is called the effective diffusion coefficient. In a porous medium, contaminant molecules must travel longer diffusion paths because of the structure of the medium and moisture in the pore space. To account for longer diffusion paths, the effective diffusion coefficient is the product of the free-air diffusion coefficient and the air-filled porosity, divided by a parameter of the medium called the tortuosity.

Partitioning between the gaseous and aqueous phases is described by Henry's Law (Equation 3-5). The Henry's Law constant is a function of the type of gas, the temperature, and the constituents of the liquid. Henry's coefficients may be experimentally determined or estimated from the vapor pressure of pure compound divided by the aqueous solubility. The equation for Henry's Law is:

$$
P^{o} K_{H}=W
$$

where:

$K_{H}=$ Henry's coefficient (1/atmosphere [atm])

$P^{o}=$ Pure component vapor partial pressure (atm)

$W=$ Dissolved gas concentration mole fraction (mole/mole) 
The transport of ${ }^{14} \mathrm{C}$ is unique in that transport will occur in the aqueous and gaseous phases. Carbon-14 is primarily produced by neutron activation of ${ }^{14} \mathrm{~N}$. Carbon-14 was also loaded onto some devices as a tracer (Carle et al., 2008). At lower aqueous phase saturation, gaseous diffusion can dominate. However, at higher aqueous phase saturations, gaseous phase tortuosity increases and aqueous phase transport dominates. The low saturation of the Yucca Flat vadose zone may result in significant gaseous phase transport and attenuation of the ${ }^{14} \mathrm{C}$ concentration in the aquifer. Pohll et al. (2003) identified ${ }^{14} \mathrm{C}$ as a major driver of the contaminant boundary for the FAULTLESS underground nuclear test. Preliminary results from the Frenchman Flat Phase II transport model (SNJV, 2008) also show this result. For these reasons a detailed discussion of ${ }^{14} \mathrm{C}$ transport is included in this section.

The ${ }^{14} \mathrm{CO}_{2}$ diffuses in response to its own concentration gradient, which is independent of the ${ }^{12} \mathrm{CO}_{2}$ concentration (Plummer et al., 2004). The diffusion coefficients of different isotopes are essentially identical and ${ }^{14} \mathrm{CO}_{2}$ transport can be described as $\mathrm{CO}_{2}$ transport. The aqueous phase contains the greater fraction of the dissolved inorganic carbon (DIC) and, at near neutral $\mathrm{pH}$, the bicarbonate ion comprises most of the DIC. The dissolved carbonate species can interact with the solid matrix in a number of ways including anion sorption and dissolution-precipitation reactions (Plummer et al., 2004). These interactions will retard the $\mathrm{CO}_{2}$ movement (see Section 3.3.6).

Plummer et al. (2004) conducted a series of transport experiments with nonreactive gas- and aqueous-phase tracers to measure the mobility of inorganic ${ }^{14} \mathrm{C}$ species in a large ( $3 \mathrm{~m}$ high) unsaturated column filled with sediment. The study was performed to develop reliable transport models of ${ }^{14} \mathrm{CO}_{2}$ released from a low-level waste burial site. Plummer et al. (2004) also performed inverse modeling of the experiment using a simple gas diffusion model and a numerical multiphase flow and transport simulator. The experiment observations were described with both models. The simple gas diffusion model indicated that the transport of ${ }^{14} \mathrm{C}$ was consistent with a gas diffusion model employing a pH-dependent gaseous diffusion retardation factor, which was $\sim 6$, at near-neutral $\mathrm{pH}$ values. The numerical model used aqueous-gas-phase partitioning calculated directly from $\mathrm{pH}$. The measured aqueous/gas concentration ratios confirmed the calculations. The study concluded that ${ }^{14} \mathrm{C}$ may enter the underlying aquifer by both gas- and liquid-phase transport. The evaluation of risks to atmospheric and groundwater receptors should consider gas transport. 
Henry's Law linearly relates the $\mathrm{CO}_{2}$ partial pressure and pore water $\mathrm{CO}_{2}$ concentration. An effective Henry's coefficient is needed for partitioning $\mathrm{CO}_{2}$ in the soil gas between all the DIC partitioned among the carbonate species in the pore water. The effective Henry’s coefficient may be determined from the total combined solubility of DIC in the carbonate species present $\left(\mathrm{H}_{2} \mathrm{CO}_{3}, \mathrm{HCO}_{3}{ }^{-}\right.$, and carbonate $\left[\mathrm{CO}_{3}{ }^{2-}\right]$ ), which is a function of geochemical conditions (i.e., $\mathrm{pH}$, temperature, and ions present). This modeling approach was tested using the FEHM simulator and the experimental data of Plummer et al. (2004) and is presented in Appendix C.

For the noncarbonate tests, partitioning of ${ }^{14} \mathrm{C}$ into the gaseous phase attenuates breakthrough to the aquifer by allowing the ${ }^{14} \mathrm{C}$ to diffuse into a much larger volume. This diffusion decreases the concentration by dilution and will reduce the breakthrough to the aquifer because a large fraction of ${ }^{14} \mathrm{C}$ will be outside of the crater footprint (see Section 5.4). Recent ${ }^{14} \mathrm{C}$ carbonate test modeling performed by Carle et al. (2008) indicates $\mathrm{CO}_{2}$ solubility limits ${ }^{14} \mathrm{C}$ transport by liquid-phase flow, and more ${ }^{14} \mathrm{C}$ reaches the water table by $\mathrm{CO}_{2}$ gas phase flow than by aqueous phase flow without gas-phase partitioning. However, the $\mathrm{CO}_{2}$ gas flow processes disperse the ${ }^{14} \mathrm{C}$ source. The results differ from those in Section 5.4 because they include the large quantity of $\mathrm{CO}_{2}$ gas generated during the carbonate detonation, which is much less in the alluvial tests.

\subsubsection{2 $\mathrm{CO}_{2}$ Gas Production and Expansion}

The thermal decomposition of carbonate rock will release enormous amounts of $\mathrm{CO}_{2}$. Dolomite will decompose into $\mathrm{CaCO}_{3}+\mathrm{MgO}+\mathrm{CO}_{2}$ and calcite will decompose into $\mathrm{CaO}+\mathrm{CO}_{2}$. The net $\mathrm{CO}_{2}$ production at all tests is $\sim 4 \times 10^{6}$ moles of $\mathrm{CO}_{2}$ per kiloton yield. At the time of maximum cavity expansion, gas pressure is expected to be near or greater than the lithostatic pressure (Carle et al., 2008). The large quantity of $\mathrm{CO}_{2}$ gas released and high gas pressure may increase the distribution of radionuclides external to the cavity region initially by pressure-driven advection and later by density-driven advection because the cavity gas will also include volatile radionuclides. This will result in larger exchange volumes for the more volatile radionuclides than was predicted for tests detonated in volcanic rock or alluvium. The initial radioactive gas distribution may be on the order of $10 \mathrm{R}_{\mathrm{c}}$, and less volatile radionuclide exchange volumes will have radii between 1 and 10 of the cavity depending on the volatility (Carle et al., 2008). 
The cavity gas movement may also contribute to other processes. For example, $\mathrm{CO}_{2}$ bubble expansion may initially dominate transport of volatile gases (e.g., $\left.{ }^{14} \mathrm{C}\right)$. However, subsequent drill-back fluid injection may increase the liquid-phase saturation and develop gravity-driven liquid flow towards the water table. Gases initially transported by the $\mathrm{CO}_{2}$ bubble expansion process can be partitioned into the liquid phase and move with water advection. The Carle et al. (2008) HANDCAR modeling suggests liquid-phase flow towards the water table could reach the bounds of the $\mathrm{CO}_{2}$ gas bubble in months to years. Therefore, the breakthrough to the water table of test-released $\mathrm{CO}_{2}$ gas and other volatile gases (e.g., ${ }^{14} \mathrm{C}$ ) could result from the combination of gas-liquid-phase exchange between different gas- and liquid-phase flow processes.

The Carle et al. (2008) HANDCAR simulation results indicate $\mathrm{CO}_{2}$ gas would initially expand radially by advection due to gaseous expansion over the time frame of days to weeks. The pressure will be near atmospheric conditions at the end of this time frame. In years to centuries, the $\mathrm{CO}_{2}$ gas would be primarily transported by diffusion and by advection due to density-driven flow.

\subsubsection{Steam Bubble Expansion}

Residual test heat is expected to raise temperatures above the boiling point for water and create a pressurized water vapor bubble within the cavity. The vapor bubble and heat will expand and rise up the chimney redistributing heat upwards (Carle et al., 2008). The water from drill-back injection will produce more steam when the water comes in contact with the residual test heat than would occur without drill-back injection. The Carle et al. (2008) flow and transport modeling of the HANDCAR detonation results indicate the steam bubble would expand approximately tens of meters outside the cavity and possibly much further up the chimney over a time frame of weeks. Subsequent shrinking and condensation of the steam bubble would lead to gas- to liquid-phase partitioning, which would allow liquid-phase flow processes to move radionuclides further.

\subsubsection{Sorption}

Contaminant sorption is a general term to describe a variety of chemical processes that bind (temporarily or permanently) contaminants to solids, either matrix or fracture minerals. Sorption along the fracture surface and in the matrix acts to temporarily store contaminants and slow contaminant migration with respect to the flowing groundwater. Sorption may be treated 
mathematically in the contaminant transport model through a linear equilibrium $\mathrm{K}_{\mathrm{d}}$ approach where the amount of contaminant stored on or in the rock is a function of its concentration in the groundwater. The transfer of the radionuclide from the water to the rock is assumed to occur instantaneously and to be completely reversible. The linear isotherm is described by the relationship:

$$
C_{S}=K_{d} C
$$

where:

$C_{S}=$ Mass sorbed onto soil (picocuries per gram [pCi/g])

$K_{d}=$ Distribution coefficient $(\mathrm{mL} / \mathrm{g})$

$C=$ Aqueous concentration (picocuries per milliliter $[\mathrm{pCi} / \mathrm{mL}]$ )

The depth of the unsaturated zone at Yucca Flat indicates that even mild radionuclide sorption will have a significant impact on the radionuclide breakthrough to the water table. McNab (2008) estimated the land surface to the water table travel time for a $0.2 \mathrm{~m} / \mathrm{yr}$ recharge rate wetting front is 300 years. This suggests that even moderately retarded radionuclides may not reach the water table within 1,000 years. McNab (2008) also performed analytical 1-D modeling of tracer transport from each unsaturated test with a subsidence crater and determined mean recharge rates required to transport radionuclides of different $\mathrm{K}_{\mathrm{d}}$ values to the water table within 1,000 years. Radionuclides with $\mathrm{K}_{\mathrm{d}}$ values above $10 \mathrm{~mL} / \mathrm{g}$ required time-averaged recharge rates in excess of $1 \mathrm{~m} / \mathrm{yr}$.

Regardless of whether the tests are saturated or unsaturated, strongly sorbing radionuclides contribute much less to the contaminant boundary extent because they do not migrate far from the source areas. The preliminary results from the Frenchman Flat Phase II transport modeling (SNJV, 2008) indicated nonsorbing radionuclides are largely responsible for the contaminant boundary.

\subsubsection{Unsaturated Conceptual Model Summary}

The radionuclides in the vadose zone will seek an equilibrium between the water, air, and porous media substances. The relative amount of radionuclide associated with each material at equilibrium is described by partition coefficients. Partitioning between the water and air is described by Henry's Law for radionuclides that may exist as gases at atmospheric conditions (i.e., ${ }^{14} \mathrm{C},{ }^{39} \mathrm{Ar}$, ${ }^{85} \mathrm{Kr}$, and ${ }^{3} \mathrm{H}$ ). Partitioning between the water and porous media is described by the $\mathrm{K}_{\mathrm{d}}$. 
The carbonate tests must consider the large quantity of $\mathrm{CO}_{2}$ gas released and high gas pressure, which will increase the distribution of radionuclides external to the cavity region compared to the silicate rock tests (Carle et al., 2008). The conceptual model will capture this process by using larger exchange volumes than were used for the silicate tests. The more volatile radionuclides will have larger exchange volumes. Carle et al. (2008) recommended using the following exchange volume radii: 1 to $3 \mathrm{R}_{\mathrm{c}}$ for nonvolatile, 3 to $6 \mathrm{R}_{\mathrm{c}}$ for the volatile, and 5 to $10 \mathrm{R}_{\mathrm{c}}$ for gaseous radionuclides. The alluvium can contain up to a few weight percent of carbonate rock. Therefore, a detonation in alluvium will also release $\mathrm{CO}_{2}$ gas from thermal decomposition of the carbonate. The conceptual model for gas- phase radionuclide transport from alluvium tests will be analogous to that for the carbonate tests.

The ${ }^{14} \mathrm{C}$ will diffuse in response to its own concentration gradient. The ${ }^{14} \mathrm{C}$ partitioning coefficients need to consider geochemical conditions present at Yucca Flat, which will be most strongly influenced by the $\mathrm{pH}$. Isotopic fractionation during the gaseous/liquid/solid exchanges is negligible (Plummer et al., 2004). The ${ }^{14} \mathrm{C}$ Henry's coefficient is an effective Henry’s coefficient that may be determined from the total combined solubility of DIC in the carbonate species present and is a function of geochemical conditions (i.e., pH, temperature, and ions present).

The subsidence craters above the tests will capture water from a larger area and focus the recharge in the crater playas. The recharge amount is much higher than the background net infiltration in undisturbed areas. Individual craters will have different recharge rates and the recharge rate will be dependent on the local catchment basin area of each crater.

The net infiltration rate can be an important factor transporting radionuclides from the unsaturated zone contaminated areas to the aquifer, and detonations without subsidence craters will have negligible recharge. The radionuclide inventory at detonations without a subsidence crater present and exchange volumes entirely above the water table can be excluded from the unsaturated test source term. However, unsaturated tests without subsidence craters in close proximity to tests with subsidence craters cannot be excluded. Similarly, unsaturated tests within close proximity to the water table cannot be excluded because drilling fluids introduced during drilling of re-entry boreholes or chimney water drainage may drive contaminants to the aquifer. 
The process of vadose drainage due to test-induced permeability in the chimney rubble may quickly transport radionuclides to the aquifer. This process most likely occurs if the chimney extends into tuffs and alluvium and the recharge is higher (i.e., northwestern Yucca Flat compared to north-central or eastern Yucca Flat).

The radionuclides in the melt glass will be excluded from the unsaturated source term because the combination of the slow dissolution rate and travel time through the unsaturated zone. The rate of glass dissolution will be slower under unsaturated conditions than under saturated conditions (Pawloski et al., 2005). The Frenchman Flat unclassified source term (SNJV, 2005) predicted $\sim 5$ percent of the melt glass will dissolve in 1,000 years under saturated conditions. The melt glass also contains the more refractory radionuclides (i.e., actinides), which tend to have higher $\mathrm{K}_{\mathrm{d}}$ values and more retardation. Carle et al. (2008) identified the trivalent radionuclides: ${ }^{151} \mathrm{Sm},{ }^{150} \mathrm{Eu},{ }^{152} \mathrm{Eu}$, ${ }^{154} \mathrm{Eu},{ }^{166 \mathrm{~m}} \mathrm{Ho},{ }^{241} \mathrm{Am}$, and ${ }^{244} \mathrm{Cm}$ as unlikely to be transported to the aquifer for the HANDCAR and KANKAKEE detonations.

The important processes identified in the unsaturated conceptual model will be directly incorporated into the CAU scale vadose zone models. The CAU scale vadose zone models have sufficiently refined discretization to simulate individual test characteristics. Alternatively, these processes will be simulated using sub-CAU scale vadose zone models, similar to those presented in Section 5.0, if using the CAU scale model becomes numerically intractable. If this is done, representative models will be constructed for categories of unsaturated tests.

\subsection{Saturated Zone Conceptual Models}

The migration of radionuclides from the saturated test exchange volume will be determined by groundwater flow, transport, and geochemical processes. The saturated tests within the Yucca Flat CAU were performed in a wide variety of hydrogeologic settings, and the processes can have very different behavior in the different settings. This section discusses the important processes and the settings that will host these processes. Section 3.4.1 includes very simplistic numerical modeling of a saturated alluvium test to illustrate the effect of altered permeability of the crushed zone on the near-field flow and transport. 


\subsubsection{Ambient Groundwater Flow}

The regional gradient, near-field permeability, and crushed permeability will determine the groundwater flow through the exchange volume and melt glass. Contrasts between the near-field and crushed zone permeability can result in convergent or divergent flow through the exchange volume. If the crushed zone has a lower permeability than the near-field, divergent flow will occur and the groundwater flux through the cavity will be less than that through an equivalent cross-sectional area outside of the cavity. This may occur if a crushed zone is created around the cavity. If the crushed zone has a higher permeability than the near-field rock, convergent flow will occur and the groundwater flux through the cavity will be greater than that through an equivalent cross-sectional area outside of the cavity. This may occur if the rock surrounding the detonation is fractured due to the detonation-induced stresses.

The HST modeling performed for the CAMBRIC detonation (Thompson et al., 1999; Tompson et al., 2005; Carle et al., 2007) and the test Areas 2 and 3 saturated test modeling by Maxwell et al. (2008) suggests the crushed zone has one to two orders of magnitude lower permeability than the near-field. The CAMBRIC detonation was performed in alluvium and the Areas 2 and 3 tests were performed in a TCU.

The HST modeling of the Yucca Flat HANDCAR and NASH carbonate detonations performed by Carle et al. (2008) suggests the crushed zone immediately surrounding the cavity will be composed of fractured rock that has a permeability one to two orders of magnitude higher than the near-field.

The HST modeling for the CHESHIRE detonation (Pawloski et al., 2001) suggests the crushed zone surrounding the cavity has a one to two orders of magnitude higher permeability. The CHESHIRE test was performed in rhyolitic lava. Phenomenological model development for the BENHAM and TYBO detonations performed in Pahute Mesa (Pawloski, 1999) suggests the damaged region outside of the cavity has a higher permeability than pre-test conditions. The working point of the BENHAM test was in a bedded TCU, but the cavity and damage zone extended into lava. The working point of the TYBO detonation was in a TCU, but the cavity and damage zone extended into tuff aquifers and lava. 
To illustrate the effects of permeability on radionuclide release from the exchange volume, three simple saturated zone models were constructed in a 3-D, 1,000 by 500 by 750 m model domain. Simulation details of the model domain and meshing scheme are presented in Section 5.0. In each model, the exchange volume was centered along the $\mathrm{x}$ and $\mathrm{z}$ axes on the $\mathrm{x}-\mathrm{z}$ plane. The radii of the cavity and exchange volumes are 70 and $90 \mathrm{~m}$, respectively, resulting in a crushed zone thickness of $20 \mathrm{~m}$.

Contrasts in the hydraulic conductivity between the undisturbed media and the crushed zone create converging and diverging flow fields about the disturbed zone. In the baseline model, the hydraulic properties of the AA HSU (see Section 5.3.3) are transferred to the crushed zone, without modification. The effect of a test-induced increase in crushed zone permeability is evaluated by increasing the permeability two orders of magnitude relative to the AA HSU properties. In the low permeability/porosity model, the crushed zone permeability was reduced by a factor of 100 , while simultaneously decreasing the porosity from 0.42 to 0.27 (SNJV, 2005). The hydraulic properties of the upper crushed zone (intersection of the chimney and the crushed zone) are equivalent to the unmodified AA HSU properties.

Groundwater flow through the exchange volume is assumed to be steady at the time of the detonation. Equilibration conditions from unaltered hydraulic properties and a temperature of $20{ }^{\circ} \mathrm{C}$ were assumed, where the hydrostatic boundary conditions enforced flow along the x-direction with a hydraulic gradient of 0.0098 (Section 5.3.5.3). A uniform concentration of nonsorbing, aqueous-phase tracer was distributed throughout the exchange volume at the simulation start. The mass breakthrough and peak aquifer concentration at a plane $5 \mathrm{~m}$ downgradient from the exchange volume is shown in Figure 3-4. The streamtraces are also shown in relation to the exchange volume of each model where the divergent and convergent velocity flow fields of the respective high and low permeability models are illustrated.

In the baseline model, the hydraulic properties of the undisturbed media and the crushed are equivalent. The streamtraces in Figure 3-4 illustrate uniform flow downgradient in the x-direction. Mass is released immediately from the exchange volume, and the maximum breakthrough at a plane $5 \mathrm{~m}$ downgradient from the exchange volume occurs $\sim 18$ years after detonation. All of the mass is released from the exchange volume within 70 years. 

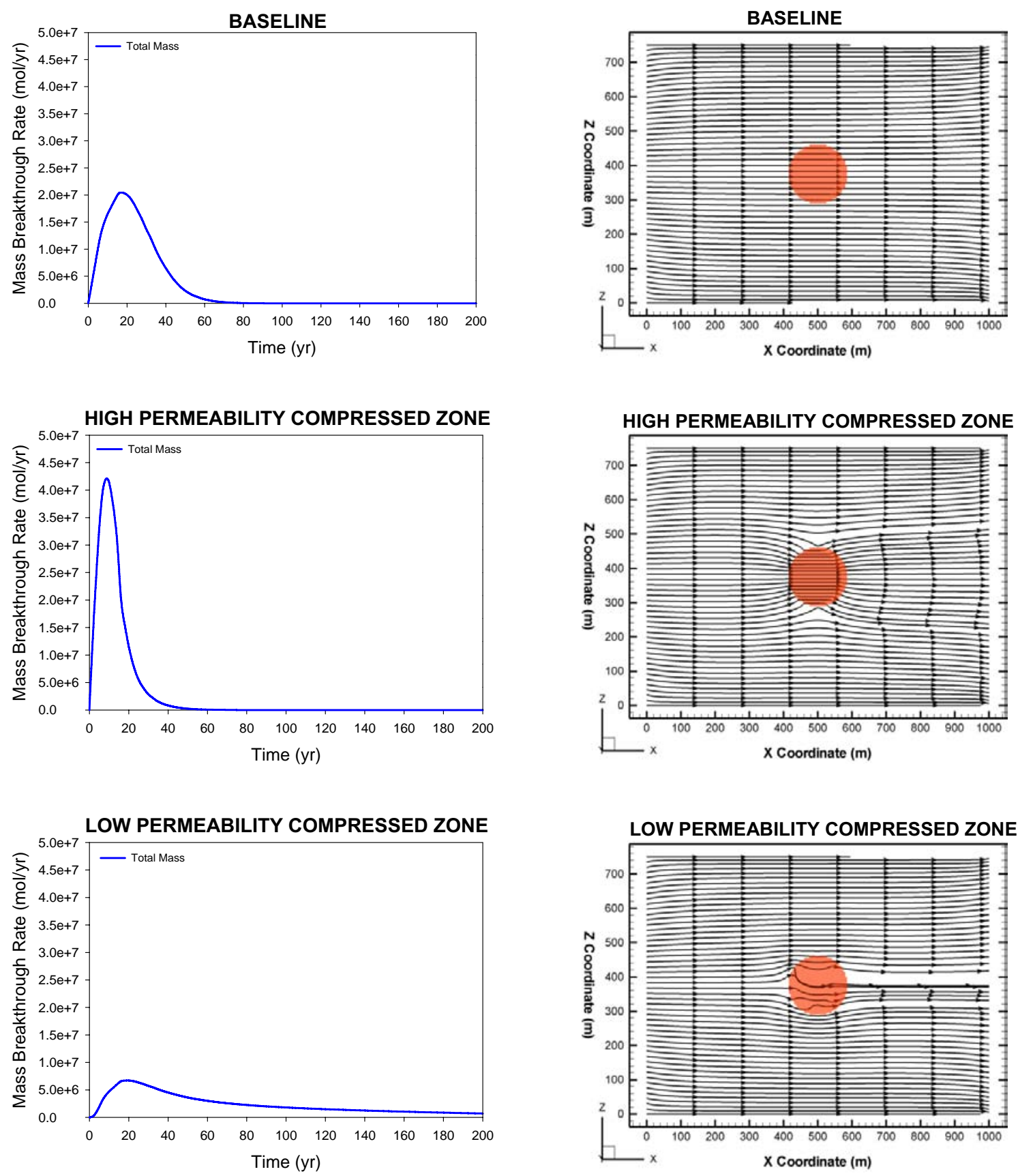

Figure 3-4

Mass Breakthrough and Streamtraces in the Saturated Zone 
In the high permeability model, the crushed zone permeability is increased by two orders of magnitude relative to the undisturbed media. The streamtraces converge within the exchange volume, flushing the tracer mass downgradient within $~ 10$ years after detonation. The mass breakthrough peak is nearly two-fold larger than the baseline model.

In the low permeability model, a prolonged, low amplitude breakthrough is observed. The maximum breakthrough occurs 20 years after detonation, similar to the baseline model. However, the mass breakthrough peak is nearly seven-fold smaller and a long breakthrough tail is observed. The streamtraces are diverted around the exchange volume, decreasing the rate at which water penetrates the exchange volume and transports mass downgradient. The release of tracer occurs over 200 years, delaying mass transfer to the downgradient boundary.

Alteration of the hydraulic properties of the crushed zone will have a significant affect on the extent of the contaminant boundary. In the event of a high permeability crushed zone, the radionuclide release is a high amplitude pulse. The low permeability scenario causes slow radionuclide release over time. This may result in a longer duration, smaller contaminant boundary downgradient because of more solute mixing with the ambient water flow. The mass breakthrough out of the low permeability crushed zone is similar to the breakthrough observed through a retardation mechanism, such as sorption, where a long tail with slow release is observed over time. In the case of short-lived radionuclides (e.g., ${ }^{3} \mathrm{H}$ ), this effect could have a significant impact on defining the contaminant boundary, because mass will decay on the time scales of the radionuclide migration out of the exchange volume.

The radial extent of the crushed zone is uncertain and is likely dependent on the mechanical characteristics of the host rock. Borg et al. (1976) indicate the explosively created permeability may extend to $2 \mathrm{R}_{\mathrm{c}}$. The crushed zone outer radii used for the saturated simulations likely represents the lower range of the possible crushed zone radii. Using a larger crushed zone radii would not change the simulation results significantly because the permeability contrast between unaltered and crushed zone altered permeability is responsible for the solute breakthrough behavior more than the radial extent. 


\subsubsection{Test-induced Pressure}

Anomalously high groundwater heads were recorded in emplacement holes and wells in Yucca Flat after subsurface testing began. These high heads were observed only in the low permeability and highly zeolitized TCUs. The high heads have persisted for decades in the saturated volcanics area known as the Tuff Pile (Wolfsberg et al., 2006), but have also been observed for shorter periods at test locations outside of the Tuff Pile (Maxwell et al., 2008). The time scale of pressure dissipation is likely influenced by specific geologic conditions and tests performed in the lowest conductivity rock will likely experience the longest time scale. It has been hypothesized that the high gradients resulting from these tests may drive contaminants down to the regional carbonate aquifer or laterally towards the faults, which may be fast-flow conduits to the regional carbonate aquifer (Wolfsberg et al., 2006).

Wolfsberg et al. (2006) performed a modeling study of the anomalously high groundwater heads within the Tuff Pile. The study focused on the area between the Yucca Fault and the Topgallant Fault in the NTS Areas 1, 2, 3, 4, and 7. The study had two primary goals: 1) evaluate processes and properties in the Tuff Pile that explain the high groundwater heads and the slow declines observed in the Tuff Pile, and 2) evaluate the potential for the system to have slowly declining heads and also have rapid transport. The study delineated a total of 28 Tertiary stratigraphic units above the LCA, which included several thin high permeability and low porosity welded tuff interbeds within the much thicker TCUs.

Wolfsberg et al. (2006) demonstrated it is possible to match the elevated heads in the low permeability units and also have high permeability units present. However, an alternative interpretation of the Tuff Pile stratigraphy suggests that there are no low porosity, high permeability welded tuffs below the Timber Mountain Group. The alternative interpretation concluded that the OSBCU HSU contains nonpartially to partially welded older tuffs, but these do not have the WTA characteristics of the typical low porosity, high permeability welded ash-flow tuff (Drellack, 2009).

Maxwell et al. (2008) performed a modeling study of selected tests performed in test Areas 2 and 3. The modeling focused on examining the role of residual high pressure on HST evolution especially in areas outside of the Tuff Pile. The conceptual model for determining the initial elevated pressure resulting from the detonation was that the cavity wall lay closer to the detonation point immediately 
after the detonation than the final $\mathrm{R}_{\mathrm{c}}$. The thermal and compressive effects of the explosion is assumed to crush, compress and push the cavity wall to a final state further from the detonations initial cavity center. The mass of solid rock in these two states is assumed to be unchanged, but occupies a smaller volume. The smaller volume resulting from the compressive effect culminates in a crushed zone with reduced porosity, reduced permeability and increased pore water pressure. The crushed zone radius typical values were estimated to be $\sim 1.3$ to $2.0 \mathrm{R}_{\mathrm{c}}(\mathrm{SNJV}, 2005)$ for the alluvial tests and 2.5 to $3 \mathrm{R}_{\mathrm{c}}$ for the TCU tests (Maxwell et al., 2008).

The Maxwell et al. (2008) modeling concluded that increased pore pressure resulting from nuclear testing in areas outside of the Tuff Pile region dissipates relatively quickly compared to areas inside the Tuff Pile. The pressure dissipates within days to years and the short period of high pressure does not result in significant radionuclide migration. The refilling of water into the test cavity likely has a larger impact on radionuclide migration than test-induced high pressure. The radionuclides distributed in the near-field following the tests will move back into the cavity, as the cavity refills. This distance is relatively small and is likely $100 \mathrm{~m}$ or less.

\subsubsection{Test-induced Thermal Convection}

The test Areas 2 and 3 saturated test modeling by Maxwell et al. (2008) concluded that increased temperatures resulting from the tests will likely have a negligible effect on pressure transients for detonations with conditions similar to those simulated (AARDVARK, BILBY, WAGTAIL, and FLAX-SOURCE). However, temperature effects may have a significant effect on radionuclide migration out of TCUs, when the high permeability chimney intersects an aquifer. The buoyancy-driven vertical flow may bring radionuclides to these high permeability layers, allowing rapid lateral spreading.

The CHESHIRE HST modeling (Pawloski et al., 2001) included a flow model designed to account for the influence of test-related and geothermal heat. The modeling concluded that heat generated by a large underground nuclear detonation such as CHESHIRE (200 to $500 \mathrm{kt}$ ) can have a significant effect on near-field groundwater flow. The presence of a high permeability chimney allows buoyancy effects from test-related heat to drive groundwater upward and away from the cavity. Within a few years, test-related heat was able to drive flow from the cavity and melt glass up through the entire $540 \mathrm{~m}$ height of the chimney, an effect that lasted several decades. 
Test-induced thermal convection will be important only for the tests with an aquifer between the working point and water table. The saturated tests with the exchange volume and chimney below the water table entirely contained in TCUs likely will not result in significant radionuclide migration away from the test-effected zones. Section 4.0 and Appendix B identify the saturated tests that necessitate the consideration for thermal convection.

\subsubsection{Melt-glass Presence and Dissolution}

The radionuclide flux to the near-field from melt glass dissolution will be controlled by the rate of glass dissolution, the concentration of the radionuclides within the melt glass, and the volume of the melt glass. The temperature-dependent glass dissolution model that was presented in the nontransient CAMBRIC HST (Tompson et al., 2005) used the following equation:

$$
r(\mathrm{~T})=k_{0} \times e^{\frac{E_{a}}{\mathrm{R}}\left(\frac{\mathrm{T}-\mathrm{T}_{0}}{\mathrm{TT}_{0}}\right)} \times A_{s} \times \prod_{i} a_{i}^{n_{i}} \times\left(1-\left(\frac{Q}{K}\right)^{1 / \sigma}\right)^{v}+A_{s} k_{f}
$$

where:

$r(\mathrm{~T})=$ Glass dissolution rate $\left(\mathrm{mol} / \mathrm{square}\right.$ meter per second $\left.\left[\mathrm{m}^{2} / \mathrm{s}\right]\right)$

$k_{0}=$ Rate coefficient $\left(\mathrm{mol} / \mathrm{m}^{2} / \mathrm{s}\right)$ at reference temperature $\mathrm{T}_{0}, 298.16 \mathrm{~K}$

$E_{a}=$ Activation Energy, 15,000 cal $/ \mathrm{mol}$

$R=$ Gas Constant, $1.98722 \mathrm{cal} / \mathrm{Kmol}$

$A_{s}=$ Reactive surface area of the glass $\left(\mathrm{m}^{2} / \mathrm{g}\right)$

$\Pi a_{i}{ }^{n}=$ Product Terms of catalytic or inhibitive species $\left(\mathrm{H}^{+}\right.$and $\left.\mathrm{OH}^{-}\right)$

$Q=$ Activity Product

$K=$ Solubility Product

$\sigma, v=$ Saturation Effect Coefficients

$k_{f} \quad=$ Close to Saturation Term (mol-glass/g sec)

$\mathrm{T}=$ Temperature $(\mathrm{K})$

$\mathrm{T}_{0}=$ Reference Temperature $(\mathrm{K})$

The temperature within the Arrhenius term will have a significant effect on glass dissolution. The Frenchman Flat unclassified source term analysis (SNJV, 2005) used a melt glass temperature history from the CAMBRIC transient flow model (Tompson et al., 2005). The glass temperature decreases from $170{ }^{\circ} \mathrm{C}$ at early times to $\sim 25^{\circ} \mathrm{C}$ after 10 years. This temperature history resulted in $\sim 0.5$ percent dissolving quickly during the first year and 5 percent of the melt glass dissolving after 1,000 years. The melt glass temperature predicted by the CHESHIRE HST (Pawloski et al., 2001) decreases from $160{ }^{\circ} \mathrm{C}$ at early times to $56^{\circ} \mathrm{C}$ after 10 years, and to $38.7^{\circ} \mathrm{C}$ after 1,000 years. 
Analytical solutions are available for heat transfer in porous media for simple geometries (i.e., line sources, spheres) (Nield and Bejan, 2006). These analytical solutions may be used to quickly estimate time temperature histories of the melt glass similar to that presented in Pohlmann et al. (2007). Alternately, numerical modeling can be used if the complexities of the problem prohibit the implications inherent in analytical solutions.

The melt glass dissolution will be a more important process for the more refractory radionuclides (i.e., actinides) that have a large fraction distributed in the melt glass. The more refractory radionuclides also tend to have higher $K_{d}$ values, more retardation, and a small influence on the contaminant boundary extent in the absence of colloid facilitated transport.

The phenomenology of a carbonate test will not produce a silicate melt puddle. However, a highly radioactive zone analogous to the silicate test melt glass is created in the cavity bottom, but this material is primarily composed of the carbonate rock decomposition products and infallen chimney rubble. There are no data available to reliably estimate a dissolution rate of the carbonate melt glass and subsequent release of radionuclides. The release of radionuclides from melt glass will be treated the same as the exchange volume. The release of radionuclides will be controlled by groundwater flux through the volume, initial amount of each radionuclide, and the radionuclide retardation. The infallen chimney rubble is dominated by tuff material for all carbonate detonations except HANDCAR, which will provide substantial retardation. Only the BOURBON carbonate detonation is expected to have a silicate glass puddle, because it was detonated in a silty limestone, and the cavity intersects overlying tuff rock, which likely resulted a large amount of silicate mineral melting and vaporizing within the cavity.

\subsubsection{Sorption in the Saturated Zone}

Retardation will have a significant impact on the radionuclide release to the groundwater. Higher retardation (or $\mathrm{K}_{\mathrm{d}}$ values) will result in lower aqueous phase concentrations and longer flux rates out of the source area. The processes for sorption within the saturated zone are the same as the unsaturated zone and are discussed in Section 3.3.6. 


\subsubsection{Saturated Zone Conceptual Model Summary}

The migration of radionuclides from the saturated test exchange volume will be determined by groundwater flow, transport, and geochemical processes. These conditions will be very different for tests performed in the different settings. The groundwater flow through the exchange volume will be determined by the regional gradient and the near-field permeability as predicted by the CAU scale models. The regional gradient can be extracted from the CAU scale models or from the water table elevation observations. Likewise, the near-field permeability can be extracted from the CAU scale models or from lithology observations at specific locations and literature permeability values for the observed lithology. The exchange volume radius will be different for tests with working points in different geology.

The transport processes associated with anomalously high-pressure gradients observed in the Tuff Pile will be captured using groundwater gradient and near-field permeability provided by the LANL Tuff Pile CAU scale model. The CAU scale modeling will capture the behavior within and outside of the Tuff Pile.

The saturated tests conceptual model will consider the effects of test heat on glass dissolution and buoyancy-driven flow. The rate of melt glass dissolution is dependent on the temperature history following the detonation. High temperatures will persist longer at locations of larger tests. The temperature history can be estimated using simple analytical solutions for thermal conduction. Significant interaction of the melt glass with water and dissolution will not occur until water refills the cavity. This will occur after temperatures within the cavity fall below the boiling point of water. The initial temperature for each test can be approximated from the boiling point of water at the hydrostatic pressure at the bottom of the glass zone.

Buoyancy-driven flow will be considered for tests with a working point in a low permeability unit and a chimney that intersects an aquifer. The tests that have chimneys entirely contained in confining units or have the water table below the high permeability units will not need to consider buoyancy-driven flow (Maxwell et al., 2008). 


\subsection{Hydrologic Source Term Uncertainty}

The purpose of the CAU scale modeling is to predict contaminant boundaries that will be used to establish a CAU compliance boundary. A contaminant boundary is the model-predicted perimeter that defines the extent of radionuclide-contaminated groundwater from underground nuclear testing above background conditions that exceed SDWA standards (CFR, 2008). The FFACO (1996, as amended February 2008) requires that the contaminant transport model predict the contaminant boundary at 1,000 years and "at a 95\% level of confidence." This requisite demands the uncertainties be quantified and included in the contaminant boundary prediction.

Prediction uncertainty is comprised of: 1) uncertainty in the conceptual model (i.e., a complex process oversimplified or not well understood) and 2) a lack of knowledge about the model parameter values. The conceptual model uncertainty can be qualitatively assessed by comparing simulation results to observations and assessing whether sufficient complexity exists to capture the observed behavior. A sensitivity analysis can be used to identify the sensitive flow and transport model parameters and the sensitive parameters will be included in the uncertainty analysis. The parametric uncertainty can be incorporated into the CAU scale modeling through statistical distributions of uncertain quantities and Monte-Carlo methods. Conceptual model uncertainty can be incorporated into the CAU scale modeling with alternative conceptual models, if observations compare equally to alternate conceptualizations. This section discusses the uncertainties that should be considered when the HST is calculated during the transport phase of the Yucca Flat CAU scale modeling. The sources of significant uncertainty associated with the unsaturated, saturated, and carbonate conceptual models include:

Radiologic source term. Bowen et al. (2001) provided accuracy ranges for classes of radionuclides. These are uncertainties in the classified source terms of individual tests. However, they provide an adequate representation of RST uncertainty in the unclassified source term because a fraction of the Bowen et al. (2001) inventory is attributed to each test. The accuracy ranges can be converted to multiplicative factor with a truncated normal distribution (SNJV, 2004).

Radionuclide source partitioning. The partitioning of the RST between the melt glass, rubble, gas, and water was taken primarily from IAEA (1998). The IAEA report describes the distribution of radionuclides from underground tests performed at the atolls of Mururoa and Fangtaufa in the south 
Pacific Ocean. Although the partitioning is uncertain, sufficient data are not available to reliably quantify this uncertainty.

Exchange volume. The exchange volume multiplier estimates the amount of mixing volume outside of the cavity due to short-term detonation forces. This may vary because hydrogeologic conditions vary for different tests. The SNJV (2004) and Carle et al. (2008) provided ranges of multiplier values that may be used to develop distributions for the multiplier.

Exchange volume hydraulic properties. If the crushed zone of the exchange volume has a much lower permeability than the near-field, divergent flow will occur around the exchange volume. The groundwater flux through the cavity will be less than that through an equivalent cross-sectional area outside of the cavity. The crushed zone has the potential to sequester most of the radionuclides if the permeability contrast between the near-field diverts most of the near-field flow around the exchange volume. The Yucca Flat CAU scale modeling of the volcanics aquifer currently being performed and the HST modeling for Yucca Flat, Frenchman Flat, and Pahute Mesa can be used to develop possible ranges of values that can be used to develop distributions.

Crater recharge rate. The crater-enhanced recharge rate is a very uncertain quantity. A crater recharge analysis is being performed as part of the CAU-flow modeling, and the analysis can be used to develop possible ranges of values. The analysis calculates subsidence crater recharge from the crater catchment basin area, precipitation and evapotranspiration.

Vadose zone chimney drainage. The drainage of pore water resulting from enhanced permeability in the chimney and cavity rubble is a very uncertain quantity. It is likely a function of rock moisture content and depth of the test. However, sufficient data are not available to reliably quantify this uncertainty for all the unsaturated tests within Yucca Flat. Compelling evidence for chimney vadose zone drainage is only available for the NASH carbonate detonation. Chimney drainage uncertainty may be introduced through the uncertainty analysis of the CAU scale unsaturated zone model or sub-CAU scale source term models. For example, alternative net infiltration rates will result in different initial rock moisture. Alternative parameter combinations that honor calibration data will result in different rock hydraulic properties, initial moisture content and chimney drainage rates. 
Drilling-fluid injection. The drilling fluid used in re-entry hole construction is an uncertain quantity and the volume used is likely larger compared to typical boreholes in similar geological settings because of residual test heat and radiological containment requirements. The uncertainty in the amount of drilling-fluid injected will be estimated from reviewing typical drill back procedures reconstructing possible drilling-fluid use. For example, most drilling fluid loss occurred when the well penetrated the cavity. Bounding fluid loss volumes may be estimated by assuming bounding periods of cavity drilling, cavity permeability, and water column height in the well bore.

Henry's Law partition coefficients for ${ }^{14} \mathrm{C}$. Henry's coefficient may be determined from the total combined solubility of DIC in the carbonate species present and is a function of geochemical conditions (i.e., pH, temperature, and ions present), which vary across Yucca Flat. A distribution of effective Henry's Law values may be created using Yucca Flat geochemical conditions from the many Yucca Flat sampling locations.

Unsaturated zone initial moisture content. The steady-state moisture content resulting from the current recharge rate is very low. These dry conditions may represent the current conditions near the surface, but may not represent the moisture content at depth. The moisture at depth may reflect a higher pluvial recharge rate during the last ice age or that the saturations were measured in volcanic rock. The unsaturated zone initial moisture content uncertainty may be represented with an alternate conceptualization of the initial moisture content. For example, a higher recharge during the last Quaternary ice age may be used to determine the initial conditions in an alternate model.

Ambient groundwater flow. The regional gradient, near-field permeability, and exchange volume permeability will determine the groundwater flow through the exchange volume and melt glass. The regional gradient and near-field permeability can be provided by the CAU scale models. Alternative CAU scale conceptual models are being constructed and the uncertainty in the ambient groundwater flow can be represented by using the alternate model data.

Sorption distribution coefficients. Experimental data and mechanistic models were used to develop distributions of $\mathrm{K}_{\mathrm{d}}$ values for different materials in the Yucca Flat Phase I contaminant transport parameters document (SNJV, 2007) and these will be used in the HST calculations. 
Amount of $\mathrm{CO}_{2}$ produced in carbonate and alluvium tests. The amount of $\mathrm{CO}_{2}$ produced will influence the $\mathrm{CO}_{2}$ bubble expansion and density-driven flow. The largest effect on the HST uncertainty will likely be due to increased or decreased gas-driven fast injection of radionuclides. This uncertainty may be adequately represented by the uncertainty in the exchange volume.

Time temperature history. The test-altered zone time temperature history will influence the rate of melt glass dissolution and the period of test-induced thermal convection. The temperature history can be estimated using simple analytical solutions for thermal conduction if heat transfer due to advection and convection is small compared to conduction. Saturated tests must also consider thermal convection in the temperature time-history calculations. The uncertainty may be introduced through uncertainty in the thermal properties of the near-field.

The uncertainty analysis will focus on the processes that contribute most to the contaminant boundary uncertainty. For example, the preliminary results from the Frenchman Flat Phase II transport model (SNJV, 2008) indicate that including complex melt glass dissolution in the uncertainty analysis will not greatly reduce uncertainty of the contaminant boundary. This is because the group of radionuclides contributing the most to the contaminant boundary are nonsorbing and are primarily released from sources outside of the melt glass. All the noninventory uncertainties are related to how the RST is translated to the HST, and the amount of source that is accessible to the groundwater. 


\subsection{Categorization of Detonations}

A total of 744 underground shaft detonations were conducted within the Yucca Flat subsurface. The Bowen et al. (2001) work divided the UGTA radionuclide inventory into five areas roughly corresponding to CAUs and further subdivided the Yucca Flat inventory by detonations where the working point depth is more than $100 \mathrm{~m}$ above the water table (unsaturated) and detonations that were performed below that level (saturated). A total of 577 of the Yucca Flat detonations were performed above the water table as defined by Bowen et al. (2001).

The large number of tests performed at Yucca Flat may preclude explicitly simulating every test in the unclassified source term. Instead, tests may be assigned to categories with similar hydrogeologic settings and represented with a single model for each category. Figures 4-1 and 4-2 illustrate the Yucca Flat test locations and denote the locations of the carbonate, saturated, and unsaturated tests. The spheres in Figures 4-1 and 4-2 are scaled to the maximum exchange volume radius. This section does not follow the Bowen et al. (2001) convention for describing tests as unsaturated or saturated and categorizes tests by the working point location relative to the water table.

This section describes the categorization of underground nuclear tests in the Yucca Flat/Climax Mine CAU. Categorization was performed to: 1) identify the tests in each conceptual model category (i.e., working point above the water table, working point below the water table, and working point in carbonate rock); 2) understand the relative importance of each category to the Yucca Flat source term related to inventory magnitude (i.e., yield or Curie contribution of unsaturated tests compared to saturated tests); and 3) reduce the number of source term models that may be needed in the HST development, which will be performed during the CAU-transport modeling. Further subcategorization of the tests in each conceptual model category may be needed during the CAU scale transport modeling to represent the range of conditions known to affect the migration of radionuclides. 


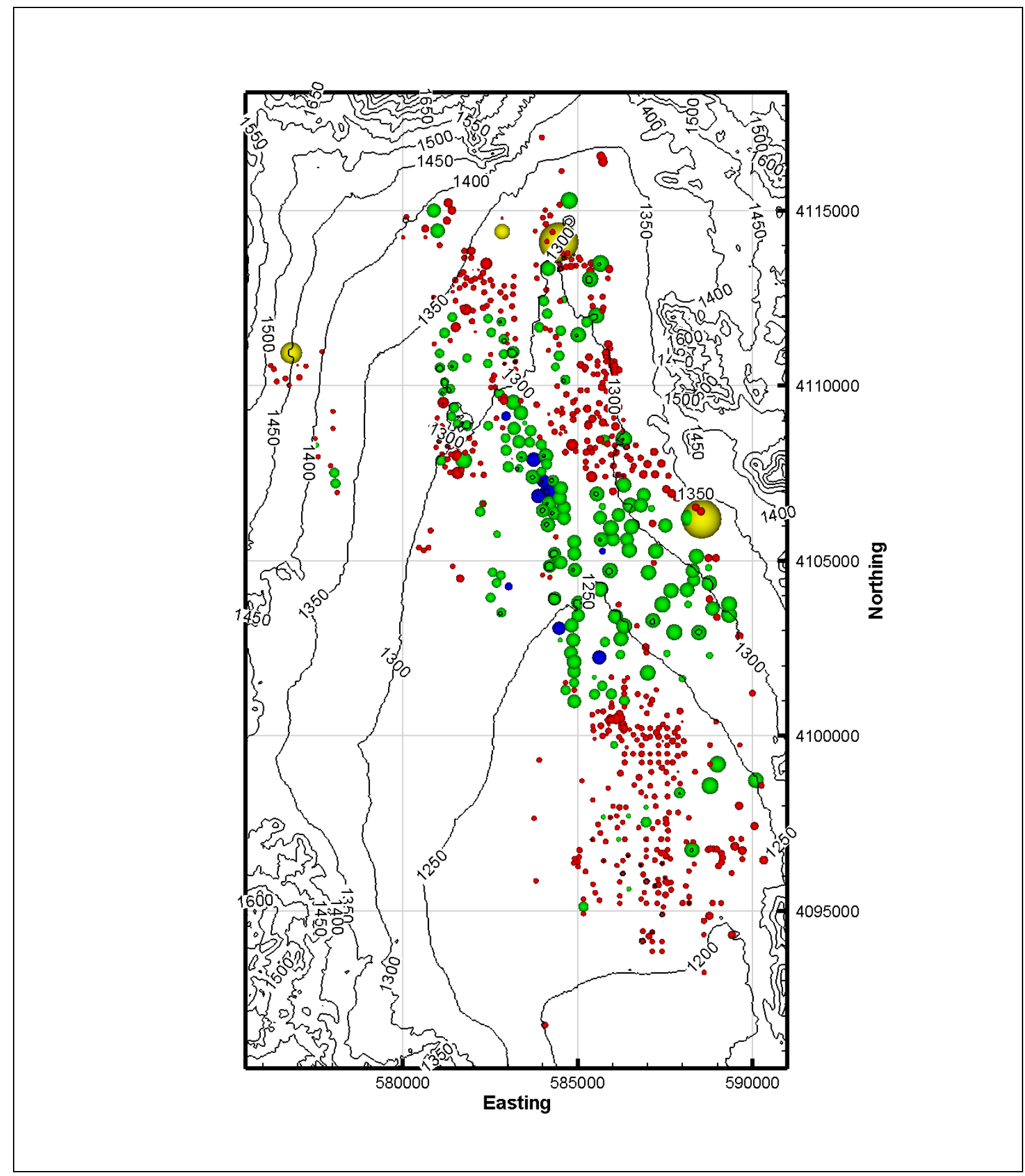

Figure 4-1

Yucca Flat CAU Underground Tests Plan View

Note: Symbol sizes are yield weighted, tests with exchange volumes above the water table are indicated in red, tests with exchange volumes spanning the water table are indicated in green, tests with exchange volumes below the water table are indicated in blue, tests performed in carbonate rock are indicated in yellow. 


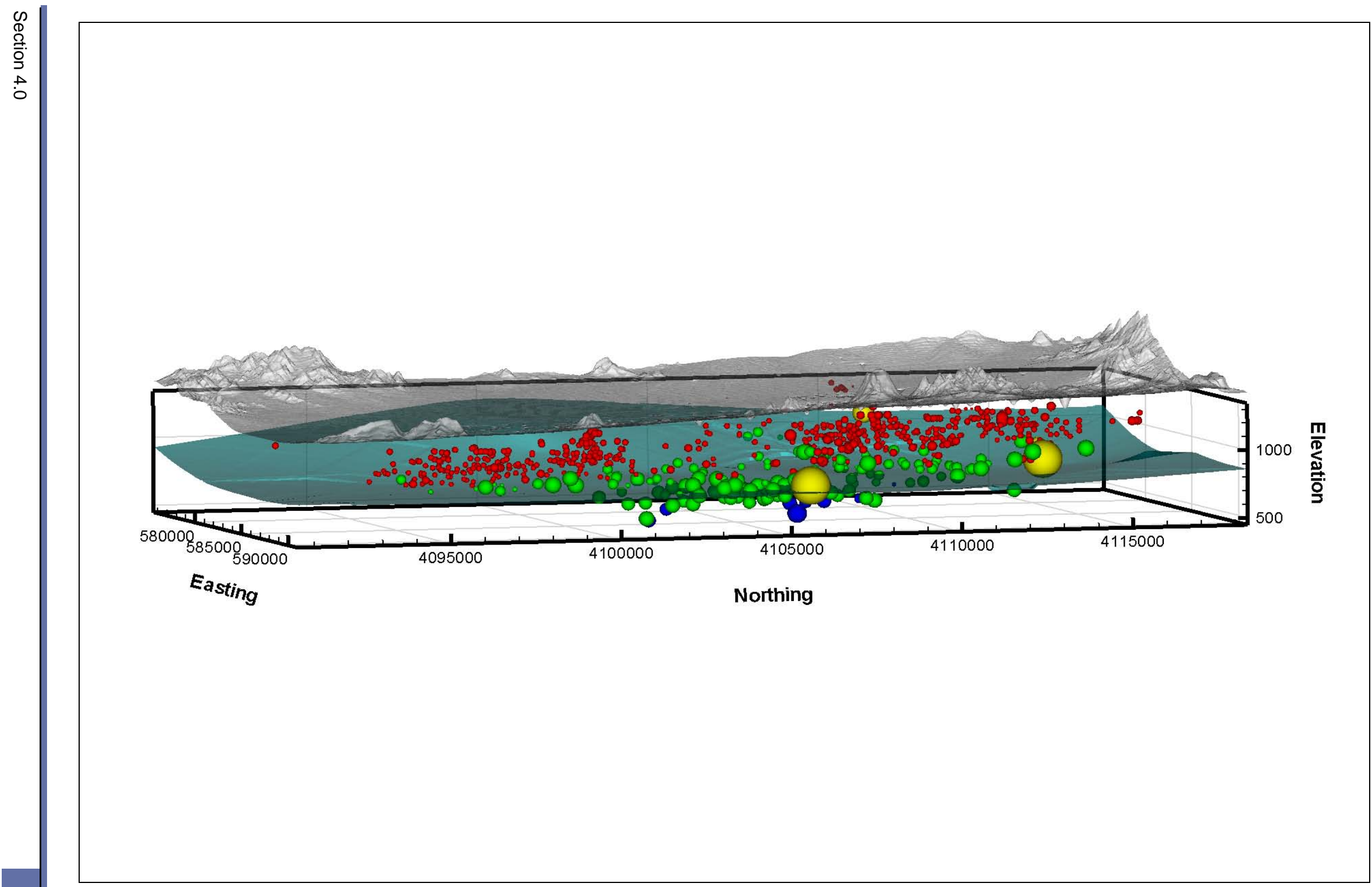


Categorization is not performed for the carbonate test conceptual model category because only four tests were performed in the carbonate rock. Each carbonate test will be individually included in the source term because the contamination resulting from these tests is in direct contact with the regional carbonate aquifer and is of particular concern. Different categorization criteria are used for the tests located above and below the water table because the important processes contributing to radionuclide migration are different. The categorization criteria for tests with working points above or below the water table are presented along with the categorization results in Sections 4.1 and 4.2, respectively.

The categorization presented in this document is a preliminary categorization effort. Some of the categorization criteria are still in development at the same time this report is being written. For example, the recharge rate occurring in each subsidence crater is a critical unsaturated test criteria. However, the CAU scale flow modeling estimating these rates is still in development.

The categorization used grouped HSU classes to reduce the possible number of test categories similar to that discussed in Pawloski et al. (2005). The HSUs with similar hydrogeology were grouped together because the groups have similar flow and transport properties. Four grouped HSU classes were identified for use in the Yucca Flat source term analysis, which included composite alluvium, composite vitric tuff, composite zeolitic tuff, and WTA. The HSUs and reactive mineral categories (RMCs) comprising the grouped HSU classes are presented in Table 4-1.

\subsection{Above Water Table Test Categorization Criteria}

The amount of infiltrating water through the unsaturated zone is likely the most important factor for transporting radionuclides from the unsaturated zone to the aquifer. The conceptual model of the Yucca Flat unsaturated tests also includes radionuclides partitioning between the gaseous and aqueous phases and transport in both phases. The important processes identified in Section 3.3 will largely define the categorization criteria. The above-the-water-table test categorization criteria included the following:

Working point above the water table. This criteria defines the tests as being in this category. 
Table 4-1

Grouped HSU Classes Used in Yucca Flat Tests Categorization

\begin{tabular}{|c|c|c|c|}
\hline HSU Class & HSUs & $\begin{array}{l}\text { Corresponding HSU } \\
\text { Dominant RMCs }\end{array}$ & Description \\
\hline Alluvium & AA1, AA2, AA3, PCUT & $\begin{array}{l}\text { VMP and ZEOL, VMP, VMP, } \\
\text { ARG }\end{array}$ & $\begin{array}{l}\text { Gravelly sand that may include } \\
\text { thin basalt flows, playa deposits, } \\
\text { and eolian sands. Generally } \\
\text { unsaturated except in deepest } \\
\text { basins. }\end{array}$ \\
\hline Vitric Tuff & TM-UVTA, TM-LVTA & DMP and VMP, VMP & $\begin{array}{l}\text { Unaltered (i.e., vitric) nonwelded } \\
\text { ash fall tuffs. Generally found } \\
\text { above the water table because } \\
\text { the saturated tuffs tend to } \\
\text { become zeolitized. }\end{array}$ \\
\hline Zeolitic Tuff & $\begin{array}{c}\text { UTCU, UTCU1, BRCU, LTCU, } \\
\text { OSBCU, ATCU }\end{array}$ & $\begin{array}{l}\text { ZEOL, ZEOL, ZEOL, DMP } \\
\text { and ZEOL, ZEOL, DMR, } \\
\text { and DMP, ARG }\end{array}$ & $\begin{array}{l}\text { Act as confining units due to the } \\
\text { secondary mineral alteration } \\
\text { reducing permeability and } \\
\text { preventing fractures. }\end{array}$ \\
\hline $\begin{array}{l}\text { Welded Tuff } \\
\text { Aquifer }\end{array}$ & TM-WTA, TSA, BRA, TUBA & $\begin{array}{c}\text { DMR and DMP, DMP and ZEOL, } \\
\text { DMP, DMP }\end{array}$ & $\begin{array}{l}\text { Denser welded ash-flow tuffs } \\
\text { that tend to be fractured. }\end{array}$ \\
\hline
\end{tabular}

Source: Modified from SNJV, 2007

ARG = Argillic

ATCU = Argillic tuff confining unit

BRA = Belted Range aquifer

BRCU = Belted Range confining unit

DMP = Devitrified mafic-poor

DMR = Devitrified mafic-rich

PCUT = Playa confining unit

TM-LVTA = Timber Mountain-Lower Vitric Tuff aquifer
TM-UVTA = Timber Mountain-Upper Vitric Tuff aquifer

TM-WTA = Timber Mountain-Welded Tuff aquifer

TSA = Topopah Spring aquifer

TUBA = Tub Spring aquifer

UTCU = Upper tuff confining unit

$\mathrm{VMP}=$ Vitric mafic-poor

ZEOL = Zeolitic

Exchange volume above the water table. Tests with working points above the water table, but with exchange volumes intersecting the water, are partially saturated (Section 3.0). The exchange volume radius for determining partially saturated tests will be the midpoint of the estimated range provided in Table 3-1. Exchange volume radii estimates were not available for welded and vitric tuff. These are estimated from other rock types that may behave similarly during the detonation. The exchange volume multiplier for the welded tuff is assumed to be the same as rhyolitic lava. The exchange volume multiplier for the vitric tuff is assumed to be the same as alluvium.

Presence of a subsidence crater. Significant recharge does not occur in the interfluve regions of Yucca Flat beyond subsidence crater boundaries. However, the subsidence craters will capture water from a larger area and focus a much higher recharge in the crater. 
Subsidence crater recharge rate. The amount of recharge in each crater may be very different and will depend on physical properties of the catchment (i.e., area, slope, and hydraulic conductivity).

Subsidence crater area. The larger craters may have less lateral water movement due to capillarity compared to smaller craters. This will result in more vertical flow and a shorter wetting front travel time to the aquifer (see Section 5.0).

Confining unit present above the water table and below the exchange volume. The very low permeability of the confining units may attenuate vertical movement of the wetting front by promoting lateral spreading. The higher saturation in confining units may reduce gaseous phase migration by increasing gas phase tortuosity. The alteration minerals present in the TCUs also have increased sorption for some radionuclides and further slow radionuclide migration to the aquifer.

Detonation depth bls. The wetting front and conservative (nonsorbing) tracer arrival time to the aquifer will be nearly coincident and independent of the working point depth. However, sorbing tracer arrival will be very different for tests with different working point depths.

Working point grouped HSU class. The working point grouped HSU will define the transport properties in the near-field. The amount of sorption occurring in the HSU will affect the initial aqueous concentration and the duration of the release. The hydraulic properties of the HSU will also affect aqueous concentration and the duration of the release by defining the saturation needed to transmit the recharge rate.

Excluding the carbonate tests, there are 664 underground detonations with working points located above the water table. The total yield for these tests is 26,339.5 kt, which is 68 percent of the total Yucca Flat unclassified yield reported by DOE/NV (2000b) for tests performed on Yucca Flat proper. There are 98 detonations with above-the-water-table working points, but with exchange volumes partially below the water table. The total yield is 14,243 kt for test exchange volumes partially below the water table. The maximum expected exchange volume radius was used to determine which tests may have exchange volume extending into the aquifer (Section 3.2.1.1 and Table 3-1). 
The tests that do not have a subsidence crater and have exchange volumes located entirely above the water table may not contribute to the aquifer contaminant boundaries because the dominant driving force for vadose zone radionuclide migration is crater-enhanced recharge flowing through the contamination zones. Gas-phase partitioning and diffusion likely attenuate aqueous phase concentrations by greatly increasing the volume of the unsaturated zone in contact with the radionuclides. There are 243 detonations that can be excluded because a subsidence crater is not present, and the exchange volume remains above the water table. The total excluded yield is 4,744 kt, which represents 18 percent of the total unsaturated test yield and 12 percent of the total Yucca Flat proper yield.

The majority of the tests with working points located above the water table have working points located in the alluvium. The alluvium contains 62 percent of the tests and 46 percent of the above the water working point test yield. The majority of these tests have working points between 100 to $400 \mathrm{~m}$ below the surface. The 200 to $300 \mathrm{~m}$ depth range has the largest number of tests (210). Fewer tests (172) were performed in the 300 to $400 \mathrm{~m}$ depth range, but the 300 to $400 \mathrm{~m}$ depth range has a larger total yield. Approximately 70 percent of the Yucca Flat proper yield for tests with working points above the water table have working points located below $300 \mathrm{~m}$, and only 39 percent of the yield is located above $300 \mathrm{~m}$. This is because the larger tests required deeper working points to contain the tests. The above water table test criteria for each test is discussed in Appendix B and included on the document CD. Tables 4-2 and 4-3 summarize the unsaturated tests performed in different HSU classes and depth intervals, respectively.

\subsection{Below the Water Table Test Categorization Criteria}

The migration of radionuclides from the saturated test exchange volume will be determined by groundwater flow and transport processes occurring in the near-field. The regional gradient, near-field permeability, and exchange volume permeability will determine the groundwater flow through the exchange volume and melt glass. The majority of the tests with working points below the water table were performed in TCUs. The regional groundwater velocity in these low permeability altered tuffs is very slow and test-related processes may have a greater affect on radionuclide migration to the near-field (i.e., heat-induced convection within the chimney or residual high 
Table 4-2

Above the Water Table Tests Categorization Summary by HSU

\begin{tabular}{|c|c|c|c|c||}
\hline \multirow{2}{*}{ HSU Class } & Number of & \multirow{2}{*}{$\begin{array}{c}\text { Total Yield } \\
\text { Detonations }\end{array}$} & \multicolumn{2}{|c|}{$\begin{array}{c}\text { Tests Without Craters and } \\
\text { With Exchange Volumes } \\
\text { above the Water Table }\end{array}$} \\
\cline { 4 - 5 } & & & $\begin{array}{c}\text { Number of } \\
\text { Detonations }\end{array}$ & $\begin{array}{c}\text { Total Yield } \\
\text { (kt) }\end{array}$ \\
\hline \hline Alluvium & 413 & 12,035 & 158 & 3,133 \\
\hline Vitric Tuff & 134 & 6,232 & 51 & 988 \\
\hline Zeolitic Tuff & 91 & 6,831 & 27 & 503 \\
\hline Welded Tuff Aquifer & 26 & 1,241 & 7 & 120 \\
\hline
\end{tabular}

Source: Modified from SNJV, 2007

Table 4-3

Above the Water Table Tests Categorization Summary by Depth

\begin{tabular}{|c|c|c|c|c|}
\hline \multirow{2}{*}{$\begin{array}{l}\text { Depth Range } \\
\text { (m) }\end{array}$} & \multirow{2}{*}{$\begin{array}{l}\text { Number of } \\
\text { Detonations }\end{array}$} & \multirow{2}{*}{$\begin{array}{c}\text { Total Yield } \\
\text { (kt) }\end{array}$} & \multicolumn{2}{|c|}{$\begin{array}{l}\text { Tests Without Craters and } \\
\text { With Exchange Volumes } \\
\text { above the Water Table }\end{array}$} \\
\hline & & & $\begin{array}{c}\text { Number of } \\
\text { Detonations }\end{array}$ & $\begin{array}{c}\text { Total Yield } \\
\text { (kt) }\end{array}$ \\
\hline $0-100$ & 22 & 420 & 22 & 420 \\
\hline $100-200$ & 172 & 3,005 & 101 & 1,810 \\
\hline $200-300$ & 210 & 4,349 & 68 & 1,550 \\
\hline $300-400$ & 160 & 6,369 & 45 & 843 \\
\hline $400-500$ & 77 & 8,507 & 7 & 121 \\
\hline $500-600$ & 23 & 3,690 & 0 & 0 \\
\hline
\end{tabular}

Source: Modified from SNJV, 2007

pressure) than the regional gradient. The important processes identified in Section 3.4 will largely define the categorization criteria. The saturated test categorization criteria included the following:

Working point below the water table. This criteria defines the tests as being in this category.

Working point grouped HSU class. The working point grouped HSU will define the transport properties in the near-field. The amount of sorption occurring in the HSU will also affect the initial 
aqueous concentration and the duration of the release. The hydraulic properties of the HSU will also affect aqueous concentration and the duration of the release.

Regional groundwater gradient in the near-field. The migration of radionuclides from the saturated test exchange volume will be determined by groundwater flow rate, which is a function of the regional gradient and near-field hydraulic properties.

Location in the Tuff Pile. The thick sequence of saturated volcanic tuffs located in central Yucca Flat have anomalously high groundwater heads. The large number of sequential tests performed in this area along with the low permeability have allowed the elevated groundwater heads to persist for decades. The high-pressure gradient may drive radionuclides toward the LCA or high permeability faults.

Absence of a high permeability unit in contact with test-effected zones. The saturated tests with the exchange volume and chimney below the water table that is entirely contained in TCUs likely will not result in significant radionuclide migration away from the test-effected zones. However, the presence of faults needs to be considered before excluding these tests from the contaminant boundary calculations.

Presence of a high permeability unit below the water table within the chimney. The test chimney may be a conduit for radionuclide migration away from tests performed in TCUs. Thermal buoyancy from test-induced heat may drive contaminants up the chimney to overlying high permeability units. The water table will act as the upper boundary for buoyancy-driven flow. However, the duration and magnitude of the release may be less than tests with a high permeability unit within the exchange volume because the buoyancy effects will diminish as the cavity cools.

Temperature history of the melt glass. High temperatures will persist longer at larger test locations and dissolution rates will be higher at the larger tests. The temperature history can be estimated using simple analytical solutions for thermal conduction.

Cavity extending into the carbonate aquifer. A few of the tests may have cavities that extend into carbonate. The carbonate regional aquifer is of particular concern because it is a water resource. The 
permeability of carbonate rock is much higher than the zeolitic TCUs above, and carbonate rock does not have sorption capacity of the zeolitic tuff for some radionuclides.

Exchange volume extending into the carbonate aquifer. The concerns for cavities extending into the carbonate aquifer also apply to exchange volumes. The number of tests is much larger because the exchange volume is much larger than the cavity.

There are 76 detonations with working points located below the water table. The total yield for these detonations is 12,173 kt, which is 31 percent of the total Yucca Flat unclassified yield reported by Bowen et al. (2001) for tests performed on Yucca Flat proper. There are 65 detonations with working points below the water table, but with exchange volumes partially above the water table. The total yield is 10,504 kt for detonation exchange volumes partially above the water table. The maximum expected exchange volume radius was used to determine which detonations may have exchange volume extending above the aquifer (Section 3.2.1.1 and Table 3-1).

The zeolitic tuff contains 82 percent of the working points and 83 percent of the test yield for detonations with working points below the water table. There are 49 detonations with exchange volumes and chimneys completely contained in TCUs. The total yield is 7,839 kt for completely contained detonations, which is approximately 64 percent of the total inventory of detonations with working points below the water table. There are three detonations with aquifers in the chimney below the water table and above the exchange volume top. There are 26 detonations with aquifers in the exchange volume. There are two detonations with aquifers in both the chimney and exchange volume. Table 4-4 summarizes categorization criteria for the confining unit detonations with aquifers in the test altered zones.

Two detonations have cavities that intersect the carbonate aquifer. The CORDUROY detonation has a $200 \mathrm{kt}$ yield and the lower $33 \mathrm{~m}$ of the cavity is within the carbonate aquifer. Also, the LAMPBLACK detonation has a 200 kt yield. However, the carbonate aquifer impact of the LAMPBACK detonation is likely considerably less than the CORDUROY detonation because only the lowest $1 \mathrm{~m}$ of the cavity lies within the carbonate aquifer. A total of 18 detonations potentially have exchange volumes located in contact with the carbonate aquifer. The maximum exchange volume radius for detonations located in zeolitic tuff is likely three times the $\mathrm{R}_{\mathrm{c}}$ (Table $3-1$ ). The working point below water table test criteria for each detonation is provided in Appendix B. Table 4-5 summarizes the saturated detonations performed in different HSU classes. 
Table 4-4

Below the Water Table Detonations Categorization Summary for Confining Unit Tests

\begin{tabular}{|c|c|c|}
\hline Categorization Criteria & $\begin{array}{c}\text { Number of } \\
\text { Detonations }\end{array}$ & Total Yield (kt) \\
\hline \hline Cavity Partially in LCA & 2 & 400 \\
\hline Exchange Volume Partially in LCA & 18 & 3,547 \\
\hline Aquifer in Chimney or Exchange Volume & 27 & 37,334 \\
\hline Aquifer in Chimney above Exchange Volume & 3 & 4,305 \\
\hline Aquifer in Exchange Volume & 26 & 350 \\
\hline Aquifers in Exchange Volume and Chimney & 2 & 379 \\
\hline
\end{tabular}

Source: Modified from SNJV, 2007

Note: The categorization results are not mutually exclusive.

Table 4-5

Saturated Detonations Categorization Summary by HSU

\begin{tabular}{|c|c|c|}
\hline HSU Class & Number of Detonations & Total Yield (kt) \\
\hline \hline Alluvium & 2 & 350 \\
\hline Vitric Tuff & 11 & 1,535 \\
\hline Zeolitic Tuff & 62 & 10,088 \\
\hline Welded Tuff Aquifer & 1 & 200 \\
\hline
\end{tabular}

Source: Modified from SNJV, 2007

\subsection{Carbonate Test Category}

On Yucca Flat proper, four underground detonations were performed in carbonate rock. These detonations are: HANDCAR, KANKAKEE, NASH, and BOURBON (Carle et al., 2008). All the carbonate detonations have working points above the water table. Only the BOURBON detonation has a working point within $100 \mathrm{~m}$ of the water. The total yield of the carbonate tests is $451 \mathrm{kt}$. Table 4-6 summarizes the carbonate detonations. 
Table 4-6

Carbonate Detonations Summary

\begin{tabular}{|c|c|c|c|}
\hline Detonation Name & Yield (kt) & $\begin{array}{c}\text { Working Point Depth } \\
(\mathbf{m})\end{array}$ & $\begin{array}{c}\text { Water Table Depth } \\
\mathbf{( m )}\end{array}$ \\
\hline \hline HANDCAR & 12 & 403 & 598 \\
\hline KANKAKEE & 200 & 455 & 575 \\
\hline NASH & 39 & 364 & 527 \\
\hline BOURBON & 200 & 560 & 601 \\
\hline
\end{tabular}

Source: Modified from Carle, 2008

\subsection{Summary of Test Categorization}

The total yield is 38,512.5 kt for all tests performed on Yucca Flat proper excluding the carbonate tests. Approximately $12,583 \mathrm{kt}$ or 33 percent of this yield may not contribute significantly to the contaminant boundary calculations because the source term is from detonations without subsidence craters or from detonations that may be completely contained in TCUs. The carbonate detonation total yield is $451 \mathrm{kt}$ and these detonations will contribute the most to the regional carbonate aquifer contaminant boundary.

The source term model development to be performed during the CAU scale transport modeling should focus on the tests with working points located below the water table. The source term model development may require further subcategorization of the above- and below- water table working point detonations to represent the range of conditions known to affect the migration of radionuclides with each category. For example, the fraction of the exchange volume comprised of an aquifer HSU will be very important for below the water table detonation source term models. Further categorization of the above water table detonations is probably not needed because each detonation will be considered individually in the CAU scale vadose zone modeling. The CAU scale vadose zone models have sufficiently refined discretization to simulate individual detonations characteristics. Additional categorization and source term work will be documented in the CAU scale transport reporting.

Maintaining excessive detail in a categorization effort will not significantly reduce the number of source term models. For example, including all possible grouped HSU class combinations falling 
within a two cavity radii result in 22 saturated detonation combinations and 34 unsaturated detonation combinations (Pawloski et al., 2005). Including 2 possible values for each of the other 8 criteria for the below the water table detonations, or 7 criteria for the above water table detonations identified in Section 4.2, results in 414 possible source term models. 


\subsection{EVAluation of Unsaturated ZONE TRANSPORT OF CARBON-14 AND TRITIUM}

\subsection{Multiphase Flow and Transport Modeling Objectives}

Previous LLNL HST modeling efforts of CAMBRIC, CHESHIRE, Area 2 and Area 3 detonations have extensively examined the processes that have the greatest impact on the magnitude and variability of radionuclide transport away from tests detonated in the saturated zone. However, a majority of the detonations within Yucca Flat occurred within the unsaturated zone. Transport of radionuclides through the vadose zone is potentially an extremely important attenuation mechanism for groundwater contamination. McNab (2008) evaluated the potential for radionuclides produced from the population of unsaturated detonations to impact groundwater variability and identified the important factors influencing wetting front propagation and radionuclide transport. These included episodic crater ponding, recharge rates, hydrostratigraphy, low permeability zones resulting from deposition of fine-grained sediments, radionuclide sorption and gas-phase partitioning. The magnitude of attenuation of nonsorbing and sorbing radionuclides that exist predominantly in the aqueous phase, such as ${ }^{129} \mathrm{I}$ and ${ }^{90} \mathrm{Sr}$, was quantified through semi-analytical models, while transport of ${ }^{39} \mathrm{Ar}$ and ${ }^{14} \mathrm{C}$ was investigated through a gas-phase diffusion model employing a retardation factor. However, McNab (2008) notes that the complex ${ }^{14} \mathrm{C}$ interactions between the aqueous, gaseous and solid phases may significantly reduce the concentration beyond the cavity radius.

As an extension of McNab's work, this analysis examines the multiphase transport of ${ }^{3} \mathrm{H}$ and ${ }^{14} \mathrm{C}$, allowing partitioning between the aqueous, gas and solid phases, to fully treat diffusion, advection and dispersion in a 3-D finite element model. Transport of ${ }^{14} \mathrm{C}$ and ${ }^{3} \mathrm{H}$ through unsaturated alluvium is investigated because it represents a large fraction of the Frenchman Flat contaminant boundary (SNJV, 2008) and may be significantly attenuated within the unsaturated zone due to gas-phase transport and radioactive decay. Only very limited site-specific data for transport properties of ${ }^{14} \mathrm{C}$ and ${ }^{3} \mathrm{H}$ are available and data are transferred from alternative sources, with the underlying goal to provide estimates of the attenuation magnitudes for Yucca Flat. The arrival times to the water table 
and peak aquifer concentrations will depend on physical aspects, such as working point depth, hydrogeologic properties of the subsurface, recharge rate through the crater bottom playas, playa areal extent, extent of gas/solid-phase partitioning, and the variability of the crushed zone hydraulic properties. Each of these effects is examined to screen the most important aspects that need to be included in the CAU scale modeling approach.

\subsection{Multiphase Conceptual Model}

Because of the large number of underground nuclear tests in the Yucca Flat vadose zone and the need to represent only key processes in the large-scale CAU transport model, detailed process analyses were conducted for vadose zone tests in alluvium with exchange volumes located entirely above the water table, emphasizing radionuclides that partition into the gas phase or have a short half-life relative to the travel time to the underlying aquifer. In particular, ${ }^{14} \mathrm{C}$ and ${ }^{3} \mathrm{H}$ are considered, given that each typically defines the extent of the contaminant boundaries and comprises the bulk of the RST.

In general, the processes that control radionuclide transport through the vadose zone include gas-phase diffusion, gas-phase advection, and aqueous-phase advection. In the carbonate tests, Carle et al. (2008) demonstrate that gas-phase advection occurs as a result of the creation of the large $\mathrm{CO}_{2}$ bubbles. Long term $\mathrm{CO}_{2}$ gas phase advection may be present at the alluvial tests, but will be significantly less than that at the carbonate tests. In this analysis, the effects of short duration gas-phase advection are assumed to be captured by the exchange volume extending beyond the cavity. Thus, with regard to volatile radionuclides (e.g., ${ }^{14} \mathrm{C},{ }^{14} \mathrm{CO}_{2},{ }^{39} \mathrm{Ar}$, and ${ }^{85} \mathrm{Kr}$ ), gas-phase diffusion is the dominant process governing the extent of transport away from the working point and into the aquifer. The importance of gas-phase partitioning is evident when considering that radionuclides in the gas-phase will rapidly diffuse towards areas of lower concentration. Because gas-phase diffusion coefficients are generally four orders of magnitude larger than the aqueous phase, radionuclide mass is distributed throughout the vadose zone over relatively short time scales in comparison to aqueous-phase diffusion time scales.

The spatial extent of gas-phase transport strongly depends on soil moisture content and diminishes with increasing saturation because contaminants must migrate through more tortuous paths. In general, Yucca Flat has low average annual rainfall and high potential evaporation rates. Essentially 
all of the background precipitation is removed via evapotranspiration (ET), leading to a low alluvium moisture content. Given the large permeability of Yucca Flat alluvium relative to the water flux, recharge is transmitted through the vadose zone at a low moisture content, resulting in rapid gas-phase transport because of the large pore space open to diffusion. However, the TCUs below the alluvium have a relatively low permeability that creates nearly saturated conditions and inhibits gas-phase transport.

The presence of both gas and aqueous phases under unsaturated conditions in the pores promotes contaminant partitioning between the gas, solid, and aqueous phases. It is assumed that the relative contaminant abundance in each phase is described through equilibrium partition coefficients. Because low aqueous-phase solute concentrations are present in the soil moisture, solute vapor-liquid equilibrium may be described through Henry's Law, which states that there is a linear relationship between the aqueous-phase solubility and the partial pressure of the gas through a proportionality constant, $\mathrm{K}_{\mathrm{H}}$. The solute solid-liquid equilibrium is assumed to behave according to a linear $\mathrm{K}_{\mathrm{d}}$ model, where the amount of contaminant sorbed is a function of its concentration in the groundwater. This approach combines a variety of molecular scale processes (e.g., surface complexation and ion exchange) into an effective partition coefficient that encapsulates the radionuclide-rock interactions.

The transfer of mass across the water table and into the groundwater is controlled by aqueous-phase diffusion and advection. As partitioning from the gas to the aqueous phase occurs, concentration gradients across the water table promote aqueous-phase diffusion. Given the smaller diffusivities, the time scales for aqueous-phase diffusion are significantly longer than gas-phase diffusion. Dispersion occurs in response to flowing water and a concentration gradient much like diffusion. The concentration profiles spread as a result of many different velocities within the distribution of interconnected pores and is captured in continuum models by a dispersion coefficient.

Precipitation becomes aquifer recharge and causes radionuclides to migrate across the water table via aqueous-phase advection. Background infiltration into the aquifer is a continuous process that has been taking place throughout the current pluvial time period. An additional concern is the effect of episodic crater ponding as a consequence of rainfall events. Subsidence craters have been shown to capture and focus precipitation in the crater bottoms resulting in a much higher local recharge rate (Hokett and Gillespie, 1996; Hokett and French, 1998 and 2000; Hokett et al., 2000; McNab, 2008; 
Pohll et al., 1996; Tyler et al., 1992; and Wilson et al., 2000). The crater recharge is significantly higher than the background net infiltration, leading to faster radionuclide breakthrough to the water table.

Overall, there is complex coupling between the various processes of attenuation within the vadose zone that requires investigation through numerical modeling. Above the water table, gas-phase diffusion may be an extremely important process to consider, where the radionuclide contamination extent will expand rapidly while simultaneously decreasing the radionuclide concentration by dilution. The soil moisture content has a large influence on the extent of gas-phase diffusion and is sensitive to the hydraulic properties of the geologic media and the background infiltration rate. Aqueous-phase advective transport provides a direct pathway to the water table, but the radionuclide arrival times can be significantly delayed due to sorption. The combined effects of each of these processes, while also considering radionuclide decay, can result in significant reductions of radionuclide concentration reaching the aquifer over a 1,000-year period. The insight gained from this analysis will be used to screen the most important processes needed for the CAU scale modeling approach.

\subsubsection{Simulation Software}

The FEHM code (Zyvoloski et al., 1997 a and b), developed by LANL, was chosen for the Yucca Flat multiphase flow and transport modeling. The FEHM program simulates 3-D, time-dependent, multiphase, nonisothermal flow and multicomponent, reactive groundwater transport through porous and fractured media. The FEHM finite-element formulation provides an accurate representation of complex 3-D geologic media and structures and their effects on subsurface flow and transport.

\subsection{Conceptual Model Implementation}

A 3-D finite element numerical model is developed to investigate groundwater flow as well as ${ }^{14} \mathrm{C}$ and ${ }^{3} \mathrm{H}$ transport through the vadose zone and into the water table. Each representative test is incorporated into a $1,000 \times 500 \times 750 \mathrm{~m}^{3}$ simulation model. The model domain encompasses the cavity, chimney, and exchange volume, as well as an aquifer with groundwater flow in the $\mathrm{x}$ direction. Symmetry through the $\mathrm{x}-\mathrm{z}$ plane (see Figure 5-1) is exploited to reduce computational burden by only discretizing one-half the cavity-chimney system. The model domain was oriented such that its longer 


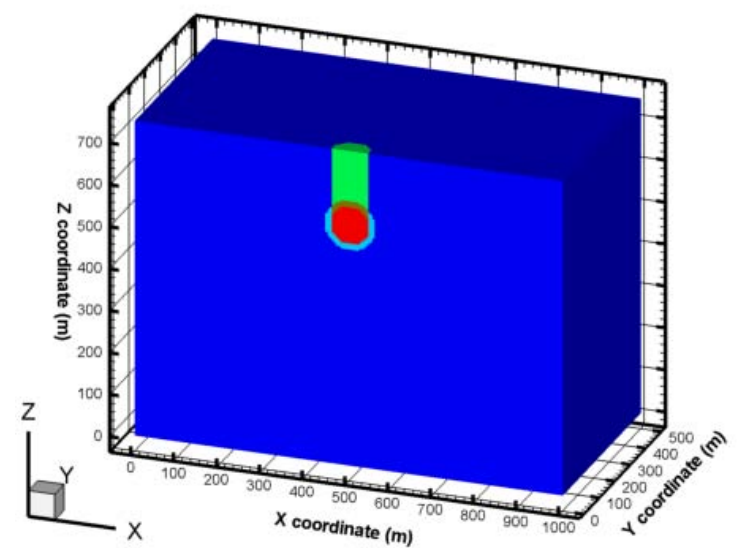

SHALLOW

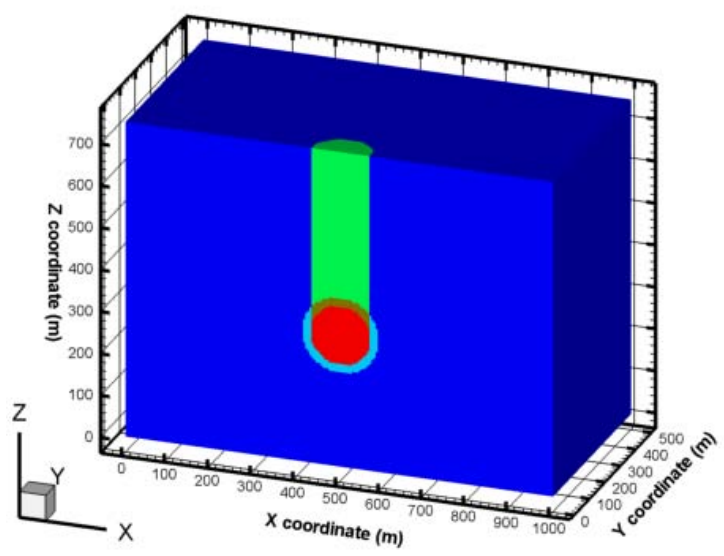

DEEP

Figure 5-1

Model Domain and Disturbed Zones for the Shallow and Deep Tests

Note: The chimney (green), cavity (red), lower crushed zone (light blue), and upper crushed zone (brown) are shown within alluvium.

(1,000 m) side is colinear with the horizontal hydraulic gradient. The model was discretized using a nonuniform, structured grid with an $87 \times 44 \times 151$ node meshing to define the corners of 554,700 quadrilateral finite-element volumes. To reduce numerical dispersion, the model discretization is sufficiently small such that many elements comprise the crater area and exchange volume, maintaining the cylindrical and spherical geometries, respectively. The crater area and exchange volume are comprised of densely refined, $5 \times 5 \times 5 \mathrm{~m}^{3}$ elements. The nonuniform grid-meshing scheme varies every $100 \mathrm{~m}$ along the $\mathrm{x}$ and $\mathrm{y}$ axes and is shown in Figure 5-2, while a uniform grid-spacing of $5 \mathrm{~m}$ was used along the $\mathrm{z}$ axis. The element volumes range from $125 \mathrm{~m}^{3}$ within the disturbed zone to $3,125 \mathrm{~m}^{3}$ near the $\mathrm{x}$ and $\mathrm{y}$ model boundaries.

\subsubsection{Lithology}

To investigate radionuclide transport through the Yucca Flat vadose zone, a simplified lithology is used, where a uniform alluvium comprises the entire model domain. Of the 668 detonations in Yucca Flat with working points above the water table, 413 detonations are located within the AA HSU (BN, 2006). Through this approach, the processes thought to have a large effect on the extent of radionuclide migration can be quantified. A detailed examination of the role of enhanced crater recharge, sensitivity of gas- and solid-phase partitioning, and the effects of high permeability crushed 


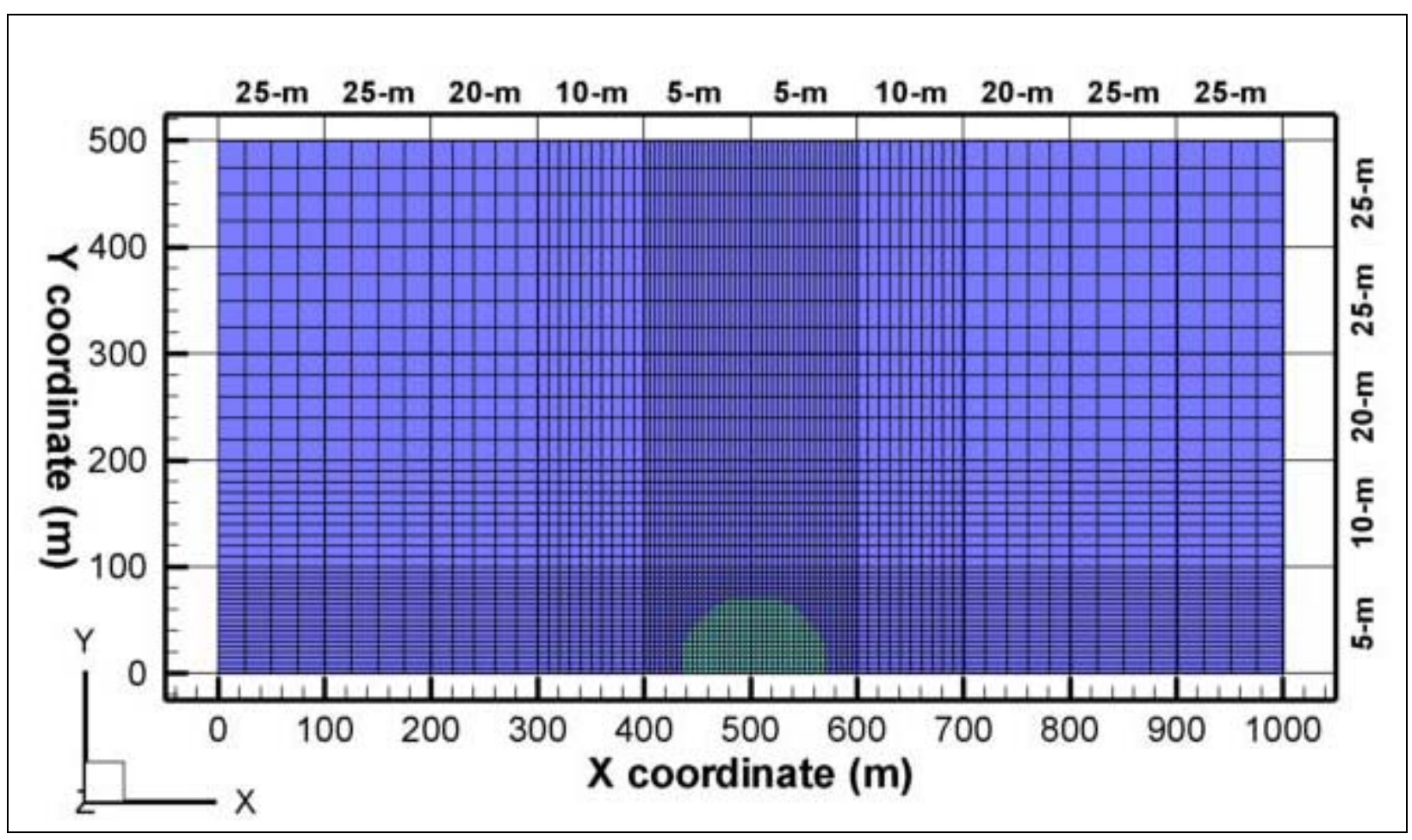

Figure 5-2

Meshing Scheme for the Shallow and Deep Models

Note: The grid spacing is varied every $100 \mathrm{~m}$ along the $\mathrm{x}$ and $\mathrm{y}$ axes. A uniform $5 \mathrm{~m}$ grid spacing is used along the $z$ axis. The crater area is shown in green.

zones is presented, while neglecting complicating factors arising from the variability in the geologic media.

\subsubsection{Disturbed Zone Physical Characteristics}

For vadose zone detonations with craters in the AA HSU, the working point depths vary from 58 to $548 \mathrm{~m}$ (SNJV, 2007). Thus, two representative models were constructed at working point depths of $175 \mathrm{~m}$ (hereafter referred to as the shallow test) and $435 \mathrm{~m}$ (deep test) in the AA HSU. The working point depths were chosen to ensure that the entire exchange volume is located above the water table.

Formation of the test cavity (i.e., the cavity above the melt glass zone) is assumed to occur immediately following detonation. According to Equation 3-1, the cavity radius is calculated from the maximum announced yield, the bulk overburden density, and the DOB (Pawloski, 1999). The overburden density used for this calculation $\left(2.1 \mathrm{~g} / \mathrm{cm}^{3}\right)$ is consistent with Tompson et al. (2004). A representative yield for the shallow case was determined by examining all vadose zone tests with 
working points between 100 and $250 \mathrm{~m}$ bls in the AA HSU. The mode maximum-announced yield (most abundant samples) for the shallow detonation is $20 \mathrm{kt}$, resulting in a cavity radius of $43.5 \mathrm{~m}$. Likewise, the representative yield for the deep case was determined by examining all vadose zone detonations conducted in the AA HSU at depths between 400 and $550 \mathrm{~m}$. For the deep test, the mode maximum-announced yield is $150 \mathrm{kt}$, resulting in a cavity radius of $67.8 \mathrm{~m}$. These cases are generic, representing typical tests for the purposes of investigating processes, and do not purport to represent conditions specific to any one test.

Differences in the hydraulic properties of the chimney and melt glass are beyond the scope of this study. Melt glass dissolution/precipitation is not considered because ${ }^{14} \mathrm{C}$ and ${ }^{3} \mathrm{H}$ do not partition into the melt glass (Maxwell et al., 2008). Thus, the hydraulic and transport properties of the melt glass and chimney are assumed to be identical to the cavity properties.

The exchange volume consists of the cavity, the crushed zones immediately surrounding the cavity, and the melt glass (Figure 3-2). According to Equation 3-3, the radius of the exchange volume is estimated as the product of the calculated cavity radius and a multiplier (Table 3-1) reflecting the potential volume around the cavity that can be immediately affected by the underground test. As recommended by Pawloski (1999) and used in the CAMBRIC steady-state model (Tompson, 2005), the alluvial test multiplicative factor is assumed to be 1.35. Thus, the exchange volume radii for the shallow and deep tests are 58.7 and $91.5 \mathrm{~m}$, respectively. Because the exchange volume is discretized uniformly into $5 \times 5 \times 5 \mathrm{~m}^{3}$ element grid blocks, the crushed zone radius is rounded to the nearest $5 \mathrm{~m}$ length increment (60 and $90 \mathrm{~m}$, respectively).

\subsubsection{Hydraulic Properties}

Characterization of unsaturated flow requires three basic hydraulic properties for each material type identified in the simulation profile:

- The moisture characteristic curve, which is the relationship between the matric potential and moisture content.

- The hydraulic conductivity curve, which is the relationship between the matric potential and the unsaturated hydraulic conductivity.

- The saturated hydraulic conductivity. 
The van Genuchten (1980) equations were used to represent the constitutive relationships between the hydraulic properties. The equation for the moisture characteristic curve is:

where:

$$
\theta=\theta_{r}+\frac{\left(\theta_{s}-\theta_{r}\right)}{\left[1+(\alpha h)^{n}\right]^{1-\frac{1}{n}}}
$$

$h=$ Suction head

$\theta=$ Volumetric moisture content

$\theta_{r}=$ Residual moisture content

$\theta_{\mathrm{s}}=$ Porosity

$n=$ Pore-size distribution index

$\alpha=$ Inverse air-entry potential

When the van Genuchten function is combined with the Mualem conductivity model (Mualem, 1976), the equation for the hydraulic conductivity curve is:

$$
K(h)=K_{s} \frac{\left\{1-(\alpha h)^{n-1}\left[1+(\alpha h)^{n}\right]^{1-1 / n}\right\}^{2}}{\left[1+(\alpha h)^{n}\right]^{0.5(1-1 / n)}}
$$

where:

$K(h)=$ Unsaturated hydraulic conductivity

$K_{s} \quad=$ Saturated hydraulic conductivity

\subsubsection{Alluvium Hydraulic Properties}

The alluvium soil moisture characteristics were taken from a characterization study of the Area 3 RWMS described in a BN (1998) report titled Hydrogeologic Characterization of the Unsaturated Zone at the Area 3 Radioactive Waste Management Site. The RWMS was used to dispose bulk low-level waste from NTS and approved off site generators. Area 3 is located within Yucca Flat and encompasses $\sim 50$ hectares (128 acres).

The purpose of the characterization study was to provide physical and hydraulic properties to develop a conceptual hydrogeologic model of the unsaturated zone. Seven boreholes were drilled using air as the drilling fluid to minimize disturbance of the core samples. The boreholes included data from undisturbed locations as well as disturbed zones within the collapse zone beneath a subsidence crater. The study concluded that hydraulic properties of the disturbed collapse zone could not be differentiated from those in the native alluvium. The study also concluded that hydraulic properties showed no trend with depth. 
The RWMS characterization study included soil moisture retention and relative permeability measurements from 124 alluvium samples. A regression analysis of the 124 alluvium samples (see Figure 5-3) provided an empirical relationship between the saturated hydraulic conductivity, $K_{s}$, and the van Genuchten $\alpha, n, \theta_{\mathrm{r}}$, and $\theta_{\mathrm{s}}$ model parameters. The empirical relationships are:

$$
\begin{gathered}
\alpha=30.03 K_{s}^{0.2813} \\
\theta_{r}=0.0171-0.0104\left(\ln K_{s}\right) \\
\theta_{s}=0.2931-0.0099\left(\ln K_{s}\right) \\
n=1.4894-0.025\left(\ln K_{s}\right)
\end{gathered}
$$

where the units of $\alpha$ and $K_{s}$ are in $\mathrm{m}^{-1}$ and meters per second (m/s), respectively. The geometric mean of the saturated hydraulic conductivity, $K_{s}$, of the 124 alluvium samples was used to establish the van Genuchten $\alpha, n, \theta_{\mathrm{r}}$, and $\theta_{\mathrm{s}}$ model parameters. This method was used for estimating the mean hydraulic properties because it considers the correlation between each van Genuchten model parameter. The van Genuchten $\alpha, n, \theta_{\mathrm{r}}$, and $\theta_{\mathrm{s}}$ model parameters and the saturated hydraulic conductivity are reported in Table 5-1. The moisture characteristic and hydraulic conductivity curves are illustrated in Figure 5-4.

It is noted that the RWMS characterization data represents samples taken from depths to a maximum of $\sim 100 \mathrm{~m}$. However, the water table occurs at $\sim 500 \mathrm{~m}$ bls. Consequently, the hydraulic properties for the deep vadose zone are an uncertain model parameter. The Yucca Flat contaminant boundary calculations will include identifying parametric model sensitivity and uncertainty.

\subsubsection{Transport Properties}

The ${ }^{14} \mathrm{C}$ and ${ }^{3} \mathrm{H}$ transport properties used in the model calculations for saturated and unsaturated alluvium are presented. The gas and aqueous-phase free diffusion $\left[\mathrm{D}_{\text {free }}(\mathrm{g})\right.$ and $\mathrm{D}_{\text {free }}(\mathrm{l})$, respectively] and dispersivity coefficients [ $\alpha(\mathrm{g})$ and $\alpha(\mathrm{l})$, respectively], baseline gas-liquid $\left(\mathrm{K}_{\mathrm{H}}\right)$ and solid-liquid $\left(\mathrm{K}_{\mathrm{d}}\right)$ partitioning coefficients, and half lives $\left(\mathrm{t}_{1 / 2}\right)$ of ${ }^{14} \mathrm{C}$ and ${ }^{3} \mathrm{H}$ are summarized in Table 5-2 and described in the sections below. The hydraulic properties of alluvium were provided in Section 5.3.3. 

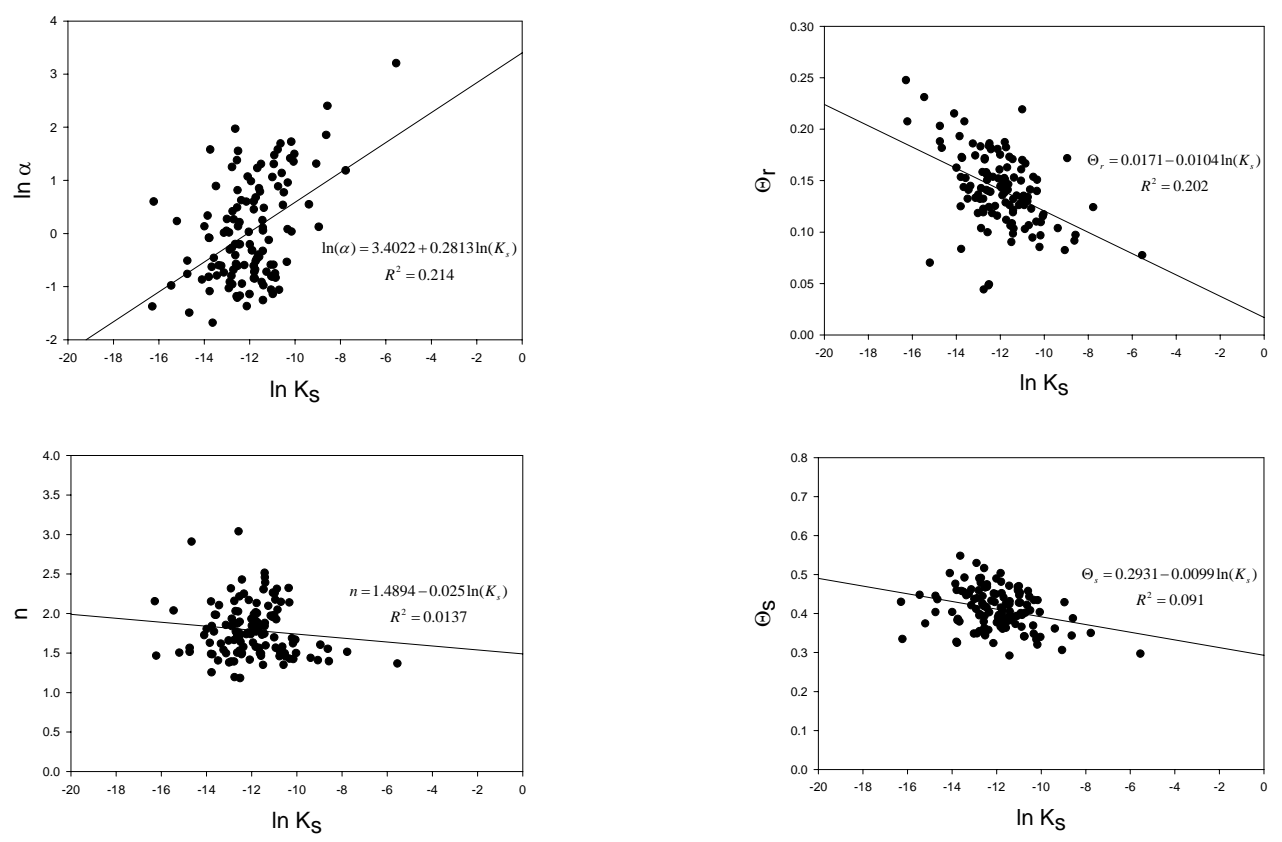

Figure 5-3

Regression Analysis of the van Genuchten Parameters

Table 5-1

van Genuchten Model Parameters for Alluvium

\begin{tabular}{|c|c|c|c|c|c|}
\hline Lithology & $\alpha\left(\mathbf{m}^{-1}\right)$ & $\theta_{\mathbf{r}}$ & $\theta_{\mathbf{s}}$ & $\boldsymbol{n}$ & $\boldsymbol{K}_{\mathbf{s}}(\mathbf{m} / \mathbf{s})$ \\
\hline \hline Alluvium & 1.030 & 0.142 & 0.412 & 1.789 & $6.201 \times 10^{-6}$ \\
\hline
\end{tabular}

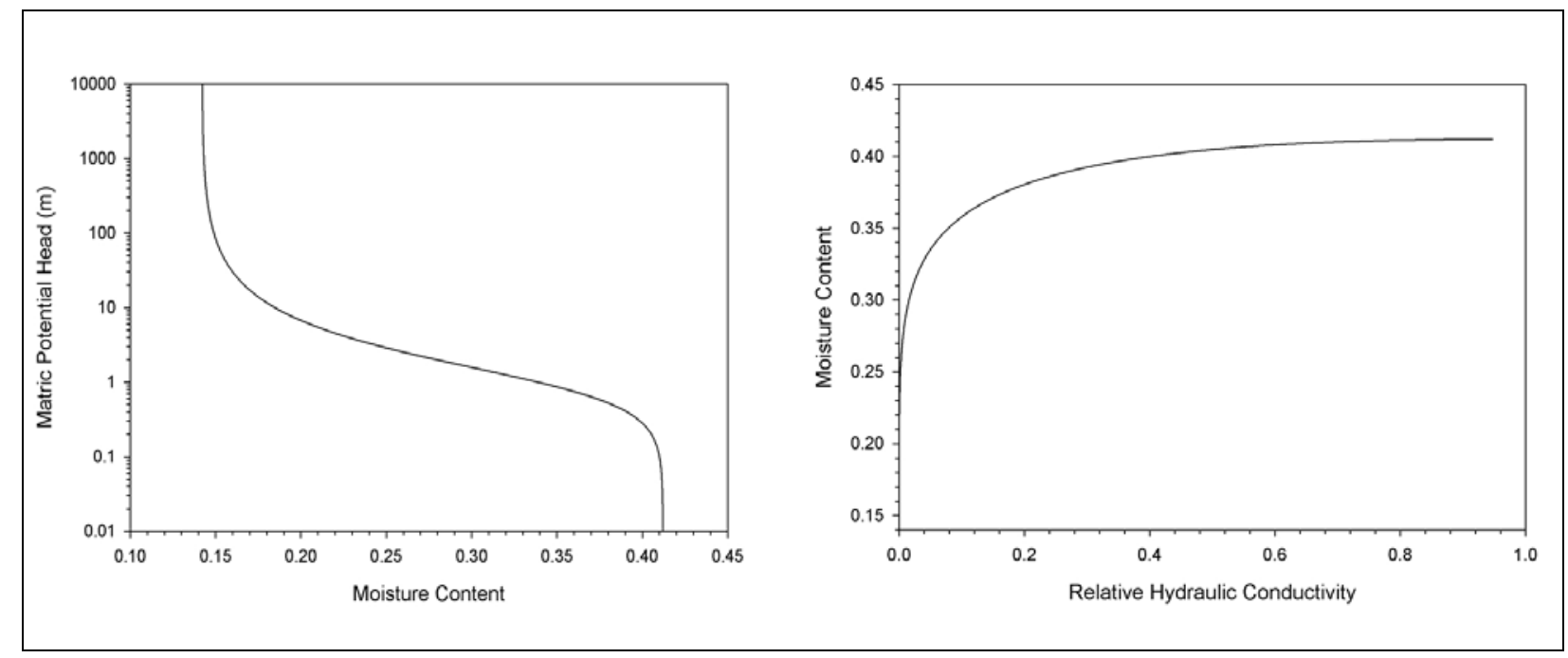

Figure 5-4

Alluvium Moisture Characteristic Curves 
Table 5-2

Summary of Transport Properties in Yucca Flat Alluvium

\begin{tabular}{|c|c|c|c|c|c|c|c|}
\hline Species & $\begin{array}{c}\mathbf{D}_{\text {free }}(\mathbf{g}) \\
\left(\mathbf{m}^{2} / \mathbf{s}\right)\end{array}$ & $\begin{array}{c}\mathbf{D}_{\text {free }}(\mathbf{l}) \\
\left(\mathbf{m}^{2} / \mathbf{s}\right)\end{array}$ & $\begin{array}{c}\alpha(\mathbf{g}) \\
(\mathbf{m})\end{array}$ & $\begin{array}{c}\alpha(\mathbf{l}) \\
(\mathbf{m})\end{array}$ & $\begin{array}{c}\mathrm{K}_{\mathrm{H}} \\
\left(\mathbf{a t m}^{-1}\right)\end{array}$ & $\begin{array}{c}\mathrm{K}_{\mathbf{d}} \\
(\mathbf{m L} / \mathbf{g})\end{array}$ & $\begin{array}{c}\mathbf{t}_{\mathbf{1} 2} \\
(\mathbf{y r})\end{array}$ \\
\hline \hline Carbon-14 & $1.85 \times 10^{-5}$ & $1.00 \times 10^{-9}$ & 5.0 & 0.0 & $3.63 \times 10^{-3}$ & 0.8 & 5730.0 \\
\hline Tritium & $2.44 \times 10^{-5}$ & $1.00 \times 10^{-9}$ & 5.0 & 0.0 & 43.3 & 0.0 & 12.3 \\
\hline
\end{tabular}

\subsubsection{Diffusivity}

The free gas and water diffusion coefficients are the proportionality constants relating the solute mass flux to the concentration gradient. The diffusion coefficients for $\mathrm{CO}_{2}$ in the aqueous and gaseous phases used in this study are $1.00 \times 10^{-9}$ and $1.85 \times 10^{-5} \mathrm{~m}^{2} / \mathrm{s}$, respectively (see Appendix $\mathrm{C}$ ). The tortuosity describes the ratio of the actual flow path to the straight line flow path of a particle moving between two points. Tortuosity lowers the effective diffusion coefficient from the free diffusion coefficient in an open system and is described by:

$$
D_{\text {eff }}=\frac{1}{\tau} D_{\text {free }}
$$

where:

$D_{\text {eff }}=$ Effective diffusion coefficient

$\tau \quad=$ Tortuosity

$D_{\text {free }}=$ Free diffusion coefficient

As summarized in the Yucca Flat Phase I contaminant transport parameters document (SNJV, 2007), all rock types within the NTS matrix diffusion database were fit to an exponential formulation of inverse tortuosity, given by the relation

$$
\frac{1}{\tau}=\phi^{n}
$$

where:

$\phi=$ Porosity

$n=$ exponent determined by lithology or by the best fit to the data set

The least squares regression exponent for all rock types at the NTS was determined to be 1.33, with a lower 95 percent confidence interval (CI) limit of 0.4 and an upper 95 percent CI limit of 3.2. The porosity of alluvium used in this analysis is $\phi=0.412$. According to the least squares regression exponent ranges reported in SNJV (2007), the inverse of the tortuosity (Equation 5-8) for alluvium is expected to range from 0.06 to 0.70 with a mean of 0.31 . For this analysis, the exponent for alluvium 
is assumed to be 1.0, yielding an inverse tortuosity of 0.412. Thus, the effective diffusivity is $4.12 \times 10^{-10}$ and $7.62 \times 10^{-6} \mathrm{~m}^{2} / \mathrm{s}$ for the $\mathrm{CO}_{2}$ vapor and aqueous-phases, respectively. For ${ }^{3} \mathrm{H}$, the free diffusion coefficient for water is $1.00 \times 10^{-9} \mathrm{~m}^{2} / \mathrm{s}$ in the aqueous phase and $2.44 \times 10^{-5} \mathrm{~m}^{2} / \mathrm{s}$ in the gaseous phase at $20^{\circ} \mathrm{C}$. The effective diffusivities are $4.12 \times 10^{-10} \mathrm{~m}^{2} / \mathrm{s}$ and $1.01 \times 10^{-5} \mathrm{~m}^{2} / \mathrm{s}$, respectively. Finally, to account for the diffusivity dependence on saturation, the FEHM simulations used the Millington-Quirk diffusion model (Millington and Quirk, 1960). The ranges of porosity values presented in SNJV (2007) indicate porosity is an uncertain model parameter. The Yucca Flat contaminant boundary calculations will include identifying parametric model sensitivity and uncertainty (see Section 3.5).

\subsubsection{Dispersion}

The Yucca Flat Phase I contaminant transport parameters document (SNJV, 2007) provides a complete review of the site-specific dispersivity data available for Yucca Flat and compares the data with the scientific literature. It concludes that a log-log linear scaling relationship is appropriate for relating the dispersivity to the transport length scale in the Yucca Flat/Climax Mine CAU groundwater flow and transport models. The log-log linear scaling relationship is given by

$$
\log \alpha=0.73 \log L-0.91
$$

where:

$\alpha=$ longitudinal dispersivity (m)

$L=$ measurement distance from the working point to the water table (m)

The average distance of the deep and shallow test to the water table is $\sim 200 \mathrm{~m}$, which provides a dispersivity value of $\sim 5 \mathrm{~m}$. It was concluded in SNJV (2007) that longitudinal dispersivity to transverse dispersivity is generally in the range of 3 to 30 and the ratio of longitudinal to transverse vertical dispersivity is generally in the range of 10 to 800. However, traditional dispersivity scaling relationships tend to over predict longitudinal and under predict transverse dispersivity for vertical flow through horizontally stratified media (Selker et al., 1999), which is likely present in the Yucca Flat alluvium. In lieu of using longitudinal to transverse dispersivity ratios provided in SNJV (2007), a uniform dispersivity value of $5 \mathrm{~m}$ was used in the ${ }^{14} \mathrm{C}$ and ${ }^{3} \mathrm{H}$ transport simulations. 


\subsubsection{Matrix Sorption}

Matrix sorption combines a variety of aqueous-phase molecular-scale processes (e.g., surface complexation and ion exchange) into an effective partition coefficient that encapsulates the radionuclide-rock interaction. As a consequence of sorption, the radionuclide arrival time to the aquifer will be delayed to an extent that depends on the magnitude of the distribution coefficient.

The ${ }^{14} \mathrm{C}$ sorption coefficient $\left(\mathrm{K}_{\mathrm{d}}\right)$ combines all effects including anion adsorption of DIC species (dissolved ${ }^{14} \mathrm{CO}_{2}, \mathrm{H}_{2} \mathrm{CO}_{3}, \mathrm{HCO}_{3}{ }^{-}$, and $\mathrm{CO}_{3}{ }^{2-}$ ) and dissolution-precipitation. Site-specific ${ }^{14} \mathrm{C}$ sorption data on Yucca Flat alluvium does not currently exist. However, batch sorption and fracture flow experiments have been conducted to evaluate ${ }^{14} \mathrm{C}$ adsorption and/or isotopic exchange onto pore and fracture surfaces of LCA core from UE-7nS and Water Well Army \#1 (Hershey et al., 2003). The effective $K_{d}$ that describes the equilibrium and kinetic sorption for the batch experiments was reported as $29.4 \mathrm{~mL} / \mathrm{g}$. In the fracture experiments, the partition coefficients were derived from retardation factors, which yields $\mathrm{K}_{\mathrm{d}}$ estimates ranging from 4.2 to $30.0 \mathrm{~mL} / \mathrm{g}$. Additional ${ }^{14} \mathrm{C}$ batch sorption and fracture flow experiments on LCA rock cores taken from Well ER-6-1 measured the apparent $K_{d}$ values to range from 28.5 to $46.3 \mathrm{~mL} / \mathrm{g}$ (Reimus et al., 2006). However, it is noted that these studies may have been affected by experimental artifacts relating to mineral precipitation that likely result in an over-estimation of the ${ }^{14} \mathrm{C} \mathrm{K}_{\mathrm{d}}$ partition coefficients.

A number of studies have investigated ${ }^{14} \mathrm{C}$ transport in natural unconsolidated soil sediments from alternative sites and have estimated the sorption coefficients. Batch ${ }^{14} \mathrm{C}$ adsorption experiments on sediments from the Subsurface Disposal Area (SDA) at Idaho National Laboratory (INL) (Dicke and Hohorst, 1997) measured mean $\mathrm{K}_{\mathrm{d}}$ values of $0.8 \mathrm{~mL} / \mathrm{g}$ (range $=0.1$ to $2.0 \mathrm{~mL} / \mathrm{g}$ ). In addition, small-scale column experiments of the SDA sediments were conducted and measured $\mathrm{K}_{\mathrm{d}}$ values of $0.8 \pm 0.1 \mathrm{~mL} / \mathrm{g}$ (Hull and Hohorst, 2001). Measured $\mathrm{K}_{\mathrm{d}}$ values in natural sediments from the Hanford Site range from 1.1 to $3.0 \mathrm{~mL} / \mathrm{g}$ (Allard et al., 1981) and from 2.5 to $4.6 \mathrm{~mL} / \mathrm{g}$ (Martin, 1991).

A $\mathrm{K}_{\mathrm{d}}$ value of $83 \mathrm{~mL} / \mathrm{g}$ has been measured from batch adsorption experiments with calcite (Allard et al., 1981), suggesting that calcite strongly interacts with ${ }^{14} \mathrm{C}$ and influences the magnitude of $K_{d}$ values in the alluvium. As a result, the mineralogy of the INL soil (Fox et al., 2004) is compared to the average mineralogy of Yucca Flat alluvium (SNJV, 2007) in the AA HSU in Table 5-3 and indicates that similar calcite mineral percentages are present in each location. 
Table 5-3

Bulk Mineralogy Comparison of INL SDA Sediment and Yucca Flat Alluvium

\begin{tabular}{|c|c|c|c|}
\hline Mineral & $\begin{array}{c}\text { INL SDA } \\
\text { (wt\%) } \\
\text { (Fox et al., 2004) }\end{array}$ & $\begin{array}{c}\text { Yucca Flat } \\
\text { Typical AA } \\
\text { (wt\%) } \\
\text { (SNJV, 2007) }\end{array}$ & $\begin{array}{c}\text { Yucca Flat } \\
\text { Altered AA } \\
\text { (wt\%) } \\
\text { (SNJV, 2007) }\end{array}$ \\
\hline \hline Calcite & $<5$ & 7.1 & 8.1 \\
\hline $\begin{array}{c}\text { Clay Minerals } \\
\text { (mixed smectite-illite, kaolinite) }\end{array}$ & 10 to 20 & 7.7 & 19.2 \\
\hline Mica & -- & 6.2 & 0.9 \\
\hline Iron Oxides & $<5$ & 0.3 & 0.0 \\
\hline Zeolite & -- & 9.9 & 27.1 \\
\hline Quartz & 50 to 75 & 23.2 & 15.9 \\
\hline Glass & -- & 15.6 & 4.6 \\
\hline Plagioclase and Feldspar & 10 to 25 & 26.2 & 27.5 \\
\hline
\end{tabular}

$\mathrm{wt} \%=$ Weight percent

Furthermore, calcite surface exchange calculations are easily computed by combining the site-specific mineralogy (see Table 5-3) and aqueous phase geochemistry data representative of Yucca Flat alluvium. Bicarbonate concentrations range from 150 to $450 \mathrm{mg} / \mathrm{L}$ in Yucca Flat alluvium and the calcite surface area and site density are assumed to be $2.2 \mathrm{~m}^{2} / \mathrm{g}$ and 5 sites $/ \mathrm{nm}^{2}$, respectively, as noted by Zavarin et al. (2002). The calcite surface exchange calculations result in ${ }^{14} \mathrm{C} \mathrm{K}_{\mathrm{d}}$ values ranging from 0.2 to $0.5 \mathrm{~mL} / \mathrm{g}$. Assuming that calcite and clay minerals are the dominant reactive minerals in the alluvium, the $\mathrm{K}_{\mathrm{d}}$ values obtained from INL are expected to predict reasonably well the effect of ${ }^{14} \mathrm{C}$ sorption to Yucca Flat alluvium when comparable mineral percentages are present. Thus, a ${ }^{14} \mathrm{C} \mathrm{K}_{\mathrm{d}}$ value of $0.8 \mathrm{~mL} / \mathrm{g}$ obtained from INL experiments in a similar unconsolidated soil is used in this analysis.

A number of studies report that there is a potential for ${ }^{3} \mathrm{H}$ to a sorb to clays and other hydrated soil minerals. Column experiments of ${ }^{3} \mathrm{H}$ breakthrough in the unsaturated soils have been previously investigated (Kjaergaard et al., 2004). In saturated sandy soils, a review of published studies confirms ${ }^{3} \mathrm{H}$ sorption, where the distribution coefficient ranges from 0.04 to $0.1 \mathrm{~mL} / \mathrm{g}$ (Thibault et al., 1990). In a separate study on the SDA sediment at INL (Fox et al., 2004), comparisons of breakthrough curves indicate that ${ }^{3} \mathrm{H}$ transport is slower than bromide $(\mathrm{Br}-)$ tracer, and a $\mathrm{K}_{\mathrm{d}}$ of 
$\sim 0.08 \mathrm{~mL} / \mathrm{g}$ for ${ }^{3} \mathrm{H}$ is reported. However, Br- tracer typically breaks through before ${ }^{3} \mathrm{H}$ because of anion exclusion effects, where it is prevented from entering smaller pores by negatively charged particle surfaces. Although Fox et al. (2004) confirm ${ }^{3} \mathrm{H}$ retardation through sorption processes in their experimental setup, the ${ }^{3} \mathrm{H}$ sorption coefficient is neglected $(0.0 \mathrm{~mL} / \mathrm{g})$ in the baseline models presented in this analysis. However, given the large debate over the validity of the $\mathrm{K}_{\mathrm{d}}$ measurement, two additional sensitivity models that account for sorption to the clay minerals within the Yucca Flat alluvium $(0.05 \mathrm{~mL} / \mathrm{g})$ are conducted to bracket the magnitude of uncertainty.

\subsubsection{Gas-phase Partitioning}

The ${ }^{14} \mathrm{C}$ gas-water partitioning coefficient value was calculated by assuming a series of equilibrium reactions in which ${ }^{14} \mathrm{C}$ is assumed to behave as ${ }^{14} \mathrm{CO}_{2}$ in the gas phase. The $\mathrm{CO}_{2}(\mathrm{~g})$ dissolves in the aqueous-phase according to the equilibrium reaction:

$$
\mathrm{CO}_{2}(g) \rightleftharpoons \mathrm{CO}_{2}(a q)
$$

Equilibrium between $\mathrm{CO}_{2}(\mathrm{~g})$ and $\mathrm{CO}_{2}(\mathrm{aq})$ can be described through Henry's Law, where the Henry's coefficient for $\mathrm{CO}_{2}$ at $20{ }^{\circ} \mathrm{C}$ is $0.000701 \mathrm{~atm}^{-1}$ (Tchobanoglous and Schroeder, 1987). Aqueous phase $\mathrm{CO}_{2}$ is in equilibrium with carbonic acid, bicarbonate and carbonate as described by the following reactions:

$$
\mathrm{CO}_{2}(a q)+\mathrm{H}_{2} \mathrm{O}(a q) \rightleftharpoons \mathrm{H}_{2} \mathrm{CO}_{3}(a q)
$$

Although equilibrium reaction is heavily weighted to the left side of the above equation, it is customary to refer to all dissolved $\mathrm{CO}_{2}$ in water as $\mathrm{H}_{2} \mathrm{CO}_{3}$. Carbonic acid dissociates to bicarbonate ion, then further dissociates to carbonate ion. The two step dissociation is expressed according to the following reactions:

$$
\begin{aligned}
& \mathrm{H}_{2} \mathrm{CO}_{3}(a q)+\mathrm{H}_{2} \mathrm{O}(a q) \rightleftharpoons \mathrm{H}_{3} \mathrm{O}^{+}(a q)+\mathrm{HCO}_{3}^{-}(a q) \\
& \mathrm{HCO}_{3}^{-}(a q)+\mathrm{H}_{2} \mathrm{O}(a q) \rightleftharpoons \mathrm{H}_{3} \mathrm{O}^{+}(a q)+\mathrm{CO}_{3}{ }^{2-}(a q)
\end{aligned}
$$

The equilibrium constant for each reaction is $\mathrm{K}_{1}=4.17 \times 10^{-7}$ and $\mathrm{K}_{2}=4.17 \times 10^{-11}$, respectively (Tchobanoglous and Schroeder, 1987). The concentrations of each dissolved carbon species is then 
summed to give the overall concentration of DIC in the system at equilibrium. Table 4-2 of McNab (2008) reports the $\mathrm{pH}$ to vary from 6.5 to 9.3 in selected wells at the NTS. For this analysis, an average $\mathrm{pH}$ of 7.0 was assumed to represent the Yucca Flat groundwater samples. The effective Henry's coefficient (gas-water partitioning coefficient) is computed by dividing the solubility by the partial pressure of $\mathrm{CO}_{2}$. Thus, the gas-water partitioning coefficient, $\mathrm{K}_{\mathrm{H}}$, is found to be $3.63 \times 10^{-3}$ $\mathrm{atm}^{-1}$. The ${ }^{14} \mathrm{C}(\mathrm{g})$ to ${ }^{14} \mathrm{C}(\mathrm{aq})$ mass ratio is 0.46 at a $\mathrm{pH}$ of 7.0 . This is consistent with the ratios reported by McNab (2008), which vary from 0.65 to 0.11 at a $\mathrm{pH}$ range of 6.5 to 7.5 .

For ${ }^{3} \mathrm{H}$, equilibrium between the gaseous and aqueous-phase is described through Henry's Law. Tritiated water is assumed to behave as pure water. Thus, the gas-water partitioning coefficient is equivalent to the vapor pressure of water at $20{ }^{\circ} \mathrm{C}$, which is reported to be $43.3 \mathrm{~atm}^{-1}$ (Tchobanoglous and Schroeder, 1987).

\subsubsection{Boundary Conditions}

\subsubsection{Background Precipitation}

In general, Yucca Flat has low average annual rainfall and high potential evaporation rates. Significant recharge does not occur in the interfluve regions of Yucca Flat. Several studies (Tyler et al., 1996; BN, 1998; Walvoord et al., 2002a and b) indicate that nearly all precipitation at Yucca Flat proper is removed via ET and the recharge is at most a few millimeters per year. Thus, a uniform background infiltration of $1 \mathrm{~mm} / \mathrm{yr}$ is applied as a boundary condition at land surface.

\subsubsection{Crater Recharge}

Among the 413 detonations conducted in the AA HSU and above the water table, 253 detonations resulted in a measurable collapsed crater (Kwicklis, 2007). The average crater area for shallow detonations with working point depths between 100 and $250 \mathrm{~m}$ is 8,053 $\mathrm{m}^{2}$, resulting in a representative crater radius of $50.6 \mathrm{~m}$. The average crater area for deep detonations with working point depths between 400 and $550 \mathrm{~m}$ is 32,492 $\mathrm{m}^{2}$, resulting in a representative crater radius of $101.7 \mathrm{~m}$. Because the crater area is discretized uniformly into $5 \times 5 \times 5 \mathrm{~m}^{3}$ element grid blocks, the crater radii were rounded to 50 and $100 \mathrm{~m}$ for the shallow and deep tests, respectively. Recharge rates varying from 5 to 5,000 mm/yr are evaluated over the crater playas to quantify the effect on transport. 
In addition, the areal extent of the playas is examined, where the playa recharge area is assumed to be one-fourth the crater area (i.e., the playa recharge radius is one-half of the crater radius).

\subsubsection{Aquifer}

An aquifer with groundwater flow was treated explicitly within the model, where an aquifer depth of $526 \mathrm{~m}$ relative to land surface was determined by averaging vadose zone detonations in the AA HSU that exhibit collapsed craters. For each emplacement hole in the alluvium, the three point method (Fienen, 2005) was applied using the three nearest water level approximations to estimate the hydraulic gradient (see Appendix A). An average hydraulic gradient of 0.0098 was computed and applied to the generic shallow and deep tests in this analysis. Hydrostatic boundary conditions were specified at the upgradient and downgradient aquifer boundaries to match the hydraulic gradient. The model domain size and aquifer depth ensured that the radionuclide mass did not interact with the model boundaries over the 1,000-year simulation period.

\subsubsection{Initial Conditions}

The simulations were conducted according to a two-step process. The initial, "equilibration” simulation represents the predetonation period of the test. Before detonation, there is no exchange volume or corresponding crater area present. The steady-state saturation profile was computed before detonation assuming a background recharge of $1 \mathrm{~mm} / \mathrm{yr}$. The alluvium saturation is essentially constant at 0.25 down to the water table (see Figure 5-5). The steady-state pressure and saturation profile is used subsequently as an initial condition for the transport calculations.

The second phase of the simulation process represents the 1,000-year period immediately after detonation. Simplifying assumptions were made to the initial conditions of the post-detonation transport simulations.

- $\quad$ The steady-state saturated profile from the equilibration phase was assumed to exist simultaneously with the formation of the crater and exchange volume at time $\mathrm{t}_{0}=0$ years. Thus, the transience of the saturation profile as the exchange volume forms is not considered.

- The radionuclide inventory for ${ }^{14} \mathrm{C}$ and ${ }^{3} \mathrm{H}$ was assumed to be distributed uniformly over the exchange volume immediately after detonation, resulting in identical aqueous-phase concentrations within each finite element volume comprising the exchange volume. The half 


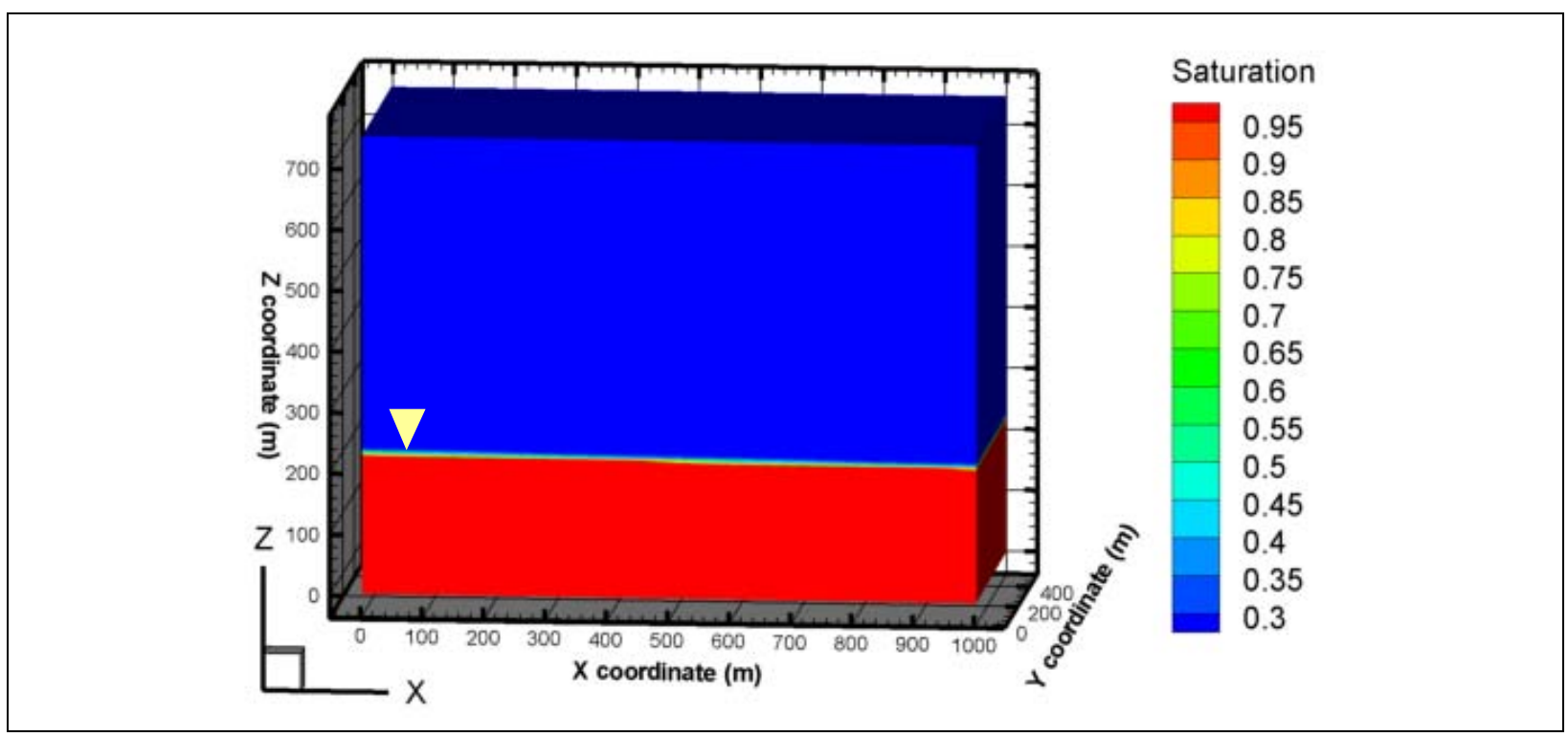

Figure 5-5

Steady-state Saturation Profile in Alluvium after 1,000 Years

symmetry model requires initializing half of the inventory in the exchange volume and multiplying breakthrough mass by a factor 2 in the simulations.

- The crater forms instantaneously, resulting in enhanced water recharge over the playa area immediately after detonation. As reported by the U.S. Congress, Office of Technology Assessment (1989) and summarized in Section 2.2.1, cavity collapse, chimneying, and crater formation typically occur within minutes and up to days after detonation.

\subsubsection{Scenarios}

The purpose of this analysis is to investigate the radionuclide attenuation mechanisms in the vadose zone. A number of simulation models are conceptualized to examine the following effects:

- Radioactive decay times: ${ }^{14} \mathrm{C}$ represents a long-lived radionuclide (5,730-year half-life) and the attenuation mechanisms are essentially independent of radioactive decay. Tritium represents a short-lived radionuclide (12.3-year half-life) that decays rapidly and may be attenuated due to the travel time to the aquifer.

- Crater-enhanced recharge rates: Crater playa recharge rates of 5, 50, 250, and $5,000 \mathrm{~mm} /$ year are investigated. A background recharge rate of $1 \mathrm{~mm} / \mathrm{yr}$ is assumed outside the playa area.

- Recharge areal extent: The playa to crater radius ratio is examined at ratios of 0.5 and 1 to investigate recharge focusing. 
- Gas-phase partitioning for ${ }^{14} \mathrm{C}$ and ${ }^{3} \mathrm{H}$ : The simulations are conducted with and without Henry's Law partitioning to test the magnitude of gas-phase transport. The gas-water partitioning coefficients, $\mathrm{K}_{\mathrm{H}}$, for ${ }^{14} \mathrm{C}$ and ${ }^{3} \mathrm{H}$ are $3.63 \times 10^{-3}$ and $43.3 \mathrm{~atm}^{-1}$, respectively.

- Solid-phase partitioning for ${ }^{14} \mathrm{C}$ and ${ }^{3} \mathrm{H}$ : The simulations are conducted with and without sorption to the solid phase. The baseline $\mathrm{K}_{\mathrm{d}}$ values for ${ }^{14} \mathrm{C}$ and ${ }^{3} \mathrm{H}$ are 0.8 and $0.0 \mathrm{~mL} / \mathrm{g}$, respectively. However, additional sensitivity models disable the ${ }^{14} \mathrm{C}$ partitioning coefficient (noted as the "No Solid-Phase Partitioning" and "No Gas or Solid-Phase Partitioning" models in Table 5-4) and enable the tritium partitioning coefficient (noted as the "Solid-Phase Partitioning” and “No Gas, but Solid-Phase Partitioning” models in Table 5-4).

- Low permeability/porosity crushed zone: The crushed zone permeability is reduced by two orders of magnitude and the crushed zone porosity is reduced from 0.412 to 0.270 to test the effects of the crushed zone on the HST (Tompson, 1999; SNJV, 2005).

Table 5-4

${ }^{14} \mathrm{C}$ and ${ }^{3} \mathrm{H}$ Multiphase Source Term Simulations

(Page 1 of 2)

\begin{tabular}{|c|c|c|c|c|c|c|}
\hline Simulation & $\begin{array}{c}\text { Crater } \\
\text { Recharge } \\
\text { Rate } \\
(\mathrm{mm} / \mathrm{yr})\end{array}$ & $\begin{array}{l}\text { Ratio of } \\
\text { Playa } \\
\text { Radius to } \\
\text { Crater } \\
\text { Radius }\end{array}$ & $\begin{array}{l}\text { Crushed } \\
\text { Zone } \\
\text { Permeability } \\
\text { Reduction } \\
\text { Factor }\end{array}$ & $\begin{array}{c}\text { Crushed } \\
\text { Zone } \\
\text { Porosity }\end{array}$ & $\begin{array}{c}{ }^{14} \mathrm{C} /{ }^{3} \mathrm{H} \\
\text { Gas-Water } \\
\text { Partitioning } \\
\text { Coefficient, } \\
\mathrm{K}_{\mathrm{H}} \\
\left(\mathrm{atm}^{-1}\right)\end{array}$ & $\begin{array}{c}{ }^{14} \mathrm{C} /{ }^{3} \mathrm{H} \\
\text { Alluvium } \\
\text { Sorption } \\
\text { Coefficient, } \\
\mathrm{K}_{\mathrm{d}} \\
(\mathrm{mL} / \mathrm{g})\end{array}$ \\
\hline Baseline & 250 & 0.5 & 1 & 0.412 & $3.63 \times 10^{-3} / 43.3$ & $0.8 / 0.0$ \\
\hline $\begin{array}{l}\text { Lowest Crater } \\
\text { Recharge Rate }\end{array}$ & 5 & 0.5 & 1 & 0.412 & $3.63 \times 10^{-3} / 43.3$ & $0.8 / 0.0$ \\
\hline $\begin{array}{l}\text { Low Crater } \\
\text { Recharge Rate }\end{array}$ & 50 & 0.5 & 1 & 0.412 & $3.63 \times 10^{-3} / 43.3$ & $0.8 / 0.0$ \\
\hline $\begin{array}{c}\text { High Crater } \\
\text { Recharge Rate }\end{array}$ & 5,000 & 0.5 & 1 & 0.412 & $3.63 \times 10^{-3} / 43.3$ & $0.8 / 0.0$ \\
\hline $\begin{array}{l}\text { Increased Playa } \\
\text { Recharge Area }\end{array}$ & 250 & 1.0 & 1 & 0.412 & $3.63 \times 10^{-3} / 43.3$ & $0.8 / 0.0$ \\
\hline $\begin{array}{l}\text { No Gas-Phase } \\
\text { Partitioning }\end{array}$ & 250 & 0.5 & 1 & 0.412 & $0.0 / 0.0$ & $0.8 / 0.0$ \\
\hline $\begin{array}{c}\text { No Solid-Phase } \\
\text { Partitioning }\left({ }^{14} \mathrm{C} \text { only) }\right.\end{array}$ & 250 & 0.5 & 1 & 0.412 & $3.63 \times 10^{-3}$ & 0.0 \\
\hline $\begin{array}{c}\text { Solid-Phase } \\
\text { Partitioning ( }{ }^{3} \mathrm{H} \text { only) }\end{array}$ & 250 & 0.5 & 1 & 0.412 & 43.3 & 0.05 \\
\hline $\begin{array}{c}\text { No Gas or } \\
\text { Solid-Phase } \\
\text { Partitioning }\left({ }^{14} \mathrm{C} \text { only }\right)\end{array}$ & 250 & 0.5 & 1 & 0.412 & 0.0 & 0.0 \\
\hline
\end{tabular}


Table 5-4

${ }^{14} \mathrm{C}$ and ${ }^{3} \mathrm{H}$ Multiphase Source Term Simulations

(Page 2 of 2)

\begin{tabular}{|c|c|c|c|c|c|c|}
\hline Simulation & $\begin{array}{c}\text { Crater } \\
\text { Recharge } \\
\text { Rate } \\
(\mathrm{mm} / \mathrm{yr})\end{array}$ & $\begin{array}{l}\text { Ratio of } \\
\text { Playa } \\
\text { Radius to } \\
\text { Crater } \\
\text { Radius }\end{array}$ & $\begin{array}{l}\text { Crushed } \\
\text { Zone } \\
\text { Permeability } \\
\text { Reduction } \\
\text { Factor }\end{array}$ & $\begin{array}{l}\text { Crushed } \\
\text { Zone } \\
\text { Porosity }\end{array}$ & $\begin{array}{c}{ }^{14} \mathrm{C} /{ }^{3} \mathrm{H} \\
\text { Gas-Water } \\
\text { Partitioning } \\
\text { Coefficient, } \\
\mathrm{K}_{\mathrm{H}} \\
\left(\mathrm{atm}^{-1}\right)\end{array}$ & $\begin{array}{c}{ }^{14} \mathrm{C} /{ }^{3} \mathrm{H} \\
\text { Alluvium } \\
\text { Sorption } \\
\text { Coefficient, } \\
\mathrm{K}_{\mathrm{d}} \\
(\mathrm{mL} / \mathrm{g})\end{array}$ \\
\hline $\begin{array}{c}\text { No Gas, but } \\
\text { Solid-Phase } \\
\text { Partitioning ( }{ }^{3} \mathrm{H} \text { only) }\end{array}$ & 250 & 0.5 & 1 & 0.412 & 0.0 & 0.05 \\
\hline $\begin{array}{c}\text { Reduced } \\
\text { Crushed Zone } \\
\text { Permeability/Porosity }\end{array}$ & 250 & 0.5 & 100 & 0.270 & $3.63 \times 10^{-3} / 43.3$ & $0.8 / 0.0$ \\
\hline $\begin{array}{c}\text { Reduced Crushed } \\
\text { Zone Permeability } \\
\text { with High Recharge } \\
\text { Rate }\end{array}$ & 5,000 & 0.5 & 100 & 0.270 & $3.63 \times 10^{-3} / 43.3$ & $0.8 / 0.0$ \\
\hline
\end{tabular}

A matrix of the conceptual models and the departures from the baseline model is summarized in Table 5-4. Test cases will be conducted for each representative depth (shallow and deep), resulting in a total of 20 simulations for ${ }^{14} \mathrm{C}$ and ${ }^{3} \mathrm{H}$.

\subsection{Simulation Results}

This section compares two generic test settings, shallow and deep, detonated at depths of 175 and $435 \mathrm{~m}$ bls, respectively. The exchange volumes are located above the water table. The exchange volume bottom of the $20 \mathrm{kt}$ shallow test (radius of the exchange volume, $\mathrm{r}_{\mathrm{e}}=50 \mathrm{~m}$ ) is $291 \mathrm{~m}$ above the water table and the bottom of the $150 \mathrm{kt}$ deep test $\left(\mathrm{r}_{\mathrm{e}}=90 \mathrm{~m}\right)$ is $1 \mathrm{~m}$ above the water table. The sensitivity studies summarized in Table 5-4 are compared to the baseline model in each subsection to illustrate the effects of varying crater recharge, playa areal extent, gas/solid-phase partitioning and the crushed zone hydraulic properties.

\subsubsection{Baseline Carbon-14 Transport for a Shallow Test}

The shallow baseline model for ${ }^{14} \mathrm{C}$ transport is introduced to illustrate the important processes included in the conceptual model. In the baseline model, ${ }^{14} \mathrm{C}$ transport is examined with a background infiltration rate of $1 \mathrm{~mm} / \mathrm{yr}$ and a crater-enhanced recharge of $250 \mathrm{~mm} / \mathrm{yr}$. The 
crater-enhanced recharge rate is the average recharge rate initially inferred from field studies by McNab (2008) and is distributed uniformly over the playa area. McNab (2008) has subsequently updated the average crater recharge rate to $200 \mathrm{~mm} / \mathrm{yr}$ in the latest revision of the report. The areal extent of the playa is one-fourth of the crater area (i.e., the playa radius is one-half of the crater radius). Both gas- and solid-phase partitioning are included. The gas-water partitioning coefficient for ${ }^{14} \mathrm{C}$ is $3.63 \times 10^{-3} \mathrm{~atm}^{-1}$ and the $\mathrm{K}_{\mathrm{d}}$ value describing the interaction between aqueous-phase ${ }^{14} \mathrm{C}$ and alluvium is $0.8 \mathrm{~mL} / \mathrm{g}$. The crushed-zone permeability and porosity are assumed to be equivalent to the undisturbed alluvium properties in the baseline model.

From a conceptual standpoint, ${ }^{14} \mathrm{C}$ gas $\left({ }^{14} \mathrm{CO}_{2}\right)$ diffuses radially outward from the working point toward areas of lower concentration immediately after detonation. The ${ }^{14} \mathrm{C}$ gas-phase diffusivity is approximately four orders of magnitude larger than aqueous-phase diffusivity, allowing the gas plume to expand throughout the vadose zone over relatively short time scales. Equilibrium between each phase is established as the plume volume continues to expand. Although the extent of ${ }^{14} \mathrm{C}$ transport is rather large, the phase concentrations are diluted because the radionuclide mass is distributed over a large volume and partitions among three phases. When the periphery of the plume reaches the water table, aqueous-phase ${ }^{14} \mathrm{C}$ is transported into the aquifer through advection, diffusion/dispersion, and ${ }^{14} \mathrm{CO}_{2}$ dissolution. Advection occurs as a result of background precipitation and crater-enhanced recharge infiltrating towards the aquifer. Aqueous-phase diffusion and dispersion are driven by concentration gradients that exist between the vadose zone and the flowing groundwater in the aquifer. As ${ }^{14} \mathrm{C}$ advects and diffuses, equilibrium between the aqueous phase and solid phase delays the breakthrough of mass to the aquifer depending on the magnitude of the partitioning coefficient.

The wetting front profile for the baseline is compared to the alternative recharge models in Figure 5-6. Depending on the recharge rate and playa areal extent, the wetting front will reach the aquifer at different times (or in some cases, not at all). The lateral spreading of the wetting front is due to capillary forces that draw water toward areas of lower saturation (i.e., areas of lower pressure). Modeling the 1,000-year transport times for 345 detonations with craters, McNab (2008) concludes that recharge rates significantly less than $200 \mathrm{~mm} / \mathrm{yr}$ can potentially transport nonsorbing tracers from the working point to the aquifer within 1,000 years. Given the small crater radius in the shallow test models $(50 \mathrm{~m}$ ) and a large portion of the wetting front that spreads in the lateral direction, recharge 
rates in excess of $50 \mathrm{~mm} / \mathrm{yr}$ are required to transport nonsorbing to tracers to the aquifer within 1,000 years.

The working point of the shallow test is located $\sim 350 \mathrm{~m}$ above the water table and $175 \mathrm{~m}$ bls. As determined from the yield-weighted Bowen inventory (Bowen et al., 2001) for a $20 \mathrm{kt}$ test, the ${ }^{14} \mathrm{C}$ inventory of $7.18 \times 10^{11}$ picocuries $(\mathrm{pCi})$ is uniformly distributed over the exchange volume $\left(\mathrm{r}_{\mathrm{e}}=50 \mathrm{~m}\right)$. Equilibrium between the gaseous ( 3 percent of the ${ }^{14} \mathrm{C}$ mass), aqueous (7 percent), and solid phases (90 percent) is established. The initial aqueous-phase concentration in the exchange volume is $\sim 1,030$ picocuries per liter (pCi/L). Forty years after detonation, ${ }^{14} \mathrm{CO}_{2}$ migrates through the vadose zone and begins to escape to the atmosphere. Mass breakthrough to the aquifer begins after $\sim 250$ years, when the periphery of the ${ }^{14} \mathrm{C}$ plume reaches the water table as a result of gas-phase diffusion. Mass is transferred across the water table through a combination of ${ }^{14} \mathrm{CO}_{2}$ dissolution, aqueous-phase advection due to background infiltration, and aqueous-phase diffusion/dispersion due to a concentration gradient that exists from the vadose zone to the aquifer. As shown in Figure 5-6A, the crater recharge eventually travels through the vadose zone and arrives at the water table $\sim 450$ years after detonation. At this time, the mass breakthrough is observed to rise as increasing amounts of ${ }^{14} \mathrm{C}$ are transferred across the aquifer through enhanced aqueous-phase advection and diffusion/dispersion (see Figure 5-7A). As a result of ${ }^{14} \mathrm{C}$ sorption to alluvium, the core of the plume remains $\sim 300 \mathrm{~m}$ above the water table after 1,000 years (see Figure 5-8A). Overall, less than 0.002 percent of the initial inventory is transported into the aquifer, and the peak aquifer concentration never exceeds $0.01 \mathrm{pCi} / \mathrm{L}$. Note that the peak aquifer concentration is tracked throughout the aquifer, not at a single spatial position, over the duration of the simulation. The SDWA dose limit for beta emission of ${ }^{14} \mathrm{C}$ is 2,000 pCi/L (CFR, 2008).

\subsubsection{Effect of Crater Recharge Rates}

The effects of enhanced/reduced crater recharge are examined by modifying the boundary conditions used in the baseline model. Simulations with crater-enhanced recharge rates of 5, 50, and $5,000 \mathrm{~mm} / \mathrm{yr}$ are compared to the baseline model recharge rate of $250 \mathrm{~mm} / \mathrm{yr}$. As an additional test of model sensitivity to crater recharge, the playa areal extent is expanded from one-fourth of the crater area in the baseline to the entire crater area while maintaining a recharge rate of $250 \mathrm{~mm} / \mathrm{yr}$. 


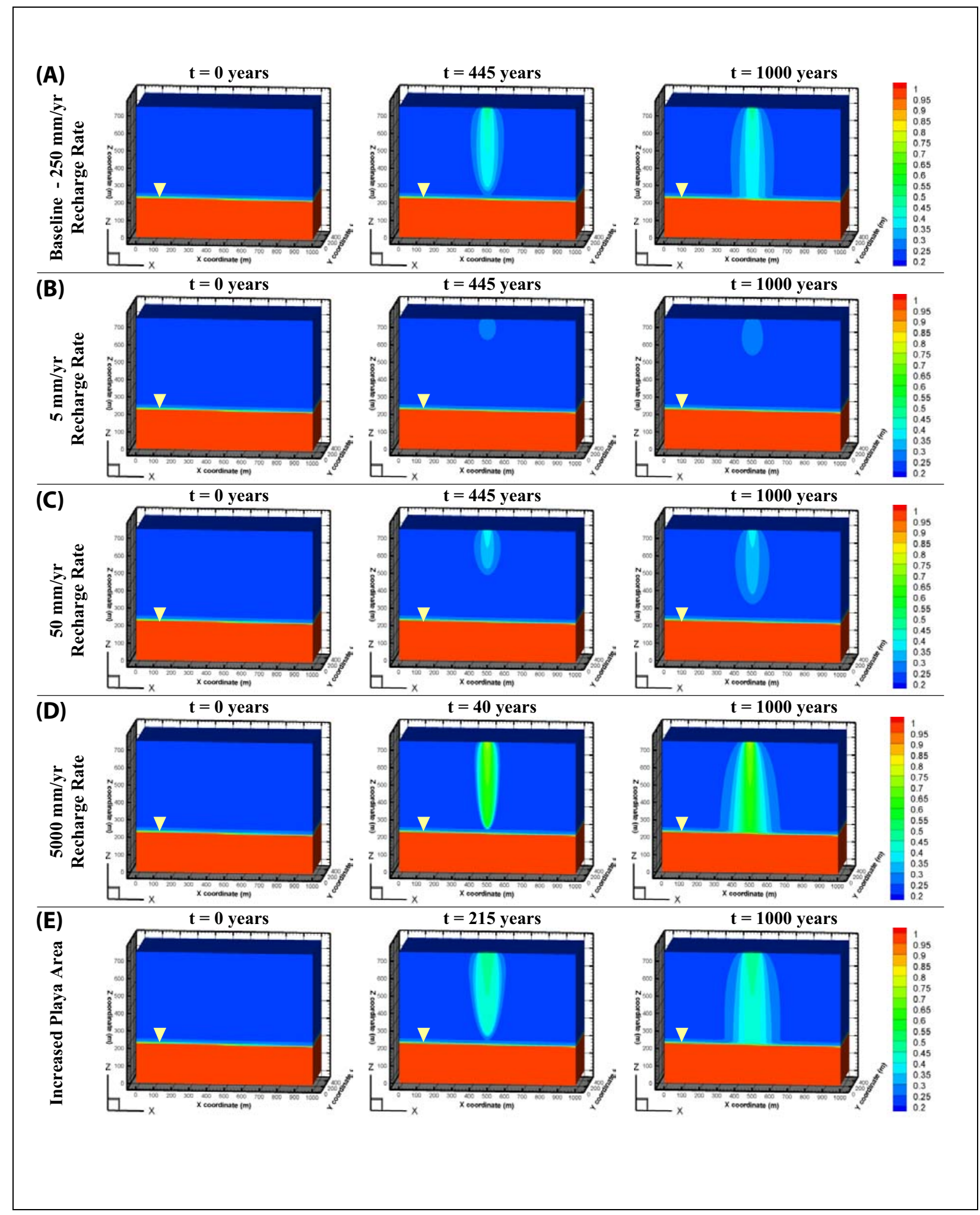

Figure 5-6

Shallow Test Saturation Profiles of Various Recharge Models

Note: The color scale represents the saturation value of each finite element volume. Note that the time intervals may differ for each respective sensitivity study. 

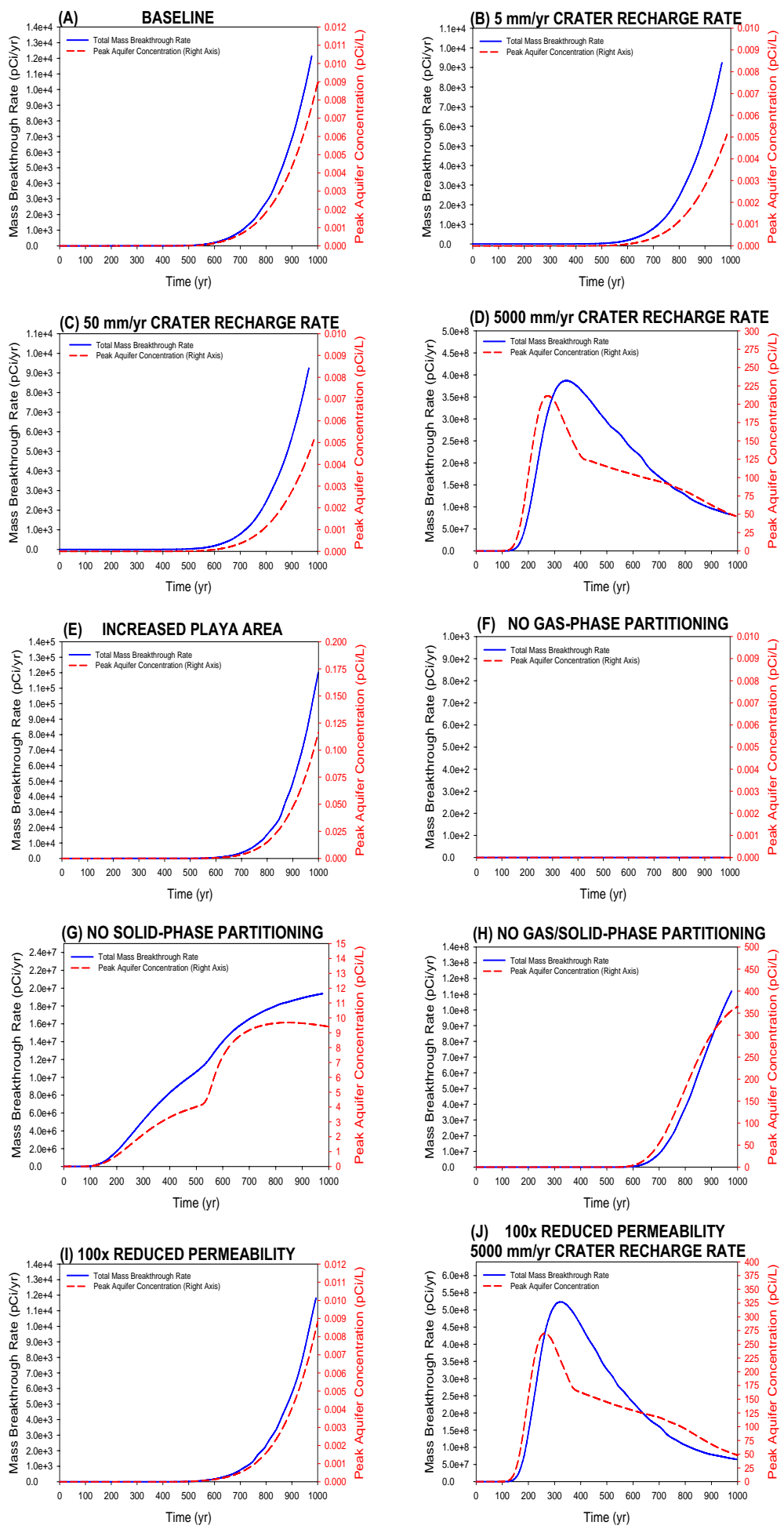

Figure 5-7

${ }^{14} \mathrm{C}$ Shallow Test Breakthrough and Peak Aquifer Concentration 


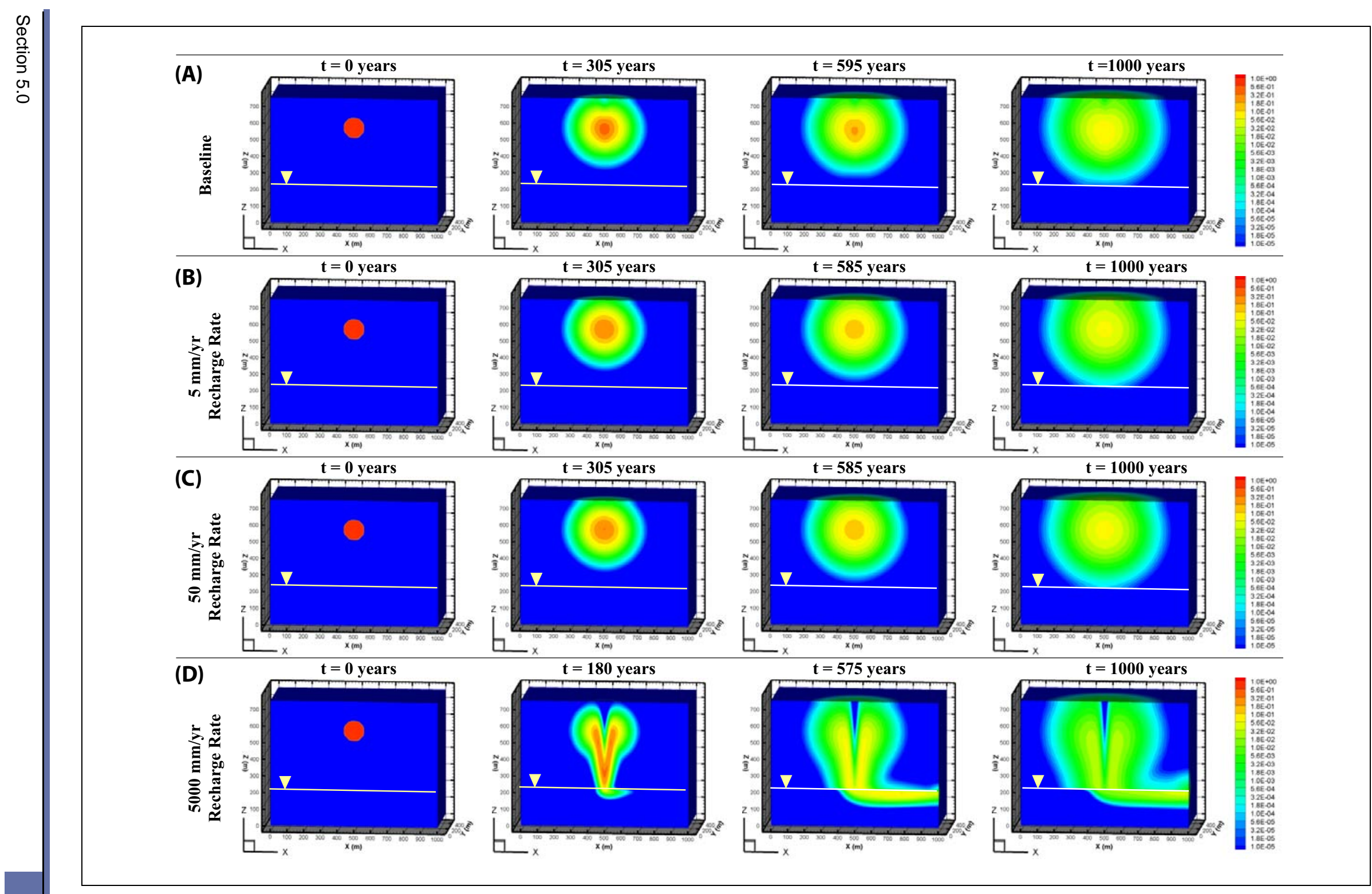

Figure 5-8

${ }^{14} \mathrm{C}$ Shallow Test Concentration Profiles of Various Recharge Models

Note: The color scale represents the current concentration relative to the initial concentration at time $t_{0}$.

Note that an exponential concentration scale is used to show the relative concentration profiles over 5 orders of magnitude. Note that the time intervals may differ for each respective sensitivity study. 
As shown in Figures 5-6B and 5-6C, when the crater recharge rate is reduced from 250 to 50 and $5 \mathrm{~mm} / \mathrm{yr}$, the wetting fronts do not reach the water table for the duration of the 1,000-year period. With reduced recharge rates, gas-phase diffusion is the only mechanism that can transport ${ }^{14} \mathrm{C}$ to the aquifer within 1,000 years. Similar behavior to the baseline model is observed, where extremely dilute concentrations are detected at the water table after $\sim 450$ years (Figures 5-8B and 5-8C). Background infiltration transfers mass across the aquifer boundary through advection, while ${ }^{14} \mathrm{CO}_{2}$ gas dissolution into the aquifer occurs via Henry's Law, and a concentration gradient at the aquifer interface is the driving force for aqueous-phase diffusion/dispersion. Because the crater recharge never reaches the aquifer, advective transport is diminished relative to the baseline (Figures 5-7B and 5-7C). In the low recharge models, less than 0.0015 percent of the initial inventory is transferred across the aquifer boundary, resulting in a peak aquifer concentrations below $0.006 \mathrm{pCi} / \mathrm{L}$.

At a high recharge rate of 5,000 mm/yr over the playa area, Figure 5-6D shows the wetting front travels to the water table in $\sim 45$ years. Aqueous-phase advection dominates radionuclide transport to the aquifer, where nearly 25 percent of the ${ }^{14} \mathrm{C}$ inventory is transported across the aquifer boundary over the 1,000-year period. As the radionuclide concentration in the flowing aquifer increases, a sharp concentration gradient develops at the aquifer boundary and causes mass transfer back into the vadose zone via diffusion and Henry’s Law partitioning (note the downgradient mass transfer illustrated in Figure 5-8D). Although mass is quickly transported to the aquifer within $\sim 45$ years, the peak aquifer concentration never exceeds $\sim 210$ pCi/L (Figure 5-7D). Nearly 85 percent of the inventory sorbs to alluvium. The recharge water dilutes the aqueous-phase plume concentration (Figure 5-8D), while gas-phase diffusion transports the radionuclide mass away from the recharge zone beneath the playa.

In addition to examining the effects of altering the crater-enhanced recharge rate, the sensitivity to the playa areal extent is evaluated by distributing the $250 \mathrm{~mm} / \mathrm{yr}$ crater recharge over the entire crater area rather than one-fourth the crater area in the baseline model. In this conceptual model, the wetting front reaches the water table in $\sim 235$ years (Figure 5-6E). Although the same recharge rate of $250 \mathrm{~mm} / \mathrm{yr}$ is applied, the wetting front reaches the water table 200 years faster than the baseline model. The fraction of water that spreads laterally due to capillarity is less for the larger recharge area, resulting in faster travel times to the aquifer. As observed in the baseline model, mass is driven to the aquifer through gas-phase diffusion and significantly diluted at the plume edges. The core of the plume migrates farther through the vadose zone than the baseline model, but remains at least 
$200 \mathrm{~m}$ above the water table after 1,000 years (see Figure 5-9B). Because the wetting front reaches the water table faster than the baseline model, an order of magnitude increase in mass transport is observed in Figure 5-7E. The increased mass breakthrough rate relative to the baseline model creates a concentration gradient that promotes mass transfer from the aquifer to the vadose zone downgradient from the plume. The peak aquifer concentration is larger than the baseline model but does not exceed $0.15 \mathrm{pCi} / \mathrm{L}$.

\subsubsection{Effect of Gas- and Solid-phase Partitioning}

The effects of including vapor-liquid and liquid-solid equilibrium partitioning are compared with the baseline model in Figures 5-7 and 5-10. The baseline recharge rate is held at $250 \mathrm{~mm} / \mathrm{yr}$ while independently disabling gas- and solid-phase partitioning. In addition, the effect of disabling both gas- and solid-phase partitioning concurrently is investigated.

To evaluate the effects of ${ }^{14} \mathrm{C}$ vapor-liquid equilibrium, gas-phase partitioning is disabled within the model. The wetting front reaches the water table after 450 years and transports ${ }^{14} \mathrm{C}$ through the vadose zone by aqueous-phase advection, diffusion and dispersion. In this case, the extent of radionuclide migration is dictated by the magnitude of the sorption coefficient. Thus, two conceptual models have been constructed using a $\mathrm{K}_{\mathrm{d}}$ value of $0.8 \mathrm{~mL} / \mathrm{g}$ (no gas-phase partitioning) and $0.0 \mathrm{~mL} / \mathrm{g}$ (no gas/solid-phase partitioning). When including sorption $\left(\mathrm{K}_{\mathrm{d}}=0.8 \mathrm{~mL} / \mathrm{g}\right), 93$ percent of the radionuclide mass initially partitions to the solid-phase, while the remaining portion is present in the aqueous-phase. The aqueous phase concentration is $\sim 1,075 \mathrm{pCi} / \mathrm{L}$ within the exchange volume. The plume core travels only $\sim 100 \mathrm{~m}$ from the working point and is $\sim 200 \mathrm{~m}$ above the water table. As shown in Figure 5-10B, the $\mathrm{K}_{\mathrm{d}}$ value is sufficiently large to the extent that the plume never reaches the water table over the duration of the 1,000-year period. However, when adsorption and gas-phase partitioning are neglected, all the radionuclide mass is in the aqueous-phase with a concentration of $\sim 15,452 \mathrm{pCi} / \mathrm{L}$ within the exchange volume. Carbon-14 reaches the aquifer before 600 years (see Figure 5-10D) and increases the peak aquifer concentration to $\sim 365 \mathrm{pCi} / \mathrm{L}$ at 1,000 years (Figure 5-7H). Although this concentration is below the maximum contaminant level (MCL), it clearly demonstrates the impact of sorption as a ${ }^{14} \mathrm{C}$ attenuation mechanism.

When enabling gas-phase partitioning and assuming a $\mathrm{K}_{\mathrm{d}}$ value of $0.0 \mathrm{~mL} / \mathrm{g}$ (no solid-phase partitioning), 32 percent of the mass initially partitions to the gas-phase and reduces the 

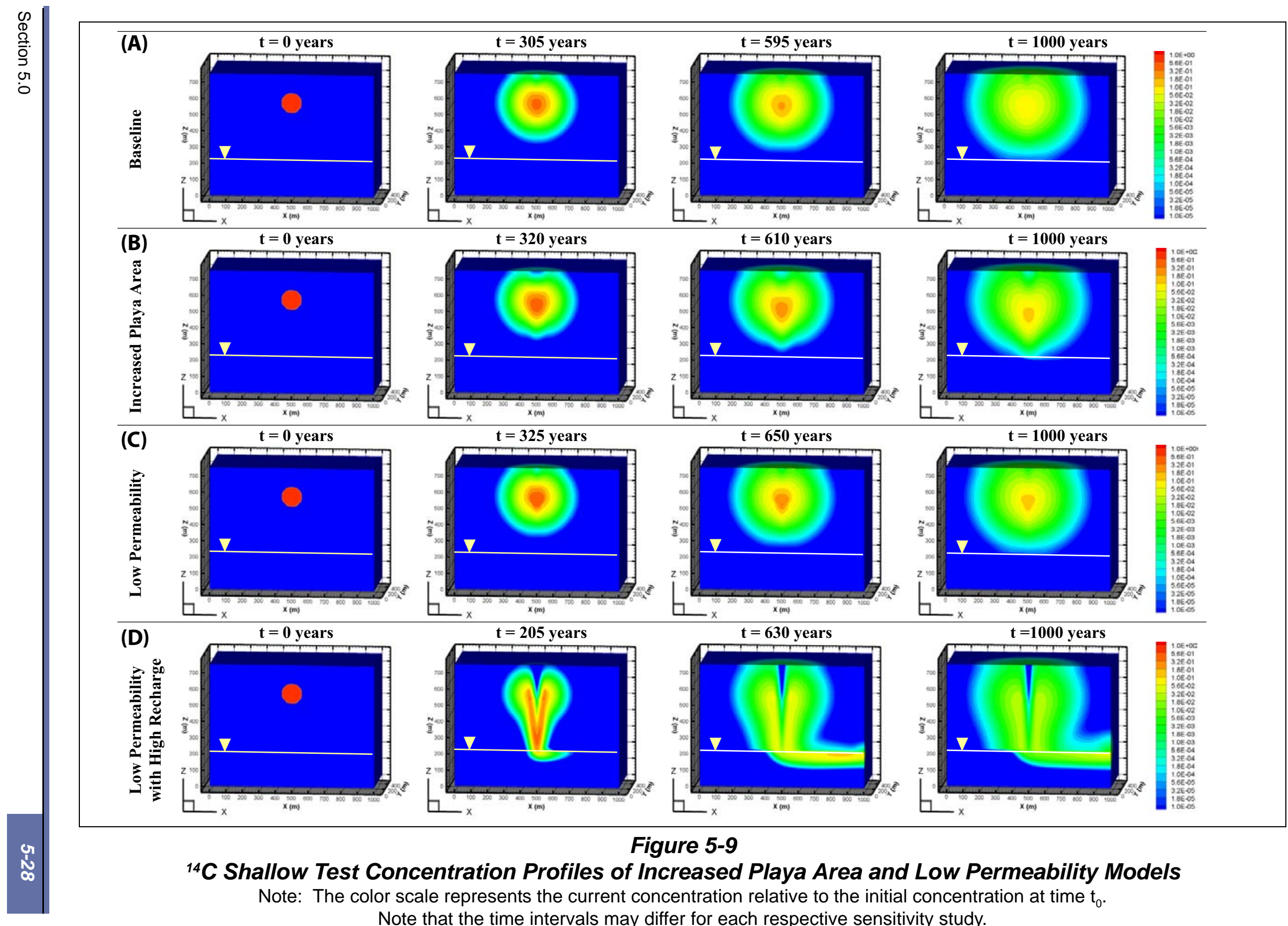

Figure 5-9

${ }^{14} \mathrm{C}$ Shallow Test Concentration Profiles of Increased Playa Area and Low Permeability Models

Note: The color scale represents the current concentration relative to the initial concentration at time $t_{0}$.

Note that the time intervals may differ for each respective sensitivity study. 


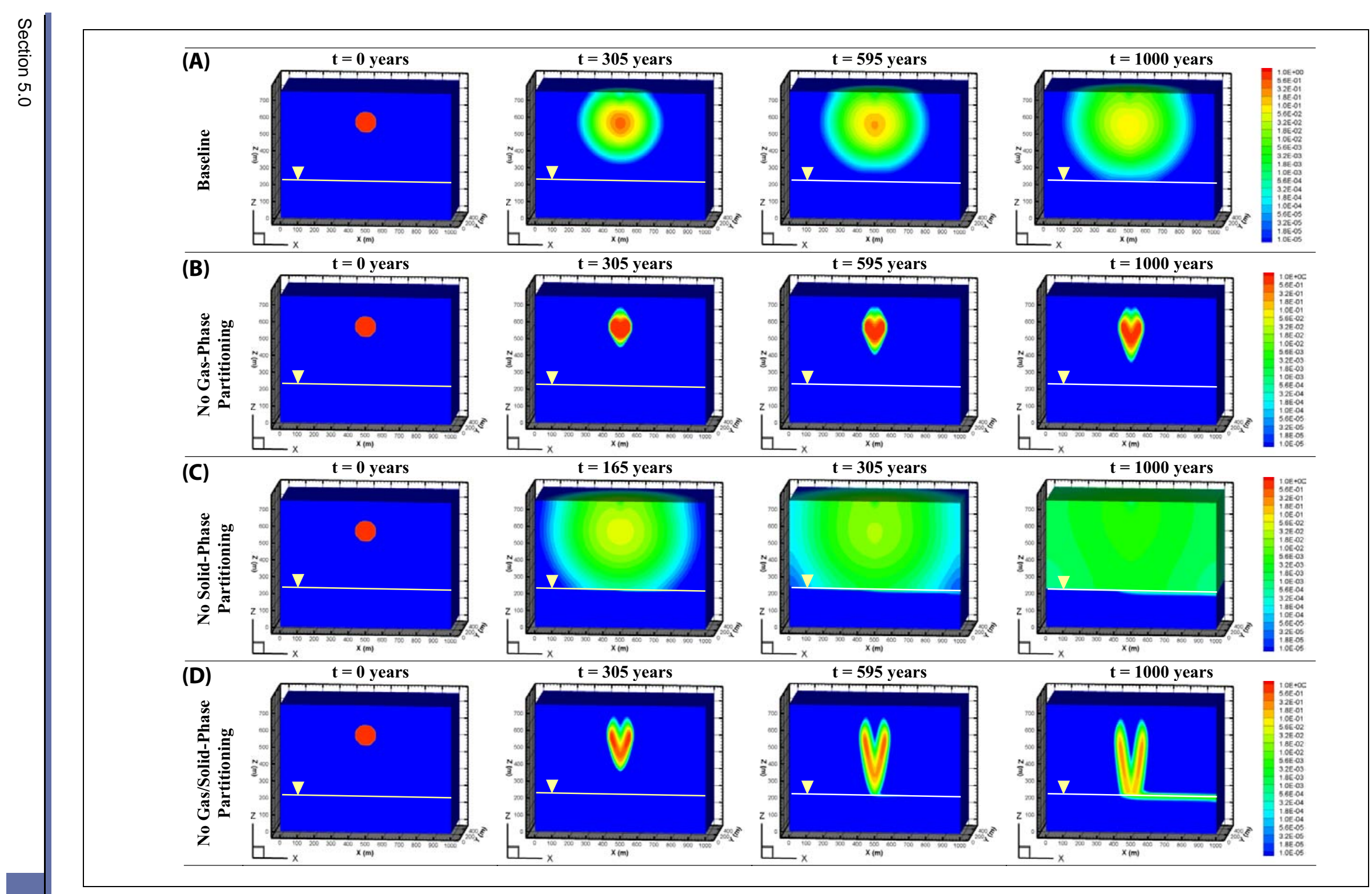

Figure 5-10

${ }^{14} \mathrm{C}$ Shallow Test Concentration Profiles of Gas/Solid-phase Partitioning Models Note: The color scale represents the current concentration relative to the initial concentration at time $\mathrm{t}_{0}$. Note that the time intervals may differ for each respective sensitivity study. 
aqueous-phase concentration to $\sim 9,462 \mathrm{pCi} / \mathrm{L}$ within the exchange volume. The breakthrough in Figure 5-7G shows two distinct regions. At early breakthrough, there is a linear increase in mass transfer to the aquifer. Carbon-14 is transported to the water table through gas-phase diffusion (Figure 5-10C) and is transferred across the aquifer boundary via diffusion/dispersion, Henry’s Law partitioning, and advective mass transport (background infiltration). Because solid-liquid equilibrium is neglected, aqueous-phase ${ }^{14} \mathrm{C}$ will move with the wetting front. As the wetting front reaches the water table, the crater recharge transports additional mass into the aquifer via advection and increases the breakthrough for the duration of the simulation. With no solid-phase partitioning to the matrix via adsorption, the peak aquifer concentration is a maximum after 750 years (Figure 5-7G), but does not exceed $10 \mathrm{pCi} / \mathrm{L}$. This conceptual model illustrates the intricate role of gas-phase partitioning to dilute the exchange volume concentration well below the MCL, especially in the absence of sorption.

\subsubsection{Effect of Crushed Zone Hydraulic Properties}

Failure of the alluvium rock as a result of the shock wave after detonation can lead to drastically different hydraulic properties within the crushed zone that may have a profound impact on radionuclide attenuation (Pawloski, 1999; Tompson et al., 2005; Maxwell et al., 2008). The transient CAMBRIC HST modeling (Carle et al., 2007) used a vertical to horizontal permeability anisotropy ratio of 0.5 in the alluvium at the CAMBRIC working point. The CAMBRIC HST modeling reduced the crushed zone permeability by a factor of 100 in the horizontal direction and 50 in the vertical direction, while simultaneously reducing the porosity from 0.32 to 0.27 . In this analysis, anisotropy is not considered and the crushed zone permeability of the shallow test is reduced by a factor of 100 in all directions, while simultaneously decreasing the porosity from 0.412 to 0.27 . Crater-enhanced recharge rates of 250 and 5,000 mm/yr are investigated and compared with the respective baseline and high recharge models described in Section 5.4.1.1.

The saturation profiles for low permeability/porosity studies are illustrated in Figure 5-11. When a $250 \mathrm{~mm} / \mathrm{yr}$ crater-enhanced recharge rate is applied over the playa area, the wetting front reaches the aquifer after $\sim 450$ years. As the wetting front moves through the disturbed zone, the crushed zone saturation increases to $\sim 0.8$, shown by the color contrast in Figure 5-11B. At a high crater-enhanced recharge rate of 5,000 mm/yr, the wetting front reaches the water table in $\sim 40$ years. Given that the 


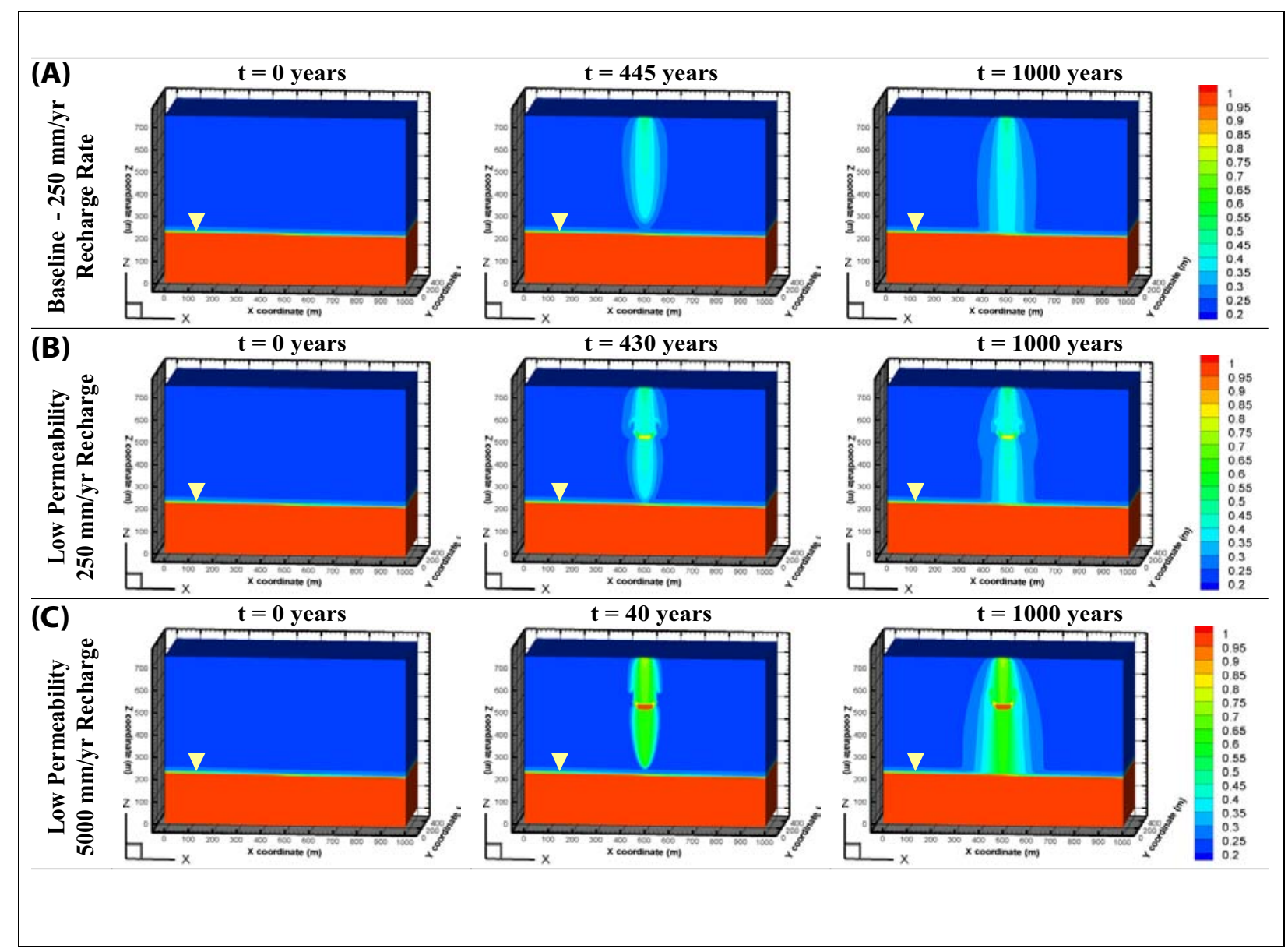

Figure 5-11

Shallow Test Saturation Profiles of the Low Permeability/Low Porosity Models

Note: The color scale represents the saturation of each finite element volume.

Note that the time intervals may differ for each respective sensitivity study.

recharge rate is larger than the saturated hydraulic conductivity, the crushed zone becomes saturated, resulting in water perching shown in Figure 5-11C.

The 250 and 5,000 mm/yr low permeability/porosity model breakthrough and peak aquifer concentrations are compared with the baseline and high recharge models in Figure 5-7. The main difference between the models is the mechanism of transport to the aquifer. By lowering the permeability/porosity, a barrier to gas-phase diffusion develops as a result of the increasing moisture content when the wetting front arrives at the exchange volume. The saturation barrier restricts gas-phase transport and confines radionuclide mass within the cavity. As the wetting front moves through the exchange volume, it encounters higher concentrations of radionuclide mass than the baseline model (see Figure 5-9C) and transports the mass out of the exchange volume by 
aqueous-phase advection. The peak aquifer concentration for the $250 \mathrm{~mm} / \mathrm{yr}$ low permeability/porosity model is $\sim 0.009 \mathrm{pCi} / \mathrm{L}$ (Figure 5-7I), which is essentially the same as the baseline model. For the high recharge model, the peak aquifer concentration increases from 210 to $270 \mathrm{pCi} / \mathrm{L}$ (Figure 5-7J) when including the permeability effects. Overall, the effect of altering the hydraulic properties of the crushed zone has a surprisingly small influence on the breakthrough curves and peak aquifer concentrations for the shallow test conducted within alluvium.

\subsubsection{Baseline Carbon-14 Transport for a Deep Test}

The working point for the deep test is located $435 \mathrm{~m}$ bls and $91 \mathrm{~m}$ above the water table. The bottom boundary of the exchange volume $\left(r_{e}=90 \mathrm{~m}\right)$ is only $1 \mathrm{~m}$ above the water table. A crater recharge rate is applied over a relatively large playa area with a radius of $50 \mathrm{~m}$ (i.e., the crater radius is $100 \mathrm{~m}$ ). As determined from the Bowen inventory (Bowen et al., 2001) for a $150 \mathrm{kt}$ test, the ${ }^{14} \mathrm{C}$ inventory of $5.39 \times 10^{12} \mathrm{pCi}$ is distributed uniformly over the exchange volume. The full suite of sensitivity models summarized in Table 5-4 are conducted for ${ }^{14} \mathrm{C}$ transport from a deep test.

For the baseline model, the initial aqueous-phase concentration in the exchange volume is $\sim 2,300 \mathrm{pCi} / \mathrm{L}$, which is just above the SDWA (CFR, 2008) regulatory limit. Assuming a background infiltration rate of $1 \mathrm{~mm} / \mathrm{yr}$ and given the proximity of the exchange volume to the water table, mass transfer across the aquifer boundary begins immediately after detonation. At early breakthrough, ${ }^{14} \mathrm{CO}_{2}$ dissolution via Henry's Law partitioning and aqueous-phase diffusion/dispersion dominate mass transfer due to the existence of a sharp concentration gradient across the aquifer interface (see Figure 5-12A). In addition, a small amount of mass advects across the aquifer boundary as a result of background infiltration. For the baseline sensitivity study (250 mm/yr crater recharge), the wetting front reaches the water table after 235 years (see Figure 5-13A), consistent with the results obtained by McNab (2008) using a $125 \mathrm{~m}$ crater radius. A large amount of mass is transported into the aquifer via advection. Meanwhile, as the mass flows downgradient, a concentration gradient from the aquifer to the vadose zone arises, causing mass transfer back into the vadose zone (see Figure 5-14A). Because the radionuclide mass reaches the aquifer quickly, it is transmitted downgradient and exits the model boundary after 235 years. As shown in Figure 5-12A, the peak aquifer concentration profile shows two distinct periods. The peak aquifer concentration steadily increases to $\sim 125 \mathrm{pCi} / \mathrm{L}$ over the first 200 years, then rapidly increases to a maximum of $\sim 690 \mathrm{pCi} / \mathrm{L}$ 

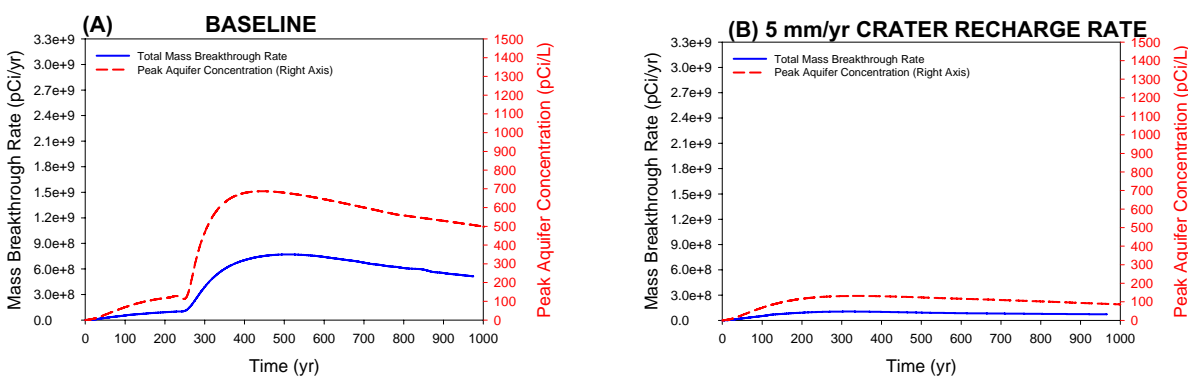

(C) $50 \mathrm{~mm} / \mathrm{yr}$ CRATER RECHARGE RATE

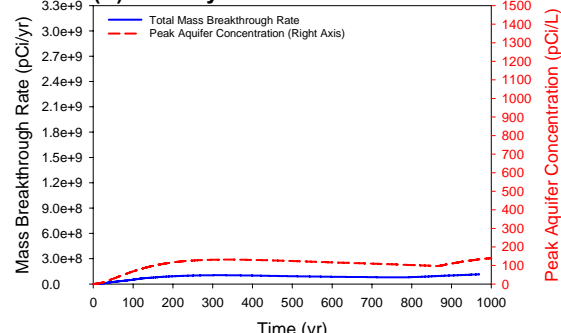

(D) $5000 \mathrm{~mm} / \mathrm{yr}$ CRATER RECHARGE RATE
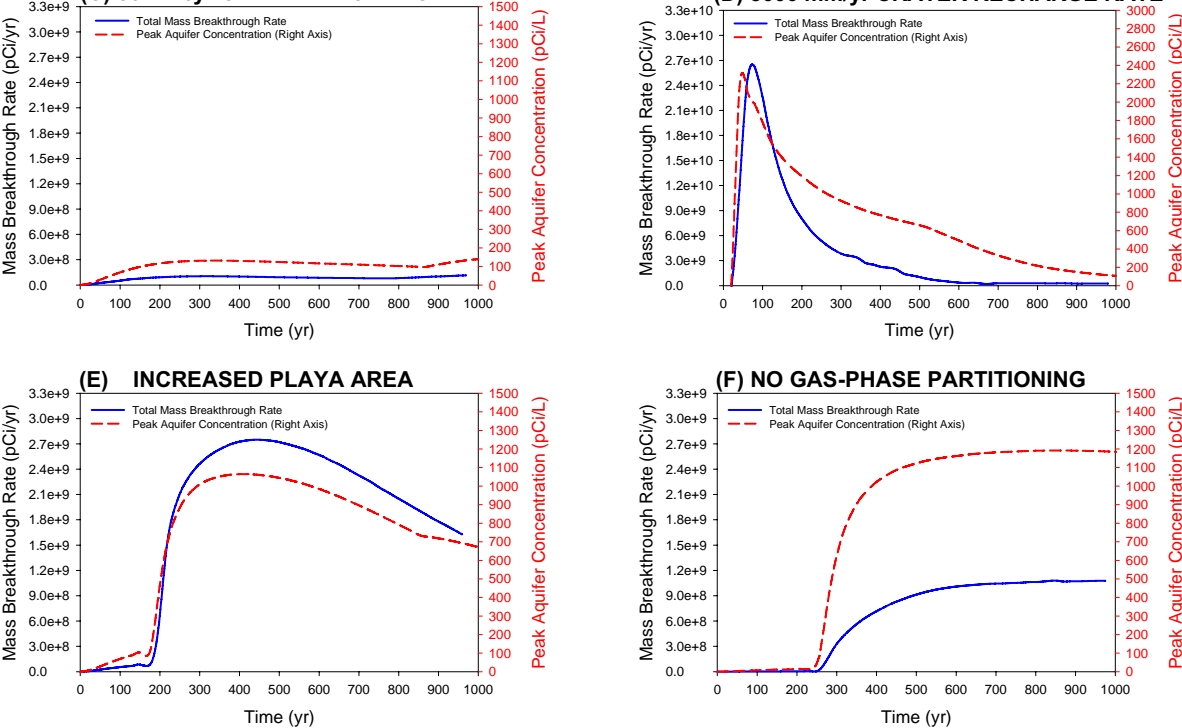

(G) NO SOLID-PHASE PARTITIONING

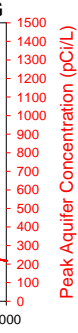

(H) NO GAS/SOLID-PHASE PARTITIONING
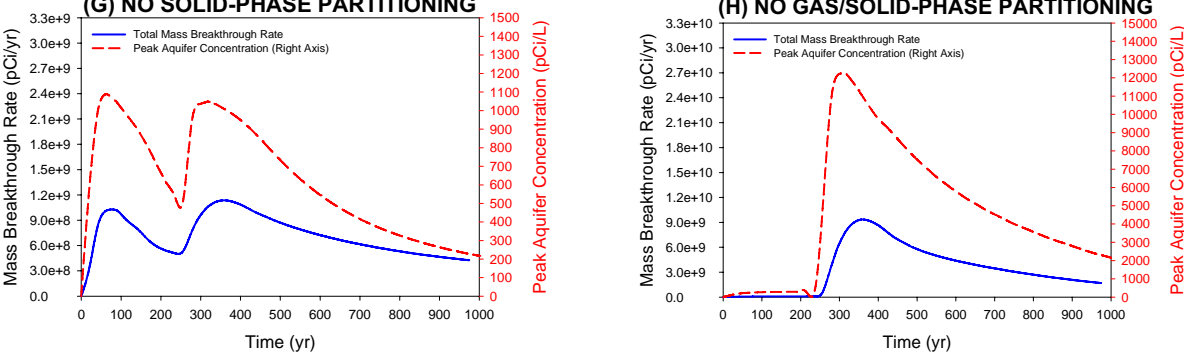

(I) 100x REDUCED PERMEABILITY

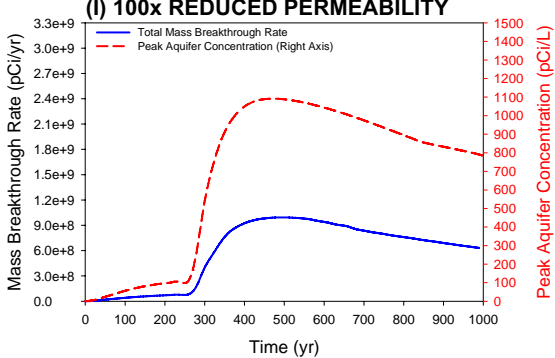

(J) 100x REDUCED PERMEABILITY $5000 \mathrm{~mm} / \mathrm{yr}$ CRATER RECHARGE RATE

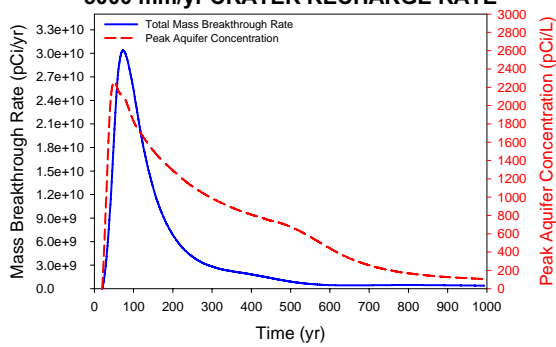

Figure 5-12

${ }^{14} \mathrm{C}$ Deep Test Breakthrough and Peak Aquifer Concentration 


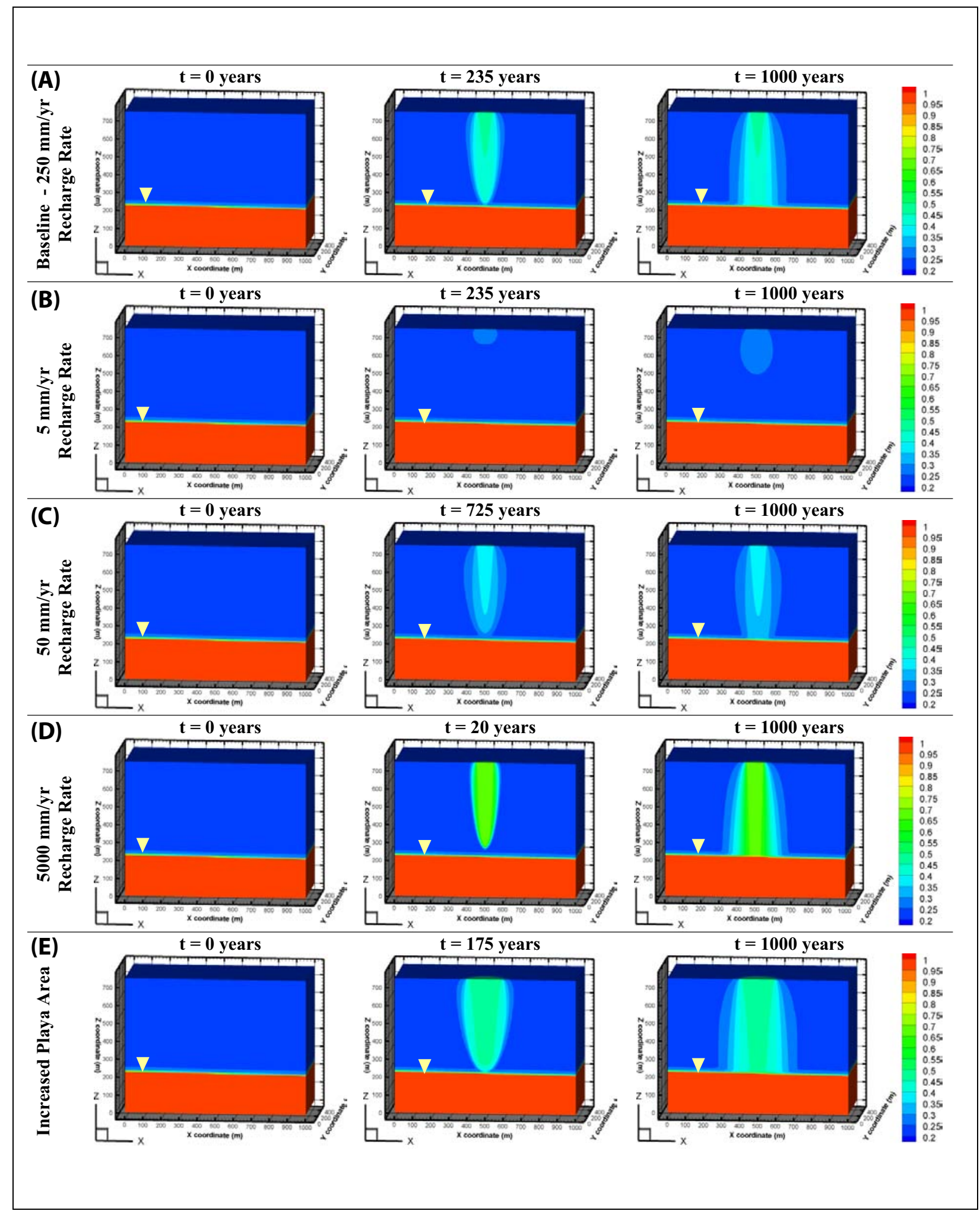

Figure 5-13

Deep Test Saturation Profiles of the Various Recharge Models

Note: The color scale represents the saturation of each finite element volume.

Note that the time intervals may differ for each respective sensitivity study. 


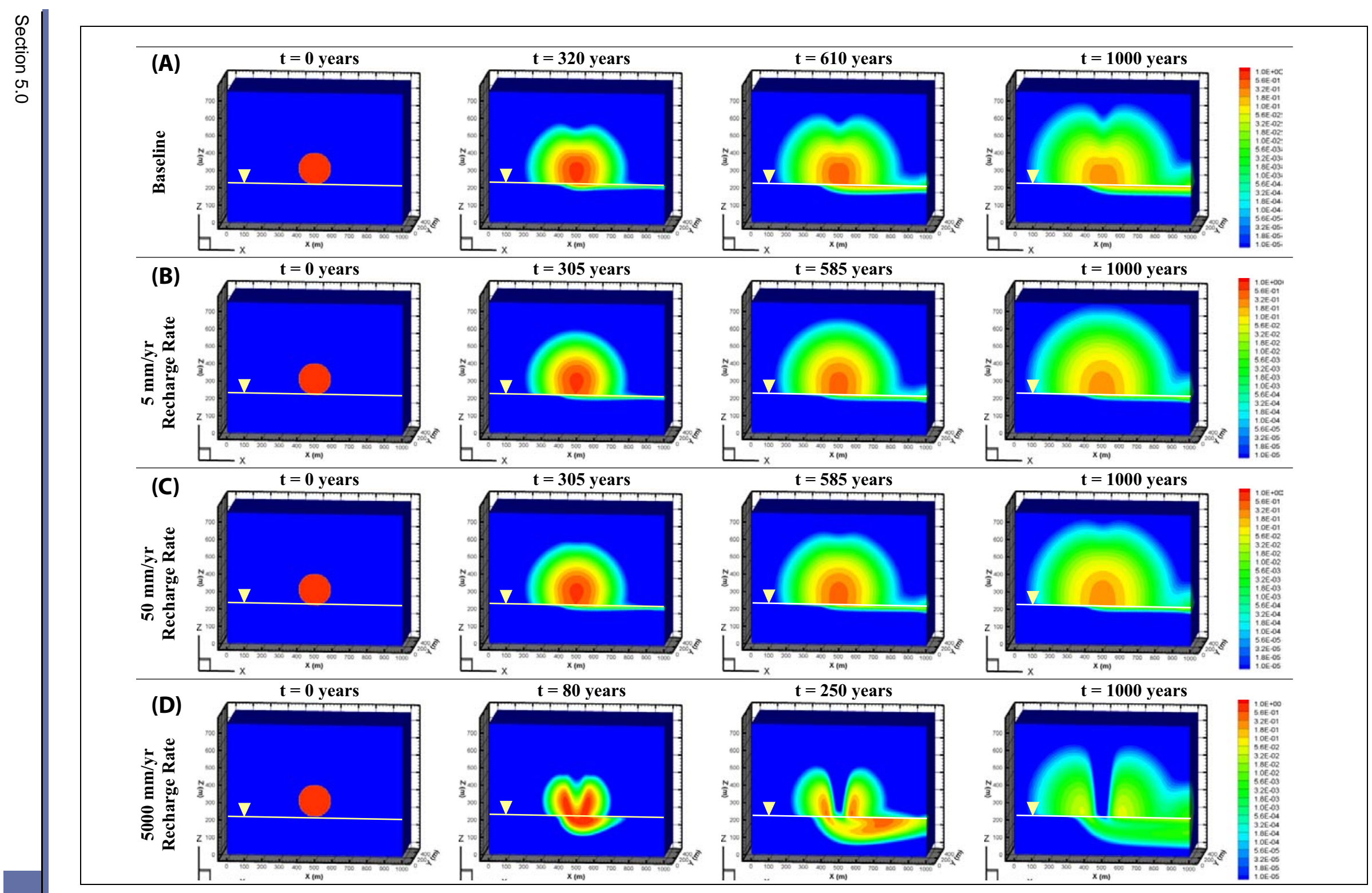

Figure 5-14

${ }^{14} \mathrm{C}$ Deep Test Concentration Profiles of Various Recharge Models

Note: The color scale represents the current concentration relative to the initial concentration at time $t_{0}$ Note that the time intervals may differ for each respective sensitivity study. 
after 400 years, before decreasing to $\sim 500 \mathrm{pCi} / \mathrm{L}$ after 1,000 years. Overall, $\sim 9.4$ percent of the initial inventory is transported to the aquifer over 1,000 years.

\subsubsection{Effect of Crater Recharge Rates}

By reducing the crater recharge rate to $50 \mathrm{~mm} / \mathrm{yr}$, the wetting front arrival time to the aquifer is delayed until $~ 725$ years after detonation, as shown in Figure 5-13C. During this period, a portion of the inventory diffuses radially outward from the working point, spreads across the vadose zone via gas-phase diffusion (see Figure 5-14C), and adsorbs to the solid-phase. Small amounts of mass are transferred across the aquifer boundary through background advection, Henry's Law partitioning, and diffusion/dispersion. A significant increase in advective transport is shown in Figure 5-12C at 800 years as a result of the crater-enhanced recharge arriving at the water table. The peak aquifer concentration reaches a maximum of $132 \mathrm{pCi} / \mathrm{L}$ at $\sim 350$ years, then decreases steadily to $\sim 97 \mathrm{pCi} / \mathrm{L}$ at $\sim 850$ years. Once the crater recharge reaches the exchange volume, there is a second increase in the peak aquifer concentration to $\sim 140 \mathrm{pCi} / \mathrm{L}$ at 1,000 years. Overall, a total of 1.5 percent of the test inventory is transported to the aquifer over 1,000 years, representing a reduction of mass breakthrough and peak aquifer concentration as compared to the baseline model.

Over the first 800 years, reduction of the crater recharge to $5 \mathrm{~mm} / \mathrm{yr}$ results in similar behavior to the $50 \mathrm{~mm} / \mathrm{yr}$ recharge model. Because the wetting front never reaches the water table for the duration of the 1,000-year period (see Figure 5-13B), there is no increase in mass transfer to the aquifer through advection at late breakthrough times. As observed in the $50 \mathrm{~mm} / \mathrm{yr}$ recharge model and shown in Figure 5-14B, a portion of the inventory diffuses throughout the vadose zone, diluting the concentration over a large volume. Over a 1,000-year period, only 1.5 percent of the test inventory is transported to the aquifer via background advection and aqueous-phase diffusion/dispersion. Thus, Figure 5-12B shows the peak aquifer concentration exhibits a maximum of $132 \mathrm{pCi} / \mathrm{L}$ at $\sim 350$ years, then steadily decreases to $\sim 85 \mathrm{pCi} / \mathrm{L}$.

At a high recharge rate of 5,000 mm/yr, Figure 5-13D shows the wetting front reaches the water table in 20 years, significantly faster than the baseline model. A maximum in mass breakthrough (Figure 5-12D) to the aquifer is observed $\sim 70$ years after detonation. Advection dominates mass transfer across the aquifer. As ${ }^{14} \mathrm{C}$ mass travels downgradient, sharp concentration gradients from the aquifer to the vadose zone develop, increasing the tendency for mass diffusion/dispersion and direct 
partitioning into the gaseous phase back to the vadose zone. The peak aquifer concentration of $\sim 2,137 \mathrm{pCi} / \mathrm{L}$ occurs $\sim 60$ years after detonation and declines to $\sim 106 \mathrm{pCi} / \mathrm{L}$ at 1,000 years.

Figure 5-14D shows that the clean water infiltrates to the water table, dilutes the concentration, and flushes the contamination downgradient. Nearly 77 percent of the initial inventory is transferred to the aquifer in the high recharge case, resulting in a peak aquifer concentration that is comparable with the MCL of 2,000 pCi/L.

The mass breakthrough and peak aquifer concentration of the baseline model are compared when increasing the playa area to the entire crater area, while maintaining a $250 \mathrm{~mm} / \mathrm{yr}$ crater-enhanced recharge rate. By increasing the playa area, the wetting front reaches the water table in 175 years as compared to 235 years for the baseline model (see Figure 5-13E). Advection due to crater-enhanced recharge dominates mass transfer to the aquifer from 175 through 1,000 years. As shown in Figure 5-12E, the breakthrough curve exhibits a maximum at $\sim 485$ years, followed by a slow decrease over the 1,000-year period. Due to the increased playa area, 33 percent of the initial inventory is transferred across the aquifer boundary as compared to only $~ 9$ percent in the baseline model. The peak aquifer concentration is higher than the baseline model, where a concentration of $\sim 1,065 \mathrm{pCi} / \mathrm{L}$ is observed at $\sim 400$ years and decreases to $670 \mathrm{pCi} / \mathrm{L}$ after 1,000 years.

Overall, increasing the crater-enhanced recharge rate and increasing the playa area result in peak aquifer concentrations that are higher than the baseline model. The high recharge model represents the highest risk scenario, where the peak aquifer concentration is of the same magnitude of the MCL. Surprisingly, the combination of gas- and solid-phase partitioning of ${ }^{14} \mathrm{C}$ significantly attenuate mass transfer to the aquifer, even in cases where the test borders the aquifer. For tests conducted above the aquifer and in the vadose zone, these results suggest that sufficient quantities of ${ }^{14} \mathrm{C}$ are not transported to the aquifer for the 1,000-year duration.

\subsubsection{Effect of Gas- and Solid-phase Partitioning}

When gas-phase partitioning is disabled (no gas-phase partitioning), advection is the primary mechanism of ${ }^{14} \mathrm{C}$ transport. At early breakthrough, background infiltration pushes ${ }^{14} \mathrm{C}$ across the aquifer boundary (Figure 5-12F). After 235 years, the wetting front reaches the water table and drives an increased amount of mass to the aquifer where it begins to migrate downgradient (see Figure 5-15B). The peak aquifer concentration plateaus at $\sim 1,190 \mathrm{pCi} / \mathrm{L}$ after $\sim 600$ years. 
Overall, 12.5 percent of the initial inventory is transported to the aquifer when the gas-phase partitioning is disabled.

When gas- and solid-phase partitioning are not included (no gas/solid-phase partitioning), $\sim 76$ percent of the initial ${ }^{14} \mathrm{C}$ inventory is transported into the aquifer as the wetting front approaches because there are no attenuation mechanisms. Because no gas-phase diffusion occurs, the wetting front bisects a concentrated exchange volume and pushes the contaminant to the aquifer. A total of 76 percent of the initial inventory is transported to the aquifer. As shown in Figure 5-12H, a maximum in the mass breakthrough curve is observed 360 years after detonation, resulting in a peak aquifer concentration of $\sim 12,200 \mathrm{pCi} / \mathrm{L}$. As more clean water infiltrates, the peak aquifer concentration becomes diluted and steadily declines to 2,150 pCi/L after 1,000 years (see Figure 5-15D).

In the case where gas-phase partitioning is enabled and the sorption coefficient is $0.07 \mathrm{~mL} / \mathrm{g}$ (no solid-phase partitioning), two maxima are observed in the breakthrough profile in Figure 5-12G. The first maximum represents mass transfer at early breakthrough that is due to precipitation, diffusion/dispersion, and Henry’s Law partitioning. Because no adsorption to alluvium occurs, the background infiltration transports significant quantities of ${ }^{14} \mathrm{C}$ across the aquifer boundary through advection. Further, the sharp concentration gradient across the aquifer boundary promotes aqueous-phase diffusion/dispersion and Henry’s Law partitioning (see Figure 5-15C). After 235 years, the wetting front reaches the water table, advecting additional mass into the aquifer as represented by the second maximum in the breakthrough plot. The peak aquifer profile also shows two peaks at $\sim 65$ and $\sim 320$ years with concentrations of $\sim 1,090$ and 1,050 pCi/L, corresponding to background infiltration and the enhanced crater recharge, respectively. Through this conceptual model, the impact of gas-phase partitioning is clearly demonstrated, where only 16 percent as compared to 76 percent (no gas/solid-phase partitioning) of the initial inventory is transported to the aquifer. This results in a significantly lower peak concentration of $\sim 1,090 \mathrm{pCi} / \mathrm{L}$ as compared to when gas-phase partitioning was neglected ( 12,200 pCi/L).

\subsubsection{Effect of Crushed Zone Hydraulic Properties}

The effect of reducing the permeability/porosity of the crushed zone is evaluated for the deep test. The concentration profiles are shown in Figure 5-16. Recharge rates of 250 and 5,000 mm/yr are 


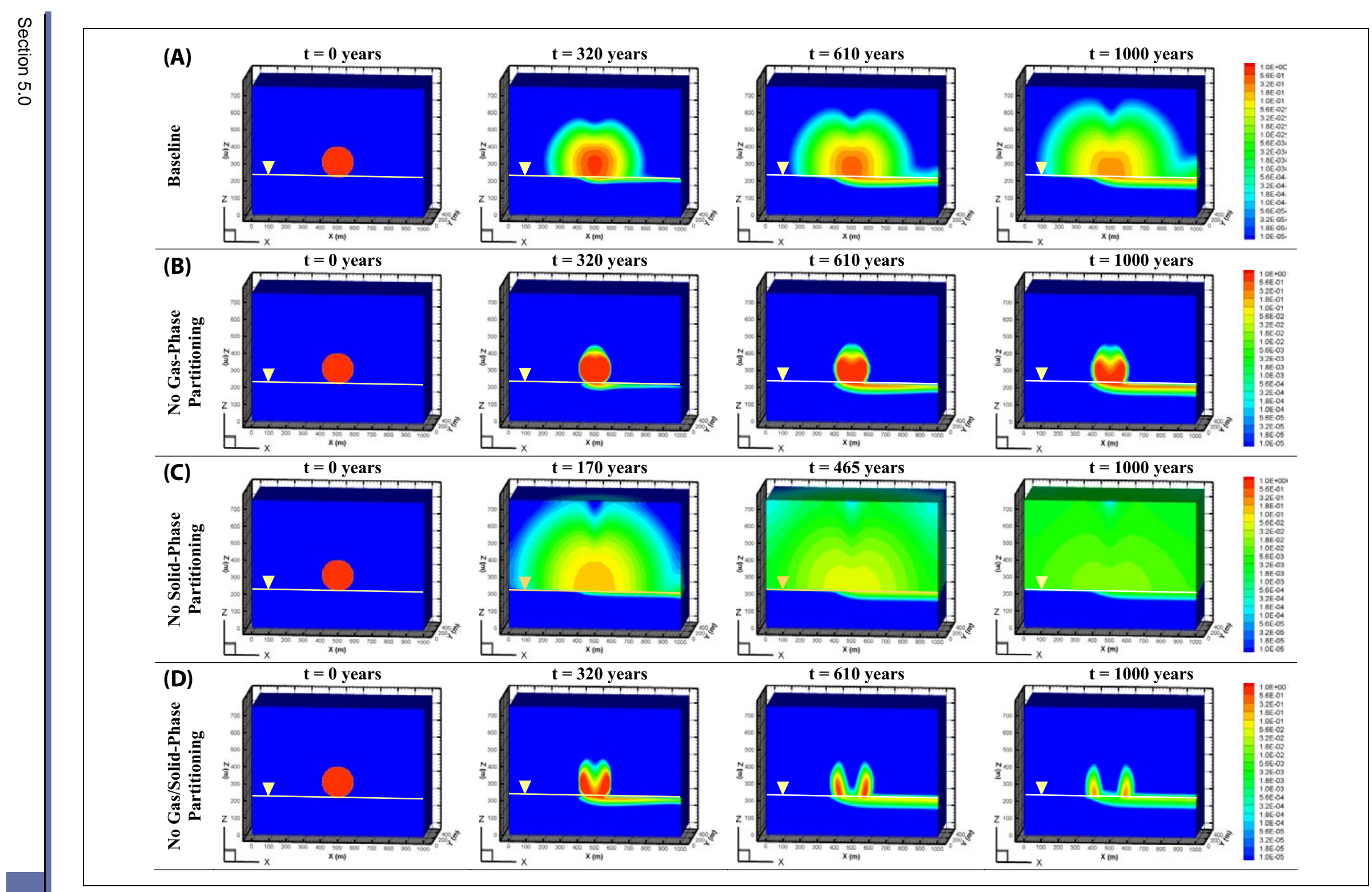

Figure 5-15

${ }^{14} \mathrm{C}$ Deep Test Concentration Profiles of Gas/Solid-phase Partitioning Models

Note: The color scale represents the current concentration relative to the initial concentration at time $t_{0}$ Note that the time intervals may differ for each respective sensitivity study. 


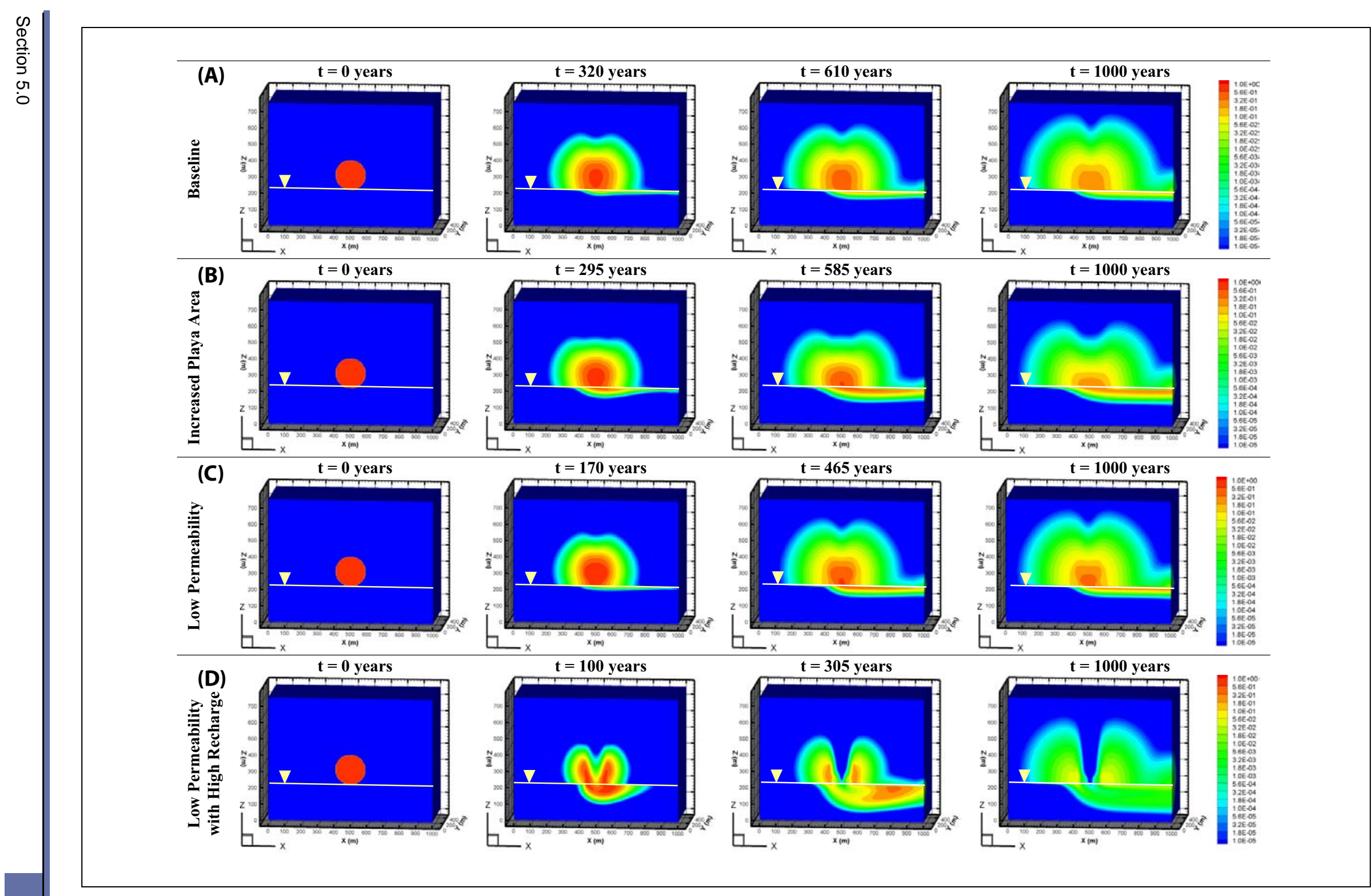

Figure 5-16

${ }^{14} \mathrm{C}$ Deep Test Concentration Profiles of Increased Playa Area and Low Permeability Models Note: The color scale represents the current concentration relative to the initial concentration at time $\mathrm{t}_{0}$. Note that the time intervals may differ for each respective sensitivity study. 
compared to the baseline and high recharge deep test results presented in Section 5.4.2.1. As illustrated in Figure 5-17B, the crater-enhanced recharge arrives at the water table in 235 years when a $250 \mathrm{~mm} / \mathrm{yr}$ recharge rate is applied. As the wetting front infiltrates, portions of the crushed zone increase to near saturated conditions, clearly shown by the color contrast in Figure 5-17B. The increase in moisture content creates a barrier to gas-phase diffusion and effectively confines ${ }^{14} \mathrm{C}$ within the cavity. Relative to the baseline model, higher aqueous-phase concentrations are present within the exchange volume at the time when crater-enhanced recharge enters. Thus, increased advective mass transport across the aquifer boundary is observed in Figure 5-12I when lowering the permeability/porosity. The amount of ${ }^{14} \mathrm{C}$ transported across the water table is $\sim 11$ percent of the initial inventory, resulting in a peak aquifer concentration of $\sim 1,090 \mathrm{pCi} / \mathrm{L}$ as compared to the baseline model of $\sim 690 \mathrm{pCi} / \mathrm{L}$.

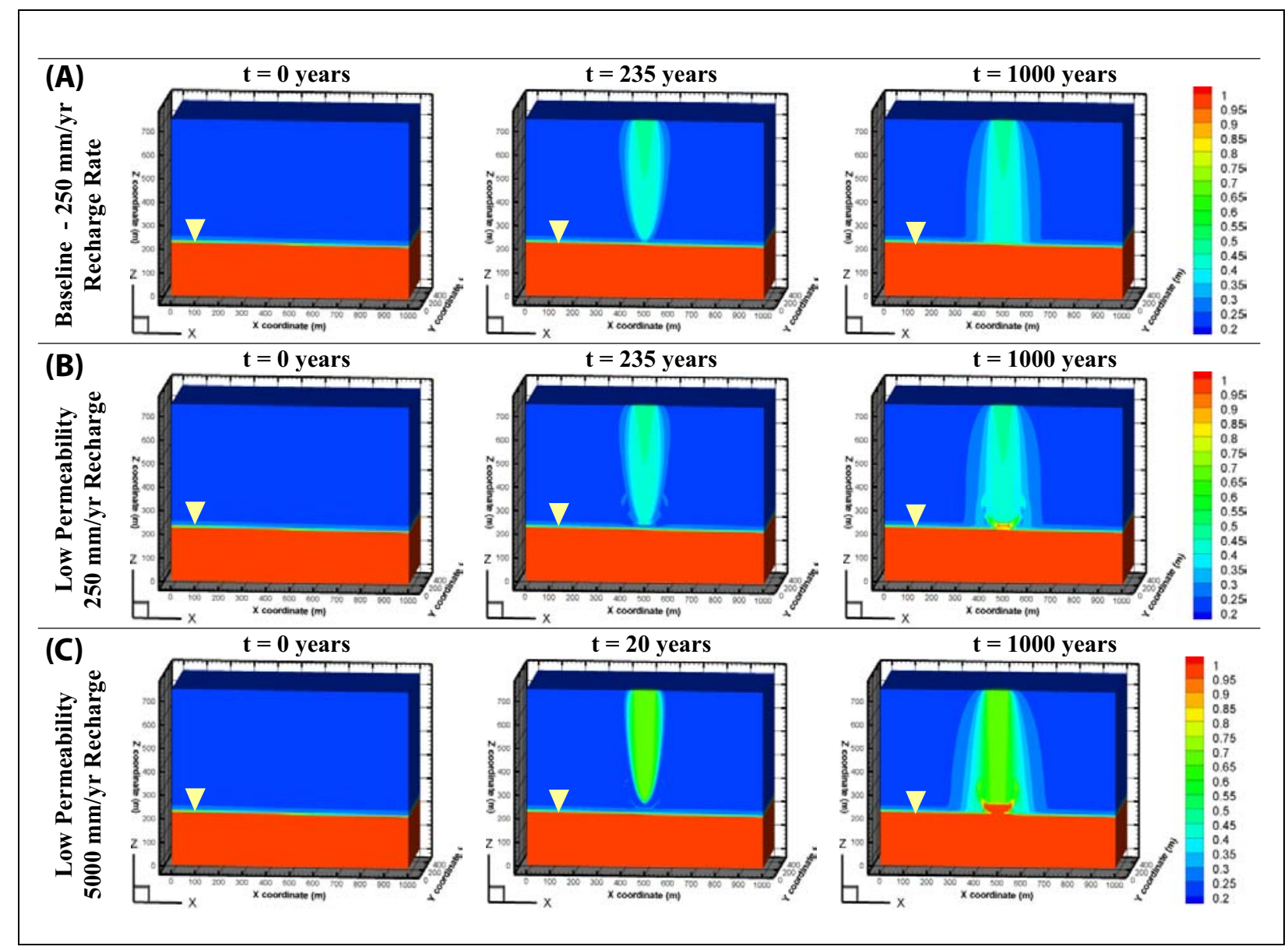

Figure 5-17

Deep Test Saturation Profiles of the Low Permeability/Low Porosity Models

Note: The color scale represents the saturation of each finite element volume and that the time intervals may differ for each respective sensitivity study. 
At a high crater-enhanced recharge rate of 5,000 mm/yr, the wetting front reaches the water table in 20 years (Figure 5-17C). Given that the recharge rate is larger than the saturated hydraulic conductivity, the crushed zone becomes saturated, resulting in water perching. In comparison to the high recharge model (Figure 5-12D) that excludes crushed zone permeability effects, Figure 5-12J shows the ${ }^{14} \mathrm{C}$ breakthrough behavior is essentially the same, where the peak aquifer concentration is $\sim 2,120 \mathrm{pCi} / \mathrm{L}$ when including the crushed zone permeability/porosity effects. As concluded from the shallow test, the overall effect of altering the hydraulic properties of the crushed zone has a relatively small influence on the breakthrough curves and peak aquifer concentrations as compared to effects of gas- and solid-phase partitioning.

\subsubsection{Tritium Transport for a Shallow Test}

The shallow baseline model for ${ }^{3} \mathrm{H}$ transport is introduced to illustrate the important processes included in the conceptual model. Tritium transport is examined with a background infiltration rate of $1 \mathrm{~mm} / \mathrm{yr}$ and a crater-enhanced recharge of $250 \mathrm{~mm} / \mathrm{yr}$ distributed over the playa area (i.e., the playa radius is one-half of the crater radius). Tritium has a very short half-life of 12.3 years, which has a profound effect on the amount of radionuclide mass breakthrough and peak aquifer concentration. Gas-phase partitioning is included in the sensitivity models, where the gas-water partitioning coefficient for ${ }^{3} \mathrm{H}$ is $43.3 \mathrm{~atm}^{-1}$. A sorption coefficient describing the interaction between aqueous-phase ${ }^{3} \mathrm{H}$ and alluvium is neglected in all but two of the sensitivity models (i.e., the "No Solid-Phase Partitioning” and “No Gas, but Solid-Phase Partitioning” [Table 5-4]), where a $0.05 \mathrm{~mL} / \mathrm{g}$ sorption coefficient is used. The crushed-zone permeability and porosity are assumed to be equivalent to the undisturbed alluvium properties in the baseline model.

As determined from the Bowen inventory (Bowen et al., 2001) for a $20 \mathrm{kt}$ test, the ${ }^{3} \mathrm{H}$ inventory of $9.31 \times 10^{15} \mathrm{pCi}$ is uniformly distributed over the exchange volume $\left(\mathrm{r}_{\mathrm{e}}=50 \mathrm{~m}\right)$, where equilibrium between the gaseous and aqueous phases is established. Essentially all of the inventory partitions to the aqueous-phase, while negligible amounts are present in the gaseous-phases. The initial aqueous-phase concentration is $\sim 2.0 \times 10^{8} \mathrm{pCi} / \mathrm{L}$. In comparison with ${ }^{14} \mathrm{C}$ transport, a significantly smaller portion of the inventory partitions into the gas phase given the smaller gas-phase partition coefficient. Gas-phase diffusion effects that were so critical in attenuating ${ }^{14} \mathrm{C}$ transport are significantly diminished for ${ }^{3} \mathrm{H}$. Advection is considerably more important for ${ }^{3} \mathrm{H}$, where background infiltration as well as crater-enhanced recharge infiltrate towards the aquifer. As an additional 
attenuating effect, the ${ }^{3} \mathrm{H}$ half-life is much smaller than the ${ }^{14} \mathrm{C}$ half-life, leading to a significant amount of radionuclide decay. Short time-scale transport processes that influence breakthrough in less than 200 years are critical to move sufficient concentrations of ${ }^{3} \mathrm{H}$ across the water table.

The wetting front profile for the baseline is compared to the alternative recharge models in Figure 5-6. The baseline wetting front travels to the aquifer in $\sim 450$ years. Because ${ }^{3} \mathrm{H}$ decays to negligible concentrations faster than the wetting front travel time to the aquifer, crater recharge rates at or below $250 \mathrm{~mm} / \mathrm{yr}$ did not result in any breakthrough across the aquifer boundary for the shallow test (see Figures 5-18, 5-19, and 5-20). Further, the gas-water partitioning coefficient is small, causing an overwhelming portion of the ${ }^{3} \mathrm{H}$ inventory to partition into the aqueous-phase. Therefore, because ${ }^{3} \mathrm{H}$ decays to negligible concentrations within 200 years, the sensitivity models that include recharge rates at $250 \mathrm{~mm} / \mathrm{yr}$ and smaller are not discussed. For the shallow test, the high recharge models are the only cases where ${ }^{3} \mathrm{H}$ transport to the aquifer becomes an issue.

\subsubsection{Effect of High Crater-enhanced Recharge on Tritium Transport}

For crater-enhanced recharge rates of 5,000 mm/yr in the shallow model, the wetting front reaches the water table in $\sim 40$ years (Figure 5-6D). Given the small influence of gas-phase partitioning, ${ }^{3} \mathrm{H}$ is transported to the aquifer via advection as the wetting front approaches the water table. As shown in Figure 5-21A, the peak aquifer concentration is $\sim 340,000 \mathrm{pCi} / \mathrm{L}$, which is significantly higher than the MCL of 20,000 pCi/L. After 110 years, the ${ }^{3} \mathrm{H}$ concentration decreases below the MCL. Reduction of the crushed zone permeability/porosity results in similar breakthrough behavior. However, an increase in peak aquifer concentration is observed due to the confining effects of the low permeability/porosity crushed zone. In this case, the peak aquifer concentration is $\sim 600,000 \mathrm{pCi} / \mathrm{L}$ and decays below the MCL after $\sim 117$ years (Figure 5-21B). Surprisingly, only $\sim 0.18$ percent and $\sim 0.37$ percent of the initial ${ }^{3} \mathrm{H}$ inventory is transported across the boundary over 200 years due to the rapid decay of ${ }^{3} \mathrm{H}$ in the models excluding and including the crushed zone effects, respectively. This emphasizes the fact that the ${ }^{3} \mathrm{H}$ inventory is nearly four orders of magnitude larger than the ${ }^{14} \mathrm{C}$ inventory and poses significant risk in the event of high recharge rates. 

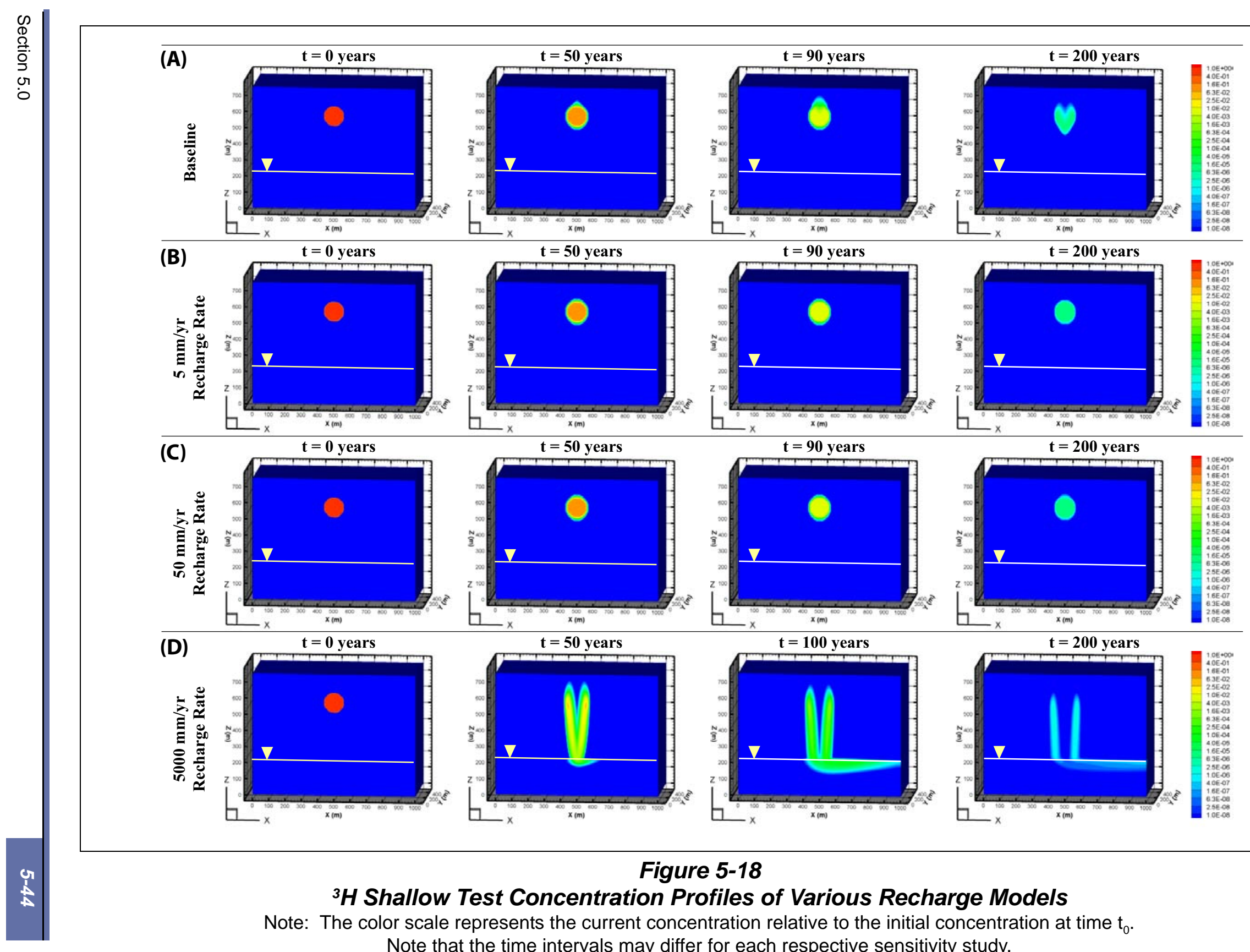

Figure 5-18

${ }^{3} \mathrm{H}$ Shallow Test Concentration Profiles of Various Recharge Models

Note: The color scale represents the current concentration relative to the initial concentration at time $t_{0}$. Note that the time intervals may differ for each respective sensitivity study. 

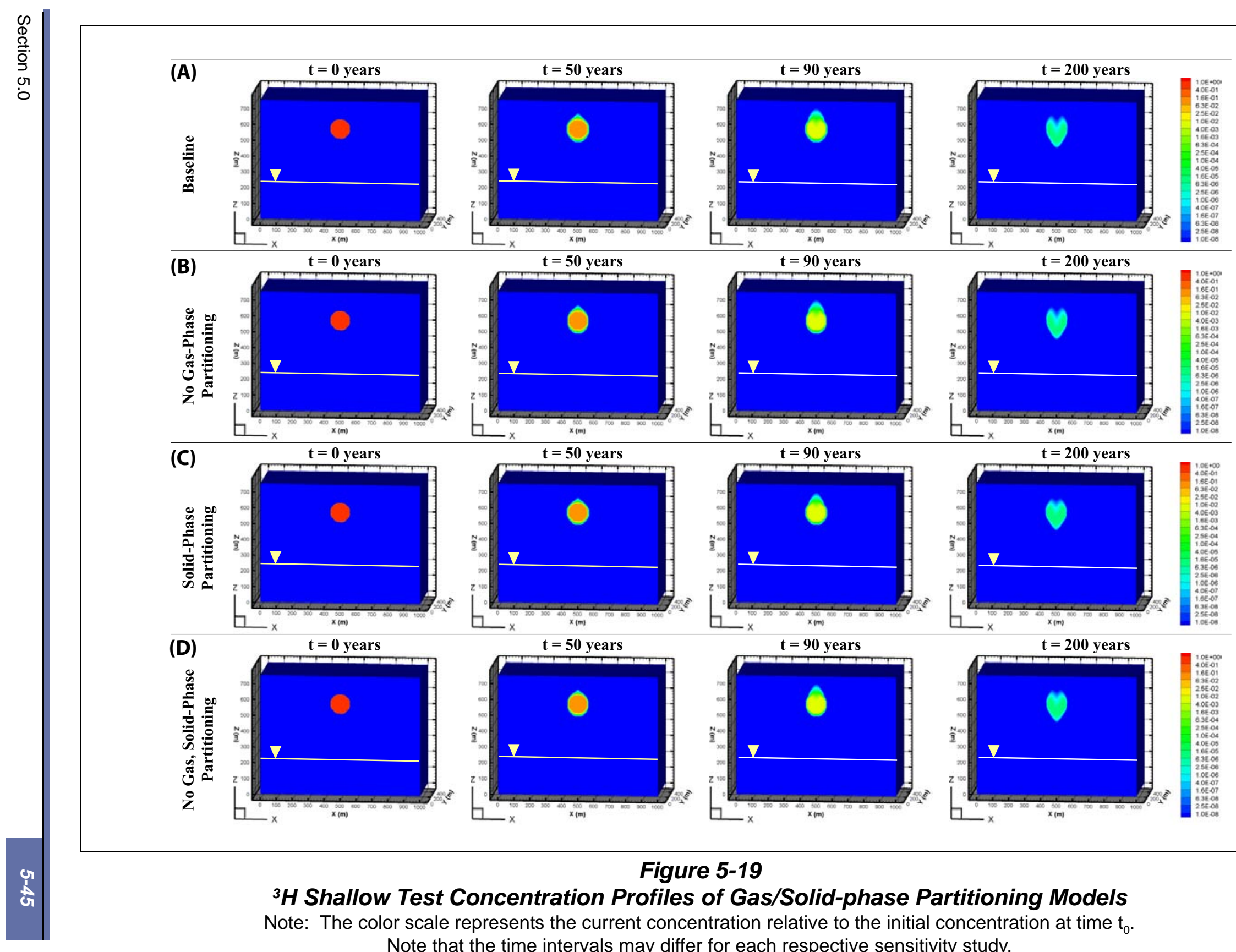

Figure 5-19

${ }^{3} \mathrm{H}$ Shallow Test Concentration Profiles of Gas/Solid-phase Partitioning Models Note: The color scale represents the current concentration relative to the initial concentration at time $\mathrm{t}_{0}$. Note that the time intervals may differ for each respective sensitivity study. 

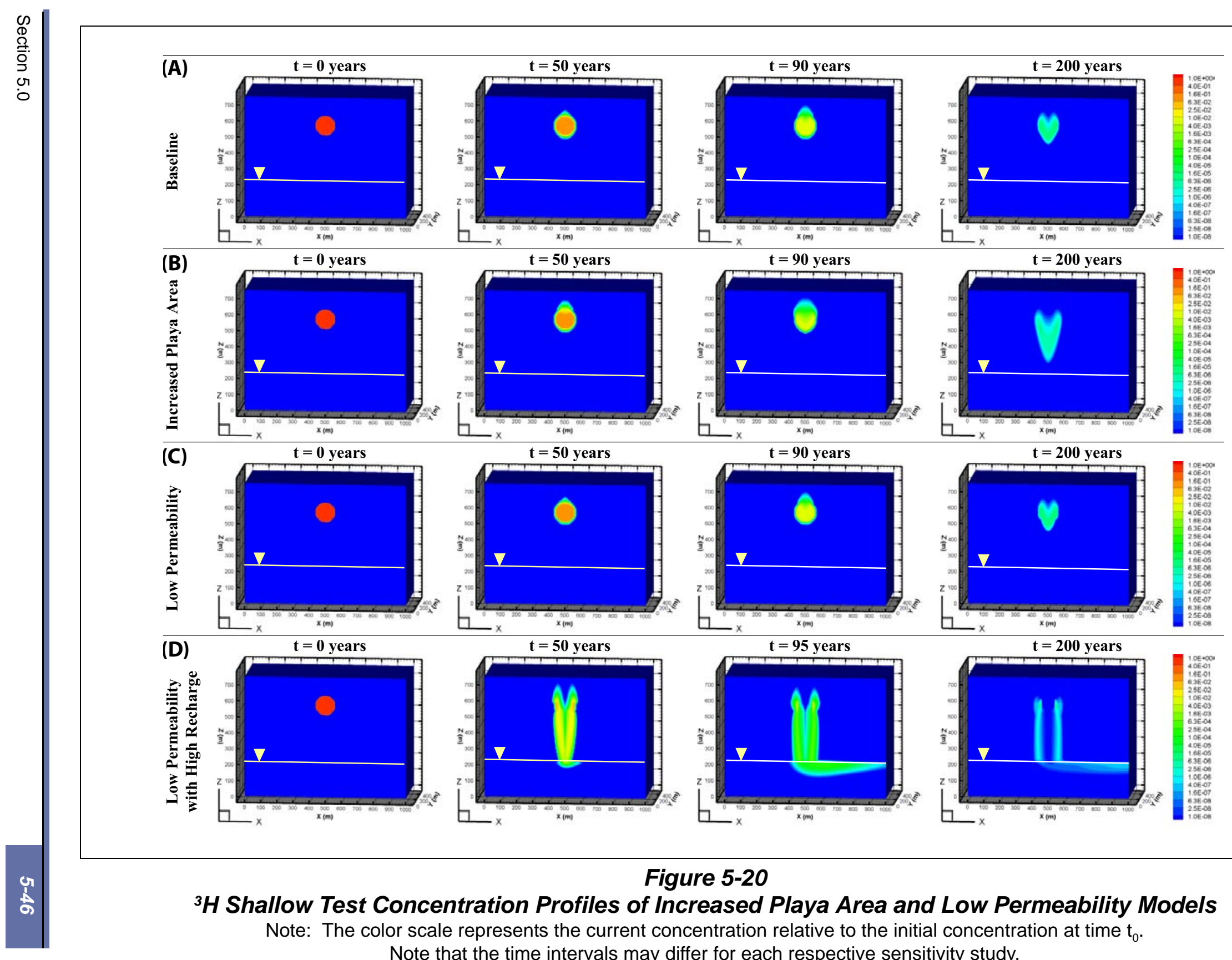

Figure 5-20

${ }^{3} \mathrm{H}$ Shallow Test Concentration Profiles of Increased Playa Area and Low Permeability Models Note: The color scale represents the current concentration relative to the initial concentration at time $\mathrm{t}_{0}$.

Note that the time intervals may differ for each respective sensitivity study. 


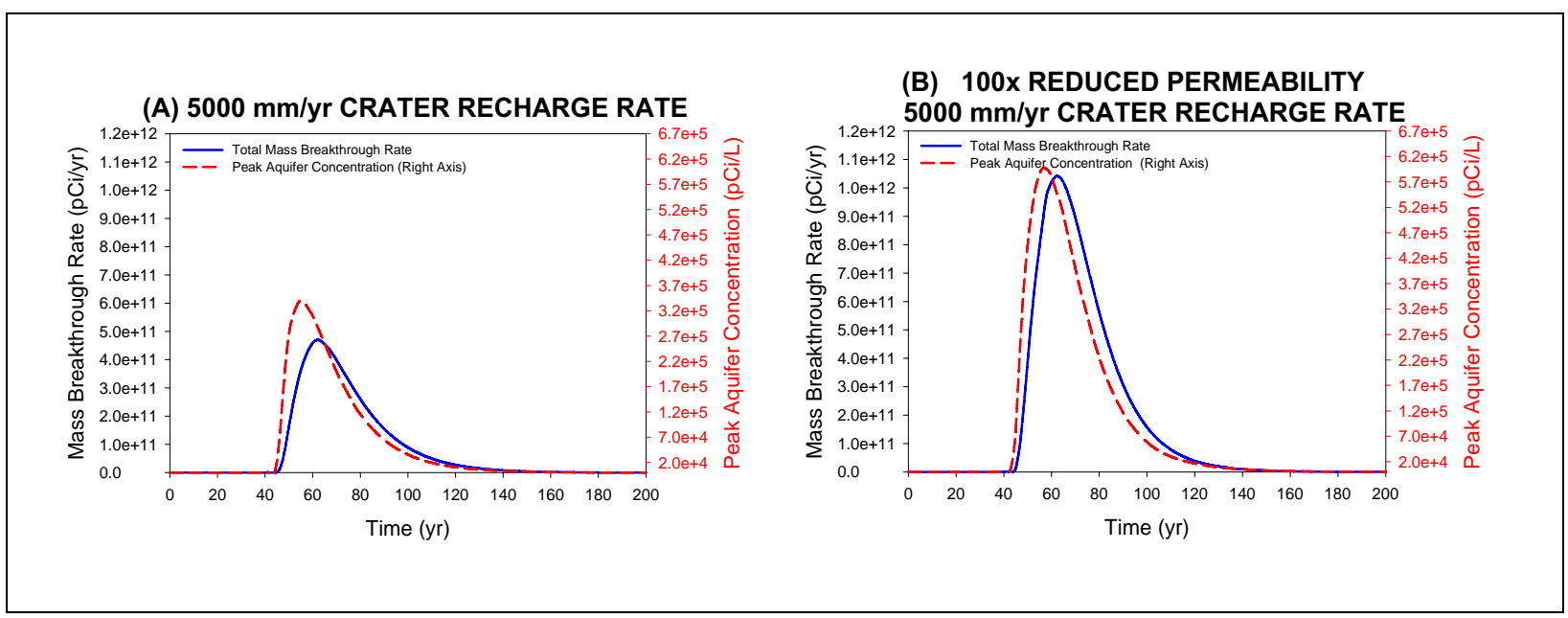

Figure 5-21

${ }^{3} \mathrm{H}$ Shallow Test Breakthrough and Peak Aquifer Concentration

\subsubsection{Tritium Transport for a Deep Test}

The working point for the deep test is located $435 \mathrm{~m}$ bls and $91 \mathrm{~m}$ above the water table. A crater recharge rate is applied over a relatively large playa area with a radius of $50 \mathrm{~m}$. As determined from the Bowen inventory (Bowen et al., 2001) for a $150 \mathrm{kt}$ test, the ${ }^{3} \mathrm{H}$ inventory of $6.98 \times 10^{16} \mathrm{pCi}$ is uniformly distributed over the exchange volume $\left(\mathrm{r}_{\mathrm{e}}=90 \mathrm{~m}\right)$. The initial aqueous-phase concentration is $\sim 4.4 \times 10^{8} \mathrm{pCi} / \mathrm{L}$. The bottom boundary of the exchange volume $\left(\mathrm{r}_{\mathrm{e}}=90 \mathrm{~m}\right)$ is only $1 \mathrm{~m}$ above the water table.

In the baseline deep test, ${ }^{3} \mathrm{H}$ is transported to the aquifer immediately after detonation. Aqueous-phase advection and diffusion/dispersion are the two mechanisms that transport mass across the water table. The background precipitation pushes ${ }^{3} \mathrm{H}$ across the aquifer boundary through advection. The baseline wetting front travel time to the aquifer is greater than 200 years (Figure 5-13A); thus, it has no influence on ${ }^{3} \mathrm{H}$ breakthrough. The driving force for diffusion/dispersion is the sharp concentration gradient across the aquifer. The breakthrough curve in Figure 5-22A shows a maximum at 16 years, then sharply declines four orders of magnitude at 200 years due to radioactive decay. Interestingly, over the course of 200 years, only 0.011 percent of the initial ${ }^{3} \mathrm{H}$ inventory ever crosses the aquifer boundary. The peak aquifer concentration occurs 20 years after detonation and is $\sim 450,000$ picocuries per year (pCi/yr), which is well above the MCL of 20,000. After $\sim 92$ years, the ${ }^{3} \mathrm{H}$ peak aquifer concentration drops below the MCL and decays to $\sim 60 \mathrm{pCi} / \mathrm{yr}$ at $\sim 200$ years. 
(A) BASELINE

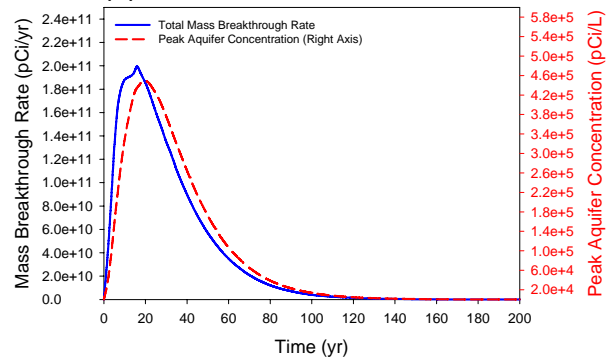

(C) $50 \mathrm{~mm} / \mathrm{yr}$ CRATER RECHARGE RATE

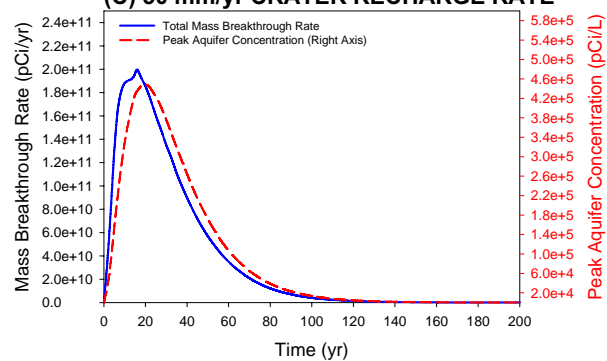

(E) INCREASED PLAYA AREA

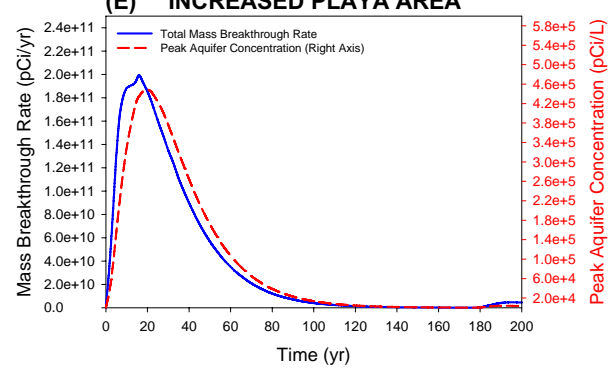

(G) SOLID-PHASE PARTITIONING
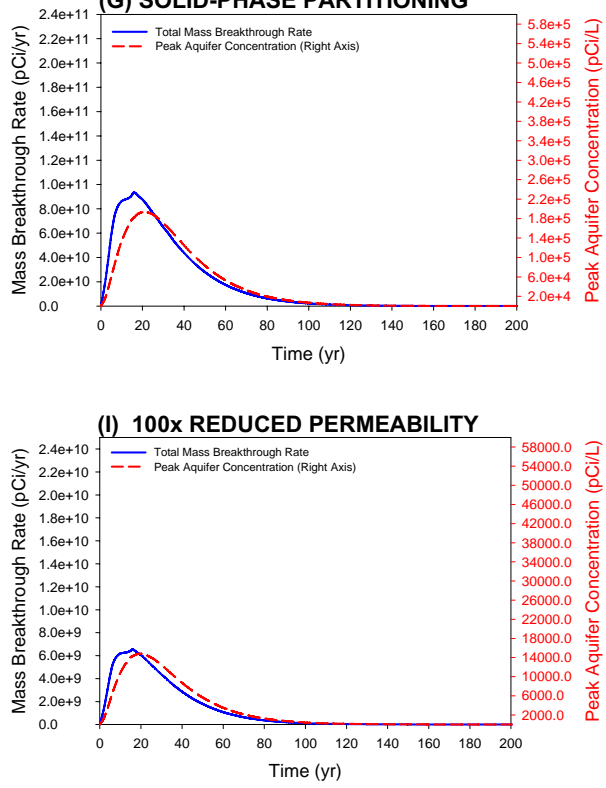

(B) $5 \mathrm{~mm} / \mathrm{yr}$ CRATER RECHARGE RATE

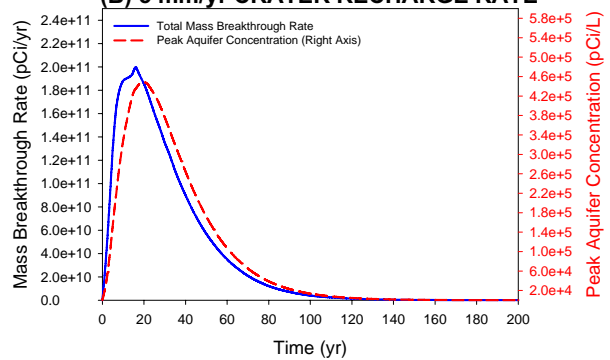

(D) $5000 \mathrm{~mm} / \mathrm{yr}$ CRATER RECHARGE RATE

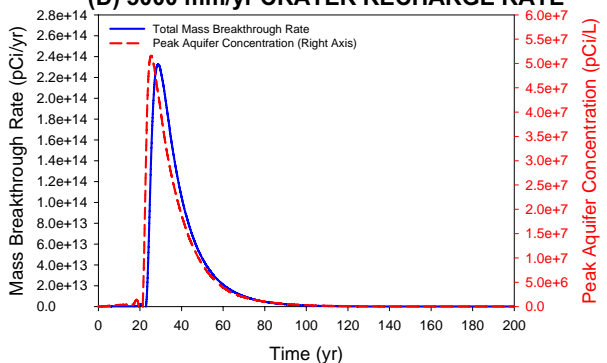

(F) NO GAS-PHASE PARTITIONING

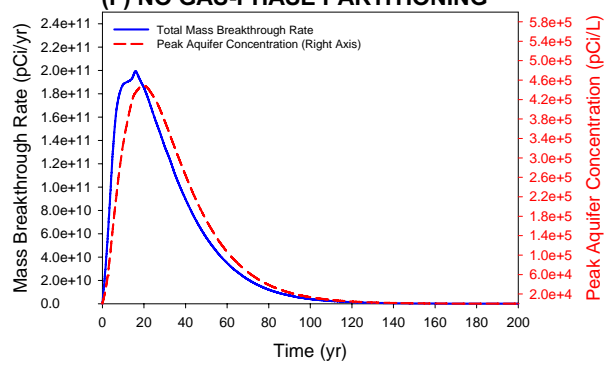

(H) NO GAS, SOLID-PHASE PARTITIONING

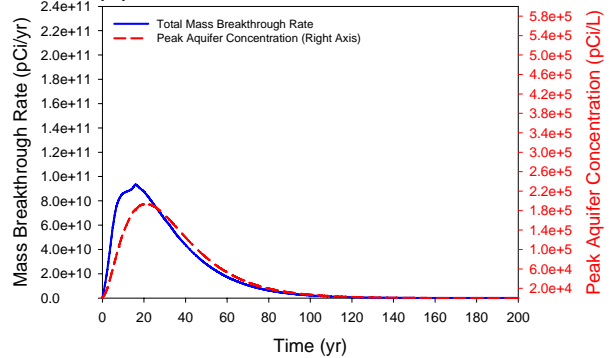

(J) 100x REDUCED PERMEABILITY $5000 \mathrm{~mm} / \mathrm{yr}$ CRATER RECHARGE RATE

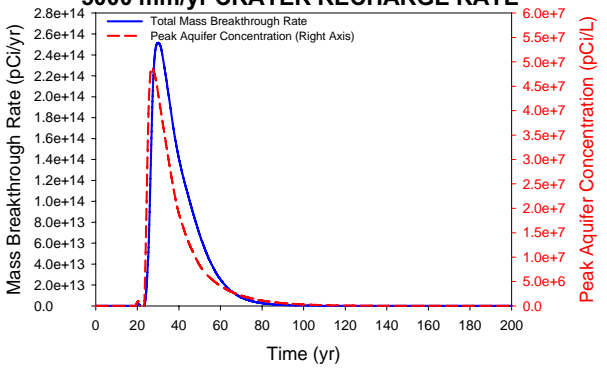

Figure 5-22

${ }^{3} \mathrm{H}$ Deep Test Breakthrough and Peak Aquifer Concentration 


\subsubsection{Effect of Crater Recharge Rates}

As shown in Figures 5-22 and 5-23, lowering the crater recharge rate to 50 and $5 \mathrm{~mm} / \mathrm{yr}$ has no effect on the ${ }^{3} \mathrm{H}$ breakthrough and peak aquifer concentrations because the wetting front travel times to the aquifer are more than 200 years. The results are identical to the baseline, where the ${ }^{3} \mathrm{H}$ is transported across through precipitation advection and diffusion/dispersion processes. The peak aquifer concentration is $\sim 450,000 \mathrm{pCi} / \mathrm{L}$ nearly 20 years after detonation and decays to $\sim 60 \mathrm{pCi} / \mathrm{L}$ at 200 years.

In the high recharge model, aqueous-phase advection dominates ${ }^{3} \mathrm{H}$ transport. The wetting front reaches the water table in $\sim 20$ years (Figure 5-13D) and transfers mass into the aquifer thereafter. A total of $\sim 6$ percent of the initial inventory is transported to the aquifer over the 1,000-year period. Figure 5-22D shows the peak aquifer concentration is extremely high and nearly exceeds 51 million $\mathrm{pCi} / \mathrm{L}$ in $\sim 25$ years, but decays below the MCL after $\sim 143$ years.

When increasing the areal extent of the recharge area to the crater area, the wetting front reaches the water table within $~ 175$ years (see Figure 5-13E). At early breakthrough, Figure 5-22E shows the behavior is identical to the baseline, where the maximum aquifer concentration of $\sim 450,000 \mathrm{pCi} / \mathrm{yr}$ is observed at $\sim 20$ years. The mass breakthrough is due to advection from background infiltration and diffusion/dispersion across the aquifer boundary. The breakthrough and peak aquifer concentration profiles steadily decrease due to radionuclide decay. The wetting front eventually reaches the water table after $\sim 175$ years, where the breakthrough and peak aquifer concentration profiles exhibit a second maximum at late breakthrough. However, the breakthrough occurs when much of the ${ }^{3} \mathrm{H}$ has already decayed. The peak aquifer concentration never exceeds $\sim 4,025 \mathrm{pCi} / \mathrm{yr}$ once the crater-enhanced recharge reaches the water table.

\subsubsection{Effect of Gas- and Solid-phase Partitioning}

The effects of disabling gas- and enabling solid-phase partitioning independently and concurrently is examined. When gas-phase partitioning is neglected, there is essentially no difference in the breakthrough or peak aquifer concentrations as compared to the baseline case (Figures 5-22F and 5-24B). This result is not surprising, given that most of the ${ }^{3} \mathrm{H}$ mass exists in the aqueous-phase ( 99.996 percent) due to the small gas-water partitioning coefficient. However, increases in 


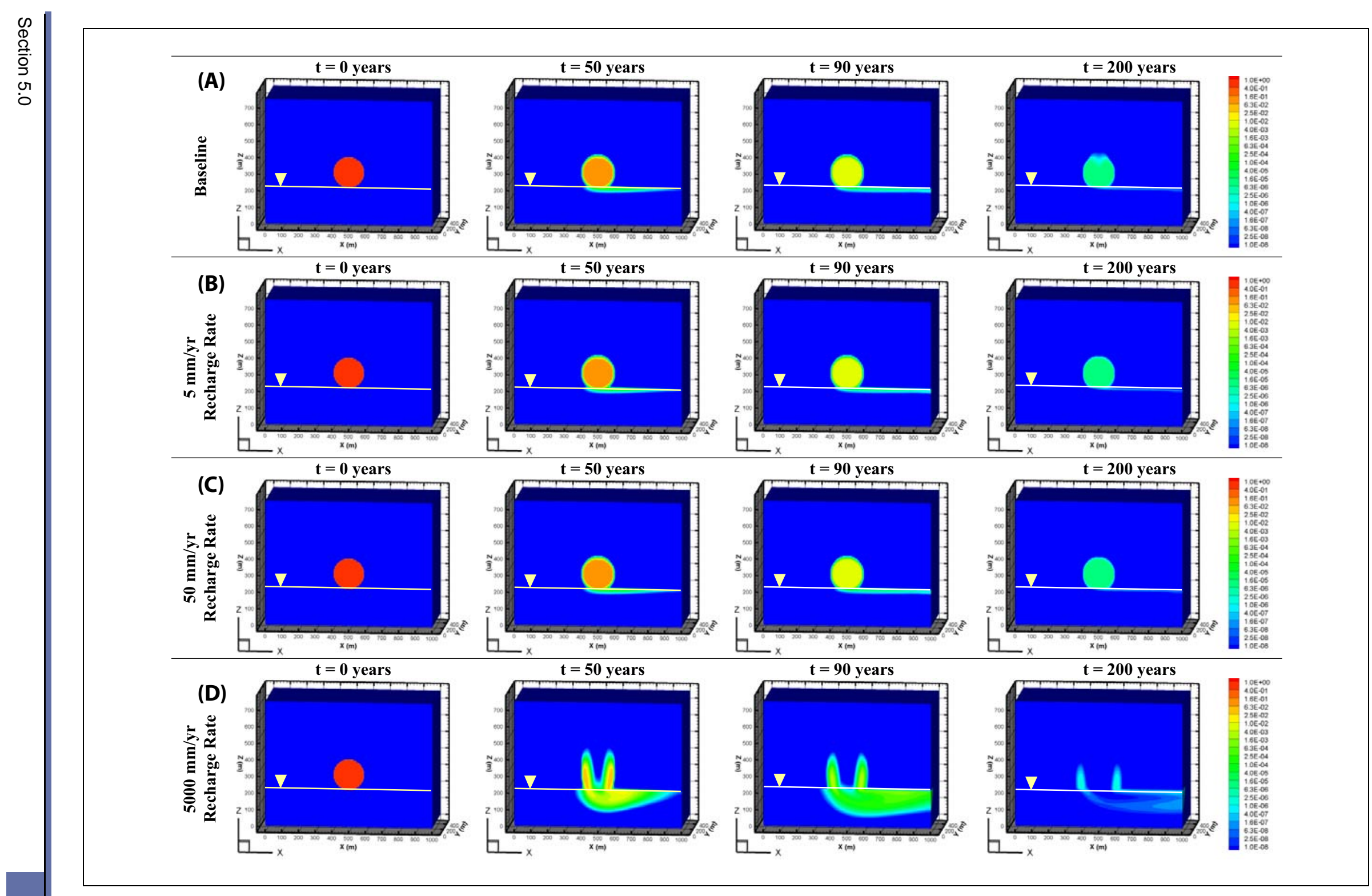

Figure 5-23

${ }^{3} \mathrm{H}$ Deep Test Concentration Profiles of Various Recharge Models

Note: The color scale represents the current concentration relative to the initial concentration at time $t_{0}$. Note that the time intervals may differ for each respective sensitivity study. 

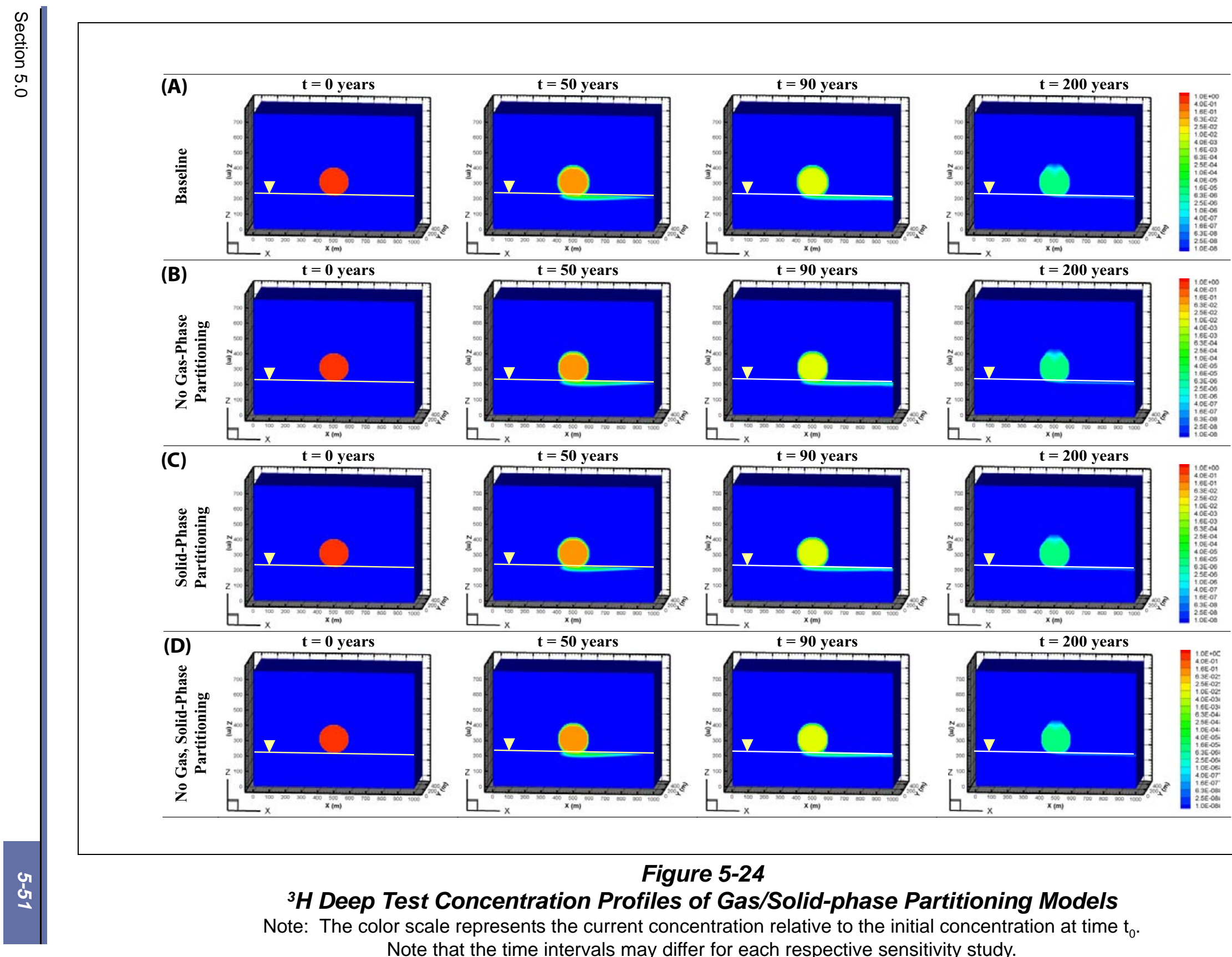

Figure 5-24

${ }^{3} \mathrm{H}$ Deep Test Concentration Profiles of Gas/Solid-phase Partitioning Models

Note: The color scale represents the current concentration relative to the initial concentration at time $\mathrm{t}_{0}$ Note that the time intervals may differ for each respective sensitivity study. 
temperature can have a large impact on the vapor pressure of water and allow ${ }^{3} \mathrm{H}$ to partition more strongly into the gas phase. The effect of increasing temperature would likely cause less ${ }^{3} \mathrm{H}$ transfer across the aquifer boundary, because the ${ }^{3} \mathrm{H}$ would partition more strongly into the gaseous phase and diffuse away from the exchange volume.

When both gas-phase partitioning and solid-phase partitioning are enabled (i.e., refer to the “Solid-Phase Partitioning” sensitivity model [Table 5-4]), the mass breakthrough exhibits a maximum at nearly the same time as the baseline ( 16 years after detonation). However, the peak aquifer concentration is $\sim 193,000 \mathrm{pCi} / \mathrm{L}$ (Figure 5-22G), nearly half the amount observed in the baseline. After $\sim 78$ years, ${ }^{3} \mathrm{H}$ decays below the MCL within the aquifer and eventually decays to $\sim 30 \mathrm{pCi} / \mathrm{L}$ after 200 years. Only 0.005 percent of the initial ${ }^{3} \mathrm{H}$ concentration crosses the aquifer boundary over 200 years. The decrease in peak aquifer concentration from $\sim 450,000 \mathrm{pCi} / \mathrm{L}$ in the baseline model to $\sim 193,000 \mathrm{pCi} / \mathrm{L}$ illustrates the effect of including ${ }^{3} \mathrm{H}$ sorption to the clay minerals. Although the ${ }^{3} \mathrm{H}$ sorption coefficient is small $\left(\mathrm{K}_{\mathrm{d}}=0.05 \mathrm{~mL} / \mathrm{g}\right)$, it can have a significant impact on the ${ }^{3} \mathrm{H}$ breakthrough characteristics. The resulting radionuclide retardation delays breakthrough to the aquifer and allows more radioactive decay to occur within the unsaturated zone. Finally, when enabling solid-phase partitioning, but disabling gas-phase partitioning (i.e., refer to the "No Gas, but Solid-Phase Partitioning” sensitivity model [Table 5-4]), essentially the same behavior is observed when enabling both gas- and solid-phase partitioning. This further suggests that gas-phase partitioning does little in attenuating ${ }^{3} \mathrm{H}$ migration to the aquifer.

\subsubsection{Effect of Crushed Zone Hydraulic Properties}

The effect of reducing the permeability/porosity of the crushed zone is evaluated for ${ }^{3} \mathrm{H}$ migration from the deep test. Recharge rates of 250 and 5,000 mm/yr are compared to the baseline and high recharge deep test results presented in Section 5.4.4.1. As illustrated in Figure 5-17B, the crater-enhanced recharge arrives at the water table in $~ 235$ years when a $250 \mathrm{~mm} / \mathrm{yr}$ recharge rate is applied. Thus, ${ }^{3} \mathrm{H}$ transport is unaffected by the crater-enhanced recharge, because it decays within 200 years, but does transfer to the water table through advection due to background infiltration (Figure 5-24C). The low permeability/porosity crushed zone impedes flow through the exchange volume. As a result, the mass breakthrough rate is approximately two orders of magnitude lower than the baseline model (see Figure 5-22I). A significant reduction in the peak aquifer concentration is 
observed to be $\sim 14,800 \mathrm{pCi} / \mathrm{L}$, which is below the MCL and a factor of 30 times smaller than the peak aquifer concentration observed in the baseline model.

Although this effect seems to be a direct result of the decreased permeability/porosity, it may in fact be an artifact of the model. Because breakthrough for the deep model occurs over short times, the results will be highly dependent on the initial conditions. The pressure profiles of the unaltered alluvium were equilibrated until steady-state before detonation and used as an initial condition in each of the sensitivity models. However, in the low permeability/porosity models, the alluvium is altered instantaneously within the model while maintaining the pressure profile from the equilibration period. This results in a lower moisture content in the crushed zone than in the surrounding, unaltered alluvium. In addition, the decreased permeability in the crushed zone results in a smaller saturated hydraulic conductivity. To transmit water through the unsaturated zone, the moisture content must increase from the equilibrated conditions before water will be transmitted through the crushed zone. This artificial transience that has been introduced into the model will have a significant effect on ${ }^{3} \mathrm{H}$, given the short half-life. While transience occurs in reality, it is impossible to account for this behavior in these simple models. Thus, it cannot be confirmed that there are approximately two orders of magnitude decrease in the peak aquifer concentration for the deep ${ }^{3} \mathrm{H}$ model. In the high recharge model with a low permeability/porosity crushed zone, aqueous-phase advection dominates ${ }^{3} \mathrm{H}$ transport (Figure 5-24D).

The wetting front reaches the water table in 20 years and transfers mass into the aquifer thereafter. Due to the high crater-enhanced recharge rate and the decreased permeability/porosity of the crushed zone, Figure 5-17C shows the bottom of the exchange volume becomes saturated. However, the crushed zone does little to the contain the radionuclide mass because transport is dominated by advection from the high recharge rate. A total of $\sim 7$ percent of the initial inventory is transported to the aquifer over the 1,000-year period. In comparison with the high recharge model, Figure 5-22J shows the breakthrough to the aquifer is slightly delayed by $\sim 2$ years. Nonetheless, the peak aquifer concentration is slightly lower and exceeds 48 million $\mathrm{pCi} / \mathrm{L}$ in $~ 27$ years but decays below the MCL after $\sim 140$ years. 


\subsection{Model Limitations}

The sensitivity studies for ${ }^{14} \mathrm{C}$ and ${ }^{3} \mathrm{H}$ transport were conducted within a uniform alluvium lithology distributed throughout the model. Of the 668 detonations in Yucca Flat with working points above the water table, 413 are located within the alluvium. In this analysis, the predetonation alluvium saturation profile is computed to be nearly constant at 25 percent over the vadose zone model domain. However, the model neglects recent climatic conditions that may influence the deeper portions of the vadose zone as well as any additional moisture introduced as a result of drilling activities.

As summarized by McNab (2008), the USGS rock properties database (2007) for the NTS indicates that the water saturation in representative alluvium and volcanic units typically exceeds 50 percent at many of the Yucca Flat working point depths in the vadose zone. However, in the USGS data cited by McNab (2008), water was artificially introduced during drilling activities at many locations, which likely leads to an overestimation of the background alluvium moisture content. Thus, the computed background alluvium saturation of 25 percent used in this analysis is plausible, assuming a background infiltration rate of $1 \mathrm{~mm} / \mathrm{yr}$.

Carle et al. (2008) have investigated the effects of post-test drilling activities at the HANDCAR detonation and have concluded that the drilling fluid saturates the carbonate rock, leading to faster travel times to the aquifer. To address this model limitation, additional sensitivity models (noted as "drillback" in Table 5-5) were developed to examine the influence of drillback fluid on ${ }^{14} \mathrm{C}$ and ${ }^{3} \mathrm{H}$ transport in the shallow and deep models. For comparison with the baseline models, a $250 \mathrm{~mm} / \mathrm{yr}$ crater-enhanced recharge rate was applied over the crater areal footprints, while the ${ }^{14} \mathrm{C}$ and ${ }^{3} \mathrm{H}$ transport parameters were equivalent to the baseline models. The total volume of water injected into the upper crushed zone of the models is based on typical drilling rates of $60 \mathrm{ft} / \mathrm{hr}$ and mud loss rates estimated at depths to the shallow and deep working points assuming angle drilling from crater edges (Section 3.3.4). In addition, two $400 \mathrm{ft}$ sidetracks are assumed necessary for the drilling activities. Assuming an average pumping rate of $400 \mathrm{gpm}$ and that loss of circulation occurs at a depth of $300 \mathrm{~m}$, the total volume of water required for drilling to the shallow and deep detonations is $\sim 450,000$ and $\sim 800,000$ gallons, respectively. The shallow and deep drillback sensitivity model results indicate that there was essentially no difference in the radionuclide breakthrough times to the aquifer or the peak aquifer concentrations when compared to the baseline models. The peak aquifer concentrations are reported in Table 5-5. The radionuclide travel times from the shallow test to the aquifer are 
dominated by crater-enhanced recharge, essentially outweighing any effects introduced from drilling activities.

In the deep tests, the working point is located closer to the aquifer. However, given the short water injection time (1.4 days) and the low initial alluvium moisture content ( $\sim 25$ saturation), the drilling fluid wetting front propagates slower and at lower saturation through alluvium as compared to carbonate rock. The porosity of carbonate rock (3 to 6 percent) at HANDCAR is significantly smaller than alluvium (41.2 percent), which may explain the higher saturations and faster travel times than observed in this analysis. Overall, the effects of drilling fluid on radionuclide transport times in alluvium are minimal relative to the crater-enhanced recharge effects and are not considered to be important transport mechanisms if significant crater-enhanced recharge is occurring.

The conceptual model also neglects dynamically changing hydraulic properties of crater playa. It is likely that the crater playa will seal as a result of fine-grained deposition, which may gradually reduce the net infiltration after a couple hundred of years (McNab, 2008). The initial range of infiltration rates for all craters across Yucca Flat likely span from the background rate $(1 \mathrm{~mm} / \mathrm{yr})$ to several meters per year. The sensitivity studies presented in this analysis assume a constant flux over the 1,000-year time period and do not consider pulsed infiltration events. However, this transient infiltration effect is expected to diminish with depth and will not significantly alter the saturation profile and peak aquifer concentrations (McNab, 2008).

In conjunction with the initial moisture content, inclusion of low permeability confining units will have the largest influence on the wetting front migration. Many of the tests have TCUs that intersect the transport pathway between the working point and the underlying aquifer. Lithology variations create complex transport pathways that are beyond the scope of this analysis. McNab (2008) previously investigated the effects of including low permeability confining units in the model and demonstrated the strong impediment of wetting front migration. In addition, previous HST modeling performed for the CAMBRIC detonation (Thompson et al., 1999 and 2005) and the test Areas 2 and 3 saturated test modeling by Maxwell et al. (2008) suggest the crushed zone has a one to two orders of magnitude lower permeability than the near-field that will impact the wetting front. As demonstrated in this analysis, high moisture content and water perching is likely at high recharge rates, creating barriers to gas-phase diffusion when including low permeability/porosity crushed zones in the model. 
Another limitation of the model is the lack of site-specific ${ }^{14} \mathrm{C}$ transport partitioning coefficients for Yucca Flat. The $\mathrm{K}_{\mathrm{d}}$ for ${ }^{14} \mathrm{C}$ from SDA sediments at the INL (Dicke and Hohorst, 1997 and Hull and Hohorst, 2001) is transferred to the Yucca Flat alluvium to evaluate the impact of including solid-liquid equilibrium in the transport models. A comparison between the Yucca Flat alluvium mineralogy and the INL alluvium mineralogy is presented in Table 5-3 and indicates that similar reactive mineral percentages exist at each site. As noted in the Yucca Flat Phase I contaminant transport parameters document (SNJV, 2007), older alluvium within Yucca Flat tends to be more tuffaceous, while the upper portion is carbonate-rich with up to 25 percent limestone and/or dolomite. While the increase in carbonate minerals is likely to attenuate ${ }^{14} \mathrm{C}$ to a larger extent, the source term models presented in this study are limited in this respect because they assume a uniform distribution of reactive minerals, resulting in an effective $K_{d}$ partitioning coefficient for the entire system.

The alluvium within Yucca Flat contains $\sim 7$ to 8 percent calcite (Table 5-3). Upon detonation, calcite that is heated to sufficiently high temperatures will decompose into $\mathrm{CO}_{2}$. The production of $\mathrm{CO}_{2}$ may result in an initial distribution beyond the exchange volume and in long term density driven flow, which is neglected in this analysis. Density driven gas-phase advection will result in faster downward gas-phase transport, leading to faster breakthrough times to the aquifer. The carbonate HST modeling of Carle et al. (2008) estimates the $\mathrm{CO}_{2}$ production rate in the four carbonate detonations in Yucca Flat. Following the same approach, the $\mathrm{CO}_{2}$ production rate is determined to be $\sim 3.0 \times 10^{5}$ mole $\mathrm{CO}_{2}$ per kt yield for Yucca Flat alluvium. Assuming perfect mixing of $\mathrm{CO}_{2}$ and air within the exchange volume, the $\mathrm{CO}_{2}$ mole fractions in the shallow and deep exchange volumes range from 29 to 45 percent. Thus, it is conceivable that density-driven flow effects may be an important factor affecting the extent of ${ }^{14} \mathrm{C}$ migration.

While every attempt was made to conservatively estimate the extent of radionuclide migration through the vadose zone, the initial radionuclide concentration within the exchange volumes may in fact underestimate the maximum possible concentration. In all NTS unclassified source term calculations, the maximum announced yield is always used (with one exception for the HANDLEY detonation at Pahute Mesa, where the yield is given as more than $1 \mathrm{Mt}$ ). Dividing the Bowen 
yield-weighted inventory by the volume of water contained within the exchange volume (neglecting sorption and gas-phase partitioning), the radionuclide concentration expression reduces to:

where:

$$
c=\frac{3 I_{B}\left(\rho_{b} D O B\right)^{3 / 4}}{4 \pi 70.2^{3} M_{e} \phi S \sum_{i} Y_{i}}
$$

$I_{B} \quad=$ Total Bowen inventory

$\rho_{\mathrm{b}} \quad=$ Overburden density

$D O B=$ Depth of burial

$\phi \quad=$ Porosity

$M_{e}=$ Exchange volume multiplier

$S=$ Saturation

$Y_{i} \quad=$ Yield of test $i$

In calculating the aqueous-phase concentration, the summation over the maximum announced yields results in the lower-bound estimate of the aqueous-phase concentration in the exchange volume. This limitation exists only in the unclassified calculations because the test-specific cavity radius and inventory are available in the classified calculations.

The peak concentrations at any spatial position within the aquifer were monitored as a function of simulation time. It is worth noting that these peak aquifer concentrations depend on the aquifer velocity. If the velocity is assumed to be faster, peak concentrations would decline and, conversely, if velocity is assumed to be more stagnant, peak concentrations would have been higher. An average hydraulic gradient of 0.0098 was used throughout this analysis, which may not reflect the conditions at specific test sites.

Finally, the models were conducted at a constant temperature of $20^{\circ} \mathrm{C}$. The temperature effects are ignored but are expected to have a large impact on the gas-water partitioning coefficient, $\mathrm{K}_{\mathrm{H}}$. Increasing temperatures will shift vapor-liquid equilibrium towards the gas-phase. Thus, more partitioning in the gas-phase is expected, causing a greater tendency for dilution effects and lower peak aquifer concentrations, especially during the period immediately following detonation when the residual test heat is high. 


\subsection{Conclusions}

This analysis examines the sensitivity of ${ }^{14} \mathrm{C}$ and ${ }^{3} \mathrm{H}$ transport in alluvium to the crater-enhanced recharge rate, playa areal extent, radioactive decay time scales, gas-phase partitioning, solid-phase partitioning, and reduced permeability/porosity within the crushed zone. The ${ }^{14} \mathrm{C}$ and ${ }^{3} \mathrm{H}$ transport sensitivity models are summarized in Table 5-5, where the initial aqueous-phase concentration, peak aquifer concentration, and percentage of mass transferred to the aquifer are compared for the shallow and deep test models.

Advective transport into the aquifer is dependent upon the crater-enhanced recharge rate and playa areal extent. For radionuclides with small or negligible gaseous- and solid-phase partitioning coefficients, advective transport dominates mass transfer across the aquifer boundary. Conservative aqueous-phase tracers with low vapor pressures (e.g., ${ }^{129} \mathrm{I}$ and ${ }^{99} \mathrm{Tc}$ ) reach the aquifer according to the wetting front travel time. In this study, crater-enhanced recharge rates varying from 5 to $5,000 \mathrm{~mm} / \mathrm{yr}$ were distributed over playa radii ranging from 25 to $100 \mathrm{~m}$. As the wetting front infiltrates through the vadose zone, water is drawn away from the recharge zone beneath the playa, causing a spreading effect in the lateral direction. The lateral spreading will impede the wetting front travel times to the aquifer and is dependent upon the playa size.

In the 20-kt shallow and 150-kt deep models, the water table is at a depth of $526 \mathrm{~m}$ bls. As the playa radius is increased from 25 to $100 \mathrm{~m}$, the respective travel times to the aquifer given a $250 \mathrm{~mm} / \mathrm{yr}$ recharge rate decrease from $\sim 450$ to $\sim 175$ years. In general, the fraction of water that spreads laterally due to capillarity is less for a larger recharge area, resulting in faster travel times to the aquifer. For extremely high recharge rates of 5,000 mm/yr, the wetting front reaches the water table in $\sim 20$ to $\sim 40$ years, depending on the playa size. When reducing the recharge rate to $50 \mathrm{~mm} / \mathrm{yr}$, the wetting front does not reach the water table in less than 1,000 years unless the playa size is increased to $50 \mathrm{~m}$, where the travel time is $\sim 725$ years. For recharge rates of $5 \mathrm{~mm} / \mathrm{yr}$, the wetting front does not reach the water table over the 1,000-year time scale for playa radii of 25 and $50 \mathrm{~m}$. Overall, advective transport is sensitive to the crater-enhanced recharge rates and playa areal extent, such that the resulting wetting front travel times to the aquifer range from 20 to more than 1,000 years.

Short-lived radionuclides such as ${ }^{3} \mathrm{H}$ will decay en route to the aquifer. With exception to the high crater recharge rates, the travel times for ${ }^{3} \mathrm{H}$ to the aquifer in the shallow test are longer than the decay 
Table 5-5

Summary of ${ }^{14} \mathrm{C}$ and ${ }^{3} \mathrm{H}$ Transport Simulations

\begin{tabular}{|c|c|c|c|c|c|c|}
\hline \multicolumn{4}{|c|}{ Shallow } & \multicolumn{3}{|c|}{ Deep } \\
\hline Simulation & $\begin{array}{c}{ }^{14} \mathrm{C} /{ }^{3} \mathrm{H} \text { Initial } \\
\text { Aqueous-Phase } \\
\text { Concentration } \\
\text { (pCi/L) }\end{array}$ & $\begin{array}{c}{ }^{14} \mathrm{C} /{ }^{3} \mathrm{H} \text { Peak } \\
\text { Aquifer } \\
\text { Concentration } \\
\text { (pCi/L) }\end{array}$ & $\begin{array}{c}{ }^{14} \mathrm{C} /{ }^{3} \mathrm{H} \text { Percentage } \\
\text { of Initial Mass } \\
\text { Transferred to the } \\
\text { Aquifer }\end{array}$ & $\begin{array}{c}{ }^{14} \mathrm{C} /{ }^{3} \mathrm{H} \text { Initial } \\
\text { Aqueous-Phase } \\
\text { Concentration } \\
\text { (pCi/L) }\end{array}$ & $\begin{array}{c}{ }^{14} \mathrm{C} /{ }^{3} \mathrm{H} \text { Peak } \\
\text { Aquifer } \\
\text { Concentration } \\
\text { (pCi/L) }\end{array}$ & $\begin{array}{c}{ }^{14} \mathrm{C} /{ }^{3} \mathrm{H} \text { Percentage } \\
\text { of Initial Mass } \\
\text { Transferred to the } \\
\text { Aquifer }\end{array}$ \\
\hline Baseline & 1,030 (2.0E8) & $0.009(0)$ & $0.002(0)$ & 2,299 (4.4E8) & 687 (4.5E5) & $9.3(0.011)$ \\
\hline Lowest Recharge Rate & 1,030 (2.0E8) & $0.005(0)$ & $0(0)$ & 2,299 (4.4E8) & 132 (4.5E5) & $1.5(0.011)$ \\
\hline Low Recharge Rate & $1,030(2.0 \mathrm{E} 8)$ & $0.005(0)$ & $0.001(0)$ & 2,299 (4.4E8) & $139(4.5 \mathrm{E} 5)$ & $1.6(0.011)$ \\
\hline High Recharge Rate & $1,030(2.0 \mathrm{E} 8)$ & 210 (3.4E5) & $25(0.18)$ & 2,299 (4.4E8) & $2,138(5.2 \mathrm{E} 7)$ & $78(5.8)$ \\
\hline $\begin{array}{l}\text { Increased Playa } \\
\text { Recharge Area }\end{array}$ & 1,030 (2.0E8) & $0.12(0)$ & $0.002(0)$ & 2,299 (4.4E8) & 1,064 (4.5E5) & $33(0.011)$ \\
\hline No Gas-Phase Partitioning & 1,075 (2.0E8) & $0(0)$ & $0(0)$ & 2,400 (4.4E8) & $1,192(4.5 E 5)$ & $13(0.011)$ \\
\hline $\begin{array}{c}\text { No Solid-Phase } \\
\text { Partitioning }\left({ }^{14} \mathrm{C} \text { only) }\right.\end{array}$ & 9,462 & 9.7 & 1.9 & 21,077 & 1,089 & 16 \\
\hline $\begin{array}{l}\text { Solid-Phase Partitioning } \\
\qquad\left({ }^{3} \mathrm{H} \text { only }\right)\end{array}$ & (1.1E8) & $(0)$ & $(0)$ & $(2.4 \mathrm{E} 8)$ & $(1.9 \mathrm{E} 5)$ & $(0.005)$ \\
\hline $\begin{array}{l}\text { No Gas or Solid-Phase } \\
\text { Partitioning }\left({ }^{14} \mathrm{C} \text { only }\right)\end{array}$ & 15,452 & 364 & 2.6 & 34,337 & 12,204 & 76 \\
\hline $\begin{array}{l}\text { No Gas, but Solid-Phase } \\
\text { Partitioning ( }{ }^{3} \mathrm{H} \text { only) }\end{array}$ & (1.1E8) & (0) & $(0)$ & (2.4E8) & (1.9E5) & $(0.005)$ \\
\hline $\begin{array}{l}\text { Reduced Crushed Zone } \\
\text { Permeability/Porosity }\end{array}$ & $\begin{array}{l}\text { cavity }=1,598(3.6 \mathrm{E} 8) \\
\quad c z=1,047(2.4 \mathrm{E} 8)\end{array}$ & $0.009(0)$ & $0.002(0)$ & $\begin{array}{c}\text { cavity }=3,560(7.9 E 8) \\
c z=2,333(5.1 E 8)\end{array}$ & 1,092 (1.5E5) & $11(0.0004)$ \\
\hline $\begin{array}{c}\text { Reduced Crushed Zone } \\
\text { Permeability/Porosity with } \\
\text { High Recharge }\end{array}$ & $\begin{array}{l}\text { cavity =1,598 (3.6E8) } \\
\quad c z=1,047(2.4 \mathrm{E} 8)\end{array}$ & 270 (6.0E5) & $29(0.37)$ & $\begin{array}{l}\text { cavity }=3,560(4.0 E 8) \\
c z=2,333(2.6 E 8)\end{array}$ & 2,173 (3.3E7) & $78(5.6)$ \\
\hline Drillback & $1,030(2.0 \mathrm{E} 8)$ & $0.009(0)$ & $0.002(0)$ & 2,299 (4.4E8) & 692 (4.5E5) & $9.4(0.0)$ \\
\hline
\end{tabular}

Note: The ${ }^{3} \mathrm{H}$ values are given in parentheses. Also, the initial concentrations of the cavity and crushed zone (cz) are shown when their porosities differ from one another 
time required to reduce the concentration below the MCL of 20,000 pCi/L. Negligible peak aquifer concentrations that are below the MCL are observed over the duration of the 1,000-year time scale. Tritium in the shallow model was transported to the aquifer when high recharge rates of 5,000 mm/yr were distributed over the playa area, resulting in a peak aquifer concentration that exceeded the MCL by 15-fold, but decayed below the MCL 115 years after detonation.

The proximity of the test to the water table has an enormous impact on radionuclide breakthrough to the aquifer. Given that the deep test borders the underlying aquifer, ${ }^{3} \mathrm{H}$ is easily transported through background infiltration and aqueous-phase diffusion/dispersion. Significant breakthrough of ${ }^{3} \mathrm{H}$ is observed, independent of crater recharge and playa area. The peak aquifer concentration is observed to increase above the MCL by approximately ten-fold.

Inclusion of vapor-liquid and solid-liquid equilibrium is essential to modeling ${ }^{14} \mathrm{C}$ transport. The sensitivity studies indicate that ${ }^{14} \mathrm{C}$ migration will be severely overestimated when neglecting sorption to alluvium and gaseous-phase partitioning. Sorption delays the radionuclide arrival time to the aquifer and reduces the aqueous-phase concentration. Gas-phase diffusion attenuates transport by spreading mass over a large volume and diluting the aqueous-phase concentration. For each representative test, the crater-enhanced recharge rates were distributed over the playa areas and varied from 5 to 5,000 mm/yr. When treating ${ }^{14} \mathrm{C}$ as a purely aqueous tracer (i.e., no gas- or solid-phase partitioning) and applying a $250 \mathrm{~mm} / \mathrm{yr}$ recharge rate over the playa area, the peak aquifer concentration exceeds the MCL by six-fold. In each sensitivity study where gaseous- and/or the solid-phase partitioning was included, the peak aquifer concentrations were sufficiently diluted below the MCL of 2,000 pCi/L over the entire 1,000-year time scale following detonation. Gaseous partitioning of ${ }^{14} \mathrm{C}$ will not decrease travel time to the aquifer but will result in significantly less mass arriving at the water table because diffusion spreads ${ }^{14} \mathrm{C}$ away from the recharge footprint.

The shock wave after detonation may alter the hydraulic properties of alluvium. Although the degree of alteration is unknown, sensitivity models were conducted to examine the effects of reducing the permeability and porosity of the crushed zone. As the wetting front moves through the exchange volume, the saturation of the crushed zone increases, creating a barrier that restricts gas-phase diffusion. For ${ }^{14} \mathrm{C}$, an increase in the aqueous-phase concentration within the exchange volume is observed when the low permeability/porosity crushed zone is included in the model. As a result, larger quantities of mass are transferred across the aquifer boundary through aqueous-phase 
advection, and the peak aquifer concentration is greater than models that exclude the crushed zone effects. For ${ }^{3} \mathrm{H}$, negligible amounts of mass partition into the gas-phase. Mass is transferred to the aquifer primarily through aqueous-phase advection. Given the short half-life, the low permeability crushed zone slows water movement and permits larger quantities of ${ }^{3} \mathrm{H}$ to decay within the exchange volume. The resulting peak aquifer concentrations are smaller than the baseline models that excluded crushed zone effects. Overall, the effect of altering the hydraulic properties of the crushed zone has a surprisingly small influence on the breakthrough curves and peak aquifer concentrations for the tests conducted in the vadose zone because only the very highest recharge rate $(5,000 \mathrm{~mm} / \mathrm{yr})$ exceeds the crushed zone hydraulic conductivity. 


\subsection{SUMMARY, LIMITATIONS, AND PATH FORWARD}

\subsection{Summary}

The Yucca Flat CAU-scale transport models require the release rate of radionuclides from the RST be defined and input into the models. This may be accomplished through direct parameterization of the processes important to the release of radionuclides from the test cavity, melt glass, and exchange volume in the CAU-scale models or through abstraction to a limited number of source term models similar to those presented in Section 5.0. Defining the radionuclide release rate for the Yucca Flat CAU transport modeling is challenging because there are hundreds of detonations that were conducted in a wide variety of hydrogeologic settings, including unsaturated and saturated tests in alluvial, volcanic, and carbonate settings.

The important processes that influence radionuclide migration for the different settings are identified and conceptual models for these settings are defined. This work does not calculate the HST for each test because knowledge of the groundwater flow rates is needed to compute the HST and the Yucca Flat CAU-scale flow models are still being developed at the time this work is performed. Instead, this work identifies the important processes that must be considered when the CAU transport modeling is performed.

Preliminary modeling of multiphase ${ }^{14} \mathrm{C}$ and ${ }^{3} \mathrm{H}$ transport is presented to estimate the magnitude of attenuation occurring within the unsaturated zone. Two representative models with working points located at a shallow and deep depths are constructed in alluvium to investigate the impact of crater-enhanced recharge, playa areal extent, radioactive decay time scales, gas-phase partitioning, solid-phase partitioning, and a reduced permeability/porosity compressed zone on ${ }^{14} \mathrm{C}$ and ${ }^{3} \mathrm{H}$ transport. The representative shallow test has a working point located $175 \mathrm{~m}$ bls, and the deep test has a working point $435 \mathrm{~m}$ bls. Carbon-14 transport is influenced by gas-phase diffusion and sorption within the alluvium. Gas-phase diffusion is an attenuation mechanism that transports ${ }^{14} \mathrm{C}$ gas (i.e., ${ }^{14} \mathrm{CO}_{2}$ ) throughout the vadose zone and exposes it to a large amount of soil moisture resulting in 
dilute aqueous-phase concentrations. Sorption to alluvium delays radionuclide arrival times to the water table and further dilutes the concentration by removing ${ }^{14} \mathrm{C}$ from the aqueous-phase. The majority of the ${ }^{14} \mathrm{C}$ source term remains in the vadose zone over the 1,000 -year period after detonation, while a comparatively small amount is transported to the aquifer through aqueous-phase diffusion, dispersion, and advection. Tritium transport behaves differently than ${ }^{14} \mathrm{C}$ transport, where aqueous-phase advection is the dominate mechanism for ${ }^{3} \mathrm{H}$ transport. Given the ${ }^{3} \mathrm{H}$ half-life of 12.3 years, short time scale processes are necessary to transport sufficient quantities to the water table. Furthermore, small quantities of ${ }^{3} \mathrm{H}$ partition to the gas- and solid-phases, resulting in relatively high aqueous-phase concentrations. The wetting fronts generally reach the water table after a majority of the ${ }^{3} \mathrm{H}$ has decayed. However, for tests conducted at or near the water table, ${ }^{3} \mathrm{H}$ quantities that pose a significant risk are easily transported into the aquifer through background precipitation infiltration and aqueous-phase diffusion/dispersion.

Of the 744 underground shaft detonations conducted within the Yucca Flat proper subsurface, 668 of these detonations have working points located above the water table. The majority of the tests with working points above the water table were performed in the alluvium, the majority of the tests with working points below the water table were performed in TCUs, and four detonations were performed in carbonate rock. The total yield is 38,512.5 kt for all detonations performed on Yucca Flat proper excluding the carbonate detonations. Approximately 12,583 kt, or 33 percent, of this yield may not contribute significantly to the contaminant boundary calculations because the source term is from unsaturated tests without subsidence craters or from saturated tests that may be completely contained in TCUs. The attenuation occurring in the unsaturated zone due to gaseous phase partitioning and radioactive decay may greatly reduce the unsaturated test source term that reaches the aquifer within 1,000 years.

\subsection{Limitations}

The multiphase transport simulations presented in Section 5.0 used simplistic estimations of the ${ }^{14} \mathrm{C}$ Henry's coefficient and surrogate sorption coefficients from studies at different locations with similar soil types. These parameters may not accurately represent Yucca Flat site specific conditions. The simulations are most useful for identifying the magnitude of radionuclide attenuation and the benefit of including these multiphase processes with site specific data in the planned CAU-scale modeling. 
The multiphase transport simulations presented in Section 5.0 also did not include the effects of residual test heat. The movement of gaseous phase radionuclides away from the test-effected area is likely greater than that simulated because the gas phase fugacity decreases at higher temperatures (i.e., the ${ }^{3} \mathrm{H}$ vapor pressure increases and $\mathrm{CO}_{2}$ aqueous solubility decreases).

There is a paucity of data for unsaturated tests to verify model predictions. Specifically, gaseous phase concentration observations are needed to verify that models are correctly simulating transport of the radionuclides known to exist in the gaseous phase (i.e., ${ }^{14} \mathrm{C},{ }^{39} \mathrm{Ar}$, ${ }^{85} \mathrm{Kr}$, and ${ }^{3} \mathrm{H}$ ). Observations of deep soil moisture or tension beneath subsidence craters are needed to verify simulations enhanced crater recharge.

\subsection{Path Forward}

The RST represents all the radioactivity remaining after an underground nuclear test. Only a subset of the RST radionuclides are available for potential transport to groundwater because some of the processes occurring in the subsurface prevent radionuclides from reaching the water table or migrating away from the source area. For example, only a small fraction of the radionuclides incorporated in melt glass will be released over a 1,000-year period because the glass dissolution process is very slow. The path forward is to develop efficient methodologies for implementing the processes that prevent the entire RST from contributing to the contaminant boundary into the source term modeling. The following recommendations for the source term modeling path forward are made based on the knowledge gained while performing this work:

- The partitioning of volatile radionuclides into the gaseous phase within the unsaturated zone will reduce aquifer concentrations and mass breakthrough. The feasibility of using the CAU-scale unsaturated models for representing unsaturated zone source release processes, including gaseous phase transport, needs to be investigated. If using the CAU-scale model becomes numerically intractable, simplified models must be constructed for categories of unsaturated tests.

- Much of the unsaturated test source term may not impact the aquifer. The unsaturated test source term should be screened by comparing the mean recharge required to transport radionuclides to the watertable calculated by McNab (2008) to mean subsidence crater recharge calculated from the catchment area, precipitation and evapotranspiration. Tests that require large recharge to transport radionuclides to the watertable in 1,000 years, but have small catchment basin areas and small mean subsidence crater recharge, may be screened from the unsaturated source term. 
- The Yucca Flat transport data document (SNJV, 2007) did not identify gaseous phase radionuclide transport parameters. The transport parameters and uncertainty need to be compiled for ${ }^{14} \mathrm{C},{ }^{39} \mathrm{Ar},{ }^{85} \mathrm{Kr}$, and ${ }^{3} \mathrm{H}$.

- The LLNL carbonate test HST study (Carle et al., 2008) used a combination of data, interpretation, and process modeling with sensitivity analysis to assess the relative likelihood (on a test-specific basis) of five unsaturated flow processes identified as contributing to the carbonate HST (not including crater infiltration and cavity situated below the water table). However, the HST work did not quantify the relative importance of the many different processes identified as being important to the carbonate test HST. The feasibility and associated error with simplifying many of these processes need to be evaluated.

- The SSM development to be performed during the CAU-scale transport modeling should focus on the saturated and carbonate tests. Efficient analytical models should be used to represent the important processes when possible. Analytical solutions are available for heat transfer in porous media for simple geometries (Nield and Bejan, 2006), or analytical expressions may be developed for the unique conditions occurring within the test altered zones in a manner similar to Tompson et al. (2004). For example, a simple exponential function may be fitted to a decaying velocity field resulting from the test-induced pressure, and an analytical expression for a transient radionuclide flux may be obtained for simplified geometries.

The multiphase transport simulations presented in Section 5.0 and Appendix C did not include an assessment of model uncertainty. The planned CAU transport modeling should include identifying multiphase flow and transport model parameter sensitivity and uncertainty. The uncertainty analysis should focus on the processes that contribute most to the contaminant boundary uncertainty and the model sensitivity analysis should be used to identify these processes. 


\subsection{REFERENCES}

Allard, B., B. Torstenfelt, and K. Andersson. 1981. "Sorption Studies of $\mathrm{H}^{14} \mathrm{CO}_{3-}$ on Some Geologic Media and Concrete.” In J.G. Moore (ed.) Scientific Basis for Nuclear Waste Management III. New York: Plenum Publication Corporation.

Ashby, S. F., 1996. "ParFlow home page” As accessed at http://computation.llnl.gov/CASC/ParFlow/parflow_home.html on 10 June 2008.

BN, see Bechtel Nevada.

Bechtel Nevada. 1998. Hydrologic Characterization of the Unsaturated Zone at the Area 3 Radioactive Waste Management Site, DOE/NV/11718-210. Las Vegas, NV.

Bechtel Nevada. 2006. A Hydrostratigraphic Model and Alternatives for the Groundwater Flow and Contaminant Transport Model of Corrective Action Unit 97: Yucca Flat-Climax Mine, Lincoln and Nye Counties, Nevada, DOE/NV/11718--1119. Las Vegas, NV.

Belcher, W.R., J.B. Blainey, F.A. D’Agnese, C.C. Faunt, M.C. Hill, R.J. Laczniak, G.M. O’Brien, C.J. Potter, H.M. Putnam, C.A. San Juan, and D.S. Sweetkind. 2004. Death Valley Regional Ground-Water Flow System, Nevada and California - Hydrogeologic Framework and Transient Ground-Water Flow Model, Scientific Investigations Report 2004-5205. U.S. Geological Survey.

Boardman, C.R. 1970. "Engineering Effects of Underground Nuclear Explosives: Symposium on Engineering with Nuclear Explosives,” Proceedings, CONF-700101: 43-67. Las Vegas, NV.

Borg, I.Y., R. Stone, H.B. Levy, and L.D. Ramspott. 1976. Information Pertinent to the Migration of Radionuclides in Groundwater at the Nevada Test Site, Part 1: Review and Analysis of Existing Information, UCRL-52078, Pt. 1. Livermore, CA: Lawrence Livermore National Laboratory.

Bowen, S.M., D.L. Finnegan, J.L. Thompson, C.M. Miller, P.L. Baca, L.F. Olivas, C.G. Geoffrion, D.K. Smith, W. Goishi, B.K. Esser, J.W. Meadows, N. Namboodiri, and J.F. Wild. 2001. Nevada Test Site Radionuclide Inventory, 1951-1992, LA-13959-MS. Los Alamos, NM: Los Alamos National Laboratory.

Butkovich, T.R. 1974. Rock Melt from an Underground Nuclear Explosion, UCRL-51554. Livermore, CA: Lawrence Livermore National Laboratory. 
CFR, see Code of Federal Regulations.

Carle, S.F., R.M. Maxwell, G.A. Pawloski, D.E. Shumaker, A.F.B. Tompson, and M. Zavarin. 2007. Evaluation of the Transient Hydrologic Source Term for the Cambric Underground Nuclear Test at Frenchman Flat, Nevada Test Site, UCRL-TR-226916. Livermore, CA: Lawrence Livermore National Laboratory.

Carle, S.F., M. Zavarin, Y. Sun, and G.A. Pawloski. 2008. Written communication regarding Evaluation of Hydrologic Source Term Processes for Underground Nuclear Tests in Yucca Flat, Nevada Test Site: Carbonate Tests. Livermore, CA: Lawrence Livermore National Laboratory.

Code of Federal Regulations. 2008. Title 40 CFR Part 141 Subchapter D, "National Primary Drinking Water Regulations.” Washington, DC: U.S. Government Printing Office.

DOE/NV, see U.S. Department of Energy, Nevada Operations Office.

Dicke, C.A., and F.A. Hohorst. 1997. Carbon-14 Distribution Co-Efficients Measured from Batch Experiments on SDA Sediments, INEEL/INT-98-00068, EDF-RWMC-1011. Idaho Falls, ID: Idaho National Engineering and Environmental Laboratory.

Drellack, S., National Security Technologies. 2008. Personal communication to P. Martian (SNJV) regarding typical Yucca Flat drilling fluid loss during post-test drilling activities, 21 January. Las Vegas, NV.

Drellack, S., National Security Technologies. 2009. Personal communication to P. Martian (SNJV) regarding Yucca Flat Tuff Pile welded tuff interbeds, 9 January. Las Vegas, NV.

FAO, see Food and Agriculture Organization of the United Nations.

FFACO, see Federal Facility Agreement and Consent Order.

Federal Facility Agreement and Consent Order. 1996 (as amended). Agreed to by the State of Nevada; U.S. Department of Energy, Environmental Management; U.S. Department of Defense; and U.S. Department of Energy Legacy Management. Appendix VI, which contains the Underground Test Area strategy, was last amended February 2008, Revision No. 2.

Fienen, M.N. 2005. "The Three-Point Problem, Vector Analysis and Extension to the N-Point Problem.” In Journal of Geoscience Education, Vol. 53(3): 257-262.

Food and Agriculture Organization of the United Nations. 1998. Crop Evapotranspiration Guidelines for Computing Crop Water Requirements, FAO Irrigation and Drainage paper 56. Rome, Italy. 
Fox, D.T., M.A. Plummer, L.C. Hull, and D.C. Cooper. 2004. Multiphase Carbon-14 Transport in a Near-Field-Scale Unsaturated Column of Natural Sediments, INEEL/EXT-04-01793. Idaho Falls, ID: Idaho National Engineering and Environmental Laboratory.

Halford, K.J., R.J. Laczniak, and D.L Galloway. 2005. Hydraulic characterization of overpressured tuffs in Central Yucca Flat, Nevada Test Site, Nye County, Nevada. U.S. Geological Survey Investigations Report 2005-5211. 35 pp.

Hershey, R.L., W. Howcroft, and P.W. Reimus. 2003. Laboratory Experiments to Evaluate Diffusion of ${ }^{14} \mathrm{C}$ into Nevada Test Site Carbonate Aquifer Matrix, DOE/NV/11508-55; Publication No. 45180. Las Vegas, NV: Desert Research Institute.

Hokett, S.L., and D.R. Gillespie. 1996. Preliminary Evaluation of Recharge Potential at Subsidence Crater U5A in Frenchman Flat, Nevada Test Site, DOE/NV/11508-15; Publication No. 45147. Las Vegas, NV: Desert Research Institute.

Hokett, S.L., and R.H. French. 1998. Evaluation of Recharge Potential at Crater U5a (Wishbone), DOE/NV/11508-32; Publication No. 45160. Las Vegas, NV: Desert Research Institute.

Hokett, S.L., and R.H. French. 2000. Evaluation of Recharge Potential at Subsidence Crater U19b, Central Pahute Mesa, Nevada Test Site, DOE/NV/26383-06; Publication No. 45161.

Las Vegas, NV: Desert Research Institute.

Hokett, S.L., D.R. Gillespie, G.V. Wilson, and R.H. French. 2000. Evaluation of Recharge Potential at Subsidence Crater U10i, Northern Yucca Flat, Nevada Test Site, DOE/NV/11508-53; Publication No. 45174. Las Vegas, NV: Desert Research Institute.

Hsieh, P.A., W. Wingle, and R.W. Healy. 2000. VS2DI - A Graphical Software Package for Simulating Fluid Flow and Solute or Energy Transport in Variably Saturated Porous Media, Water-Resources Investigations Report 99-4130. Lakewood, CO: U.S. Geological Survey.

Hull, L.C., and F.A. Hohorst. 2001. Transport Models for Radioactive Carbon at RWMC, INEEL/EXT-01-00894. Idaho Falls, ID: Idaho National Engineering and Environmental Laboratory.

IAEA, see International Atomic Energy Agency.

IT, see IT Corporation.

International Atomic Energy Agency. 1998. The Radiological Situation at the Atolls of Mururoa and Fangataufa, Technical Report, Volume 3: Inventory of Radionuclides Underground at the Atolls, IAEA-MFTR-3. Proceedings of an IAEA Conference, Vienna, 30 June - 3 July, to present the results of the International Study. Vienna, Austria. 
IT Corporation. 1999. Value of Information Analysis for Corrective Action Unit 97: Yucca Flat, Nevada Test Site, Nevada, DOE/NV/13052--079; ITLV/13052--079. Las Vegas, NV.

Kjaergaard, C., T.G. Poulsen, P. Moldrup, and L.W. de Jonge. 2004. "Colloid Mobilization and Transport in Undisturbed Soil Columns. I. Pore Structure Characterization and Tritium Transport.” In Vadose Zone Journal, Vol. 3: 413-423.

Kwicklis, E., Los Alamos National Laboratory. 2007. Personal communication to P. Martian (Stoller-Navarro Joint Venture) regarding crater areas and the Los Alamos National Laboratory Yucca Flat crater database, 7 December. Los Alamos, NM.

Kwicklis, E., Los Alamos National Laboratory. 2008. Personal communication to P. Martian (Stoller-Navarro Joint Venture) regarding unsaturated vadose zone CAU scale modeling performed by Los Alamos National Laboratory, 28 September. Los Alamos, NM.

Laczniak, R.L., J.C. Cole, D.A. Sawyer, and D.A. Trudeau. 1996. Summary of Hydrogeologic Controls on the Movement of Groundwater Flow at the Nevada Test Site, Nye County, Nevada, Water-Resources Investigations Report 96-4109. Carson City, NV: U.S. Geological Survey.

Martin, W.J. 1991. "The Interaction of Carbon-14 Carbonate Solution Species with Semiarid Sediment.” In 37th Annual Conference on Bioassay. Ottawa, ON, Canada: Pacific Northwest Laboratory.

Maxwell, R.M., R.L. Detwiler, Q. Hu, A.F.B. Tompson, S. Kollet, and S.K. Roberts. 2008. Written communication regarding Evaluation of Hydrologic Source Term Processes for Underground Nuclear Tests in Yucca Flat, Nevada Test Site: Saturated. Livermore, CA: Lawrence Livermore National Laboratory.

McNab, W.W. 2008. Written communication regarding Evaluation of Hydrologic Source Term Processes for Underground Nuclear Tests in Yucca Flat, Nevada Test Site: Unsaturated Tests and the Impact of Recharge. Livermore, CA: Lawrence Livermore National Laboratory.

Millington, R.J. and J.P. Quirk. 1960. “Transport in Porous Media.” In Transactions of $7^{\text {th }}$ International Congress of Soil Science, Vol. 1: 97-106.

Mualem, Y. 1976. “A New Model for Predicting the Unsaturated Hydraulic Conductivity of Unsaturated Porous Media.” In Water Resources Research, Vol. 12: 513-522.

Nield, D.A., and A. Bejan. 2006. Convection in Porous Media, Third Edition. New York, NY: Springer Science+Business Media, Inc.

Nitao, J.J. 1998. User's Manual for the USNT Module of the NUFT Code, Version 2.0 (NP-Phase, NC-Component, Thermal), UCRL-MA-130653. Livermore, CA: Lawrence Livermore National Laboratory. 
Olsen, C.W. 1967. “Time History of Cavity Pressure and Temperature Following a Nuclear Detonation in Alluvium.” In Journal of Geophysical Research, Vol. 72: 5037-5041; UCRL--70379. Livermore, CA: University of California.

Parkhurst, D.L., and C.A.J. Appelo. 2002. User's Guide to PHREEQC (Version 2) - A Computer Program for Speciation, Batch Reaction One-Dimensional Transport, and Inverse Geochemical Calculations, Water-Resources Investigations Report 99-4259. U.S. Geological Survey.

Pawloski, G.A. 1999. Development of Phenomenological Models of Underground Nuclear Tests on Pahute Mesa, Nevada Test Site-BENHAM and TYBO, UCRL-ID-136003. Livermore, CA: Lawrence Livermore National Laboratory.

Pawloski, G.A., A.F.B. Tompson, and S.F. Carle. 2001. Evaluation of the Hydrologic Source Term from Underground Nuclear Tests on Pahute Mesa at the Nevada Test Site: CHESHIRE Test, UCRL-ID-147023. Livermore, CA: Lawrence Livermore National Laboratory.

Pawloski, G.A., G. WoldeGabriel, and I. Farnham. 2005. Written communication regarding Categorization of Underground Nuclear Tests on Yucca Flat and Climax Mine, Nevada Test Site, for Use in Radionuclide Transport Models. Livermore, CA: Lawrence Livermore National Laboratory; Los Alamos, NM: Los Alamos National Laboratory; and Las Vegas, NV: Stoller-Navarro Joint Venture.

Pawloski, G.A., A.F.B. Tompson, S.F. Carle, R.L. Detwiler, Q. Hu, S. Kollet, R.M. Maxwell, W.W. McNab, S.K. Roberts, D.E. Shumaker, Y. Sun, and M. Zavarin. 2008. Written communication regarding Evaluation of Hydrologic Source Term Processes for Underground Nuclear Tests in Yucca Flat, Nevada Test Site: Introduction and Executive Summary. Livermore, CA: Lawrence Livermore National Laboratory.

Plummer, M.A., L.C. Hull, and D.T. Fox. 2004. “Transport of Carbon-14 in a Large Unsaturated Soil Column. Special Section: Understanding Subsurface Flow and Transport Processes at the Idaho National Engineering \& Environmental Laboratory (INEEL) Site.” In Vadose Zone Journal, Vol. 3: 109-121.

Pohll, G.M., J.J. Warwick, and S.W. Tyler. 1996. “Coupled Surface-Subsurface Hydrologic 13 Model of a Nuclear Subsidence Crater at the Nevada Test Site.” In Journal of Hydrology, Vol. 186 (Issues 1-4): 43-62.

Pohll, G., K. Pohlmann, J. Daniels, A. Hassan, and J. Chapman. 2003. Contaminant Boundary at the Faultless Underground Nuclear Test, DOE/NV/13609-24; Publication No. 45196. Las Vegas, NV: Desert Research Institute.

Pohlmann, K., M. Ye, D. Reeves, D. Decker, J. Chapman, and M. Zavarin. 2007. Modeling of Groundwater Flow and Radionuclide Transport at the Climax Mine sub-CAU, Nevada Test Site, DOE/NV/26383-06; Publication No. 45226. Las Vegas, NV: Desert Research Institute. 
Reimus, P.W., R.L. Hershey, D.L. Decker, S.D. Ware, C. Papelis, S. Earman, and A. Abdel-Fattah. 2006. Tracer Transport Properties in the Lower Carbonate Aquifer of Yucca Flat, LA-UR-06-0486. Los Alamos, NM: Los Alamos National Laboratory.

Selker, J. S., C. K. Keller, and J. T. McCord. 1999. Vadose Zone Processes, Boca Raton, FL: CRC Press LLC.

SNJV, see Stoller-Navarro Joint Venture.

Shaw Environmental, Inc. 2003. Modeling Approach/Strategy for Corrective Action Unit 97, Yucca Flat and Climax Mine, Shaw/13052-305. Las Vegas, NV.

Smith, D.K. 1993. Review of Literature Pertaining to the Leaching and Sorption of Radionuclides Associated with Nuclear Explosive Melt Glasses, UCRL-ID-113370. Livermore, CA: Lawrence Livermore National Laboratory.

Smith, D.K. 1995a. Challenges in Defining a Radiologic and Hydrologic Source Term for Underground Nuclear Test Centers, Nevada Test Site, Nye County, Nevada, UCRL-JC-120389. Livermore, CA: Lawrence Livermore National Laboratory.

Smith, D.K. 1995b. Phenomenology of Underground Nuclear Explosions Conducted at the Nevada Test Site with Emphasis on Recent Experience at BASEBALL (U7ba) and INGOT (U2gg), Milestone 189703. Livermore, CA: Lawrence Livermore National Laboratory.

Smith, D.K. 2002. Evaluation of the Radiochemistry of Near-Field Water Samples at the Nevada Test Site Applied to the Definition of a Hydrologic Source Term, UCRL-ID-149049. Livermore, CA: Lawrence Livermore National Laboratory.

Stoller-Navarro Joint Venture. 2004. Unclassified Source Term and Radionuclide Data for the Groundwater Flow and Contaminant Transport Model of Corrective Action Units 101 and 102: Central and Western Pahute Mesa, Nye County, Nevada, Rev. 0, S-N/99205. Las Vegas, NV.

Stoller-Navarro Joint Venture. 2005. Unclassified Source Term and Radionuclide Data for Corrective Action Unit 98: Frenchman Flat Nevada Test Site, Nevada, Rev. 0, S-N/99205--058. Las Vegas, NV.

Stoller-Navarro Joint Venture. 2006a. Geochemical and Isotopic Evaluation of Groundwater Movement in Corrective Action Unit 97: Yucca Flat/Climax Mine, Nevada Test Site, Nevada, Rev. 0, S-N/99205--070. Las Vegas, NV.

Stoller-Navarro Joint Venture. 2006b. Phase I Hydrologic Data for the Groundwater Flow and Contaminant Transport Model of Corrective Action Unit 97: Yucca Flat/Climax Mine, Nevada Test Site, Nye County, Nevada, Rev. 0, S-N/99205--077. Las Vegas, NV. 
Stoller-Navarro Joint Venture. 2007. Phase I Contaminant Transport Parameters for the Groundwater Flow and Contaminant Transport Model of Corrective Action Unit 97: Yucca Flat/Climax Mine, Nevada Test Site, Nye County, Nevada, Rev. 0, S-N/99205--096. Las Vegas, NV.

Stoller-Navarro Joint Venture. 2008. Written communication regarding Phase II Transport Model of Corrective Action Unit 98: Frenchman Flat, Nevada Test Site, Nye County, Nevada, Rev. 0. Las Vegas, NV.

Tchnobanoglous, G., and E.D. Schroeder. 1987. Water Quality. Davis, CA: University of California at Davis.

Thibault, D.H., M.I. Sheppard, and P.A. Smith. 1990. A Critical Compilation and Review of Default Soil Solid/Liquid Partition Coefficients, $K_{d}$, for Use in Environmental Assessments, AECL-10125. Pinawa, Manitoba, Canada: Whiteshell Nuclear Research Establishment.

Thompson, J.L. 1999. Laboratory and Field Studies Related to Radionuclide Migration at the Nevada Test Site: October 1, 1997-September 30, 1998, LA-13576-PR. Los Alamos, NM: Los Alamos National Laboratory.

Tompson, A.F.B., C.J. Bruton, and G.A. Pawloski (eds.). 1999. Evaluation of the Hydrologic Source Term from Underground Nuclear Tests in Frenchman Flat at the Nevada Test Site: The CAMBRIC Test, UCRL-ID-132300. Livermore, CA: Lawrence Livermore National Laboratory.

Tompson, A.F.B., D.K. Smith, and G.B. Hudson. 2002. Analysis of Radionuclide Migration Through a 200-m Vadose Zone Following a 16-year Infiltration Event, UCRL-ID-146979. Livermore, CA: Lawrence Livermore National Laboratory.

Tompson, A.F.B., M. Zavarin, C.J. Bruton, and G.A. Pawloski. 2004. Methods for Calculating a Simplified Hydrologic Source Term for Frenchman Flat Sensitivity Studies of Radionuclide Transport Away from Underground Nuclear Tests, UCRL-TR-201817. Livermore, CA: Lawrence Livermore National Laboratory.

Tompson, A.F.B., R.M. Maxwell, S.F. Carle, M. Zavarin, G.A. Pawloski, and D.E. Shumaker. 2005. Evaluation of the Non-Transient Hydrologic Source Term from the CAMBRIC Underground Nuclear Test in Frenchman Flat, Nevada Test Site, UCRL-TR-217191. Livermore, CA: Lawrence Livermore National Laboratory.

Tyler, S.W., W.A. McKay, J.W. Hess, R.L. Jacobson, and K. Taylor. 1986. Effects of Surface Collapse Structures on Infiltration and Moisture Redistribution, DOE/NV/10384-04; Publication No. 45045. Las Vegas, NV: Desert Research Institute.

Tyler, S.W., S.W. McKay, and T.M. Miheve. 1992. “Assessment of Soil Moisture Movement in Nuclear Subsidence Craters.” In Journal of Hydrology, Vol. 139: 159-181. 
Tyler, S.W., J.B. Chapman, S.H. Conrad, D.P. Hammermeister, D.O. Blout, J.J. Miller, M.J. Sully, and J.M. Ginanni. 1996. "Soil-Water Flux in the Southern Great Basin, United States: Temporal and Spatial Variations Over the Last 120,000 Years.” In Water Resources Research, Vol. 32(6): 1481-1499.

USGS, see U.S. Geological Survey.

U.S. Congress, Office of Technology Assessment. 1989. The Containment of Underground Explosions, OTA-ISC-414. Washington, DC: U.S. Government Printing Office.

U.S. Department of Energy, Nevada Operations Office. 1997a. Regional Groundwater Flow and Tritium Transport Modeling and Risk Assessment of the Underground Test Area, Nevada Test Site, Nevada, DOE/NV--477. Las Vegas, NV.

U.S. Department of Energy, Nevada Operations Office. 1997b. Shaft and Tunnel Nuclear Detonations at the Nevada Test Site: Development of a Primary Database for the Estimation of Potential Interactions with the Regional Groundwater System, DOE/NV--464 UC-700. Las Vegas, NV.

U.S. Department of Energy, Nevada Operations Office. 2000a. Corrective Action Investigation Plan for Corrective Action Unit 97: Yucca Flat/Climax Mine, Nevada Test Site, Nevada, DOE/NV--659. Las Vegas, NV.

U.S. Department of Energy, Nevada Operations Office. 2000b. United States Nuclear Tests, July 1945 through September 1992, DOE/NV--209, Rev. 15. Las Vegas, NV.

U.S. Geological Survey. 2007. "Rock Property Database, Nevada Test Site and Vicinity, Nye County, Nevada.” As accessed at http://pubs.usgs.gov/ds/2007/297/ on 10 June 2008.

Vanderborght, J., and H. Vereecken. 2007. "Review of Dispersivities for Transport Modeling in Soils.” In Vadose Zone Journal Vol. 6: 29-52. Soil Science Society of America.

van Genuchten, M.Th. 1980. “A Closed-Form Equation for Predicting the Hydraulic Conductivity of Unsaturated Soils.” In Soil Science Society of America Journal, Vol. 44: 892-898.

Walvoord, M.A., M.A. Plummer, F.M. Phillips, and A.V. Wolfsberg. 2002a. "Deep Arid System Hydrodynamics 1. Equilibrium States and Response Times in Thick Desert Vadose Zones.” In Water Resources Research, Vol. 38(12): 1308.

Walvoord, M.A., F.M. Phillips, S.W. Tyler, and P.C. Hartsough. 2002b. “Deep Arid System Hydrodynamics 2. Application to Paleohydrologic Reconstruction Using Vadose Zone Profiles from the Northern Mojave Desert.” In Water Resources Research, Vol. 38(12): 1291.

Werth, G.C. 1970. The Handcar Nuclear Explosion in Dolomite, UCRL-50951. Livermore, CA: Lawrence Livermore National Laboratory. 
Wilson, G.V., D.M. Ely, S.L. Hokett, and D.R. Gillespie. 2000. "Recharge from a Subsidence Crater at the Nevada Test Site.” In Soil Science Society of America Journal, Vol. 64: 1570-1581. Madison, WI.

Wolfsberg, A., L. Glascoe, G. Lu, A. Olson, P. Lichtner, M. McGraw, T. Cherry, and G. Roemer. 2002. TYBO/BENHAM: Model Analysis of Groundwater Flow and Radionuclide Migration from Underground Nuclear Tests in Southwestern Pahute Mesa, Nevada, LA-13977.

Los Alamos, NM: Los Alamos National Laboratory.

Wolfsberg, A, J. Boryta, E. Keating, P. Stauffer, C. Gable, and S. Kelkar. 2006. Written communication regarding Analysis and Evaluation of Elevated Groundwater Heads and Their Impact on Flow and Solute Transport in the Tuff Pile: Areas 3, 4, and 7 of the Nevada Test Site, Nye County, Nevada. Los Alamos, NM: Los Alamos National Laboratory.

Zavarin, M., S.K. Roberts, T.P. Rose, and D.L. Phinney. 2002. Validating Mechanistic Sorption Model Parameters and Processes for Reactive Transport in Alluvium, UCRL-ID-149728. Livermore, CA: Lawrence Livermore National Laboratory.

Zyvoloski, G.A., B.A. Robinson, Z.V. Dash, and L.L. Trease. 1997a. Summary of Models and Methods for the FEHM Application - A Finite-Element Heat- and Mass-Transfer Code, LA-13307-MS. Los Alamos, NM: Los Alamos National Laboratory.

Zyvoloski, G.A., B.A. Robinson, Z.V. Dash, and L.L. Trease. 1997b. User's Manual for the FEHM Application - A Finite-Element Heat- and Mass-Transfer Code, LA-13306-M. Los Alamos, NM: Los Alamos National Laboratory. 


\section{Appendix A}

Underground Nuclear Tests in the Yucca Flat/Climax Mine Corrective Action Unit 


\section{A.1.0 Underground Nuclear Tests in the Yucca FLAT/Climax Mine CoRRECTIVE ACtION UNIT}

A CD attachment to this appendix contains the Microsoft Excel files that describe the Yucca Flat detonations, conceptual model assignment, and the test categorization criteria (see Section 4.0). There were 747 underground nuclear detonations conducted in shafts and tunnels in the Yucca Flat/Climax Mine CAU. Of the 747, 744 detonations were in Yucca Flat proper and three detonations in the Climax Mine tunnel complex (DOE/NV, 2000). Unclassified information related to the underground nuclear tests conducted within the Yucca Flat/Climax Mine CAU is compiled primarily in two reports, United States Nuclear Tests, July 1945 through September 1992 (DOE/NV, 2000) and Shaft and Tunnel Nuclear Detonations at the Nevada Test Site: Development of a Primary Database for the Estimation of Potential Interactions with the Regional Groundwater System (DOE/NV, 1997).

The term yield refers to the total effective energy released in a nuclear explosion and is usually expressed in terms of equivalent tonnage of TNT required to produce the same energy release in an explosion. Announced yield ranges are reported in DOE/NV (2000); the specific yields for many tests remain classified. The announced yields for some Yucca Flat tests were termed slight, low, or intermediate. Between 1945 and 1963, a less-than-20-kt yield was defined as low, while a 20- to 200-kt yield range was referred to as intermediate. In a few cases, the term "slight” was used without amplification (DOE/NV, 2000). The Yucca Flat unclassified inventory calculations presented in this report used the upper yield range value and the tests defined to have a slight yield were assumed to have a $20 \mathrm{kt}$ maximum yield.

Nuclear devices were emplaced in one of four types of geologic medium in Yucca Flat and Climax Mine: alluvial deposits, Tertiary volcanics, carbonate rocks, or intrusives. The emplacement location is the working point, and the vertical depth to the device primary center line is the depth of burial. The water table depths were estimated by interpolating regional and local (Yucca Flat and Pahute Mesa) water table surfaces and were selected as being the most representative estimate of the regional water table based on the data available at the time (SNJV, 2006). The HSUs associated with each working point are described in BN (2006). The test categorization presented in Section 4.0 
used grouped HSU classes to reduce the possible number of categories. The HSUs with similar hydrogeology were grouped together because the groups have similar flow and transport characteristics.

The cavity radius was calculated from the maximum announced yield, the bulk overburden density, and the depth of burial as illustrated in Equation 3-1. The maximum exchange volume was determined from the maximum cavity radius multiplier values provided in Table 3-1. The tests with working points in the alluvium, vitric tuff, and welded tuff use a value of 2 . The zeolitic tuff use a value of 3. The subsidence crater area data were obtained from the LANL Geographical Information System Laboratory (Kwicklis, 2007).

These data are summarized in the file "YF Conceptual Model Categorization Information.xls" on the document CD. The file contains the following three work sheets:

All Detonations. A summary of data for all the Yucca Flat detonations. The data includes, the name and date of each detonation, name of the emplacement holes, location easting and northing, surface elevation, announced yields, source term yield, depths of burial, estimated depths to the water table, the HSU associated with the working point, Yucca Flat or Climax Mine location, source term conceptual model.

Above Water Table Tests. A summary of data for categorization of the tests with working points located above the water table. These data include detonation name, cavity radius, maximum exchange volume radius, working point grouped HSU, working point distance above the water table, working point depth below land surface, subsidence crater area, presence of a confining unit below the exchange volume and above the water table, exchange volume extending below the water table (partially saturated), and identification of tests with subsidence craters and exchange volume above water table (excluded inventory tests). The four carbonate detonations comprise a unique category apart from the above the water table tests category and are excluded from the summary table.

Below Water Table Tests. A summary of data for categorization of the tests with working points located below the water table. The data include detonation name, cavity radius, maximum exchange volume radius, working point grouped HSU, distance below the water table, working point depth, presence of a high permeability unit in chimney, presence of a high permeability unit in chimney or exchange volume, cavity extending into the carbonate aquifer, exchange volume extending into the carbonate aquifer, presence in the Tuff Pile, and exchange volume extending above the water table (partially saturated). 


\section{A.2.0 RefERENCES}

BN, see Bechtel Nevada.

Bechtel Nevada. 2006. A Hydrostratigraphic Model and Alternatives for the Groundwater Flow and Contaminant Transport Model of Corrective Action Unit 97: Yucca Flat-Climax Mine, Lincoln and Nye Counties, Nevada, DOE/NV/11718--1119. Las Vegas, NV.

DOE/NV, see U.S. Department of Energy, Nevada Operations Office.

Kwicklis, E., Los Alamos National Laboratory. 2007. Personal communication to P. Martian (SNJV) regarding crater areas and the Los Alamos National Laboratory Yucca Flat crater database, 7 December. Los Alamos, NM.

SNJV, see Stoller-Navarro Joint Venture.

Stoller-Navarro Joint Venture. 2006. Phase I Hydrologic Data for the Groundwater Flow and Contaminant Transport Model of Corrective Action Unit 97: Yucca Flat/Climax Mine, Nevada Test Site, Nye County, Nevada, Rev. 0, S-N/99205--077. Las Vegas, NV.

U.S. Department of Energy, Nevada Operations Office. 1997. Shaft and Tunnel Nuclear Detonations at the Nevada Test Site: Development of a Primary Database for the Estimation of Potential Interactions with the Regional Groundwater System, DOE/NV--464 UC-700. Las Vegas, NV.

U.S. Department of Energy, Nevada Operations Office. 2000. United States Nuclear Tests, July 1945 through September 1992, DOE/NV--209, Rev. 15. Las Vegas, NV. 
Appendix B

Radionuclide Inventory of the Yucca Flat/Climax Mine Corrective Action Unit 


\section{B.1.0 Radionuclide INVENTORY OF THE Yucca FLat/Climax Mine Corrective Action Unit}

A CD attachment to this appendix contains the Microsoft Excel files that describe the Yucca Flat comprehensive unclassified radionuclide inventory. The inventory for the noncarbonate test is found in the report, Nevada Test Site Radionuclide Inventory, 1951-1992 (Bowen et al., 2001). This inventory provides an estimate of radioactivity remaining underground at the NTS after nuclear testing. Carle et al. (2008) identified additional unclassified sources of information for estimating the ${ }^{14} \mathrm{C}$ and ${ }^{39} \mathrm{Ar}$ inventory for the HANDCAR detonation, and the ${ }^{3} \mathrm{H}$ and ${ }^{85} \mathrm{Kr}$ inventory for the NASH detonation. The additional sources provided lower or comparable inventories for each radionuclide except the HANDCAR ${ }^{14} \mathrm{C}$. A total of $5.3 \mathrm{Ci}$ (0.085 moles) of ${ }^{14} \mathrm{C}$ was reported as loaded onto the HANDCAR device as a tracer, which is approximately one order of magnitude greater than the yield-weighted estimate. This value was used in place of the Bowen et al. (2001) yield weighted ${ }^{14} \mathrm{C}$ inventory for the HANDCAR detonation.

The individual inventory for each Yucca Flat detonation was obtained in three steps:

1) normalizing the Bowen et al. (2001) inventory by the total Yucca Flat yield above and below the water table, 2) multiplying the normalized inventory by the individual detonation yield and 3 ) decay correcting the individual detonation yield from September 23, 1992, to time $\left(t_{0}\right)$ of each detonation (Section 2.3). This inventory is in the Excel spreadsheet "YF Radionuclide Inventory.xls" on the accompanying $\mathrm{CD}$. 


\section{B.2.0 REFERENCES}

Bowen, S.M., D.L. Finnegan, J.L. Thompson, C.M. Miller, P.L. Baca, L.F. Olivas, C.G. Geoffrion, D.K. Smith, W. Goishi, B.K. Esser, J.W. Meadows, N. Namboodiri, and J.F. Wild. 2001. Nevada Test Site Radionuclide Inventory, 1951-1992, LA-13959-MS. Los Alamos, NM: Los Alamos National Laboratory.

Carle, S.F., M. Zavarin, Y. Sun, and G.A. Pawloski. 2008. Written communication regarding Evaluation of Hydrologic Source Term Processes for Underground Nuclear Tests in Yucca Flat, Nevada Test Site: Carbonate Tests. Livermore, CA: Lawrence Livermore National Laboratory. 
Appendix C

FEHM Simulations of a Multiphase Radionuclide Experiment 


\section{C.1.0 fehm Simulations of a Multiphase RADIONUCLIDE EXPERIMENT}

The INL conducted a series of transport experiments with nonreactive gas-phase, aqueous-phase, and inorganic ${ }^{14} \mathrm{C}$ tracers in a large unsaturated soil column filled with a sediment taken from playas adjacent to a low-level radioactive waste SDA (Plummer et al., 2004).

Inverse modeling of the INL meso-scale column flow and transport experiment was performed to verify the multiphase parameterization of the FEHM model for simulating ${ }^{14} \mathrm{C}$ migration in the unsaturated zone at Yucca Flat. The simulation objectives are to understand the gross physics and chemistry of ${ }^{14} \mathrm{C}$ movement in the vadose zone, and test FEHM parameterization for simulating these processes. 


\section{C.2.0 experiment Description}

The purpose of the meso-scale column experiment was to improve the understanding of the coupled processes that influence contaminant fate and transport in the vadose zone. These processes include: 1) water movement from precipitation, $\mathrm{PET}$, and percolation, 2) $\mathrm{CO}_{2}$ production from plant and microbial respiration, 3) geochemical reactions that can change pore water $\mathrm{pH}$ and redistribute $\mathrm{CO}_{2}$ between the solid, aqueous, and gaseous phases, and 4) $\mathrm{CO}_{2}$ diffusion/advection between subsurface and atmosphere.

The meso-scale experiment was performed in a $9.8 \mathrm{ft}$ high by $3 \mathrm{ft}$ diameter column filled with a calcareous silty-clay sediment taken from a location near the INL SDA. The sediment was 50 to 75 percent quartz, 10 to 25 percent plagioclase and K-feldspar, 10 to 20 percent clay minerals, 5 percent olivine and pyroxene, 5 percent calcite and 5 percent Fe. The fine grain size fraction (less than 75 micrometers $[\mu \mathrm{m}])$ is 40 to 55 percent quartz, 30 to 45 percent clay minerals, 5 to 10 percent plagioclase and K-feldspar, 5 to 10 percent calcite, and 5 percent iron oxides; with trace amounts (5 percent) of gypsum and other minerals (Plummer et al., 2004).

The effective height of the soil in the column was $2.44 \mathrm{~m}$ between water application and extraction points. The column surface was open to the atmosphere and the column bottom was subject to a vacuum designed to provide near steady-state water movement through the column. The column instrumentation includes sampling ports at different depths to measure soil matric potential, water content, water chemistry, soil gas composition, and temperature (Seitz, 2004). Tritium as $\mathrm{HTO},{ }^{14} \mathrm{C}$ as radio-labeled sodium carbonate, and uranium tracers were introduced and monitored in gaseous and aqueous phases. Figure C.2-1 contains a photograph and schematic of the column experiment. A steady 1-liter-per-day (L/day) flow rate was maintained through the column. The water is removed from the column bottom by applying a vacuum through suction candles.

Gas and liquid tracer tests were performed in the column to estimate transport parameters. The gas tracer test consisted of injecting 10 cubic centimeters $\left(\mathrm{cm}^{3}\right)$ of pure sulfur hexafluoride $\left(\mathrm{SF}_{6}\right)$ gas $5 \mathrm{ft}$ 


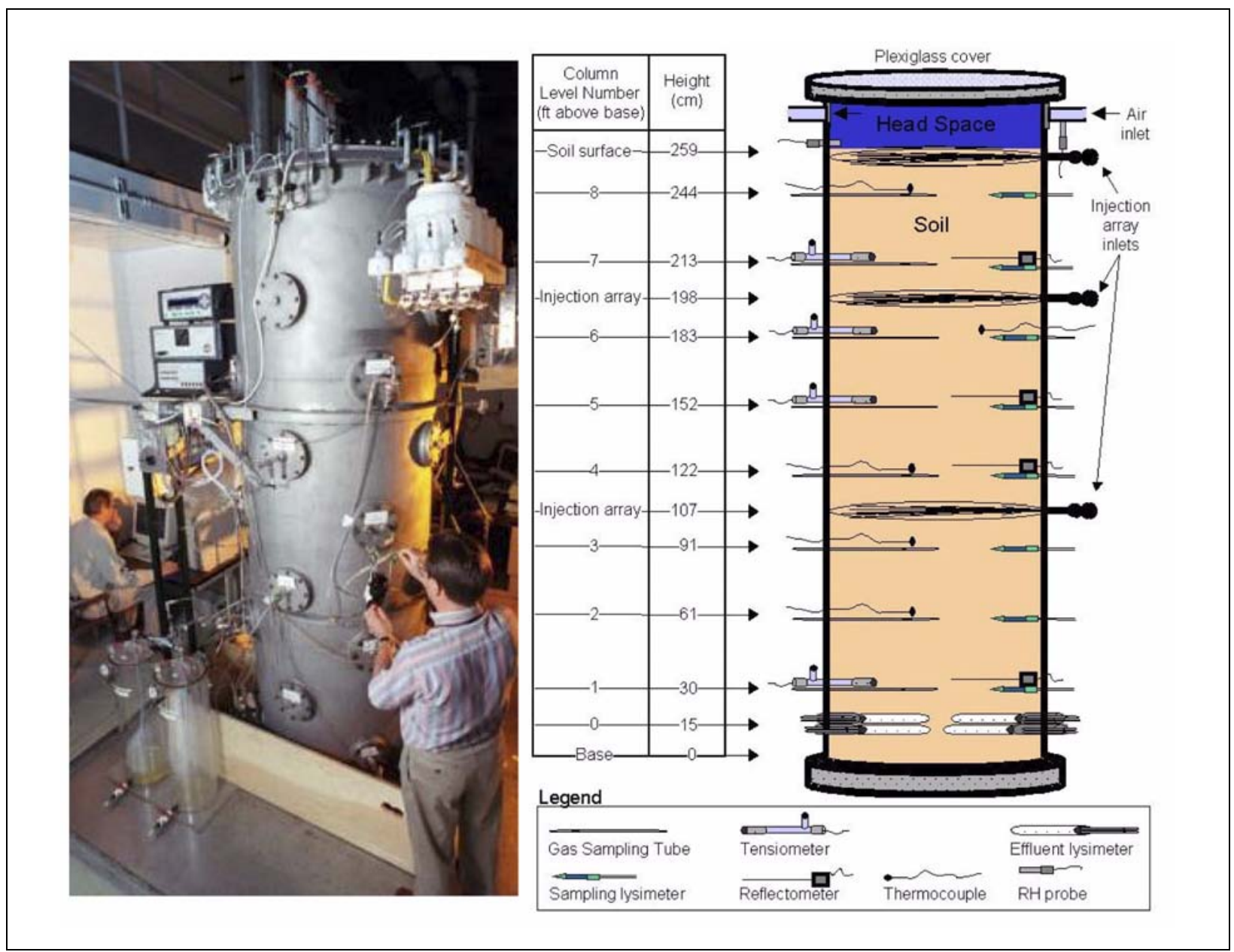

\section{Figure C.2-1 \\ Mesoscale Column Experiment}

Source: Seitz, 2004

below the soil surface and monitoring at 1.5, 2.5, 3.5, 4.5, 5.5, 6.5, and $7.5 \mathrm{ft}$ below the soil surface. The gas was allowed to diffuse out the column top, which is purged at $6.13 \mathrm{~L} /$ day with ambient air. The liquid tracer test consisted of injecting a 0.24 liter (L) slug of 9,875 micrograms per milliliter $(\mu \mathrm{g} / \mathrm{mL})$ lithium-bromide solution into the column at a point $2 \mathrm{ft}$ below the soil surface after the column attained a $1 \mathrm{~L} /$ day steady-state water flow rate. The $\mathrm{Br}$ was monitored and observed at 2.5, 3.5, and $4.5 \mathrm{ft}$ below the soil surface.

The radionuclide transport experiment was started on August 22, 2002, by injecting a solution containing ${ }^{3} \mathrm{H},{ }^{14} \mathrm{C}$, and uranium, at a depth $2 \mathrm{ft}$ below the soil surface, over 4 hours. The radionuclide solution contained 1.6 millicuries (mCi) ${ }^{14} \mathrm{C}$ (as radio-labeled bicarbonate), $0.6 \mathrm{mCi}{ }^{3} \mathrm{H}$ (as $\mathrm{HTO}$ ), and 5.07 milligrams uranium in 2.850 L of water (Plummer et al., 2004). 


\section{C.3.0 Model Parameters}

The conceptual model for ${ }^{14} \mathrm{C}$ transport in the column is that ${ }^{14} \mathrm{C}$ injected from the radio-labeled carbonate will partition between the pore-water and pore-gas phases. The gaseous phase will move upward toward the surface because of diffusion from concentration gradients. The aqueous phase ${ }^{14} \mathrm{C}$ will partition into the solid phase by sorbing onto the porous media. The aqueous phase will be transported with the bulk water movement and diffuse with aqueous concentration gradient, but the movement can be retarded due to sorption on the porous matrix. The distribution of ${ }^{14} \mathrm{C}$ in the aqueous phase will also partition among the carbonate species.

To model the meso-scale column, it is necessary to specify initial conditions, boundary conditions, and two sets of model parameters. The first set is the soil hydraulic properties, which governs the water movement in the meso-scale column, and the second set is the transport properties, which governs the ${ }^{14} \mathrm{C}$ migration. The selection of hydraulic and transport properties are discussed in Sections C.4.0 and C.5.0. 


\section{C.4.0 estimating Soll Hydraulic Properties}

To solve the governing equations for variably saturated flow, FEHM requires parameterization of saturation versus capillary pressure and saturation versus permeability relationships. The van Genuchten (1980) model was used to describe the constitutive relationships. The equation for the moisture characteristic curve is:

$$
\theta=\theta_{r}+\frac{\left(\theta_{s}-\theta_{r}\right)}{\left[1+(\alpha h)^{n}\right]^{1-\frac{1}{n}}}
$$

where:

$h=$ Suction head (units consistent with $1 / \alpha$ )

$\theta=$ Volumetric moisture content

$\theta_{r}=$ Residual moisture content

$\theta_{s}=$ Porosity

$n=$ Pore-size distribution index

$\alpha=$ Inverse air-entry potential (units consistent with $1 / h$ )

When the van Genuchten (1980) function is combined with the Mualem conductivity model (Mualem 1976), the equation for the hydraulic conductivity curve is:

$$
K(h)=K_{s} \frac{\left\{1-(\alpha h)^{n-1}\left[1+(\alpha h)^{n}\right]^{1-1 / n}\right\}^{2}}{\left[1+(\alpha h)^{n}\right]^{0.5(1-1 / n)}}
$$

where:

$K(h)=$ Unsaturated hydraulic conductivity (units consistent with $K_{s}$ )

$K_{s}=$ Saturated hydraulic conductivity [units consistent with $K(h)$ ]

Initial estimates of the constitutive equation parameters were obtained from laboratory analysis of soil core samples taken from the INLs Engineered Barrier Test Facility (EBTF) (Porro, 2001). The EBTF is a landfill earthen barrier experimental facility located near the SDA. The facility is testing different barrier designs proposed for SDA remediation. The EBTF constitutive parameters were then adjusted modestly to match the observed moisture content and tracer breakthrough in the meso-column experiment. The initial and final values for the parameters discussed above and the sources of the values are presented in Table C.4-1. 
Table C.4-1

Hydrologic Constitutive Parameters

\begin{tabular}{|c|c|c|c|}
\hline Parameter & Initial Value & Final Value & Source \\
\hline \hline $\mathrm{K}_{\mathrm{s}}$ & $1.21 \mathrm{E}-6(\mathrm{~m} / \mathrm{s})$ Isotropic & $3.58 \mathrm{E}-6(\mathrm{~m} / \mathrm{s})$ Isotropic & Calibrated \\
\hline$\theta_{\mathrm{s}}$ & 0.47 & 0.38 & Calibrated \\
\hline$\theta_{\mathrm{r}}$ & 0.023 & 0.019 & Porro, 2001 \\
\hline$\alpha$ & $2.56 \mathrm{~m}^{-1}$ & $0.44 \mathrm{~m}^{-1}$ & Calibrated \\
\hline $\mathrm{n}$ & $\mathrm{NM}$ & 1.5 & Calibrated \\
\hline
\end{tabular}

$\mathrm{NM}=$ Not measured

A lower than expected soil porosity was needed to match both the aqueous and gaseous phase tracers. Either the bromide or $\mathrm{SF}_{6}$ tracers could be matched with measured porosity by adjusting the moisture characteristic curve and decreasing the aqueous or gaseous phase saturation. However, a saturation that matched one tracer would result in a saturation that was too large to match the other tracer. The final simulated porosity value suggests that a fraction of the soil pores are not well connected or the column was compacted to a higher bulk density than the EBTF laboratory samples.

The simulated moisture steady-state moisture content was 0.29. The actual moisture content of the column is unknown due to a large uncertainty in measurement techniques, but estimating the moisture content from the steady-state Darcy velocity and the bromide travel time to the monitoring ports suggests the moisture content is 0.29 . 


\section{C.5.0 estimating TRansport Properties}

The transport parameters needed to model ${ }^{14} \mathrm{C}$ movement include: 1) the water/soil partition coefficient, 2) water/gas partition coefficient, 3) soil tortuosity, 4) gas diffusion coefficient, and 5) water diffusion coefficient. Each of these parameters are discussed in turn.

The water/gas partition coefficient describes the amount of solute sorbed onto the solid and the concentration of the solute. This relationship can be linear or nonlinear and several models have been formulated for the relationship. A linear sorption isotherm using a single parameter $\left(\mathrm{K}_{d}\right)$ was used to partition the ${ }^{14} \mathrm{C}$ between the aqueous and solid phases. The linear isotherm is described by the relationship:

$$
C_{S}=K_{d} C
$$

where:

$C_{S}=$ Mass sorbed onto soil (pCi/g)

$K_{d}=$ Distribution coefficient $(\mathrm{mL} / \mathrm{g})$

$C=$ Aqueous concentration $(\mathrm{pCi} / \mathrm{mL})$

The water/gas partition can be described using Henry's Law, which states that for dilute solutions there is a linear relationship between the partial vapor pressure in the gaseous phase and the aqueous phase concentration. Henry's Law relates the total $\left({ }^{14} \mathrm{C}\right.$ and $\left.{ }^{12} \mathrm{C}\right) \mathrm{CO}_{2}$ partial pressure and total pore water $\mathrm{CO}_{2}$. However, the linear nature of Henry's Law allows correct partitioning even if only the ${ }^{14} \mathrm{C}$ fraction of all $\mathrm{C}$ is simulated. The Henry's coefficient needed for partitioning $\mathrm{CO}_{2}$ between the pore water and gas is an effective Henry's coefficient. The effective Henry's coefficient may be determined from the total combined solubility of DIC in the carbonate species present $\left(\mathrm{H}_{2} \mathrm{CO}_{3}\right.$, $\mathrm{HCO}_{3}{ }^{-}$, and $\mathrm{CO}_{3}{ }^{2-}$ ), which is a function of geochemical conditions (i.e., $\mathrm{pH}$ and temperature). The effective Henry's Law was calculated for a $\mathrm{pH}$ of 7 and temperature of $25^{\circ} \mathrm{C}$. 
Section 5.3.4.4 discusses the calculation of the effective $\mathrm{CO}_{2}$ Henry's coefficient in more detail. The equation for Henry's Law is:

$$
P^{o} K_{H}=W
$$

where:

$K_{H}=$ Henry's coefficient (1/atm)

$P^{o}=$ Pure component vapor partial pressure (atm)

$W=$ Dissolved gas concentration mole fraction (mole/mole)

The free gas and water diffusion coefficients are the proportionality constants relating the solute mass flux to the concentration gradient. These values were obtained from the literature.

The tortuosity describes the ratio of the actual flow path to the straight line flow path of a particle moving between two points. Tortuosity lowers the effective diffusion coefficient from the free diffusion in an open system and is described by:

$$
D_{\text {eff }}=\frac{D_{\text {free }}}{\tau}
$$

where:

$D_{\text {eff }}=$ Effective diffusion coefficient

$D_{\text {free }}=$ Free diffusion coefficient

$\tau \quad=$ Tortuosity

The tortuosity of the phase will increase with decreasing phase saturations and the FEHM simulations used the Millington Quirk diffusion model. The meso-scale tortuosity was estimated through calibration to the shape of the gas tracer breakthrough curves. The longitudinal and transverse dispersivity values were $0 \mathrm{~m}$. Calibration to the shape of the $\mathrm{Br}$ breakthrough curve did not require additional dispersion beyond that contributed by the diffusion coefficient. The numerical dispersion inherent in the FEHM simulations likely contributed to the simulations total dispersion. The transport parameters used in this study are provided in Table C.5-1. 
Table C.5-1

Transport Parameters

\begin{tabular}{|c|c|c|c|}
\hline Parameter & Species & Value & Sources \\
\hline Gaseous $D_{\text {free }}$ & $\mathrm{SF}_{6}$ & $1.10 \times 10^{-5}\left(\mathrm{~m}^{2} / \mathrm{day}\right)$ & Hull and Hohorst, 2001 \\
\hline Gaseous $D_{\text {free }}$ & $\mathrm{CO}_{2}$ & $1.85 \times 10^{-5}\left(\mathrm{~m}^{2} /\right.$ day $)$ & Hull and Hohorst, 2001 \\
\hline Aqueous $D_{\text {free }}$ & $\mathrm{SF}_{6}$ & $1 \times 10^{-9}\left(\mathrm{~m}^{2} / \mathrm{s}\right)$ & Calibrated to breakthrough \\
\hline Aqueous $D_{\text {free }}$ & $\mathrm{CO}_{2}$ & $1 \times 10^{-9}\left(\mathrm{~m}^{2} / \mathrm{s}\right)$ & Calibrated to breakthrough \\
\hline Aqueous $D_{\text {free }}$ & Bromide & $1 \times 10^{-9}\left(\mathrm{~m}^{2} / \mathrm{s}\right)$ & Calibrated to breakthrough \\
\hline$\tau$ & All & 2 & Calibrated to breakthrough \\
\hline $\mathrm{K}_{\mathrm{H}}$ & $\mathrm{CO}_{2}$ & $6.24 \times 10^{-4}(1 / \mathrm{atm})$ & Kehow, 2001 \\
\hline $\mathrm{K}_{\mathrm{H}}$ & Total Carbonate DIC & $3.42 \times 10^{-3}$ (1/atm) & Calculated for $\mathrm{pH}=7$ and $\mathrm{T}=25^{\circ} \mathrm{C}$ \\
\hline $\mathrm{K}_{\mathrm{H}}$ & $\mathrm{SF}_{6}$ & 0.0 & Calibrated to breakthrough \\
\hline $\mathrm{K}_{\mathrm{d}}$ & $\mathrm{CO}_{2}$ & $0.8(\mathrm{~mL} / \mathrm{g})$ & Hull and Hohorst, 2001 \\
\hline
\end{tabular}




\section{C.6.0 SMULATION ProfLE}

The simulation domain was a 1-D vertical profile using cartesian coordinates. Horizontal cell dimensions are $0.81 \times 0.81 \mathrm{~m}$ and provide the same cross-sectional area as the $0.46 \mathrm{~m}$ radius column. The vertical discretization used 200 computational nodes to simulate the $2.44 \mathrm{~m}$ giving a 1.22 centimeter grid block thickness. The top model boundary condition was one L/day water flux and atmospheric (99.7 kilopascals) gas phase pressure. The bottom boundary condition was a fixed saturation of 0.76 , which corresponds to steady-state saturation at the specified water flux rate. 


\section{C.7.0 SMULATION RESULTS}

The simulation results showed good agreement with the experimental data with only adjustment of the soil moisture characteristic curve parameters.

The $\mathrm{SF}_{6}$ measurements showed a lingering tail on the breakthrough curve, which was not seen in the simulations. This may be due to some $\mathrm{SF}_{6}$ gas remaining in the injection lines continuing to slowly diffuse into the column. The simulation assumed nearly instantaneous injection of all $\mathrm{SF}_{6}$ gas. However, the injection lines volume accounts for $\sim 1.4 \mathrm{~cm}^{3}$ of the $10 \mathrm{~cm}^{3} \mathrm{SF}_{6}$ volume, and the lines were not purged after injection.

The simulated and observed ${ }^{14} \mathrm{C}$ concentrations had the best agreement, indicating the effective Henry's coefficient correctly partitioned ${ }^{14} \mathrm{C}$ between the aqueous and gaseous phases. The experimental and simulation results also indicate that differential $\mathrm{CO}_{2}$ production with depth is not significantly affecting ${ }^{14} \mathrm{C}$ migration. Simulated and observed tracer breakthroughs for $\mathrm{Br}, \mathrm{SF}_{6}$, aqueous-phase ${ }^{14} \mathrm{C}$, and gaseous-phase ${ }^{14} \mathrm{C}$ are illustrated in Figures C.7-1 through C.7-4, respectively. 


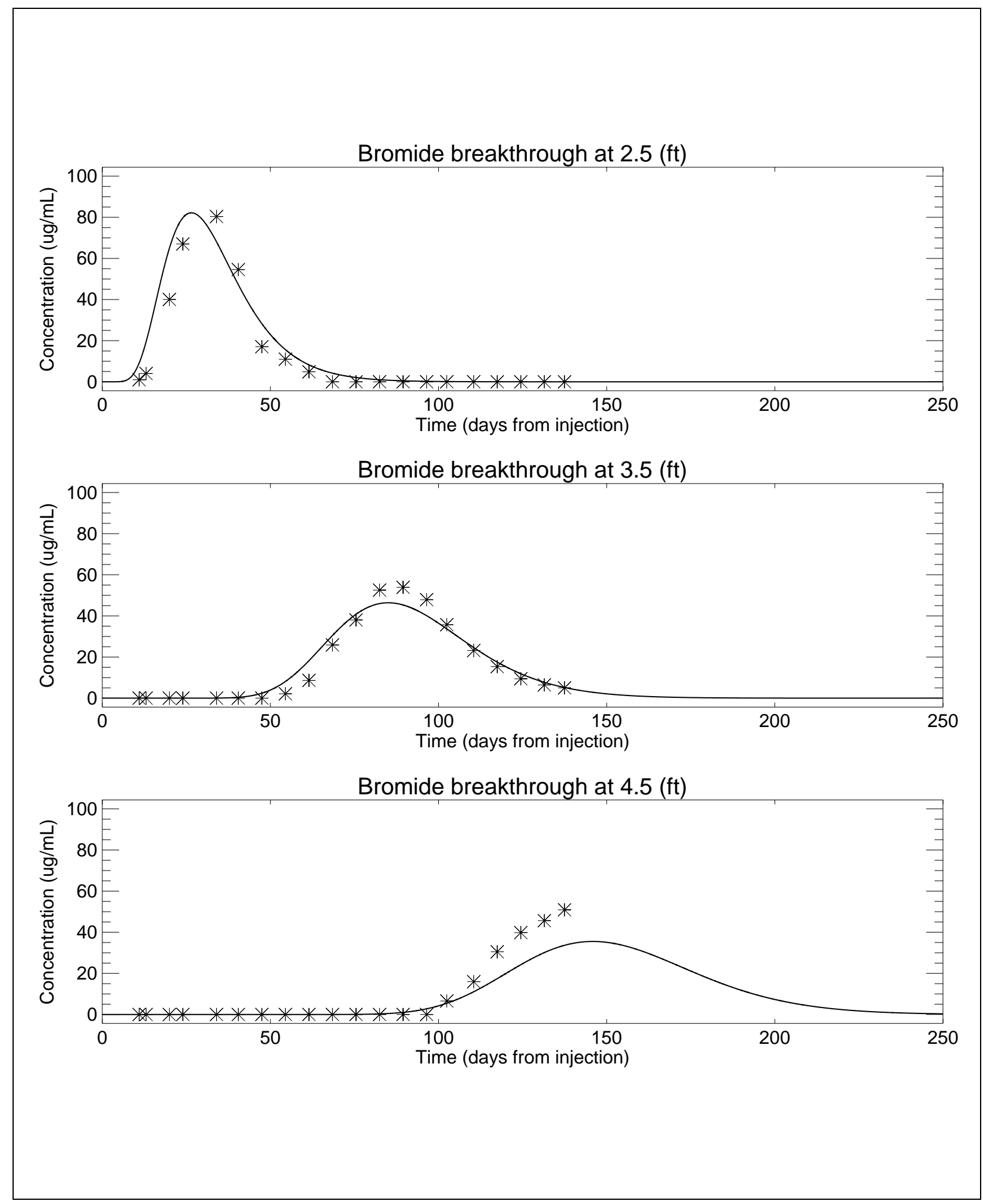

Figure C.7-1

$\mathrm{Br}$ Tracer Breakthrough at Depth

(Solid line denotes simulated concentration.) 


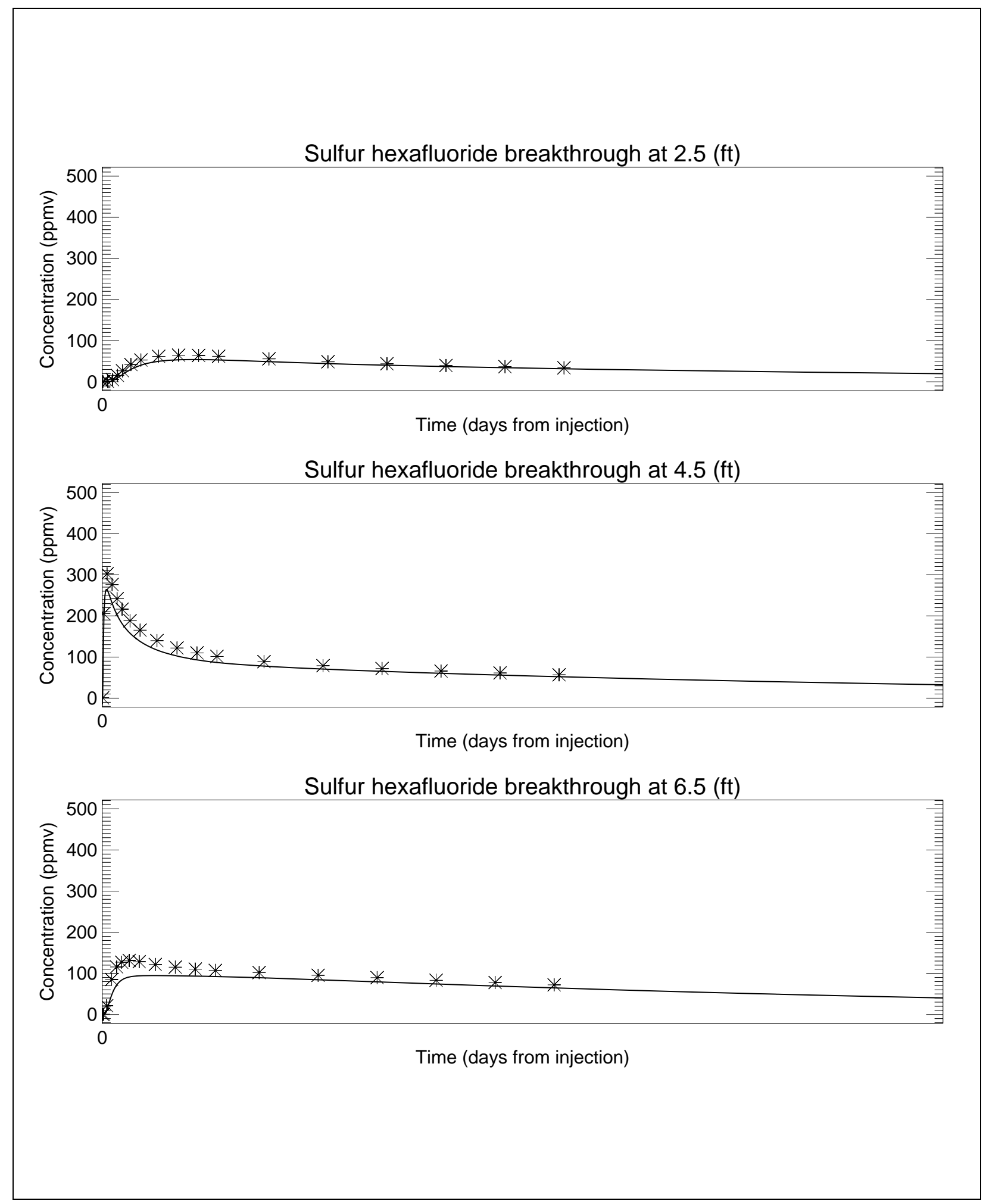

Figure C.7-2

$\mathrm{SF}_{6}$ Tracer Breakthrough at Depth

(Solid line denotes simulated concentration.) 


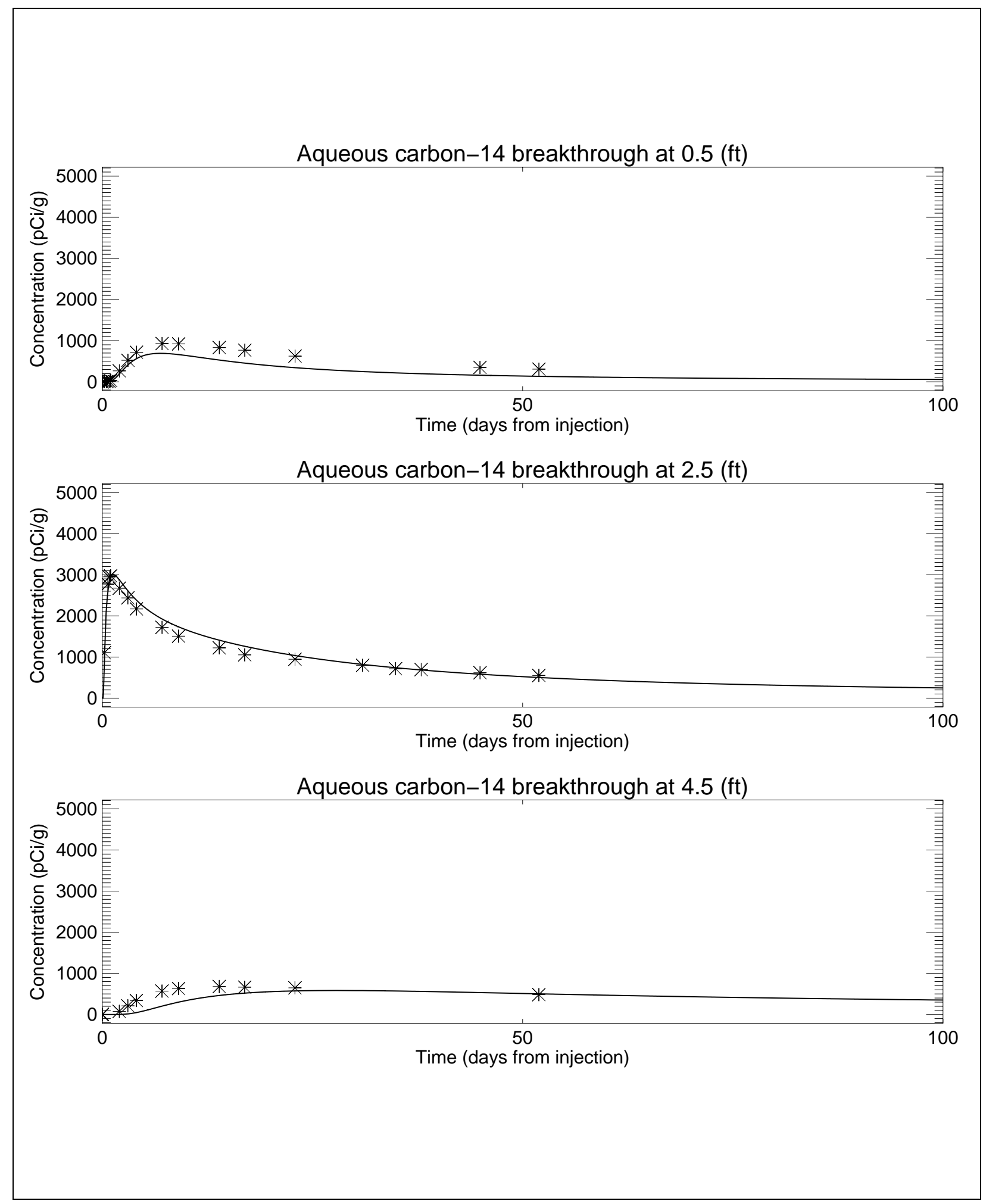

Figure C.7-3

Aqueous ${ }^{14} \mathrm{C}$ Tracer Breakthrough at Depth

(Solid line denotes simulated concentration.) 


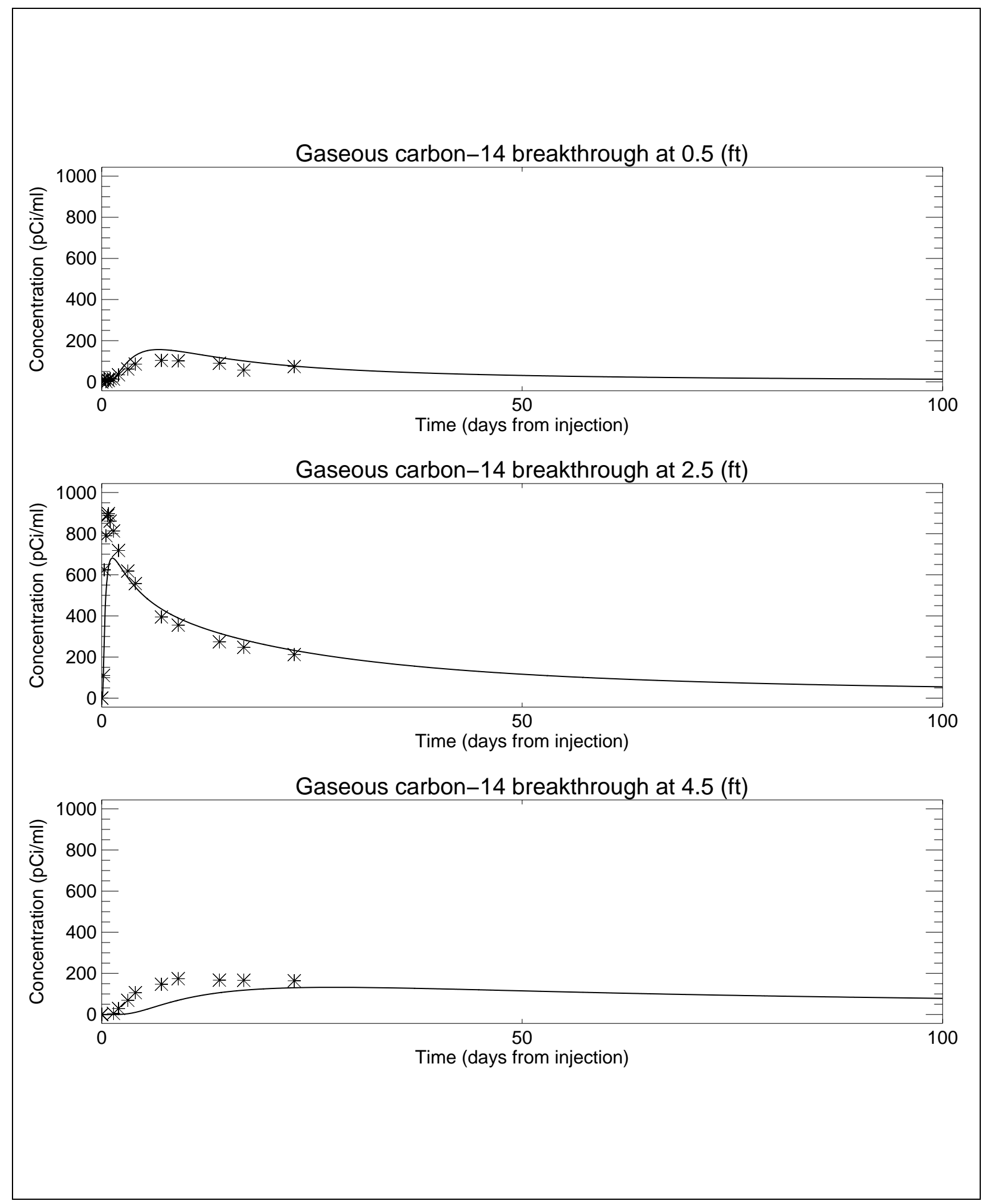

Figure C.7-4

Gaseous ${ }^{14} \mathrm{C}$ Tracer Breakthrough at Depth

(Solid line denotes simulated concentration.) 


\section{8.0 conclusions}

The simulation results show good agreement with the experimental data indicating that flow and transport properties were successfully estimated and the models adequate predictive capability to model ${ }^{14} \mathrm{C}$ fate and transport. However, NTS specific parameters are needed for predictive simulation of ${ }^{14} \mathrm{C}$ at Yucca Flat.

More specific conclusions include: 1) the effective Henry's coefficient adequately partitioned ${ }^{14} \mathrm{C}$ between the aqueous and gaseous phases, 2) ${ }^{14} \mathrm{C}$ can be simulated as moving independently of the $\mathrm{CO}_{2}$ concentration seen in the column, and 3) a linear sorption isotherm for ${ }^{14} \mathrm{C}$ adequately mimicked ${ }^{14} \mathrm{C}$ aqueous-phase sorption in the unsaturated system. Although the modeling presented in this report concluded ${ }^{14} \mathrm{C}$ can be adequately simulated as moving independently of the $\mathrm{CO}_{2}$ concentration, the meso-column investigators (Plummer et al., 2004) found that changes in $\mathrm{CO}_{2}$ affected $\mathrm{pH}$ sufficiently to affect aqueous/gas phase ${ }^{14} \mathrm{CO}_{2}$ partitioning and diffusive transport.

The model parameters used to match the tracer tests are not necessarily unique and a different combination of parameters could produce similar results. Furthermore, the model sensitivity to these parameters was not investigated. 


\section{C.9.0 REFERENCES}

Hull, L.C., and F.A. Hohorst. 2001. Transport Models for Radioactive Carbon Dioxide at RWMC, INEEL/EXT-01-00894, August. Idaho Falls, ID: Idaho National Engineering and Environmental Laboratory.

Kehow, A.E. 2001. Applied Chemical Hydrogeology. Upper Saddle River, NJ: Prentice-Hall, Inc.

Mualem, Y. 1976. “A New Model for Predicting the Unsaturated Hydraulic Conductivity of Unsaturated Porous Media.” In Water Resources Research, Vol. 12: 513-522.

Plummer, M.A., L.C. Hull, and D.T. Fox. 2004. "Transport of Carbon-14 in a Large Unsaturated Soil Column. In: Special Section: Understanding Subsurface Flow and Transport Processes at the Idaho National Engineering \& Environmental Laboratory (INEEL) Site.” In Vadose Zone Journal, Vol. 3: 109-121.

Porro, I. 2001. "Hydrologic Behavior of Two Engineered Barriers following Extreme Wetting." In Journal of Environmental Quality, Vol. 30: 655-667.

Seitz, R.R. 2004. “Applying INEEL Research and Technologies to Improve LLW Disposal,” ICP/CON-04-00247; OSTI ID: 911059. In Waste Management '04 Conference, 29 February 4 March, Tucson, AZ. Idaho Falls, ID: Idaho Completion Project; Bechtel BWXT Idaho, LLC.

van Genuchten, M.Th. 1980. "A Closed-Form Equation for Predicting the Hydraulic Conductivity of Unsaturated Soils.” In Soil Science Society of America Journal, Vol. 44: 892-898. 


\title{
Appendix D
}

Comments from Nevada Division of Environmental Protection

\author{
(10 Pages)
}

Pages 1-2: Revision 1 comments

Pages 3-10: Revision 0 comments 


\section{NEVADA ENVIRONMENTAL RESTORATION PROJECT}

DOCUMENT REVIEW SHEET

\begin{tabular}{|c|c|c|c|c|c|c|}
\hline \multicolumn{2}{|c|}{ 1. Document Title/Number: } & \multicolumn{2}{|c|}{$\begin{array}{l}\text { Final Unclassified Source Term and Radionuclide Data for Corrective Action Unit } \\
\text { 97: Yucca Flat/Climax Mine, Nevada Test Site, Nevada }\end{array}$} & \multirow{2}{*}{\begin{tabular}{|l|} 
2. Document Date: \\
4. Originator/Organization:
\end{tabular}} & \multicolumn{2}{|l|}{$5 / 27 / 2009$} \\
\hline \multicolumn{2}{|l|}{ 3. Revision Number: } & \multicolumn{2}{|l|}{1} & & \multicolumn{2}{|l|}{ Stoller-Navarro } \\
\hline \multicolumn{2}{|c|}{$\begin{array}{l}\text { 5. Responsible NNSA/NSO Federal } \\
\text { Sub-Project Director: }\end{array}$} & \multicolumn{2}{|l|}{ Bill Wilborn } & 6. Date Comments Due: & & \\
\hline \multicolumn{7}{|l|}{ 7. Review Criteria: } \\
\hline \multicolumn{2}{|c|}{ 8. Reviewer/Organization/Phone No: } & \begin{tabular}{l|l} 
: & Tim Murphy, NDEP, 486-2850
\end{tabular} & & 9. Reviewer's Signature: & & \\
\hline $\begin{array}{l}\text { 10. Comment } \\
\text { Number/Location }\end{array}$ & 11. Type* & 12. Comment & \multicolumn{3}{|c|}{ 13. Comment Response } & 14. Accept \\
\hline $\begin{array}{l}\text { 6.) Page 2-6, } \\
\text { Section 2.3.1, 1st } \\
\text { Paragraph, 5th } \\
\text { Sentence }\end{array}$ & Mandatory & $\begin{array}{l}\text { Original Comment No. } 6 \text { was not changed as requested by } \\
\text { NDEP and the text in Section } 2.3 .1 \text { and Figure } 1-1 \text { remain } \\
\text { in disagreement. The Rainier Mesa/Shoshone Mountain } \\
\text { group does not include Area } 30 .\end{array}$ & \multicolumn{3}{|c|}{$\begin{array}{l}\text { The sentence has been corrected as: "The Rainier } \\
\text { Mesa/Shoshone Mountain group includes Areas 12, } 16 \\
\text { and 17." }\end{array}$} & \\
\hline $\begin{array}{l}\text { 14.) Page 5-9, } \\
\text { Section 5.3.3.1, } \\
\text { Last Sentence }\end{array}$ & Mandatory & $\begin{array}{l}\text { Original Comment No. } 14 \text { referenced Section 5.3.3.1, } \\
\text { which describes Alluvium Hydraulic Properties. The } \\
\text { response to original Comment No. } 13 \text { pertains to Vadose } \\
\text { zone chimney drainage. It is not clear how the comment } \\
\text { response for No. } 13 \text { applies to Comment No. } 14 \text { since the } \\
\text { two referenced Sections are describing two different } \\
\text { issues. }\end{array}$ & \multicolumn{3}{|c|}{$\begin{array}{l}\text { Section 5.3.3.1 last paragraph, the last sentence is } \\
\text { corrected as: "Consequently, the hydraulic properties for } \\
\text { the deep vadose zone are an uncertain model parameter." } \\
\text { The following sentence is added to the end of the } \\
\text { paragraph: "The Yucca Flat contaminant boundary } \\
\text { calculations will include identifying parametric model } \\
\text { sensitivity and uncertainty (see Section 3.5)." } \\
\text { Section 3.5, 2nd paragraph, the following sentence is } \\
\text { added after the 2nd sentence: "A sensitivity analysis can } \\
\text { be used to identify the sensitive flow and transport model } \\
\text { parameters and the sensitive parameters will be included } \\
\text { in the uncertainty analysis." } \\
\text { Section } 6.3, \text { the following paragraph is added to the end of } \\
\text { this section: "The multiphase transport simulations } \\
\text { presented in Section } 5.0 \text { and Appendix C did not include } \\
\text { an assessment of model uncertainty. The planned CAU } \\
\text { transport modeling should include identifying multiphase } \\
\text { flow and transport model parameter sensitivity and } \\
\text { uncertainty. The uncertainty analysis should focus on the } \\
\text { processes that contribute most to the contaminant } \\
\text { boundary uncertainty and the model sensitivity analysis } \\
\text { should be used to identify these processes." }\end{array}$} & \\
\hline
\end{tabular}




\section{NEVADA ENVIRONMENTAL RESTORATION PROJECT}

DOCUMENT REVIEW SHEET

\begin{tabular}{|c|c|c|c|c|c|c|}
\hline \multicolumn{2}{|c|}{ 1. Document Title/Number: } & \multicolumn{2}{|c|}{$\begin{array}{l}\text { Final Unclassified Source Term and Radionuclide Data for Corrective Action Unit } \\
\text { 97: Yucca Flat/Climax Mine, Nevada Test Site, Nevada }\end{array}$} & \multirow{2}{*}{\begin{tabular}{|l|} 
2. Document Date: \\
4. Originator/Organization:
\end{tabular}} & \multicolumn{2}{|l|}{$5 / 27 / 2009$} \\
\hline \multicolumn{2}{|l|}{ 3. Revision Number: } & 1 & & & \multicolumn{2}{|l|}{ Stoller-Navarro } \\
\hline \multicolumn{2}{|c|}{$\begin{array}{l}\text { 5. Responsible NNSA/NSO Federal } \\
\text { Sub-Project Director: }\end{array}$} & Bill Wilborn & & 6. Date Comments Due: & & \\
\hline \multicolumn{7}{|l|}{ 7. Review Criteria: } \\
\hline \multicolumn{2}{|c|}{ 8. Reviewer/Organization/Phone No: } & : Tim Murphy, NDEP, 486-2850 & & 9. Reviewer's Signature: & & \\
\hline $\begin{array}{l}\text { 10. Comment } \\
\text { Number/Location }\end{array}$ & 11. Type* & 12. Comment & \multicolumn{3}{|c|}{ 13. Comment Response } & 14. Accept \\
\hline $\begin{array}{l}\text { 15.) Page 5-11, } \\
\text { Section 5.3.4.1, } \\
\text { 3rd Paragraph, } \\
\text { 3rd Sentence }\end{array}$ & Mandatory & $\begin{array}{l}\text { The response to Original Comment No. } 15 \text { does not } \\
\text { address the original question of "Will the effect of this } \\
\text { uncertainty be investigated?" }\end{array}$ & \multicolumn{3}{|c|}{$\begin{array}{l}\text { Section 5.3.4.1 last paragraph, the following sentence is } \\
\text { added after the last sentence: "The ranges of porosity } \\
\text { values presented in SNJV, (2007) indicate porosity is an } \\
\text { uncertain model parameter. The Yucca Flat contaminant } \\
\text { boundary calculations will include identifying parametric } \\
\text { model sensitivity and uncertainty (see Section 3.5)." } \\
\text { Section 3.5, 2nd paragraph, the following sentence is } \\
\text { added after the 2nd sentence: "A sensitivity analysis can } \\
\text { be used to identify the sensitive flow and transport model } \\
\text { parameters and the sensitive parameters will be included } \\
\text { in the uncertainty analysis." } \\
\text { Section 6.3, the following paragraph is added to the end of } \\
\text { this section: "The multiphase transport simulations } \\
\text { presented in Section } 5.0 \text { and Appendix C did not include } \\
\text { an assessment of model uncertainty. The planned CAU } \\
\text { transport modeling should include identifying multiphase } \\
\text { flow and transport model parameter sensitivity and } \\
\text { uncertainty. The uncertainty analysis should focus on the } \\
\text { processes that contribute most to the contaminant } \\
\text { boundary uncertainty and the model sensitivity analysis } \\
\text { should be used to identify these processes." }\end{array}$} & \\
\hline
\end{tabular}




\section{NEVADA ENVIRONMENTAL RESTORATION PROJECT}

DOCUMENT REVIEW SHEET

\begin{tabular}{|c|c|c|c|c|c|c|}
\hline \multicolumn{2}{|c|}{ 1. Document Title/Number: } & \multicolumn{2}{|c|}{$\begin{array}{l}\text { Draft Unclassified Source Term and Radionuclide Data for Corrective Action Unit } \\
\text { 97: Yucca Flat/Climax Mine, Nevada Test Site, Nevada }\end{array}$} & \multirow{2}{*}{\begin{tabular}{|l|} 
2. Document Date: \\
4. Originator/Organization: \\
\end{tabular}} & \multicolumn{2}{|l|}{$2 / 25 / 2009$} \\
\hline \multicolumn{2}{|l|}{ 3. Revision Number: } & \multicolumn{2}{|l|}{0} & & \multicolumn{2}{|l|}{ Stoller-Navarro } \\
\hline \multicolumn{2}{|c|}{$\begin{array}{l}\text { 5. Responsible NNSA/NSO Federal } \\
\text { Sub-Project Director: }\end{array}$} & \multicolumn{2}{|l|}{ Bill Wilborn } & 6. Date Comments Due: & \multicolumn{2}{|l|}{ 3/30/2009 } \\
\hline \multicolumn{2}{|c|}{ 7. Review Criteria: } & \multicolumn{2}{|l|}{ Full } & & & \\
\hline \multicolumn{2}{|c|}{ 8. Reviewer/Organization/Phone No: } & Tim Murphy, NDEP, 486-2850 & & 9. Reviewer's Signature: & & \\
\hline $\begin{array}{l}\text { 10. Comment } \\
\text { Number/Locatio }\end{array}$ & 11. Type* & 12. Comment & \multicolumn{3}{|c|}{ 13. Comment Response } & 14. Accept \\
\hline $\begin{array}{l}\text { 1.) Page 1-5, } \\
\text { Section 1.2, 1st } \\
\text { Paragraph, Last } \\
\text { Sentence }\end{array}$ & Mandatory & $\begin{array}{l}\text { Based on Figure 1-1, Area } 12 \text { should also be included in } \\
\text { this sentence. }\end{array}$ & \multicolumn{3}{|c|}{$\begin{array}{l}\text { The sentence has been changed to: "This CAU includes } \\
\text { portions of NTS Areas } 1 \text { through } 4,6 \text { through 12, and } 15 \\
\text { (Figure 1-1)". }\end{array}$} & \\
\hline $\begin{array}{l}\text { 2.) Page 1-9, } \\
\text { Figure 1-3 }\end{array}$ & Mandatory & $\begin{array}{l}\text { In the CADD portion of the figure, there is no box around } \\
\text { "NDEP CADD Review." Please add the box. }\end{array}$ & \multicolumn{3}{|c|}{$\begin{array}{l}\text { A box has been added around "NDEP CADD Review" in } \\
\text { Figure 1-3. }\end{array}$} & \\
\hline $\begin{array}{l}\text { 3.) Page 1-10, 1st } \\
\text { Paragraph, 1st } \\
\text { Sentence }\end{array}$ & Mandatory & $\begin{array}{l}\text { "...6) model validation,... Based on the revisions to the } \\
\text { Federal Facility Agreement and Consent Order (FFACO) } \\
\text { currently under review, model validation will be replaced with } \\
\text { model evaluation. Although model validation is used in the } \\
\text { Yucca Flat Corrective Action Investigation Plan, it is } \\
\text { advisable to change the term to model evaluation. }\end{array}$ & \multicolumn{3}{|c|}{$\begin{array}{l}\text { The sixth item in the list has been changed to "model } \\
\text { evaluation" as suggested by NDEP. }\end{array}$} & \\
\hline $\begin{array}{l}\text { 4.) Page 2-1, } \\
\text { Section 2.0, 2nd } \\
\text { Paragraph, 2nd } \\
\text { Sentence }\end{array}$ & Mandatory & Please define what is meant by "several". & \multicolumn{3}{|c|}{$\begin{array}{l}\text { The sentence has been changed to "The LLNL defines the } \\
\text { near-field as the subsurface environment located within } \\
\text { several (1-10) cavity radii (Rc) of the test." Ten cavity radii is } \\
\text { the maximum extent of initial contamination considered in } \\
\text { the LLNL HST models and modeling documentation. }\end{array}$} & \\
\hline
\end{tabular}


NEVADA ENVIRONMENTAL RESTORATION PROJECT

DOCUMENT REVIEW SHEET

\begin{tabular}{|c|c|c|c|c|c|c|}
\hline \multicolumn{2}{|c|}{ 1. Document Title/Number: } & \multicolumn{2}{|c|}{$\begin{array}{l}\text { Draft Unclassified Source Term and Radionuclide Data for Corrective Action Unit } \\
\text { 97: Yucca Flat/Climax Mine, Nevada Test Site, Nevada }\end{array}$} & \multirow{2}{*}{\begin{tabular}{|l|} 
2. Document Date: \\
4. Originator/Organization: \\
\end{tabular}} & \multicolumn{2}{|l|}{$2 / 25 / 2009$} \\
\hline \multicolumn{2}{|l|}{ 3. Revision Number: } & \multicolumn{2}{|l|}{0} & & \multicolumn{2}{|l|}{ Stoller-Navarro } \\
\hline \multicolumn{2}{|c|}{$\begin{array}{l}\text { 5. Responsible NNSA/NSO Federal } \\
\text { Sub-Project Director: }\end{array}$} & \multicolumn{2}{|l|}{ Bill Wilborn } & 6. Date Comments Due: & \multicolumn{2}{|l|}{ 3/30/2009 } \\
\hline \multicolumn{2}{|c|}{ 7. Review Criteria: } & \multicolumn{2}{|l|}{ Full } & & & \\
\hline \multicolumn{2}{|c|}{ 8. Reviewer/Organization/Phone No: } & \multicolumn{2}{|l|}{ Tim Murphy, NDEP, 486-2850 } & 9. Reviewer's Signature: & & \\
\hline $\begin{array}{l}\text { 10. Comment } \\
\text { Number/Locatio }\end{array}$ & 11. Type* & 12. Comment & \multicolumn{3}{|c|}{ 13. Comment Response } & 14. Accept \\
\hline $\begin{array}{l}\text { 5.) Page 2-1, } \\
\text { Section 2.0, 1st } \\
\text { Bullet; Page 2-28, } \\
\text { Section 2.4.3.1, } \\
\text { 2nd Paragraph, } \\
\text { 1st Sentence; } \\
\text { Page 3-4, Section } \\
\text { 3.2.1.1, 1st } \\
\text { Bullet, 4th } \\
\text { Sentence; Page 3- } \\
\text { 22, Section 3.4.1, } \\
\text { 2nd Paragraph, } \\
\text { 1st Sentence; } \\
\text { Page 5-30, } \\
\text { Section 5.4.1.3, } \\
\text { 1st Paragraph, } \\
\text { 2nd Sentence }\end{array}$ & \begin{tabular}{|l} 
Mandatory \\
\\
\end{tabular} & $\begin{array}{l}\text { Reference Carle et al., } 2007 \text { is included in Section } 7.0 \text {, } \\
\text { References as both } 2006 \text { and } 2007 \text {. From the Office of } \\
\text { Scientific and Technical Information website, this reference } \\
\text { is published as } 2006 \text {. Please correct the reference on these } \\
\text { pages and in the Reference Section. }\end{array}$ & \multicolumn{3}{|c|}{$\begin{array}{l}\text { The most current version of (UCRL-TR-226916) is dated } \\
\text { March 2007. The } 2006 \text { reference has been removed from } \\
\text { Section 7.0. }\end{array}$} & \\
\hline $\begin{array}{l}\text { 6.) Page 2-6, } \\
\text { Section 2.3.1, 1st } \\
\text { Paragraph, 5th } \\
\text { Sentence }\end{array}$ & Mandatory & $\begin{array}{l}\text { Based on Figure 1-1, the Rainier Mesa/Shoshone Mountain } \\
\text { group includes Areas } 12,16,17 \text {, and } 19 \text {, not the areas } \\
\text { listed in the sentence. Please correct this sentence. }\end{array}$ & \multicolumn{3}{|c|}{$\begin{array}{l}\text { The sentence has been corrected as: "The Rainier } \\
\text { Mesa/Shoshone Mountain group includes Areas 12, 16, 17, } \\
\text { and 30." }\end{array}$} & \\
\hline
\end{tabular}




\section{NEVADA ENVIRONMENTAL RESTORATION PROJECT}

DOCUMENT REVIEW SHEET

\begin{tabular}{|c|c|c|c|c|c|c|}
\hline \multicolumn{2}{|c|}{ 1. Document Title/Number: } & \multicolumn{2}{|c|}{$\begin{array}{l}\text { Draft Unclassified Source Term and Radionuclide Data for Corrective Action Unit } \\
\text { 97: Yucca Flat/Climax Mine, Nevada Test Site, Nevada }\end{array}$} & \multirow{2}{*}{\begin{tabular}{|l|} 
2. Document Date: \\
4. Originator/Organization: \\
\end{tabular}} & \multicolumn{2}{|l|}{$2 / 25 / 2009$} \\
\hline \multicolumn{2}{|l|}{ 3. Revision Number: } & \multicolumn{2}{|l|}{0} & & \multicolumn{2}{|l|}{ Stoller-Navarro } \\
\hline \multicolumn{2}{|c|}{$\begin{array}{l}\text { 5. Responsible NNSA/NSO Federal } \\
\text { Sub-Project Director: }\end{array}$} & \multicolumn{2}{|l|}{ Bill Wilborn } & 6. Date Comments Due: & \multicolumn{2}{|l|}{ 3/30/2009 } \\
\hline \multicolumn{2}{|c|}{ 7. Review Criteria: } & \multicolumn{2}{|l|}{ Full } & & & \\
\hline \multicolumn{2}{|c|}{ 8. Reviewer/Organization/Phone No: } & Tim Murphy, NDEP, 486-2850 & & 9. Reviewer's Signature: & & \\
\hline $\begin{array}{l}\text { 10. Comment } \\
\text { Number/Locatio }\end{array}$ & 11. Type* & 12. Comment & \multicolumn{3}{|c|}{ 13. Comment Response } & 14. Accept \\
\hline $\begin{array}{l}\text { 7.) Page 2-6, } \\
\text { Section 2.3.1, } \\
\text { Table } 2-1\end{array}$ & Mandatory & $\begin{array}{l}\text { "Accuracy" should be presented in a consistent unit; } \\
\text { therefore "a factor of } 10 \text { " should be changed to a } \\
\text { percentage. Additionally, is } 300 \% \text { a realistic approximation? }\end{array}$ & \multicolumn{3}{|c|}{$\begin{array}{l}\text { The unclassified radionuclide inventory and accuracy is } \\
\text { provided by Bowen et al. (2001). These values can not be } \\
\text { changed. Bowen et al. (2001) states "The } 300 \% \text { uncertainty } \\
\text { applies to devices with unusual designs and tests for which } \\
\text { performance is only known approximately". Table } 2-1 \text { has } \\
\text { been changed to report the activation product uncertainty as } \\
1,000 \% \text {. }\end{array}$} & \\
\hline $\begin{array}{l}\text { 8.) Page 2-8, } \\
\text { Section 2.3.1, } \\
\text { 2nd Paragraph, } \\
\text { 1st Sentence }\end{array}$ & Mandatory & $\begin{array}{l}\text { "1) separately normalizing the Yucca Flat above and below } \\
\text { the water table inventories reported in Bowen et al. (2001)." } \\
\text { Please add the word in to the sentence. }\end{array}$ & \multicolumn{3}{|c|}{$\begin{array}{l}\text { Item } 1 \text { in the sentence has been changed to "1) separately } \\
\text { normalizing the Yucca Flat above and below the water table } \\
\text { inventories reported in Bowen et al. (2001)" }\end{array}$} & \\
\hline $\begin{array}{l}\text { 9.) Page 2-12, } \\
\text { Section 2.3.2, 1st } \\
\text { Paragraph, 4th } \\
\text { and 5th } \\
\text { Sentences }\end{array}$ & Mandatory & $\begin{array}{l}\text { For completeness the radionuclides indicated as excluded } \\
\text { in these two sentences should be listed. }\end{array}$ & \multicolumn{3}{|c|}{$\begin{array}{l}\text { The following sentence has been added: "The excluded } \\
\text { radionuclides are } 26 \mathrm{Al}, 40 \mathrm{~K}, 113 \mathrm{mCd}, 232 \mathrm{Th}, 242 \mathrm{Pu} \text {, and } \\
\text { 243Am." }\end{array}$} & \\
\hline $\begin{array}{l}\text { 10.) Page 2-20, } \\
\text { Test-induced } \\
\text { heat, 5th } \\
\text { Sentence }\end{array}$ & Mandatory & $\begin{array}{l}: \text { "... only tests with exchange volumes and chimneys fully } \\
\text { contained in confining units can be screened from the } \\
\text { source term." Please add the word units in the sentence. }\end{array}$ & \multicolumn{3}{|c|}{$\begin{array}{l}\text { The sentence has been changed to "Although the effect of } \\
\text { test-induced heat would be most pronounced with an aquifer } \\
\text { in both the exchange volume and chimney, only tests with } \\
\text { exchange volumes and chimneys fully contained in } \\
\text { confining units can likely be screened from the source } \\
\text { term.". }\end{array}$} & \\
\hline
\end{tabular}




\section{NEVADA ENVIRONMENTAL RESTORATION PROJECT}

DOCUMENT REVIEW SHEET

\begin{tabular}{|c|c|c|c|c|c|c|}
\hline \multicolumn{2}{|c|}{ 1. Document Title/Number: } & \multicolumn{2}{|c|}{$\begin{array}{l}\text { Draft Unclassified Source Term and Radionuclide Data for Corrective Action Unit } \\
\text { 97: Yucca Flat/Climax Mine, Nevada Test Site, Nevada }\end{array}$} & \multirow{2}{*}{\begin{tabular}{|l|} 
2. Document Date: \\
4. Originator/Organization: \\
\end{tabular}} & \multicolumn{2}{|l|}{$2 / 25 / 2009$} \\
\hline \multicolumn{2}{|l|}{ 3. Revision Number: } & \multicolumn{2}{|l|}{0} & & \multicolumn{2}{|l|}{ Stoller-Navarro } \\
\hline \multicolumn{2}{|c|}{$\begin{array}{l}\text { 5. Responsible NNSA/NSO Federal } \\
\text { Sub-Project Director: }\end{array}$} & \multicolumn{2}{|l|}{ Bill Wilborn } & 6. Date Comments Due: & \multicolumn{2}{|l|}{$3 / 30 / 2009$} \\
\hline \multicolumn{2}{|c|}{ 7. Review Criteria: } & \multicolumn{2}{|l|}{ Full } & & & \\
\hline \multicolumn{2}{|c|}{ 8. Reviewer/Organization/Phone No: } & Tim Murphy, NDEP, 486-2850 & & 9. Reviewer's Signature: & & \\
\hline $\begin{array}{l}\text { 10. Comment } \\
\text { Number/Locatio }\end{array}$ & 11. Type* & 12. Comment & 13. Comment Response & \multicolumn{2}{|l|}{ Response } & 14. Accept \\
\hline $\begin{array}{l}\text { 11.) Page 2-27, } \\
\text { Section 2.4.2, 6th } \\
\text { Bullet }\end{array}$ & Mandatory & $\begin{array}{l}\text { The two sentences in this bullet contradict one another. The } \\
\text { first sentence should be corrected to state that "Only } \\
\text { nonsorbing nuclides..." }\end{array}$ & \multicolumn{3}{|c|}{$\begin{array}{l}\text { The sixth bullet has been changed to "Only nonsorbing } \\
\text { nuclides from the nuclear tests in Climax Mine granite stock } \\
\text { need to be considered for the CAU scale transport model. } \\
\text { Sorbing nuclides likely will not contribute to a contaminant } \\
\text { boundary for the CAU." }\end{array}$} & \\
\hline $\begin{array}{l}\text { 12.) Page 3-15, } \\
\text { Section 3.3.5.1, } \\
\text { 1st Paragraph, } \\
\text { 3rd Sentence }\end{array}$ & Mandatory & $\begin{array}{l}\text { "... will retard radionuclides that exist into both the gaseous } \\
\text { and aqueous phases..." The into should be in. }\end{array}$ & \multicolumn{3}{|c|}{$\begin{array}{l}\text { The sentence has been changed to "Soil moisture will } \\
\text { increase the gas-phase tortuosity and will retard } \\
\text { radionuclides that exist in both the gaseous and aqueous } \\
\text { phases by partitioning of the gas phase into the relatively } \\
\text { immobile aqueous phase." }\end{array}$} & \\
\hline $\begin{array}{l}\text { 13.) Page 3-32, } \\
\text { Vadose zone } \\
\text { chimney drainage }\end{array}$ & Mandatory & $\begin{array}{l}\text { How will the uncertainty in the vadose zone drainage be } \\
\text { handled? }\end{array}$ & \multicolumn{3}{|c|}{$\begin{array}{l}\text { The following sentences have been added to the vadose } \\
\text { zone chimney drainage discussion: "Chimney drainage } \\
\text { uncertainty may be introduced through the uncertainty } \\
\text { analysis of the CAU scale unsaturated zone model or sub- } \\
\text { CAU scale source term models. For example, alternative } \\
\text { net infiltration rates will result in different initial rock } \\
\text { moisture. Alternative parameter combinations that honor } \\
\text { calibration data will result in different rock hydraulic } \\
\text { properties, initial moisture content and chimney drainage } \\
\text { rates." }\end{array}$} & \\
\hline $\begin{array}{l}\text { 14.) Page 5-9, } \\
\text { Section 5.3.3.1, } \\
\text { Last Sentence }\end{array}$ & Mandatory & $\begin{array}{l}\text { "Consequently, the properties may not accurately represent } \\
\text { hydrologic conditions in the deep vadose zone." Will this } \\
\text { possibility be investigated or included in the uncertainty } \\
\text { analysis? }\end{array}$ & \multicolumn{3}{|c|}{ Please see response to comment 13 . } & \\
\hline
\end{tabular}




\section{NEVADA ENVIRONMENTAL RESTORATION PROJECT}

DOCUMENT REVIEW SHEET

\begin{tabular}{|c|c|c|c|c|c|c|}
\hline \multicolumn{2}{|c|}{ 1. Document Title/Number: } & \multicolumn{2}{|c|}{$\begin{array}{l}\text { Draft Unclassified Source Term and Radionuclide Data for Corrective Action Unit } \\
\text { 97: Yucca Flat/Climax Mine, Nevada Test Site, Nevada }\end{array}$} & \multirow{2}{*}{\begin{tabular}{|l|} 
2. Document Date: \\
4. Originator/Organization:
\end{tabular}} & \multicolumn{2}{|l|}{ 2/25/2009 } \\
\hline \multicolumn{2}{|l|}{ 3. Revision Number: } & 0 & & & \multicolumn{2}{|l|}{ Stoller-Navarro } \\
\hline \multicolumn{2}{|c|}{$\begin{array}{l}\text { 5. Responsible NNSA/NSO Federal } \\
\text { Sub-Project Director: }\end{array}$} & \multicolumn{2}{|l|}{ Bill Wilborn } & 6. Date Comments Due: & \multicolumn{2}{|l|}{ 3/30/2009 } \\
\hline \multicolumn{2}{|c|}{ 7. Review Criteria: } & \multicolumn{2}{|l|}{ Full } & & & \\
\hline \multicolumn{2}{|c|}{ 8. Reviewer/Organization/Phone No: } & Tim Murphy, NDEP, 486-2850 & & 9. Reviewer's Signature: & & \\
\hline $\begin{array}{l}\text { 10. Comment } \\
\text { Number/Locatio }\end{array}$ & 11. Type* & 12. Comment & \multicolumn{3}{|c|}{ 13. Comment Response } & 14. Accept \\
\hline $\begin{array}{l}\text { 15.) Page 5-11, } \\
\text { Section 5.3.4.1, } \\
\text { 3rd Paragraph, } \\
\text { 3rd Sentence }\end{array}$ & Mandatory & $\begin{array}{l}\text { Please clarify the term "inverse tortuosity". In this } \\
\text { application, it appears to be equal to the porosity of the } \\
\text { alluvium. Based on SNJV (2007) information presented, } \\
\text { there is uncertainty in this inverse tortuosity value. Will the } \\
\text { effect of this uncertainty be investigated? }\end{array}$ & \multicolumn{3}{|c|}{$\begin{array}{l}\text { The sentence has been changed to "According to the least } \\
\text { squares regression exponent ranges reported in SNJV } \\
\text { (2007), the inverse of the tortuosity (Equation } 5-8 \text { ) for } \\
\text { alluvium is expected to range from } 0.06 \text { to } 0.70 \text { with a mean } \\
\text { of } 0.31 \text {. }\end{array}$} & \\
\hline $\begin{array}{l}\text { 16.) Page 5-12, } \\
\text { Section 5.3.4.2, } \\
\text { 2nd Paragraph, } \\
\text { 1st Sentence }\end{array}$ & Mandatory & $\begin{array}{l}\text { Generally longitudinal dispersivity in ground water studies } \\
\text { relates to the flow in the horizontal direction. In Section } \\
5.3 .4 .2 \text { of this document, the distance of the test to the } \\
\text { water table is defined as the L value in the equation, which } \\
\text { is a vertical distance. It is not clear that the dispersivity- } \\
\text { scale relationships developed in the referenced document } \\
\text { on SNJV (2007) are based on the scale defined in this } \\
\text { document as the distance from the test to the water table. It } \\
\text { appears that the equations developed in SNJV (2007) are all } \\
\text { for longitudinal and transverse dispersivity. Please clarify } \\
\text { this issue. }\end{array}$ & \multicolumn{3}{|c|}{$\begin{array}{l}\text { The second paragraph in Section } 5.3 .4 .2 \text { has been changed } \\
\text { to the following: } \\
\text { "The average distance of the deep and shallow test to the } \\
\text { water table is } 200 \text { m, which provides a dispersivity value of } \\
\sim 5 \text { m. SNJV (2007) concluded that longitudinal dispersivity } \\
\text { to transverse dispersivity is generally in the range of } 3 \text { to } 30 \\
\text { and the ratio of longitudinal to transverse vertical dispersivity } \\
\text { is generally in the range of } 10 \text { to } 800 \text {. However, traditional } \\
\text { dispersivity scaling relationships tend to over-predict } \\
\text { longitudinal and under-predict transverse dispersivity for } \\
\text { vertical flow through horizontally stratified media (Selker et } \\
\text { al., 1999), which is likely present in the Yucca Flat } \\
\text { unsaturated alluvium. In lieu of using longitudinal to } \\
\text { transverse dispersivity ratios provided in SNJV (2007), a } \\
\text { uniform dispersivity value of } 5 \text { m was used in the } 14 \mathrm{C} \text { and } \\
3 \mathrm{H} \text { transport simulations." }\end{array}$} & \\
\hline
\end{tabular}




\section{NEVADA ENVIRONMENTAL RESTORATION PROJECT}

DOCUMENT REVIEW SHEET

\begin{tabular}{|c|c|c|c|c|c|c|}
\hline \multicolumn{2}{|c|}{ 1. Document Title/Number: } & \multicolumn{2}{|c|}{$\begin{array}{l}\text { Draft Unclassified Source Term and Radionuclide Data for Corrective Action Unit } \\
\text { 97: Yucca Flat/Climax Mine, Nevada Test Site, Nevada }\end{array}$} & \multirow{2}{*}{\begin{tabular}{|l|} 
2. Document Date: \\
4. Originator/Organization: \\
\end{tabular}} & \multicolumn{2}{|l|}{$2 / 25 / 2009$} \\
\hline \multicolumn{2}{|l|}{ 3. Revision Number: } & \multicolumn{2}{|l|}{0} & & \multicolumn{2}{|l|}{ Stoller-Navarro } \\
\hline \multicolumn{2}{|c|}{$\begin{array}{l}\text { 5. Responsible NNSA/NSO Federal } \\
\text { Sub-Project Director: }\end{array}$} & \multicolumn{2}{|l|}{ Bill Wilborn } & 6. Date Comments Due: & \multicolumn{2}{|l|}{ 3/30/2009 } \\
\hline \multicolumn{2}{|c|}{ 7. Review Criteria: } & \multicolumn{2}{|l|}{ Full } & & & \\
\hline \multicolumn{2}{|c|}{ 8. Reviewer/Organization/Phone No: } & Tim Murphy, NDEP, 486-2850 & & 9. Reviewer's Signature: & & \\
\hline $\begin{array}{l}\text { 10. Comment } \\
\text { Number/Locatio }\end{array}$ & 11. Type* & 12. Comment & \multicolumn{3}{|c|}{ 13. Comment Response } & 14. Accept \\
\hline $\begin{array}{l}\text { 17.) Page 5-12, } \\
\text { Section 5.3.4.2, } \\
\text { 2nd Paragraph, } \\
\text { 3rd Sentence }\end{array}$ & Mandatory & $\begin{array}{l}\text { Please elaborate on the reasoning for using a uniform value } \\
\text { of } 5 \mathrm{~m} \text { in the } 14 \mathrm{C} \text { and } 3 \mathrm{H} \text { transport simulations. Also, on } \\
\text { page } 9-28 \text { of the referenced SNJV (2007) document, the } \\
\text { statement is made that the longitudinal dispersivity value } \\
\text { has uncertainty associated with the range. How will this } \\
\text { uncertainty be addressed? }\end{array}$ & \multicolumn{3}{|c|}{$\begin{array}{l}\text { Please see response to comment } 16 \text {. The Yucca Flat } \\
\text { transport model uncertainty analysis will include dispersivity } \\
\text { uncertainty. }\end{array}$} & \\
\hline $\begin{array}{l}\text { 18.) Page 5-24, } \\
\text { Figure 5-7 }\end{array}$ & Mandatory & $\begin{array}{l}\text { Figures 5-7A through 5-7J should all be presented in full } \\
\text { scale. The scales do not all have to be identical. } \\
\text { Additionally, the small inserts can not be read as } \\
\text { presented. Fewer figures need to be put on one page. }\end{array}$ & \multicolumn{3}{|c|}{ Figure 5-7 has been updated without the small insets. } & \\
\hline $\begin{array}{l}\text { 19.) Page 5-30, } \\
\text { Section 5.4.1.3, } \\
\text { 1st Paragraph, } \\
\text { 3rd Sentence }\end{array}$ & Mandatory & $\begin{array}{l}\text { Please explain in the text why in this analysis the crushed } \\
\text { zone permeability is reduced by a factor of } 100 \text { in the } \\
\text { horizontal and vertical directions as compared to the Carle } \\
\text { et al. (2006) which reduced the crushed zone permeability } \\
\text { by a factor of } 100 \text { in the horizontal and } 50 \text { in the vertical. }\end{array}$ & \multicolumn{3}{|c|}{$\begin{array}{l}\text { The first paragraph in Section 5.4.1.3 has been changed to } \\
\text { contain the following explanation: } \\
\text { "The transient CAMBRIC HST modeling (Carle et al., 2007) } \\
\text { used a vertical to horizontal permeability anisotropy ratio of } \\
0.5 \text { in the alluvium at the CAMBRIC working point. The } \\
\text { CAMBRIC HST modeling reduced the crushed zone } \\
\text { permeability by a factor of } 100 \text { in the horizontal direction } \\
\text { and } 50 \text { in the vertical direction, while simultaneously } \\
\text { reducing the porosity from } 0.32 \text { to } 0.27 \text {. In this analysis, } \\
\text { anisotropy is not considered and the crushed zone } \\
\text { permeability of the shallow test is reduced by a factor of } \\
100, \text { while simultaneously decreasing the porosity from } \\
0.412 \text { to } 0.27 . "\end{array}$} & \\
\hline
\end{tabular}




\section{NEVADA ENVIRONMENTAL RESTORATION PROJECT}

DOCUMENT REVIEW SHEET

\begin{tabular}{|c|c|c|c|c|c|c|}
\hline \multicolumn{2}{|c|}{ 1. Document Title/Number: } & \multicolumn{2}{|c|}{$\begin{array}{l}\text { Draft Unclassified Source Term and Radionuclide Data for Corrective Action Unit } \\
\text { 97: Yucca Flat/Climax Mine, Nevada Test Site, Nevada }\end{array}$} & \multirow{2}{*}{\begin{tabular}{|l|} 
2. Document Date: \\
4. Originator/Organization: \\
\end{tabular}} & \multicolumn{2}{|l|}{$2 / 25 / 2009$} \\
\hline \multicolumn{2}{|l|}{ 3. Revision Number: } & \multicolumn{2}{|l|}{0} & & \multicolumn{2}{|l|}{ Stoller-Navarro } \\
\hline \multicolumn{2}{|c|}{$\begin{array}{l}\text { 5. Responsible NNSA/NSO Federal } \\
\text { Sub-Project Director: }\end{array}$} & \multicolumn{2}{|l|}{ Bill Wilborn } & 6. Date Comments Due: & \multicolumn{2}{|l|}{ 3/30/2009 } \\
\hline \multicolumn{2}{|c|}{ 7. Review Criteria: } & \multicolumn{2}{|l|}{ Full } & & & \\
\hline \multicolumn{2}{|c|}{ 8. Reviewer/Organization/Phone No: } & \multirow{2}{*}{$\begin{array}{l}\text { Tim Murphy, NDEP, 486-2850 } \\
\text { 12. Comment }\end{array}$} & & 9. Reviewer's Signature: & & \\
\hline $\begin{array}{l}\text { 10. Comment } \\
\text { Number/Locatio }\end{array}$ & 11. Type* & & \multicolumn{2}{|c|}{ 13. Comment Response } & & 14. Accept \\
\hline 20.) Page 5-33 & Mandatory & $\begin{array}{l}\text { Figure } 5-12 \mathrm{~A} \text { through } 5-12 \mathrm{~J} \text { should all be presented in full } \\
\text { scale. The scales do not all have to be identical. } \\
\text { Additionally, the small inserts can not be read as } \\
\text { presented. Fewer figures need to be put on one page. }\end{array}$ & \multicolumn{3}{|c|}{ Figure 5-12 has been updated without the small insets. } & \\
\hline 21.) Page 5-48 & Mandatory & $\begin{array}{l}\text { Figure } 5-22 \mathrm{~A} \text { through } 5-22 \mathrm{~J} \text { should all be presented in full } \\
\text { scale. The scales do not all have to be identical. } \\
\text { Additionally, the small inserts can not be read as } \\
\text { presented. Fewer figures need to be put on one page. }\end{array}$ & \multicolumn{3}{|c|}{ Figure 5-22 has been updated without the small insets. } & \\
\hline $\begin{array}{l}\text { 22.) General } \\
\text { Comment on } \\
\text { Section } 5.0\end{array}$ & Mandatory & $\begin{array}{l}\text { In this Section, the modeling is described as being } \\
\text { conducted for half the exchange volume and symmetry } \\
\text { assumed. In the text, the initial aqueous-phase } \\
\text { concentration in the exchange volume is stated as being } \\
\text { calculated based on the total volume of the exchange } \\
\text { volume and uniformly distributed. Please describe the } \\
\text { method used to calculate the breakthrough plots for the } \\
\text { total concentration from the modeling results for half the } \\
\text { exchange volume. }\end{array}$ & \multicolumn{3}{|c|}{$\begin{array}{l}\text { The following sentence has been added to the } 2 \text { nd bullet in } \\
\text { Section } 5.3 .6 \text { : "The half symmetry model requires initializing } \\
1 / 2 \text { of the inventory in the exchange volume and multiplying } \\
\text { breakthrough mass by a factor } 2 \text { in the simulations." }\end{array}$} & \\
\hline
\end{tabular}


NEVADA ENVIRONMENTAL RESTORATION PROJECT

DOCUMENT REVIEW SHEET

\begin{tabular}{|c|c|c|c|c|c|c|}
\hline \multicolumn{2}{|c|}{ 1. Document Title/Number: } & \multicolumn{2}{|c|}{$\begin{array}{l}\text { Draft Unclassified Source Term and Radionuclide Data for Corrective Action Unit } \\
\text { 97: Yucca Flat/Climax Mine, Nevada Test Site, Nevada }\end{array}$} & \multirow{2}{*}{\begin{tabular}{|l|} 
2. Document Date: \\
4. Originator/Organization:
\end{tabular}} & \multicolumn{2}{|l|}{$2 / 25 / 2009$} \\
\hline \multicolumn{2}{|l|}{ 3. Revision Number: } & \multicolumn{2}{|l|}{0} & & \multicolumn{2}{|l|}{ Stoller-Navarro } \\
\hline \multicolumn{2}{|c|}{$\begin{array}{l}\text { 5. Responsible NNSA/NSO Federal } \\
\text { Sub-Project Director: }\end{array}$} & \multicolumn{2}{|l|}{ Bill Wilborn } & 6. Date Comments Due: & \multicolumn{2}{|l|}{$3 / 30 / 2009$} \\
\hline \multicolumn{2}{|c|}{ 7. Review Criteria: } & \multicolumn{2}{|l|}{ Full } & & & \\
\hline \multicolumn{2}{|c|}{ 8. Reviewer/Organization/Phone No: } & \multicolumn{2}{|l|}{ Tim Murphy, NDEP, 486-2850 } & 9. Reviewer's Signature: & & \\
\hline $\begin{array}{l}\text { 10. Comment } \\
\text { Number/Locatio }\end{array}$ & 11. Type* & 12. Comment & 13. Comment $\mathrm{R}$ & Response & & 14. Accept \\
\hline $\begin{array}{l}\text { 23.) Page 6-1, } \\
\text { Section } 6.1,1 \mathrm{st} \\
\text { Paragraph, 2nd } \\
\text { Sentence }\end{array}$ & Mandatory & $\begin{array}{l}\text { The NDEP does not approve of "simplifying assumptions." It } \\
\text { is not acceptable under Quality Control procedures. The } \\
\text { other methods of defining the release rate of radionuclides } \\
\text { are scientifically based whereas "simplifying assumptions" } \\
\text { is not. "Simplifying assumptions" should be removed from } \\
\text { this sentence." }\end{array}$ & $\begin{array}{l}\text { The first paragra } \\
\text { following: } \\
\text { "The Yucca Flat } \\
\text { release rate of re } \\
\text { input into the mc } \\
\text { direct paramete } \\
\text { release of radior } \\
\text { exchange volum } \\
\text { abstraction to a } \\
\text { similar to those } \\
\text { radionuclide rele } \\
\text { modeling is chal } \\
\text { detonations whic } \\
\text { hydrogeologic s } \\
\text { tests in alluvial, }\end{array}$ & $\begin{array}{l}\text { ph of Section } 6.1 \text { has been } \\
\text { CAU-scale transport model } \\
\text { adionuclides from the RST b } \\
\text { odels. This may be accomp } \\
\text { rization of the processes imp } \\
\text { nuclides from the test cavity, } \\
\text { e in the CAU-scale models } \\
\text { limited number of source ter } \\
\text { presented in Section } 5 \text {. Def } \\
\text { ease rate for the Yucca Flat } \\
\text { lenging because there are h } \\
\text { ch were conducted in a wide } \\
\text { ettings, including unsaturate } \\
\text { volcanic, and carbonate set }\end{array}$ & $\begin{array}{l}\text { changed to the } \\
\text { s require the } \\
\text { e defined and } \\
\text { lished through } \\
\text { oortant to } \\
\text {, melt glass, and } \\
\text { or through } \\
\text { rm models } \\
\text { fining the } \\
\text { CAU transport } \\
\text { undreds of } \\
\text { variety of } \\
\text { d and saturated } \\
\text { tings." }\end{array}$ & \\
\hline $\begin{array}{l}\text { 24.) Page C-16, } \\
\text { Section C.8.0, } \\
\text { 3rd Paragraph, } \\
\text { 2nd Sentence }\end{array}$ & Mandatory & $\begin{array}{l}\text { Model sensitivity to the parameters should be investigated. } \\
\text { Will this be done in future modeling studies? }\end{array}$ & $\begin{array}{l}\text { The Yucca Flat } \\
\text { model paramete }\end{array}$ & $\begin{array}{l}\text { Phase I transport modeling } \\
\text { r sensitivity and uncertainty }\end{array}$ & will investigate & \\
\hline
\end{tabular}




\section{DISTRIBUTION}

\section{$\underline{\text { Copies }}$}

Tim Murphy

State of Nevada

Nevada Division of Environmental Protection

2030 E. Flamingo Road, Suite 230

Las Vegas, NV 89119-0818

W.R. Wilborn

Environmental Restoration Project

U.S. Department of Energy

National Nuclear Security Administration

Nevada Site Office

P.O. Box 98518, M/S 505

Las Vegas, NV 89193-8518

K.C. Thompson

Environmental Restoration Project

U.S. Department of Energy

National Nuclear Security Administration

Nevada Site Office

P.O. Box 98518, M/S 505

Las Vegas, NV 89193-8518

Alicia Tauber

Environmental Management Records

U.S. Department of Energy

National Nuclear Security Administration

Nevada Site Office

P.O. Box 98518, M/S 505

Las Vegas, NV 89193-8518

NNSA/NSO, Read File

Environmental Management Records

U.S. Department of Energy

National Nuclear Security Administration

Nevada Site Office

P.O. Box 98518, M/S 505

Las Vegas, NV 89193-8518
1 Hard copy w/Electronic media

2 Electronic media

2 Hard copies w/Electronic media

1 Hard copy w/Electronic media

1 Electronic media 


\section{$\underline{\text { Copies }}$}

U.S. Department of Energy

National Nuclear Security Administration

Nevada Site Office

Technical Library

P.O. Box 98518, M/S 505

Las Vegas, NV 89193-8518

U.S. Department of Energy

Office of Scientific and Technical Information

P.O. Box 62

Oak Ridge, TN 37831-0062

Southern Nevada Public Reading Facility

c/o Nuclear Testing Archive

P.O. Box 98521, M/S NLV 400

Las Vegas, NV 89193-8521

Northern Nevada Public Reading Facility

c/o Nevada State Library \& Archives

100 N Stewart Street

Carson City, NV 89701-4285

Celeste Sandoval

Nye County

Nuclear Waste Repository Project Office

1210 E. Basin Road, Suite \#6

Pahrump, NV 89060

Naomi Becker

Los Alamos National Laboratory

Bikini Atoll Rd., SM30

Los Alamos, NM 87545

Walt McNab

Lawrence Livermore National Laboratory

7000 East Avenue, L-530

Livermore, CA 94550-9234

Bonnie Thompson

U.S. Geological Survey

Water Resources Division

160 North Stephanie Street

Henderson, NV 89074
1 Electronic media

1 Electronic media

2 Electronic media

1 Electronic media

1 Electronic media
1 Electronic media

1 Electronic media 


\section{$\underline{\text { Copies }}$}

Ed Kwicklis

1 Electronic media

Los Alamos National Laboratory

Bikini Atoll Rd., SM-30

Los Alamos, NM 87545

Chuck E. Russell

1 Electronic media

Desert Research Institute

755 E. Flamingo

Las Vegas, NV 89119

Ken Ortego

1 Electronic media

National Security Technologies, LLC

P.O. Box 98521, M/S NLV 082

Las Vegas, NV 89193-8521

Sam Marutzky

1 Electronic media

Stoller-Navarro Joint Venture

P.O. Box 98518, M/S 505

Las Vegas, NV 89193-8518

Bruce Crowe

1 Electronic media

Stoller-Navarro Joint Venture

P.O. Box 98518, M/S 505

Las Vegas, NV 89193-8518

Peter Martian

1 Electronic media

Stoller-Navarro Joint Venture

P.O. Box 98518, M/S 505

Las Vegas, NV 89193-8518

Gregory Ruskauff

1 Electronic media

Stoller-Navarro Joint Venture

P.O. Box 98518, M/S 505

Las Vegas, NV 89193-8518

Stoller-Navarro Joint Venture

1 Hard copy w/Electronic media

Central Files

P.O. Box 98518, M/S 505

Las Vegas, NV 89193-8518 